\title{
Effects of botulinum toxin A injections and bimanual task-oriented therapy on hand functions and bimanual activities in unilateral Cerebral Palsy
}

Citation for published version (APA):

Speth, L. A. W. M. (2015). Effects of botulinum toxin A injections and bimanual task-oriented therapy on hand functions and bimanual activities in unilateral Cerebral Palsy. [Doctoral Thesis, Maastricht University]. Maastricht University. https://doi.org/10.26481/dis.20150916ls

Document status and date:

Published: 01/01/2015

DOI:

10.26481/dis.20150916ls

Document Version:

Publisher's PDF, also known as Version of record

Please check the document version of this publication:

- A submitted manuscript is the version of the article upon submission and before peer-review. There can be important differences between the submitted version and the official published version of record.

People interested in the research are advised to contact the author for the final version of the publication, or visit the DOI to the publisher's website.

- The final author version and the galley proof are versions of the publication after peer review.

- The final published version features the final layout of the paper including the volume, issue and page numbers.

Link to publication

\footnotetext{
General rights rights.

- You may freely distribute the URL identifying the publication in the public portal. please follow below link for the End User Agreement:

www.umlib.nl/taverne-license

Take down policy

If you believe that this document breaches copyright please contact us at:

repository@maastrichtuniversity.nl

providing details and we will investigate your claim.
}

Copyright and moral rights for the publications made accessible in the public portal are retained by the authors and/or other copyright owners and it is a condition of accessing publications that users recognise and abide by the legal requirements associated with these

- Users may download and print one copy of any publication from the public portal for the purpose of private study or research.

- You may not further distribute the material or use it for any profit-making activity or commercial gain

If the publication is distributed under the terms of Article $25 \mathrm{fa}$ of the Dutch Copyright Act, indicated by the "Taverne" license above, 
Effects of botulinum toxin $A$ injections and bimanual task-oriented therapy on hand functions and bimanual activities in unilateral Cerebral Palsy

Lucianne Speth 


$\begin{array}{ll}\text { Cover } & \text { Willemiek Zweiphenning } \\ \text { Layout } & \text { Renate Siebes, Proefschrift.nu } \\ \text { Printed by } & \text { Ipskamp Drukkers BV } \\ \text { ISBN } & 978-94-90791-35-3\end{array}$

\section{(C) 2015 Lucianne Speth}

All rights reserved. No part of this publication may be reproduced or transmitted in any form or by any means, electronic or mechanical, including photocopy, recording, or any information storage or retrieval system, without permission in writing form from the author. The copyright of the manuscripts that have been accepted for publication or those published has been transferred to the respective journals. 


\title{
Effects of botulinum toxin $A$ injections and bimanual task-oriented therapy on hand functions and bimanual activities in unilateral Cerebral Palsy
}

\author{
PROEFSCHRIFT \\ ter verkrijging van de graad van doctor aan de Universiteit Maastricht, \\ op gezag van de Rector Magnificus, Prof. dr. L.L.G. Soete \\ volgens het besluit van het College van Decanen, \\ in het openbaar te verdedigen \\ op woensdag 16 september 2015 om 10.00 uur \\ door \\ Lucia Anne Wilhelmina Maria Speth
}




\section{Promotores}

Prof. dr. J.S.H. Vles

Prof. dr. R.J.E.M. Smeets

\section{Copromotor}

Dr. Y.J.M. Janssen-Potten (Adelante)

\section{Beoordelingscommissie}

Prof. dr. J.A.M.F.C. Verbunt (voorzitter)

Prof. dr. A.C.H. Geurts (UMC St. Radboud Nijmegen)

Prof. A.M. Gordon PhD (Columbia University New York)

Prof. dr. L.W. van Rhijn

Dr. R.J. Vermeulen

De onderzoeken vermeld in dit proefschrift zijn verricht in Adelante, in het kenniscentrum in Hoensbroek en in de kinderrevalidatie in Valkenburg, in samenwerking met kinderneurologie in het MUMC te Maastricht.

Financiële ondersteuning voor dit onderzoek in de vorm van subsidies is gegeven door het Johanna Kinderfonds, de Stichting Rotterdams Kinderrevalidatie Fonds Adriaanstichting, de Phelps Stichting, het Profileringsfonds azM, de Stichting Vooruit, de Elisabeth Strouven stichting, de Kanunnik Salden-Nieuwenhof stichting en Adelante.

Voor de publicatie van dit proefschrift is financiële ondersteuning verleend door Ipsen Farmaceutica B.V. Hoofddorp, Nederland. 


\section{Contents}

$\begin{array}{lll}\text { Chapter } 1 & \text { Introduction and outline of this thesis } & \mathbf{7}\end{array}$

$\begin{array}{lll}\text { Chapter } 2 \text { Unilateral Cerebral Palsy: epidemiology, etiology, imaging and } & 15\end{array}$ treatment of hand function problems

Chapter 3 Botulinum toxin A and upper limb functional skills in hemiparetic cerebral palsy: a randomized trial in children receiving intensive therapy

Chapter 4 Observational Skills Assessment Score: reliability in measuring amount and quality of use of the affected hand in unilateral Cerebral Palsy

Chapter 5 Effects of botulinum toxin A and/or bimanual task-oriented therapy on upper extremity impairments in unilateral Cerebral Palsy: an explorative study

Chapter 6 Effects of botulinum toxin A and/or bimanual task-oriented therapy on upper extremity activities in unilateral Cerebral Palsy: a clinical trial

Chapter 7 Discussion and conclusions

Samenvatting en discussie

Addendum Valorisatie

Dankwoord

Curriculum Vitae 


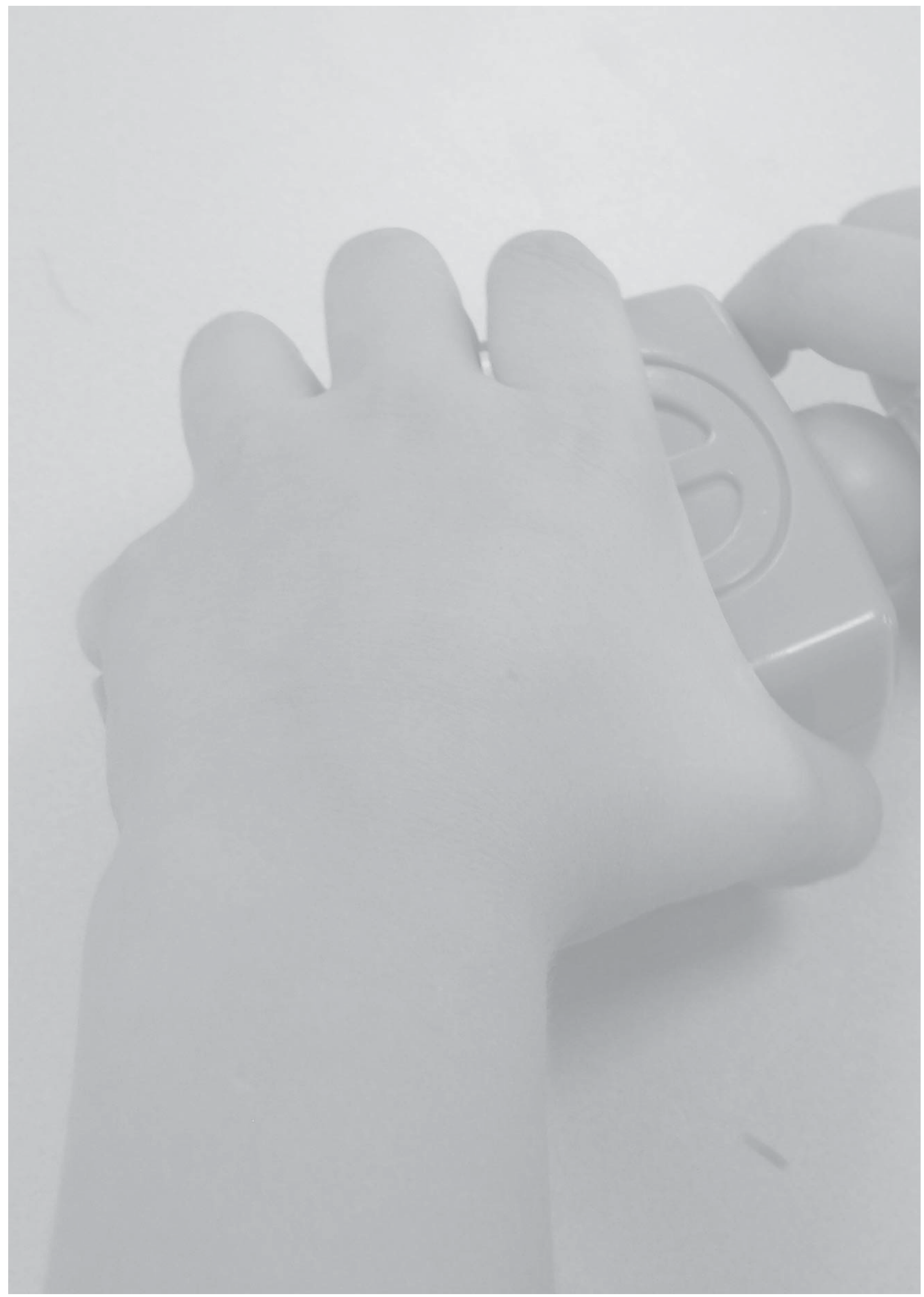




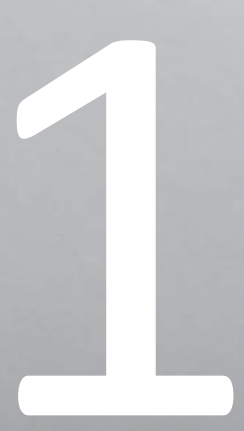

Introduction and outline of this thesis 
The main topic of this thesis is to describe the effects of treatment options that are currently used to improve hand functions and bimanual activities in children with unilateral Cerebral Palsy (uCP), i.e. botulinum toxin A injections (BoNT-A) and bimanual task-oriented therapy (BITT). To measure treatment effects in bimanual activities, a special assessment, the Observational Skills Assessment Score (OSAS) was developed.

In the second chapter the epidemiology, aetiology, imaging of uCP as well as the treatment of hand function problems in children with uCP are described. ${ }^{1} \mathrm{UCP}$, also called hemiplegic Cerebral Palsy (CP), has a prevalence of 0.6 per 1,000 live births, and amounts to about $30 \%$ of the CP subtype proportion. ${ }^{2} \mathrm{MRI}$ findings most often observed in $\mathrm{UCP}$ are periventricular white matter lesions (PWML), gray matter lesions, mainly infarcts of the middle cerebral artery, and brain maldevelopments. The MRI scan indicates a correlation of the total lesion volume and degree of Wallerian degeneration of the pyramidal tract at the anterior portion of the posterior limb of the internal capsule with motor impairment of the hand..$^{3-6}$ There are two types of central motor reorganisation in UCP. Children with contralateral cortical motor projections to their hemiplegic hand have better hand function than children with ipsilateral projections. Strong mirror movements are only present in children with ipsilateral projections. All children with basal ganglia abnormalities, irrespective of whether the primary lesion is in the periventricular white matter or in the cortical gray matter, are in the group with ipsilateral motor projections to the hemiplegic hand. Better hand function was found in children with PWML than in those with gray matter lesions. ${ }^{7}$

A problem that often occurs in children with uCP is developmental disregard. Taub et al. first described learned-non-use in stroke patients and introduced Constraint-Induced Movement Therapy (CIMT) in these patients to improve use of the affected arm by restraining the nonaffected arm. ${ }^{8}$ Rather than learned-non-use, a child may not develop neural pathways involved in movement because of the lack of ability to experience age-appropriate sensorimotor stimuli that lead to the development of upper extremity skills: developmental disregard. ${ }^{9} \mathrm{CIMT}$ and also bimanual intensive movement therapy (BIMT) have proven to be effective treatment options in children with uCP to improve bimanual performance. ${ }^{10-12}$ When comparing CIMT and BIMT, both treatment options lead to improvement in unilateral capacity and bimanual performance with no clear difference between these treatments. However, CIMT seems to have a higher effect on unilateral capacity, and BIMT on bimanual performance..$^{13-15}$

At the end of the last century the use of (BoNT-A) became an important treatment option to reduce spasticity in children with CP. At first it was used in the lower limb to improve 
walking. ${ }^{16}$ Then, there was little evidence to guide the choice of treatment to improve upper extremity (UE) functions in children with $\mathrm{UCP} .{ }^{17}$ Therefore, chapter 3 presents the results, published in 2005, of our randomized controlled trail on the additional effect of BoNT-A in children with $\mathrm{UCP}$ receiving intensive bimanual therapy on UE functions and skills. ${ }^{18}$ At that time the effects of BoNT-A in the UE at the function level of the International Classification of Functioning, Disability and Health (ICF) of the World Health Organization (WHO) (http:// www.who.int/classifications/icf/en/) were clear: tone reduction and improvement in range of motion (ROM). ${ }^{19}$ Because it is important to know whether children, after BoNT-A injections (under general anaesthesia) are able to use their affected hand in daily practice, such as during play and self-care, measurements at the activity level of the ICF are important. Until then, the results of BoNT-A in the UE at activity level were inconclusive..$^{20}$ Therefore, in our study we used the Melbourne Assessment of Unilateral Upper Limb Functions (MUUL), ${ }^{21}$ specifically developed for children with $\mathrm{CP}$, measuring unilaterally at activity level. However, the MUUL did not demonstrate much change from the baseline in both treatment groups. This finding is probably due to the fact that the MUUL is not responsive enough to detect these changes, as it contains many items relating to target accuracy, which we expected not to be influenced by BoNT-A. The MUUL was also not specifically designed to measure the affected hand, which has an assisting function in bimanual tasks in children with uCP.

Therefore, we developed the OSAS to measure quality and amount of use of the affected hand in standardised, age appropriate tasks in which bimanual use is essential. In chapter 4 the results of an agreement and reliability study of the OSAS are presented. ${ }^{22}$ In general, the OSAS seems to be a reliable tool for assessing the quality of use, i.e. capacity, of the affected hand in bimanual activities in children with UCP. It has an additional value to the Assisting Hand Assessment (AHA) that measures spontaneous use of the affected hand in bimanual performance. ${ }^{23,24}$

To measure the effects of BoNT-A and/or BITT on function and activity level of the ICF, in 2008 the BoBiVa (Botuline toxine Bimanuele Vaardigheden) study was started. This is a multicentre study, which was registered at the ISRCTN registry (http://www.controlledtrials.com/ISRCTN69541857). The BoBiVa study was designed as a multicentre, randomized controlled trial on the effect of BoNT-A injections combined with BITT, or either separately, in children with UCP on upper extremity (UE) functions and skills. As we considered the effects on spontaneous use of the affected hand in bimanual functioning of utmost importance, power analysis was done on the AHA, which was our main outcome measure. The study started with a factorial design. Due to disappointing patient enrolment, we had to adapt 
the design and a delay occurred. In 2008 patient enrolment started and in the end of 2011 the last measurement was completed. The most spastic muscles hampering function and bimanual activities were injected once in both the BoNT-A treatment groups. The BITT program consisted of half an hour of physiotherapy (PT) and one hour of occupational therapy (OT), 2 times a week, for 12 weeks. At the start, bimanual goals were set using the Canadian Occupational Performance Measure (COPM). ${ }^{25}$ An important feature of this therapy programme is the generalization of the learned goal-based activities at home. Parents reported that they spent 40 to 60 minutes a day practising these goals.

In chapter 5 the results of the BoBiVa study at the function level of the ICF, UE Range of Motion (ROM), spasticity and functional strength, are reported. ${ }^{26}$ Outcome measures at body function level of the ICF were spasticity in wrist and elbow (difference in angle of catch (AOC) and passive ROM, expressed as SPAT), ${ }^{27}$ active and passive ROM of wrist (with flexed and extended fingers), elbow and thumb measured with a $\mathrm{MIE}^{\circledR}$ clinical goniometer (MIE ${ }^{\circledR}$ medical research $\mathrm{Ltd}$ ), fist and key grip strength, maximal voluntary contractions (MVC) with E-LINK (Biometrics ${ }^{\circledR}$ Ltd) and unimanual and bimanual functional grip strength.

In chapter $\mathbf{6}$ the effects of BoNT-A and/or BITT on UE activities are described. The primary outcome measure was the AHA for bimanual performance. For bimanual performance, also the ABILHand-Kids questionnaire $(A K)^{28}$ was completed. The OSAS was used to measure quality of use of the affected hand and goal achievement was measured with Goal Attainment Scaling (GAS), ${ }^{29}$ and the COPM.

The conclusions of this thesis are discussed in chapter 7; a summary and implications for further research are given. 


\section{REFERENCES}

1 Speth L, Vles J. Unilateral Cerebral Palsy: Epidemiology, Etiology, Imaging and Treatment of Hand Function Problems. Handbook on Cerebral Palsy. Editor: Harold Yates. 2014 Nova Science Publishers. ISBN: 978-1-63321-852-9: 41-51.

2. Krägeloh-Mann I, Cans C. Review Article. Cerebral palsy update. Brain Devel 2009; 31: 537-544.

3. De Vries LS, Van der Grond J, Van Haastert IC, Groenendaal F. Prediction of Outcome in New-born Infants with Arterial Ischemic Stroke Using Diffusion-Weighted Magnetic Resonance Imaging. Neuropediatrics 2005; 36: 12-20.

4. Staudt M, Niemann G, Grodd W, Krägeloh-Mann I. The Pyramidal Tract in Congenital Hemiparesis: Relationship between Morphology and Function in Periventricular Lesions. Neuropediatrics 2000; 31: 257-264.

5. Bleyenheuft Y, Grandin CB, Cosnard G, Olivier E, Thonnard JL. Corticospinal Dysgenesis and Upper-Limb Deficits in Congenital Hemiplegia: A Diffusion Tensor Imaging Study. Pediatrics 2007; 120; e1502-e1511.

6. Holmström L, Lennartsson F, Eliasson AC, Flodmark O, et al. Diffusion MRI in corticofugal fibers correlates with hand function in unilateral cerebral palsy. Neurology 2011; 77: 775-783.

7. Holmström L, Vollmer B, Tedroff K, Islam M, et al. Hand function in relation to brain lesions and corticomotor-projection pattern in children with unilateral cerebral palsy. Dev Med Child Neurol 2010; 52: $145-152$.

8. Taub E, Uswatte G, Pidikiti R. Constraint-induced movement therapy: A new family of techniques with broad Application to Physical Rehabilitation-A Clinical Review. J Rehabil Res Dev 1999; 36(3): 237-251. Review.

9. DeLuca S, Echols K, Landesman Ramey S, Taub E. Pediatric constraint-induced movement therapy for a young child with cerebral palsy: two episodes of care. Phys Ther 2003; 83: 1003-1013.

10. Hoare BJ, Wasiak J, Imms C, Carey L. Constraint-induced movement therapy in the treatment of the upper limb in children with hemiplegic cerebral palsy. Cochrane Database Syst Rev 2007; (2): CD004149.

11. Aarts PB, Jongerius PH, Geerdink YA, van Limbeek J, Geurts AC. Effectiveness of modified constraintinduced movement therapy in children with unilateral spastic cerebral palsy: a randomized controlled trial. Neurorehabil Neural Repair 2010; 24: 509-518.

12. Gordon AM, Schneider JA, Chinnan A, et al: Efficacy of a hand-arm bimanual intensive therapy (HABIT) in children with hemiplegic cerebral palsy: a randomized control trial. Dev Med Child Neurol 2007; 49: 830-838.

13. Gordon AM, Hung YC, Brandao M, Ferre CL, Kuo HC, Friel K, Petra E. Bimanual training and constraintinduced movement therapy in children with hemiplegic cerebral palsy: a randomized trial. Neurorehabil Neural Repair 2011; 25: 692-702.

14. Sakzewski L, Ziviani J, Abbott JF, Macdonell RA, Jackson GD, Boyd RN. Randomized trial of constraintinduced movement therapy and bimanual training on activity outcomes for children with congenital hemiplegia. Dev Med Child Neurol 2011; 53: 313-320.

15. Deppe W, Thuemmler K, Fleischer J, Berger C, Meyer S, Wiedemann B. Modified constraint-induced movement therapy versus intensive bimanual training for children with hemiplegia - a randomized controlled trial. Clin Rehabil 2013; 27(10): 909-920.

16. Cosgrove AP, Corry IS, Graham HK. Botulinum toxin in the management of the lower limb in cerebral palsy. Dev Med Child Neurol 1994; 36: 386-396. 
17. Boyd RN, Morris ME, Graham HK. Management of upper limb dysfunction in children with cerebral palsy: a systematic review. Eur J Neurol 2001; 8(Suppl. 5): 150-166.

18. Speth LA, Leffers $P$, Janssen-Potten YJ, Vles JS. Botulinum toxin A and upper limb functional skills in hemiparetic cerebral palsy: a randomized trial in children receiving intensive therapy. Dev Med Child Neurol 2005; 47(7): 468-473.

19. Corry IS, Cosgrove AP, Walsh EG, McClean D, Graham HK. Botulinum toxin A in the hemiplegic upper limb: a double-blind trial. Dev Med Child Neurol 1997; 39: 185-193.

20. Fehlings D, Rang M, Glazier J, Steele C. An evaluation of botulinum-A toxin injections to improve upper extremity function in children with hemiplegic cerebral palsy. J Pediatrics 2000; 137: 331-337.

21. Randall M, Carlin JB, Chondros P, Reddihough D. Reliability of the Melbourne assessment of unilateral upper limb function. Dev Med Child Neurol 2001; 43: 761-767.

22. Speth L, Janssen-Potten $Y$, Leffers P, Rameckers E, Defesche A, Geers R, et al. Observational skills assessment score: reliability in measuring amount and quality of use of the affected hand in unilateral cerebral palsy. BMC Neurol 2013; 13: 152.

23. Krumlinde-Sundholm L, Eliasson A. Development of the Assisting Hand Assessment: A Rasch-built measure intended for children with unilateral upper limb impairments. Scand J Occup Ther 2003; 10: 16-26.

24. Krumlinde-Sundholm L, Holmefur M, Kottorp A, Eliasson A-C. The Assisting Hand Assessment: current evidence of validity, reliability, and responsiveness to change. Dev Med Child Neurol 2007; 49: 259-264.

25. Verkerk GJ, Wolf MJ, Louwers AM, Meester-Delver A, Nollet F. The reproducibility and validity of the Canadian Occupational Performance Measure in parents of children with disabilities. Clin Rehabil 2006; 20(11): 980-988.

26. Speth L, Janssen-Potten Y, Leffers P, Rameckers E, Defesche A, WinkensB, Becher J, Smeets R, Vles H. Effects of botulinum toxin $A$ and/or bimanual task-oriented therapy on upper extremity impairments in unilateral Cerebral Palsy: an explorative study. Eur J Paediatr Neurol 2015; 19(3): 336-348.

27. Scholtes VA, Becher JG, Beelen A, Lankhorst GJ. Clinical assessment of spasticity in children with cerebral palsy: a critical review of available instruments. Dev Med Child Neurol 2006; 48: 64-73.

28. Arnould C PM, Renders A, Thonnard JL. ABILHAND-Kids: a measure of manual ability in children with cerebral palsy. Neurology 2004; 63: 1045-1052.

29. Steenbeek D, Ketelaar M, Galama K, Gorter JW. Goal attainment scaling in paediatric rehabilitation: a critical review of the literature. Dev Med Child Neurol 2007; 49(7): 550-556. 


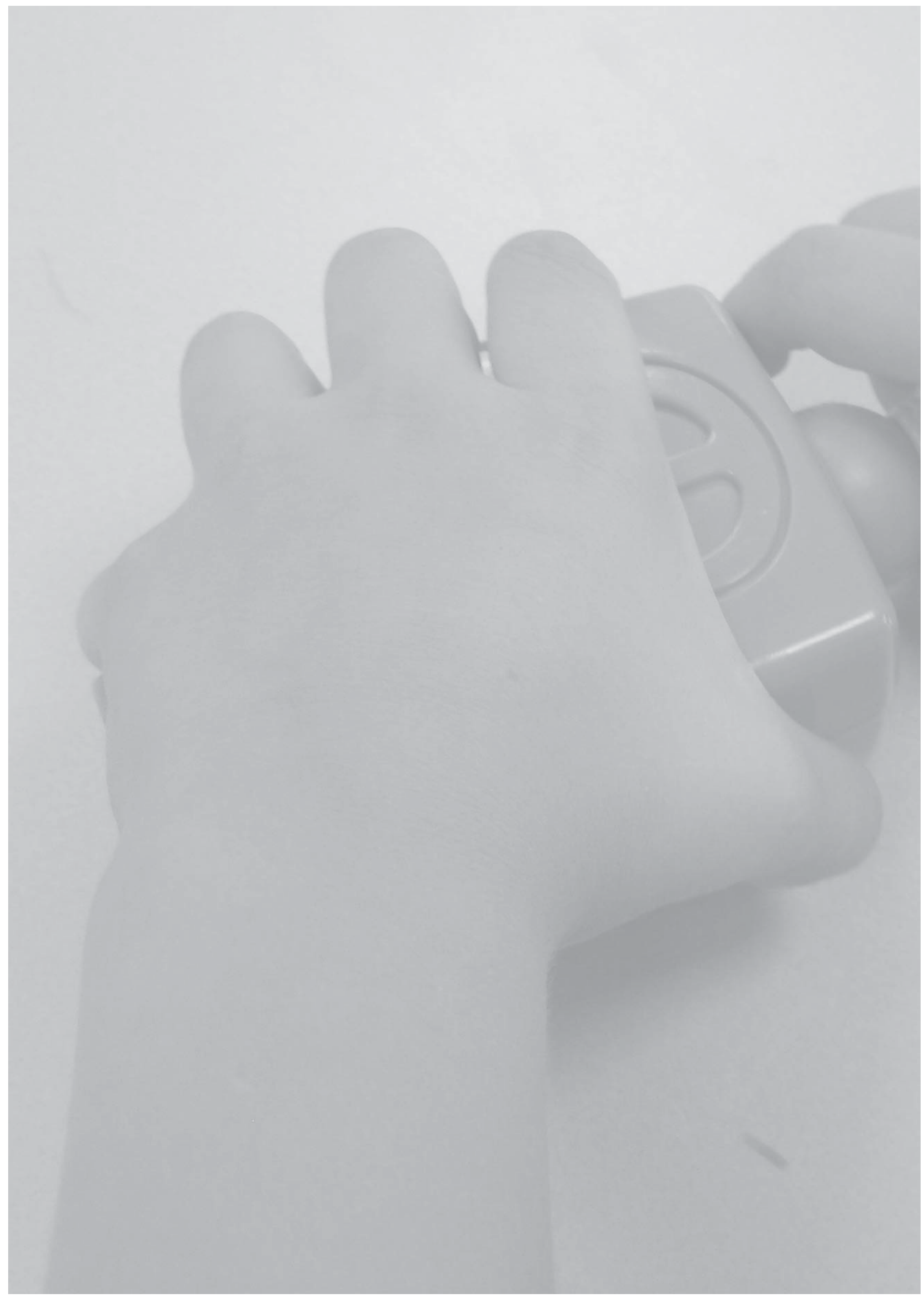




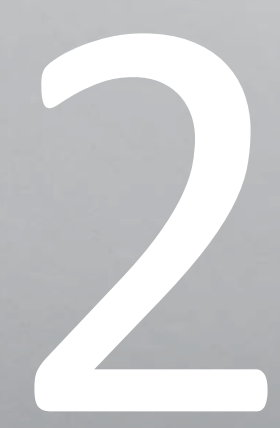

\section{Unilateral Cerebral Palsy: epidemiology, etiology, imaging and treatment of hand function problems}

Lucianne Speth, Hans Vles 


\begin{abstract}
Cerebral Palsy (CP) describes a group of permanent disorders of development of movement and posture, causing activity limitation, that are attributed to non progressive disturbances that occurred in the developing fetal or infant brain. The prevalence of $\mathrm{CP}$ remains constant over the last years at 2.11 per 1,000 live births. Unilateral spastic CP (uCP), also called hemiplegic $\mathrm{CP}$, has a prevalence of 0.6 per 1,000 live births, and amounts about $30 \%$ of the CP subtype proportion. In children with a birth weight of 2,500 g or more, there is an increase of de uCP subtype.

The definition of CP gives no etiological explanation. However, with the introduction of modern neuro-imaging, we are more informed in detail about the different etiological and risk factors. Different etiology will have different consequences with concern to cortical and sub cortical re-organization.

In this review chapter we will focus on a vascular event (hypoxic ischemic, $\mathrm{HI}$ or stroke) as a cause for uCP, using definitions related to gestational age.

Ultrasound (US) and Magnetic Resonance Imaging (MRI) are not only of importance in studying etiology but also can be of help to determine the time the insult took place.

The clinical presentation of $\mathrm{UCP}$ is variable due to the severity and localization of the lesion, associated pathology and the aspect of the incident: chronic $\mathrm{HI}$ versus acute asphyxia. With the introduction of new neuro-imaging techniques, such as functional MRI (fMRI) and Diffusion Tensor Imaging (DTI), we are more informed about the relation of structure and function and the possibilities of neuronal adaptation. This is of utmost clinical importance, because the way the re-organization of neuronal networks (ipsi or contra lateral) takes place and the severity and localization of the lesion correlates with hand function and bimanual performance and even influences therapy outcome.

Developmental disuse is a problem typically occurring in uCP and also influencing therapy outcome. Evidence of several treatment modalities of unilateral hand function problems in children with unilateral $\mathrm{CP}$, i.e. bimanual intensive goal directed treatment, constraint induced movement therapy and botulinum toxin A treatment, will be discussed.
\end{abstract}




\section{Definition}

Cerebral Palsy (CP) describes a group of permanent disorders of development of movement and posture, causing activity limitation, that are attributed to non progressive disturbances that occurred in the developing fetal or infant brain. The motor disorders of cerebral palsy are often accompanied by disturbances of sensation, perception, cognition, communication, and behaviour; by epilepsy, and by secondary musculoskeletal problems. ${ }^{1}$

\section{Epidemiology}

According to a systematic review and meta-analysis the prevalence of $\mathrm{CP}$ remains constant over the last years at 2.11 per 1,000 live births despite the increased survival of at risk preterm infants. ${ }^{2}$

Unilateral spastic $\mathrm{CP}(\mathrm{UCP})$, also called hemiplegic $\mathrm{CP}$, has a prevalence of 0.6 per 1,000 live births, and amounts about $30 \%$ of the CP subtype proportion. ${ }^{3} \mathrm{MRI}$ findings most often observed in $\mathrm{CCP}$ are periventricular white matter lesions (PWML), focal periventricular gliosis or post-haemorrhagic porencephalic lesions in $36 \%$, cortical or deep gray matter lesions, mainly infarcts of the middle cerebral artery (MCA) in 31\% and brain maldevelopments, mainly focal cortical dysplasia or unilateral schizencephaly in $16 \%$ of the cases. PWML occur significantly more often in preterm uCP than in term ( $86 \%$ vs. $20 \%$ ) and cortical or deep gray matter lesions significantly less often ( $0 \%$ vs. $41 \%$ ). Brain maldevelopments occur in preterm UCP nearly as often as in term uCP (14\% vs. $16 \%) .{ }^{3}$ In a Canadian study of 213 children with CP $31.8 \%$ had the hemiplegic neurological subtype. Of the children with UCP $18.3 \%$ had PWML, $12.7 \%$ brain malformation, $26.8 \%$ cerebro vascular accidents, $19.7 \%$ gray matter injury, $2.8 \%$ intracranial haemorrhage, $15.5 \%$ non-specific and $4.2 \%$ had normal neuro imaging findings. Due to an underrepresentation of premature born children in the cohort in this study, there was less PWML. ${ }^{4}$ Trends in prevalence of CP in children born with a birth weight of 2,500 $\mathrm{g}$ or above in Europe show a decrease in the bilateral spastic-CP subtype and an increase in UCP, with a stable prevalence of CP of 0.99 per 1,000 live birth in 1998 and a significant decrease in neonatal mortality. The prevalence of UCP increased significantly from 0.37 to 0.46. The type of CP was spastic in $84.9 \%$ of cases (bilateral in $45.7 \%$, unilateral in $39.2 \%$ ). ${ }^{5}$ 


\section{Incidence, etiology and clinical presentation of perinatal stroke}

Focal brain injury occurs most frequently as a consequence of infarction of the left MCA, or more rarely as a consequence of cerebral sinus venosus thrombosis (CSVT). Neurodevelopmental morbidity occurs in over $50 \%$ of the children. ${ }^{6}$ With an incidence of $1 / 2,800$ to $1 / 5,000$ new births, perinatal arterial ischemic stroke (PAIS) is the most frequent form of cerebral infarction in children. ${ }^{7}$ Perinatal ischemic stroke is defined as a group of heterogeneous conditions in which there is focal disruption of cerebral blood flow secondary to arterial or cerebral venous thrombosis or embolization, between 20 weeks of fetal life through the 28th postnatal day, confirmed by neuroimaging or neuropathologic studies. Three subcategories can be distinguished: fetal ischemic stroke, diagnosed before birth from fetal imaging or in stillbirths on the basis of neuropathological examination; neonatal ischemic stroke, diagnosed after birth and on or before the 28th postnatal day (including in preterm infants); presumed perinatal ischemic stroke, diagnosed in infants over 28 days of age in whom it is presumed (but not certain) that the ischemic event occurred sometime between the 20th week of fetal life through the 28th postnatal day. The hypothesis is that an infarction that occurred later in infancy or childhood would have been symptomatic at the time of the first occurrence.

Risk factors for PAIS are: thrombotic history, infertility, previous pregnancy related disorders in the mother; first pregnancy, primiparity, twin pregnancy, pre-eclampsia, gestational diabetes, chorioamnionitis, premature rupture of membranes; signs of fetal distress, intervention during delivery (notably emergency caesarean section); male sex, extreme birth weight, polycytemia, hypoglycaemia, meningitis, congenital heart disease, extra-corporeal membrane oxygenation in the newborn; lipoprotein (a) >30 ng/ml, factor V Leiden and factor II G20210A mutation, antiphospholipid antibodies in either mother or child.

$60 \%$ of the infants present early symptoms. In more than $90 \%$ the presenting symptoms are tonic/clonic seizures, focal in $74 \%$, leading to a status epilepticus in one third of the infants. 46 of 100 infants had persistently altered tone, 36 a decreased level of consciousness, and 16 had focal deficit. Confirmation of a suspected infarct from ultrasound (US) scan should be done directly with magnetic resonance imaging (MRI), which provides further insight in the timing of the infarct and in the outcome. The development of the MRI findings during the first 3 days show there is a short time frame in which the neonatal stroke occurs, and makes the hypothesis of a placento-cerebral embolism during pregnancy prior to labour less probable. $67 \%$ of the infants with corticospinal tract involvement on MRI developed 
hemiplegia ( $\mathrm{UCP}$ ) versus $6 \%$ of those without. $26 \%$ of these infants with neonatal stroke, who were followed up until 24 months of age, had motor impairments, mostly uCP.

In $40 \%$ of the infants with PAIS the clinical presentation is delayed. All these children present at the age of 5 months with motor problems as early handedness, decreased hand use, rigidity of the upper limb or fisting, which has been well observed by the parents while playing or dressing. 14 to $25 \%$ of these children present with seizures. The timing of the clinically silent vascular event leading to stroke is uncertain in these patients in the pre- or perinatal period. Also there is uncertainty regarding the mechanisms of the event. In some cases the images show a clear arterial ischemic pattern of injury (presumed perinatal ischemic stroke), but in other cases the findings are more equivocal and some cases suggest periventricular venous infarction, primary parenchymal haemorrhage, or even a non-vascular mechanism. ${ }^{7}$ Golomb et al. found that 76 of 111 children with PAIS (68\%) had cerebral palsy, most commonly hemiplegic $(66 / 76 ; 87 \%){ }^{8}$ Both delayed presentation (presumed perinatal infarction) and male sex were associated with CP. Most of the children with perinatal co morbidities were children with neonatal presentation.

\section{Imaging in relation to reorganization and hand function}

De Vries et al. mentioned the additional value of diffusion weighted MRI (DW-MRI) to establish cortical tract injury in newborn infants with PAIS. The presence of increased signal intensity at the posterior limb of the internal capsule and the cerebral peduncles is followed by Wallerian degeneration and development of uCP. ${ }^{9}$ This is in agreement with Staudt et al. finding a correlation of the total lesion volume and degree of Wallerian degeneration of the pyramidal tract at the anterior portion of the posterior limb of the internal capsule at the MRI scan, with motor impairment of the hand in adults with congenital hemi paresis due to periventricular lesions. ${ }^{10}$

Central motor reorganization in hemiplegic $\mathrm{CP}$ was first investigated by Carr et al. using focal transcranial magnetic stimulation (TMS) of the cortex. Two types of reorganization patterns were found. In both forms TMS demonstrated novel ipsilateral pathways form the undamaged motor cortex to the hemiplegic hand. Ipsilateral projections were not found from the damaged motor cortex. In subjects who had intense mirror movements, the corticospinal axons descending from the ipsilateral cortex had branched abnormally projecting to each side of the spinal cord. This was not the case in subjects without mirror movements. Good EMG responses in the hand after TMS of the contralateral cortex corresponded to good 
hand function whereas absent EMG responses meant poor hand function unless mirror movements were present. ${ }^{11}$

Holmström et al. studied the relationship between brain lesions, cortico-motor projections and hand function in children with UCP. ${ }^{12}$ There was no relation between mirror movements and hand function and performance, although the children with clear sensory problems performed poor on hand function assessments. Children with mild PWML performed better than children with severe $(>50 \%)$ white matter loss or children with gray matter lesions. In the majority of these severely affected children, there was also involvement of the basal ganglia or the thalamus. Children with contralateral motor projections to their hemiplegic hand showed better hand function than children with ipsilateral projections. Also children with mixed projections performed better than children with ipsilateral projections. Strong mirror movements were only present in children with ipsilateral projections. In the group with white matter lesions, all children with contralateral motor-projection patterns had mild or moderate white-matter loss, whereas all children with ipsilateral projections had severe white-matter loss. All children with basal ganglia abnormalities, irrespective of whether the primary lesion was in the periventricular white matter or in the cortical gray matter, were in the group with ipsilateral motor projections to the hemiplegic hand. Although the most impaired hand function was seen in the ipsilateral motor projection group, some children in this group had fairly good ability. ${ }^{12}$ With diffusion tensor imaging (DTI) of corticofugal fibers clear correlations between hand function and performance in $\mathrm{UCP}$ and the size of the contralateral corticospinal tract in the cerebral peduncle and the anterior part of the posterior limb of the capsula interna were found..$^{13,14}$

Better hand function, measured with the Melbourne Assessment of Upper Limb Function (MUUL), ${ }^{15}$ was found in children with PWML than in those with gray matter lesions. ${ }^{16}$ This was also a conclusion of Holmefur et al., who measured hand function development from 1.5 to 8 years of age with the Assisting Hand Assessment (AHA). ${ }^{17,18}$ Their most important finding was that the absence of a concurrent lesion to the basal ganglia and thalamus had the highest predictive power of better development of hand function, independent of the basic type of lesion. The extent of white-matter damage also predicted hand function development. Rose et al. found a significant negative correlation from a reduction of volume of the precentral gyrus of children with congenital hemiplegia due to periventricular damage and preserved corticospinal tract projections from the damaged hemisphere with bimanual performance, measured with the AHA. ${ }^{19}$ They also concluded that the sensorimotor thalamic pathways correlated more significantly with paretic hand functions than did the corticospinal tracts. 


\section{Developmental disregard and treatment options of unilateral impairments in hand function}

An often-occurring problem in children with uCP is developmental disregard. Learned-nonuse was for the first time described by Taub in stroke patients, based on his experimental research with deafferentation of one limb by dorsal rhizotomy in monkeys. ${ }^{20} \mathrm{He}$ introduced Constraint-Induced Movement Therapy (CIMT) in stroke patients to improve training and use of the affected arm by restraining the non-affected arm. Charles et al. also used the term learned-non-use in their publication about the effect of CIMT in children with uCP. ${ }^{21}$ Unlike adults with hemiplegia, who have had functional use of the upper extremities before the time of the insult; children with uCP have not used the involved upper limb typically from birth. DeLuca et al. introduced the term developmental disregard in their case study of the effect of CIMT in a young developing child. ${ }^{22}$ Rather than learned-non-use, a child may not develop neural pathways involved in movement because of the lack of ability to experience age-appropriate sensorimotor stimuli that lead to the development of upper extremity skills.

CIMT has proven to be an effective treatment option in children with UCP to improve bimanual performance. ${ }^{23,24}$ Also bimanual intensive movement therapy, BIMT, or HABIT, as Charles and Gordon called it, has proven to have a positive effect on bimanual performance, measured with the AHA. ${ }^{25}$ Comparing CIMT and BIMT, both treatment options lead to improvement in unilateral capacity and bimanual performance with no clear difference between these treatment options, yet CIMT seems to have more effect on unilateral capacity and BIMT on bimanual performance. ${ }^{26-28}$ In their review of intensive upper limb therapy Andersen et al. conclude that although CIMT and BIMT have similar improvements in unilateral capacity and bimanual performance outcomes, considering participant and caregiver goal achievement, evidence favors a bimanual approach ${ }^{29}$ They discussed type and duration of restraint of the unaffected limb in CIMT, and age of treatment. BIMT is an option in children with severe hand function impairments, or children who have clear bimanual goals in which the assistance of the affected hand is needed. In both treatment options, intensity of treatment influences outcome. After botulinum toxin A (BoNT-A) injections CIMT offered no added value compared to less intensive bimanual occupational therapy (OT) in improving bimanual performance. ${ }^{30}$ According to the Cochrane review BoNT-A injections in the upper limb in uCP clearly reduce spasticity and improve range of motion. ${ }^{31}$ Comparing BoNT-A and OT aimed at improving bimanual skills with OT alone, the effect on unilateral capacity is questionable. Review of the pooled data showed small positive effects at the MUUL and the Quality of Upper Extremities 
Skills Test (QUEST) ${ }^{32}$ at three months after BoNT-A, which disappeared at 6 months. No bimanual performance outcome measures were used. There were clear positive effects at Goal Attainment Scaling (GAS) and limited positive effect at the Canadian Occupational Performance Measure (COPM). Olesch et al. studied very young children (mean age 3 years 8 months) with uCP. They found no significant differences between BoNT-A + OT and OT alone at the QUEST, but also positive effects at GAS of BoNT-A + OT. ${ }^{33}$

\section{Effects of several treatment modalities on brain structure and imaging}

Comparing the therapeutic response of BoNT-A injections with physiotherapy with physiotherapy alone using DTI and clinical scores in diplegic CP children a significant change in motor and sensory fiber bundle size and improvement in clinical score was found due to physiotherapy, but no additional effect of BoNT-A was found. ${ }^{34}$ In a study investigating whether the type of cortical reorganization (identified by TMS) influenced the efficacy of CIMT in adolescents with $\mathrm{UCP}$, both patients controlling their affected hand via ipsilateral corticospinal projections from the contralesional hemisphere and patients with preserved crossed corticospinal projections from the affected hemisphere to the affected hand significantly improved in quality of upper extremity movements. This was accompanied by a significant gain of speed in patients with preserved crossed projections, whereas patients with ipsilateral projections tended to show speed reduction..$^{35}$ The patients with preserved contralateral projections had a unilateral corticosubcortical infarction in the MCA territory and those with ipsilateral projections from the contralesional hemisphere had PWML. In a later publication of this research group about the same study population, two types of exercise-induced neuroplasticity were revealed. ${ }^{36}$ Individuals with ipsilateral corticospinal projections had a decrease in transsynaptic premotor cortex excitability (measured by TMS) and a decrease in synaptic activity of the primary motor cortex during active movements of the paretic hand (measured by functional MRI) after CIMT, whereas patients with contralateral projections after CIMT showed an increase in primary motor cortex excitability and also in activation in the sensorimotor cortex. Both individuals with ipsilateral and those with contralateral projections showed evidence for significant increase in synaptic activity of the sensory cortex during stimulation of the paretic hand (measured with magneto encephalography) after CIMT. Also after CIMT, Islam et al. found improvement in movement speed of the affected hand and in bimanual performance, measured with the AHA, but not in MUUL scores, irrespective of corticomotor projection pattern. ${ }^{37}$ In their study with kittens in which the primary motor cortex activity was blocked unilaterally during a critical postnatal 
period, Friel et al. found that early training of the affected limb in combination with restraint of the unaffected limb restored corticospinal tract (CST) connections, improved primary motor cortex (M1) activity and increased spinal interneuron number on the contralateral, relative to the ipsilateral side, and abrogated limb control impairments. ${ }^{38}$ Delayed training in adolescence restored CTS connections and M1 activity, but not contralateral spinal interneuron numbers or motor performance. Restraint alone only restored CST connectivity.

\section{Conclusion}

UCP has a prevalence of 0.6 per 1,000 live births and amounts about $30 \%$ of the CP subtype proportion. In children born with a birth weight of $2,500 \mathrm{~g}$ or above there is an increase in prevalence.

MRI findings most often observed in UCP are PWML, gray matter lesions, mainly infarcts of the MCA, and brain maldevelopments.

PAIS is the most frequent form of cerebral infarction in children. Risk factors for PAIS are mentioned. $60 \%$ of the infants with PAIS have early symptoms, mostly tonic/clonic seizures; in $40 \%$ there is a delayed clinical presentation at the age of 5 months with motor problems as early handedness.

There is a correlation of the total lesion volume and degree of Wallerian degeneration of the pyramidal tract at the anterior portion of the posterior limb of the internal capsule at the MRI scan, with motor impairment of the hand. There are two types of central motor reorganization in UCP. Children with contralateral motor projections to their hemiplegic hand have better hand function than children with ipsilateral projections. Strong mirror movements are only present in children with ipsilateral projections. All children with basal ganglia abnormalities, irrespective of whether the primary lesion is in the periventricular white matter or in the cortical gray matter, are in the group with ipsilateral motor projections to the hemiplegic hand. Better hand function was found in children with PWML than in those with gray matter lesions. The absence of a concurrent lesion to the basal ganglia and thalamus has the highest predictive power of better development of hand function, independent of the basic type of lesion. The sensorimotor thalamic pathways correlate more significantly with paretic hand functions than the corticospinal tracts.

An often-occurring problem in children with uCP is developmental disregard. Comparing CIMT and BIMT, both treatment options lead to improvement in unilateral capacity and bimanual 
performance with no clear difference between these treatment options, yet CIMT seems to have more effect on unilateral capacity and BIMT on bimanual performance. Comparing BoNT-A and OT aimed at improving bimanual skills with OT alone, the effect on unilateral capacity is questionable.

Individuals with ipsilateral corticospinal projections had a decrease in transsynaptic premotor cortex excitability and a decrease in synaptic activity of the primary motor cortex during active movements of the paretic hand after CIMT, whereas patients with contralateral projections after CIMT showed an increase in primary motor cortex excitability and also in activation in the sensorimotor cortex. Both individuals with ipsilateral and those with contralateral projections showed evidence for significant increase in synaptic activity of the sensory cortex during stimulation of the paretic hand after CIMT. In an animal study early training of the affected limb in combination with restraint of the non-affected limb is more effective in restoring central nervous system structure, than training in adolescence or restraint alone. Therefore, knowing the type of cortical reorganization pattern can be useful in the choice of the treatment modality, although improvement of bimanual performance after CIMT was obtained irrespective of the corticomotor projection pattern. Neural plasticity mechanisms in the developing brain are enhanced, which have positive and negative implications. Exercise leads to improvement of trained skills by reorganization of neuronal networks with more effect if training takes place at younger age, in which there is a post-natal burst in synaptogenesis followed by activity-dependent pruning of excessive synapses later in the post-natal period. Due to the vulnerability associated with plasticity of the developing brain, environmental enrichment has a positive effect on learning and memory ability, but sensory deprivation has negative effects, because developing neurons are dependent on a stable level of neuronal depolarization and are vulnerable to loss of stimulation by excitatory neurotransmitters. ${ }^{39}$ Increasing skilled activity of the affected limb in bimanual performance from an early age on seems to be important to improve optimal regeneration of the CST and promote possible contralesional hemisphere cortical projections. Restricting movement of the less affected upper limb for long periods of time without training of the affected limb may disrupt the normal development of the CST and its cortical projection patterns. Therefore, restriction of the less affected upper limb should be done moderately at early age. Training of the affected limb from early age on as an assisting hand in bimanual play and meaningful skills to achieve bimanual goals, seems to be supported by this evidence. 


\section{References}

1 Rosenbaum P, Paneth N, Leviton A, Goldstein M, Bax M, Damiano D, Jacobsson B: A report: the definition and classification of cerebral palsy April 2006. Dev Med Child Neurol 2007; 49(109): 8-14.

2. Oskoui M, Coutinho F, Dykeman J, Jette N. An update on the prevalence of cerebral palsy: a systematic review and meta-analysis. Dev Med Child Neurol 2013; 55: 509-519.

3. Krägeloh-Mann I, Cans C. Review Article. Cerebral palsy update. Brain Dev 2009; 31: 537-544.

4. Towsley K, Shevell MI, Dagenais L on behalf of the REPAQ consortium. Population-based study of neuroimaging findings in children with cerebral palsy. Eur J Paediatr Neurol 2011; 15: 29-35.

5. Selier E, Surman G, Himmelmann K, et al. Trends in prevalence of cerebral palsy in children born with a birthweight of 2,500 g or over in Europe from 1980 to 1998. Eur J Epidemiol 2010; 25: 635-642.

6. Rutherford MA, Ramenghi LA, Cowan FM. Neonatal Stroke. Review. Arch Dis Child Fetal Neonatal Ed. 2012; 97: F377-F384.

7. Chabrier S, Husson B, Dinomais $M$ et al. New insights (and new interrogations) in perinatal arterial ischemic stroke. Mini review. Thromb Res 2011; 127: 13-22.

8. Golomb MR, Garg BP, Saha C, Azzouz F, Williams LS. Cerebral palsy after perinatal arterial ischemic stroke. J Child Neurol 2008; 23: 279-286.

9. De Vries LS, Van der Grond J, Van Haastert IC, Groenendaal F. Prediction of outcome in new-born infants with arterial ischaemic stroke using diffusion-weighted magnetic resonance imaging. Neuropediatrics 2005; 36: 12-20.

10. Staudt M, Niemann G, Grodd W, Krägeloh-Mann I. The pyramidal tract in congenital hemiparesis: relationship between morphology and function in periventricular lesions. Neuropediatrics 2000; 31: 257-264.

11. Carr LJ, Harrisson LM, Evans AL, Stephens JA. Patterns of central motor organization in hemiplegic cerebral palsy. Brain 1993; 116(Pt 5): 1223-1247.

12. Holmström L, Vollmer B, Tedroff K, Islam $\mathrm{M}$ et al. Hand function in relation to brain lesions and corticomotor-projection pattern in children with unilateral cerebral palsy. Dev Med Child Neurol 2010; 52: 145-152.

13. Bleyenheuft $Y$, Grandin CB, Cosnard G, Olivier E, Thonnard JL. Corticospinal Dysgenesis and Upper-Limb Deficits in Congenital Hemiplegia: A Diffusion Tensor Imaging Study. Pediatrics 2007; 120: e1502-e1511.

14. Holmström L, Lennartsson F, Eliasson AC, Flodmark O, et al. Diffusion MRI in corticofugal fibers correlates with hand function in unilateral cerebral palsy. Neurology 2011; 77: 775-783.

15. Randall M, Carlin JB, Chondros P, Reddihough D. Reliability of the Melbourne assessment of unilateral upper limb function. Dev Med Child Neurol 2001; 43: 761-767.

16. Feys $\mathrm{H}$, Eyssen $\mathrm{M}$, Jaspers $\mathrm{E}$, et al. Relation between neuroradiological findings and upper limb function in hemiplegic cerebral palsy. Eur J Paediatr Neurol 2010; 14: 167-177.

17. Holmefur M, Kits A, Bergström, Krumlinde-Sundholm L, et al. Neuroradiology can predict the development of hand function in children with unilateral cerebral palsy. Neurorehabil Neural Repair 2013; 27(1): 72-78.

18. Krumlinde-Sundholm L, Eliasson A. Development of the Assisting Hand Assessment: A Rasch-built measure intended for children with unilateral upper limb impairments. Scand J Occup Ther 2003; 10: 16-26. 
19. Rose S, Guzetta A, Pannek K, Boyd R. MRI structural connectivity, disruption of primary sensorimotor pathways, and hand function in cerebral palsy. Brain Connect 2011; 1(4): 309-316.

20. Taub E, Uswatte G, Pidikiti R. Constraint-induced movement therapy: A new family of techniques with broad Application to Physical Rehabilitation-A Clinical Review. J Rehabil Res Dev 1999; 36(3): 237-251. Review.

21. Charles J, Lavinder G, Gordon AM. Effects of Constraint-Induced Therapy on Hand Function in Children with Hemiplegic Cerebral Palsy. Pediatr PhysTher 2001; 13(2): 68-76.

22. DeLuca S, Echols K, Landesman Ramey S, Taub E. Pediatric Constraint-Induced Movement Therapy for a Young Child With Cerebral Palsy: Two Episodes of Care. Phys Ther 2003; 83: 1003-1013.

23. Hoare BJ, Wasiak J, Imms C, Carey L. Constraint-induced movement therapy in the treatment of the upper limb in children with hemiplegic cerebral palsy. Cochrane Database Syst Rev 2007; (2): CD004149.

24. Aarts PB, Jongerius PH, Geerdink YA, van Limbeek J, Geurts AC. Effectiveness of modified constraintinduced movement therapy in children with unilateral spastic cerebral palsy: a randomized controlled trial. Neurorehabil Neural Repair 2010; 24: 509-518.

25. Gordon AM, Schneider JA, Chinnan A, et al. Efficacy of a hand-arm bimanual intensive therapy (HABIT) in children with hemiplegic cerebral palsy: a randomized control trial. Dev Med Child Neurol 2007; 49: 830-838.

26. Gordon AM, Hung YC, Brandao M, Ferre CL, Kuo HC, Friel K, Petra E. Bimanual training and constraintinduced movement therapy in children with hemiplegic cerebral palsy: a randomized trial. Neurorehabil Neural Repair 2011; 25: 692-702.

27. Sakzewski L, Ziviani J, Abbott JF, Macdonell RA, Jackson GD, Boyd RN. Randomized trial of constraintinduced movement therapy and bimanual training on activity outcomes for children with congenital hemiplegia. Dev Med Child Neurol 2011; 53: 313-320.

28. Deppe W, Thuemmler K, Fleischer J, Berger C, Meyer S, Wiedemann B. Modified constraint-induced movement therapy versus intensive bimanual training for children with hemiplegia - a randomized controlled trial. Clin Rehabil 2013; 27(10), 909-920.

29. Andersen JC, Majnemer A, O'Grady K, Gordon AM. Intensive Upper Extremity Training for Children with Hemiplegia: From Science to Practice. Semin Pediatr Neurol 2013; 20: 100-105.

30. Hoare B, Imms C, Villanueva E, Rawicki HB, Mattyas T, Carey L. Intensive therapy following upper limb botulinum toxin $A$ injection in young children with unilateral cerebral palsy: a randomized trial. Dev Med Child Neurol 2013; 55: 238-247.

31. Hoare BJ, Wallen MA, Imms C, Villanueva E, Rawicki HB, Carey L. Botulinum toxin A as an adjunct to treatment in the management of the upper limb in children with spastic cerebral palsy (UPDATE). Cochrane Database Syst Rev 2010; (1): CD003469. Review.

32. DeMatteo C, Law M, Russell D, Pollock N, Rosenbaum P, Walter S. The reliability and validity of the quality of upper extremity skills test. Phys Occ Ther Pediatr 1993; 13(2): 1-18.

33. Olesch CA, Greaves S, Imms C, Reid SM, Graham HK. Repeat botulinum toxin-A injections in the upper limb of children with hemiplegia: a randomized controlled trial. Dev Med Child Neurol 2010, 52: 79-86.

34. Chaturvedi SK, Rai Y, Chourasia A, Goel P, et al. Comparative assessment of therapeutic response to physiotherapy with or without botulinum toxin injection using diffusion tensor tractography and clinical scores in term diplegic cerebral palsy children. Brain Devel 2013, 35: 647-653.

35. Kuhnke N, Juenger $\mathrm{H}$, Walther M, Mall V, Staudt M. Do patients with congenital hemiparesis and ipsilateral corticospinal projections respond differently to constraint-induced movement therapy? Dev Med Child Neurol 2008; 50: 898-903. 
36. Juenger $\mathrm{H}$, Kuhnke $\mathrm{N}$, Braun $\mathrm{C}$, Ummenhofer $\mathrm{F}$, et al. Two types of exercise-induced neuroplasticity in congenital hemiparesis: a transcranial magnetic stimulation, functional MRI, and magnetoencephalographic study. Dev Med Child Neurol 2013; 55: 941-952.

37. Islam M, Nordstrand L, Holmström L, Kits A, Forssberg H, Eliasson AC. Is outcome of constraint-induced movement therapy in unilateral cerebral palsy dependent on corticomotor projection pattern and brain lesion characteristics? Dev Med Child Neurol 2014; 56: 252-258.

38. Friel K, Chakrabarty S Kuo HC, Martin J. Using Motor Behavior during an Early Critical Period to RestoremSkilled Limb Movement after Damage to the Corticospinal System during Development. J Neurosci 2012; 32(27): 9265-9276.

39. Johnston MV. Plasticity in the Developing Brain: Implications for Rehabilitation. Dev Disabil Res Rev 2009; 15: 94-101. 


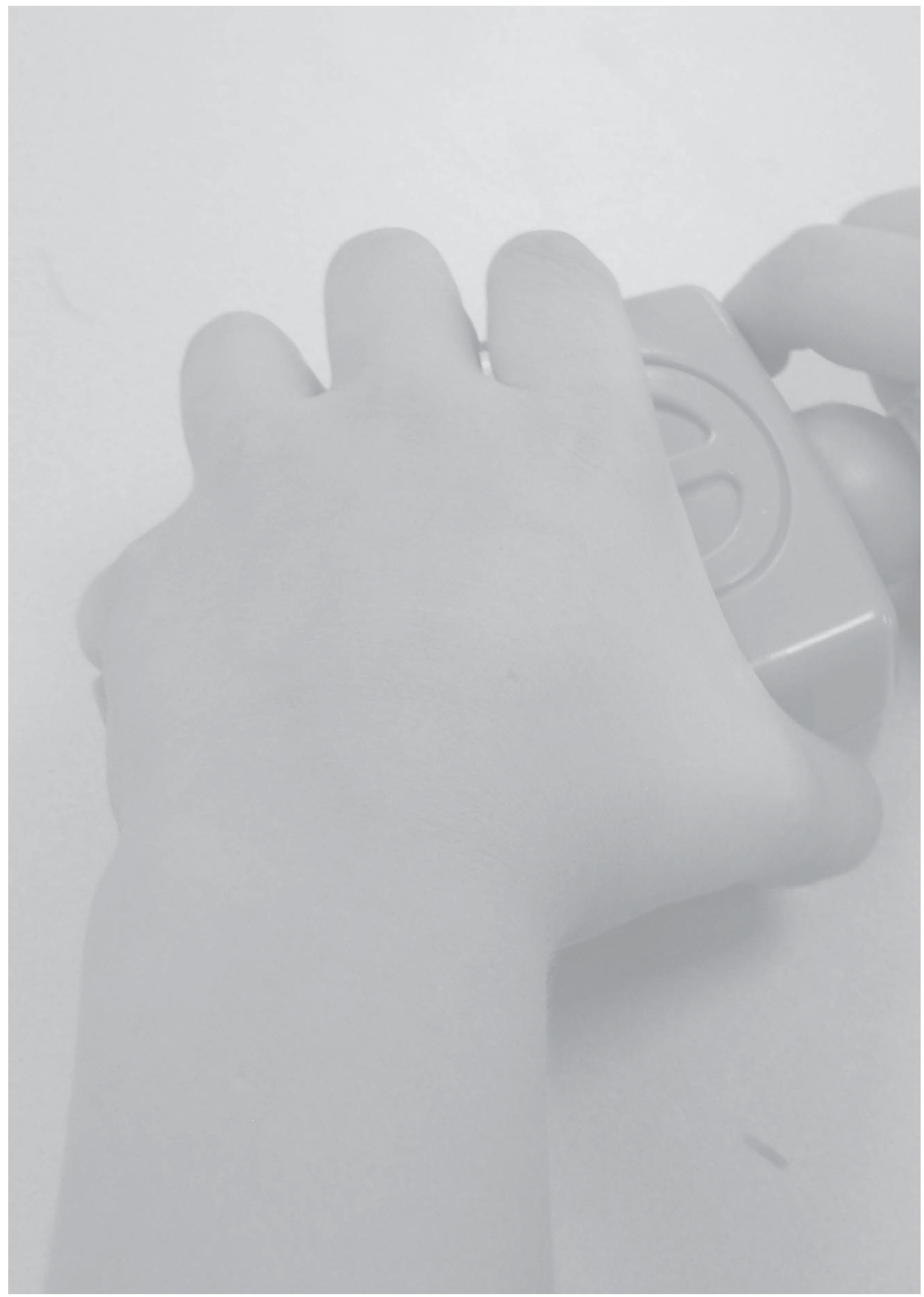




\section{Botulinum toxin A and upper limb functional skills in hemiparetic cerebral palsy: a randomized trial in children receiving intensive therapy}




\section{ABSTRACT}

The objective of this study was to determine whether the use of intramuscular botulinum toxin A (BTX-A) increases upper limb function and skills in the context of a specific therapy programme in children with hemiparetic cerebral palsy. Twenty children (nine females, 11 males) aged 4 to 16 years who were thought likely to benefit from BTX-A treatment were included. After matched pairs were made, on the basis of Zancolli grade and age, randomization took place. All patients were given structured rehabilitation (physiotherapy and occupational therapy three times a week for 6 months), and half of the patients received intramuscular BTX-A. No placebo injections were given in the control group. Participants were assessed at baseline, at 2 and 6 weeks, and at 3, 6, and 9 months after injection. The Ashworth scale, active range of motion of arm joints, the Melbourne assessment of upper limb function, the Pediatric Evaluation of Disability Inventory, and the nine-hole peg test were used for outcome measurement. Observers were blinded for treatment allocation only for scoring the Melbourne test. The children in the treatment group showed a clinically relevant increase in active dorsal flexion, and tone reduction of the wrist. For the functional outcome measures, no statistically significant differences between the groups could be demonstrated. Intramuscular BTX-A added to an intensive therapy programme reduces impairment for at least 9 months; the effect on activity level is still uncertain. 


\section{BACKGROUND}

The beneficial effect of botulinum toxin A (BTX-A) injections (for pharmacology see Brin 1997) ${ }^{1}$ on children with spastic lower limb muscles has been quite well established. . $^{2,3}$ However, with regard to arm-hand function in children with cerebral palsy (CP), a recent systematic review concluded that there is very little evidence to guide the choice of treatment. ${ }^{4}$ Beside some uncontrolled studies, ${ }^{5-7}$ only two small, randomized studies of BTX-A in the treatment of arm function problems in children with $\mathrm{CP}$ have been published. In a randomized, double blind placebo-controlled study describing the effects of BTX-A injections into the upper limb in 14 patients with $\mathrm{CP}$, Corry et al. found a significant increase in active elbow and thumb extension, and a significantly reduced tone at wrist and elbow, at 12-week follow-up. ${ }^{8}$ The results on activity level of the International Classification of Functioning, Disability and Health (ICF) were inconclusive. ${ }^{9}$

Fehlings et al. studied the additional effect of BTX-A injections in the arm muscles in 29 children with hemiplegic $\mathrm{CP}$ receiving occupational therapy in a randomized single-blind trial. ${ }^{10}$ They reported some improvement at activity level of the ICF, as measured with the Quality of Upper Extremity Skills Test (QUEST) and also in the self-care domain of the Pediatric Evaluation of Disability Inventory (PEDI).

Injections of BTX-A are proved to be effective at impairment level (tone, active range of motion [ROM]) for a period of 12 weeks. ${ }^{8}$ In the Fehlings et al. study, in which the children received limited occupational therapy once every 2 weeks, modest functional effects were found. ${ }^{10}$ Increasing the intensity of therapy might increase functional improvement at activity level (ICF). ${ }^{9}$ This hypothesis is corroborated by the theory of Huttenlocher. ${ }^{11}$ Furthermore, it is known that BTX-A injections into the lower limb seem to be more effective than injections into the upper limb. This can be explained by the inevitable greater practice of the affected lower limb during walking when spasticity is reduced by BTX-A. ${ }^{4}$

The aim of the present study was to evaluate the additional effect of BTX-A injections on upper-limb function and skills in children with hemiparetic $C P$ who were receiving an intensive rehabilitation programme. 


\section{METHOD}

\section{Participants}

After approval of the Medical Ethical Committee of the Rehabilitation Foundation Limburg and the Academic Hospital Maastricht as well as the Dutch Medical Ethical Board and after informed assent, 20 patients (nine females, 11 males, aged 4 to 16y) with hemiparetic CP and a minimum developmental age of 3 years who were thought likely to receive functional benefit from BTX-A injections were included in the study.

The children were recruited from our paediatric rehabilitation centre or referred to us from neighbouring centres. Patients with obvious contractures (deficit of elbow extension, supination and wrist dorsal flexion of $30^{\circ}$ or more) and severe impairment of hand function, unable to initiate voluntary movement (Zancolli III) were excluded. ${ }^{12}$

\section{Study design}

Ten pairs of patients were formed by matching as closely as possible for age and Zancolli grade (Figure 3.1). One child of every pair was randomly allocated to either the BTX-A or the control group by choosing one opaque envelope of 10 (five BTX-A and five control), assigning the other child automatically to the other group. Sex was not considered relevant in the matching process.

\section{Injection technique and dosage}

The BTX-A injections were given under general anaesthesia in the daycare department of the Academic Hospital Maastricht. To determine which muscle to inject, each patient was given an individual clinical examination. Spastic hypertonia of a specific muscle disturbing strength and/or function in daily activities in relation to the Zancolli grade and House score were criteria for injecting that specific muscle. ${ }^{14}$ The target muscles were located with the help of electrical stimulation. ${ }^{15}$

Botox from Allergan was used (dilution $5 \mathrm{U}$ per $0.1 \mathrm{ml}$ ). The dosages were 2 to $3 \mathrm{U} / \mathrm{kg}$ body weight above the elbow, 1 to $2 \mathrm{U} / \mathrm{kg}$ in the forearm, limited to no more than $50 \mathrm{U}$ at any one site, with an overall maximum dose of $400 \mathrm{U} / \mathrm{kg}$ body weight. ${ }^{3}$ In Table 3.1 an overview of the injected muscles and some patient characteristics are given. For ethical reasons regarding 

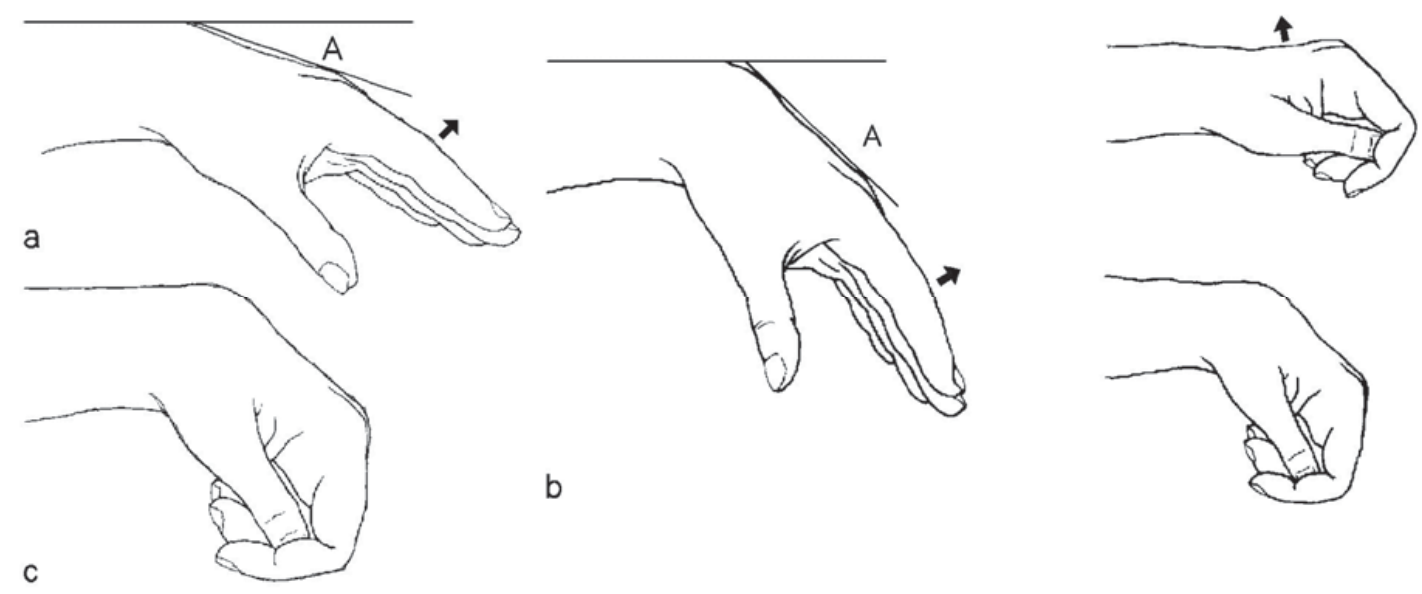

Figure 3.1 Zancolli classification (Zancolli and Zancolli 1987).

Diagram of grip and release pattern according to Zancolli. (a) Pattern I active finger extension with less than $20^{\circ}$ (angle A) of wrist palmar flexion. (b) Pattern II active finger extension with more than $20^{\circ}$ (angle A) of wrist palmar flexion; Zancolli IIA with wrist dorsal flexion possibility with fisted hand; Zancolli IIB no possibility of dorsal flexion of active wrist. (c) Pattern III: no active finger extension possible. (From Hoeksma et al. 1995; used with permission. $)^{13}$

general anaesthesia without further necessary medical intervention, no placebo injections were given in the control group.

\section{Therapy programme and splinting}

The therapy programme for all the children consisted of 30 minutes of physiotherapy and 30 minutes of occupational therapy, by experienced child therapists, three times a week for a period of 6 months. A treatment protocol, describing time and degree of stretching, wearing of orthoses, time of strength and coordination training and task-specific training, was made for each level of hand function impairment (Zancolli grade). This was tailored to the individual patient, based on individual goal setting and clinical reasoning. Active ROM was treated by stretch techniques and passive ROM by the use of orthoses. All children wore a night splint with the elbow extended, the forearm neutral between pronation and supination, and the wrist in dorsal flexion with the thumb in abduction and the fingers in opposition. During the day only the children graded Zancolli IIB wore a cock-up splint almost all day; the children with less impairment needed a cock-up or a web-space splint only during specific activities. Strength and coordination were trained using specific activities and skills (more repeats, more weight bearing) according to individual goal setting for each patient. Skill training was performed in accordance with the theory of Fitts and Posner. ${ }^{16}$ 


\section{Follow-up and outcome measures}

Outcome measures were collected at baseline, at 2 and 6 weeks, and at 3, 6, and 9 months after treatment. At 6 months the therapy programme ended.

At impairment level (ICF) ${ }^{9}$ outcome measures were active ROM of thumb abduction, wrist dorsal flexion, and supination, assessed in sitting position. For the wrist, the zero point was with the hand in the neutral position (straight in line with the forearm), and dorsal flexion was rated as positive degrees. For supination the neutral position was with the palm of the hand vertically oriented, and supination was rated positively. For the thumb, neutral $\left(0^{\circ}\right)$ was with the thumb against the palm, with abduction rated positively. The maximum deviation in degrees achieved voluntarily by the child was measured by a research physiotherapist who was not blinded to the child's treatment group, by using a clinical goniometer (UK patent 840.1841; MIE Medical Research Ltd.). Wrist and elbow tone were measured with the Ashworth score, taken in the supine position. ${ }^{17}$

At activity level (ICF) the Melbourne assessment of unilateral upper limb function developed by Randall in 1999 was used because it measures unilateral upper limb function in children with spasticity in the relevant age group, and can be scored from video recordings. ${ }^{18,19}$ It was performed and videotaped by experienced and trained occupational therapists. The videos of the Melbourne assessment were coded and scored in random order by a movement scientist who was unaware of the child's treatment group. The PEDI ${ }^{20,21}$ was administered completely at baseline and at 6 months. During the other measurement sessions only the PEDI self-care scale was obtained. The nine-hole peg test was administered to measure velocity. ${ }^{22}$ Finally, both the parents and the children themselves judged the functional use of their affected hand on a seven-point scale from very bad $(-3)$ to moderate $(0)$ to very good $(+3)$.

At baseline and at 9 months after the start of treatment the Zancolli score ${ }^{12}$ and the House score $^{14}$ for thumb position (Table 3.1) were recorded.

\section{Statistical analysis}

Data processing was performed with SPSS for Windows version 11.0. For each outcome variable the change from the base- line value was calculated. The Mann-Whitney $U$ test was used to assess the differences in these changes between the two groups. The level of significance was set at $p<0.05$, one-sided. Because of the small number of patients no statistical correction for baseline differences was performed. 


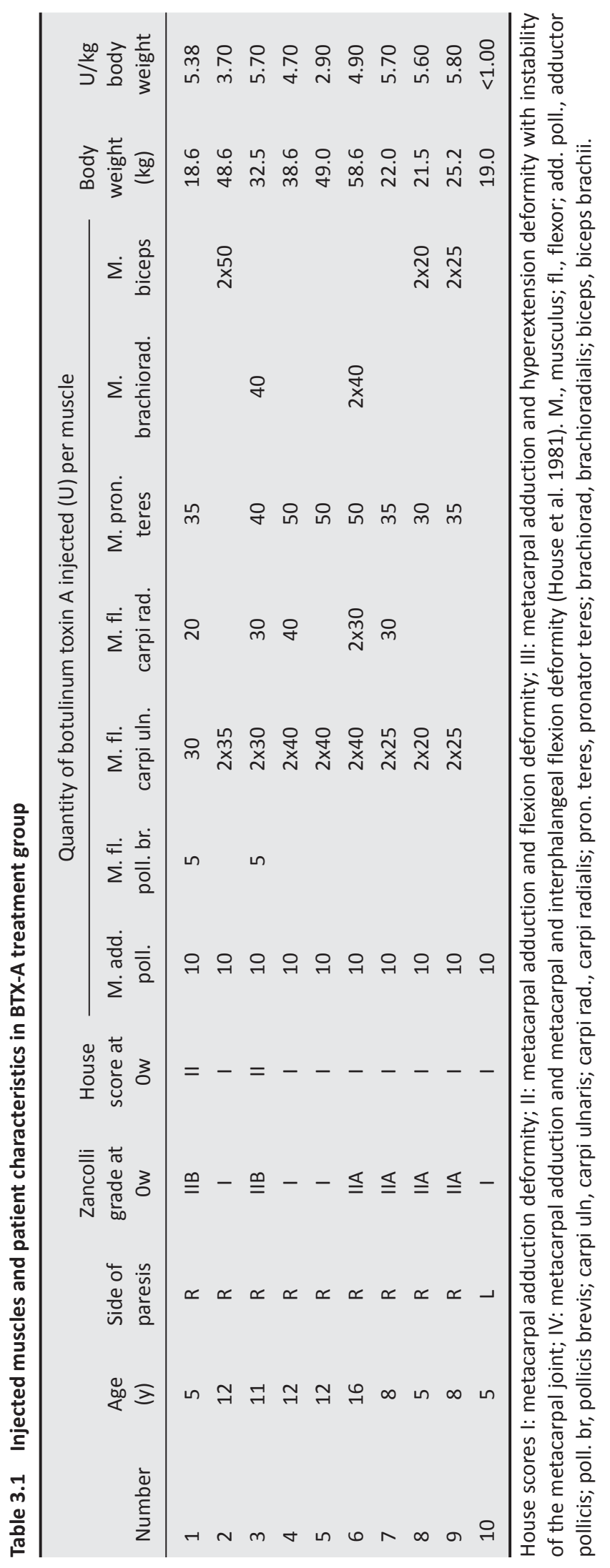




\section{RESULTS}

The children underwent the injections under general anaesthesia without any problems. No side effects or complaints about the treatment were reported. All participants completed the therapy and the measurement programme. Because of lack of cooperation from some of the younger children there were some missing values.

Baseline characteristics from both groups are shown in Table 3.2. Apart from the side of paresis, active dorsal flexion and supination, there was no large difference between the groups. However, putting all baseline scores together, the condition of the patients in the

Table 3.2 Characteristics and baseline scores in compared treatment groups

\begin{tabular}{|c|c|c|}
\hline \multirow[b]{2}{*}{ Characteristic } & \multicolumn{2}{|c|}{$\begin{array}{l}\text { Median score/degrees ( } \mathrm{min} / \mathrm{max} \text { ) or } \\
\text { frequencies at baseline }\end{array}$} \\
\hline & BTX-A (n-10) & Control $(n=10)$ \\
\hline Side paresis & $9 \mathrm{R}, 1 \mathrm{~L}$ & $3 \mathrm{R}, 7 \mathrm{~L}$ \\
\hline Mean age in years (range) & $9.4(5-16)$ & $9.7(4-16)$ \\
\hline \multicolumn{3}{|l|}{ Sex } \\
\hline Male & 5 & 4 \\
\hline Female & 5 & 6 \\
\hline \multicolumn{3}{|l|}{ Zancolli } \\
\hline 1 & 4 & 5 \\
\hline$\| \mathrm{A}$ & 4 & 1 \\
\hline IIB & 2 & 4 \\
\hline \multicolumn{3}{|l|}{ House score } \\
\hline 1 & 8 & 6 \\
\hline II & 2 & 3 \\
\hline III & - & 1 \\
\hline Active dorsal flexion wrist & $-18(-51$ to 45$)$ & $-6(-55$ to 55$)$ \\
\hline Active thumb abduction & 26 (12 to 44$)$ & 21 (-10 to 37$)$ \\
\hline Active supination & $6(-62$ to 50$)$ & $-24(-70$ to 50$)$ \\
\hline \multicolumn{3}{|l|}{ Ashworth wrist } \\
\hline 0 & 7 & 5 \\
\hline 1 & 2 & 4 \\
\hline 2 & 1 & 1 \\
\hline \multicolumn{3}{|l|}{ Ashworth elbow } \\
\hline 0 & 3 & 3 \\
\hline 1 & 6 & 5 \\
\hline 2 & 1 & - \\
\hline Melbourne assessment score (\%) & 69 (52 to 77$)$ & 61 (46 to 79$)$ \\
\hline PEDI self-care raw score & 67 (54 to 73 ) & 70 (47 to 73 ) \\
\hline
\end{tabular}

BTX-A, botulinum toxin A; L, left; PEDI, Pediatric Evaluation of Disability Inventory; R, right. 
control group was worse. Only active dorsal flexion of the wrist and the PEDI self-care score were better in the control group.

Median scores and frequencies of the outcome measures at the different follow-up times are shown in Tables 3.3 and 3.4. Wrist tone decreased in both study groups. In the BTX-A group there was maximal reduction already at 2 weeks after the injection, whereas the improvement in the control group was gradual. In both groups there was gradual improvement of elbow tone, at 2 weeks somewhat more in the treatment group. The improvement in active dorsal flexion of the wrist in the treatment group was larger than in the control group. This did not reach statistical significance for any follow-up period. Active thumb abduction showed modest changes in both treatment groups.

The statistically significant change in active supination at 2 weeks and at 9 months in favour of the control group can be explained by the very low baseline scores from three children with a Zancolli IIB score in this group. For reasons that are not clear, they achieved substantially better scores 2 weeks later. These results are, therefore, contradictory, despite eight patients receiving blockades in the pronator teres. Active supination in the BTX-A group steadily improved over the first 3 months and declined thereafter.

At activity level the Melbourne assessment was the primary outcome measure. The percentage score did not show much change from baseline in both groups. Some of the items of the Melbourne assessment are to do with fluency and target accuracy, which are

Table 3.3 Frequencies of Ashworth scores for wrist and elbow

\begin{tabular}{|c|c|c|c|c|c|c|c|c|}
\hline & \multirow[b]{2}{*}{ Group } & \multirow[b]{2}{*}{ Ash score } & \multicolumn{6}{|c|}{ Frequency } \\
\hline & & & Owk & $2 w k$ & $6 w k$ & $3 \mathrm{mo}$ & $9 \mathrm{mo}$ & $9 \mathrm{mo}$ \\
\hline \multirow[t]{6}{*}{ Wrist } & BTX-A & 0 & 7 & 10 & 10 & 10 & 10 & 10 \\
\hline & & 1 & 2 & 0 & 0 & 0 & 0 & 0 \\
\hline & & 2 & 1 & 0 & 0 & 0 & 0 & 0 \\
\hline & Control & 0 & 5 & 6 & 7 & 9 & 8 & 9 \\
\hline & & 1 & 4 & 2 & 2 & 1 & 2 & 1 \\
\hline & & 2 & 1 & 2 & 1 & 0 & 0 & 0 \\
\hline \multirow[t]{6}{*}{ Elbow } & BTX-A & 0 & 3 & 7 & 5 & 7 & 6 & 8 \\
\hline & & 1 & 6 & 2 & 4 & 2 & 3 & 1 \\
\hline & & 2 & 1 & 1 & 1 & 1 & 1 & 1 \\
\hline & Control & 0 & 3 & 4 & 6 & 5 & 6 & 6 \\
\hline & & 1 & 5 & 3 & 3 & 3 & 4 & 3 \\
\hline & & 2 & 2 & 3 & 1 & 2 & 0 & 1 \\
\hline
\end{tabular}

BTX-A, botulinum toxin A; Ash. score, Ashworth score. 


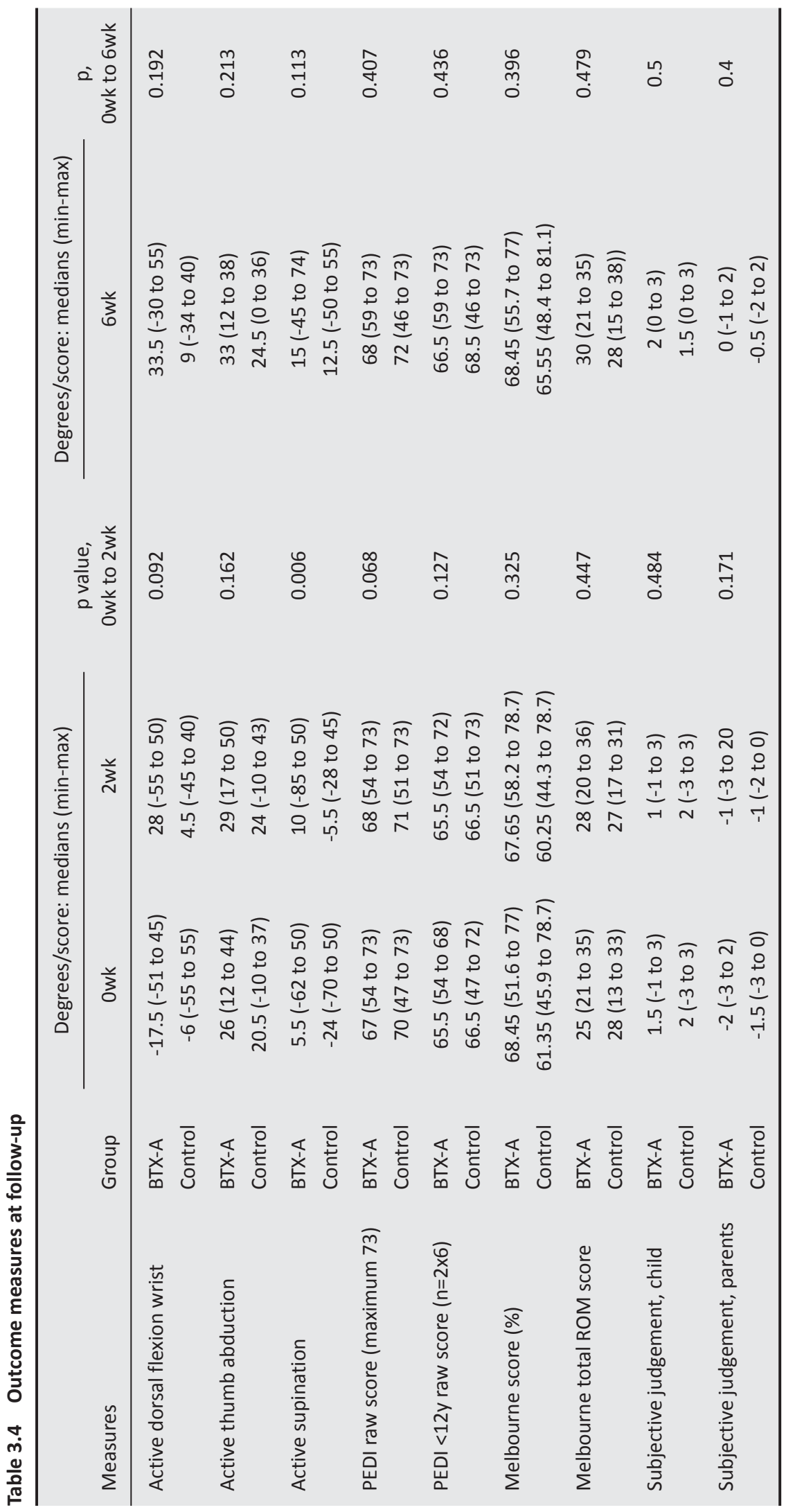




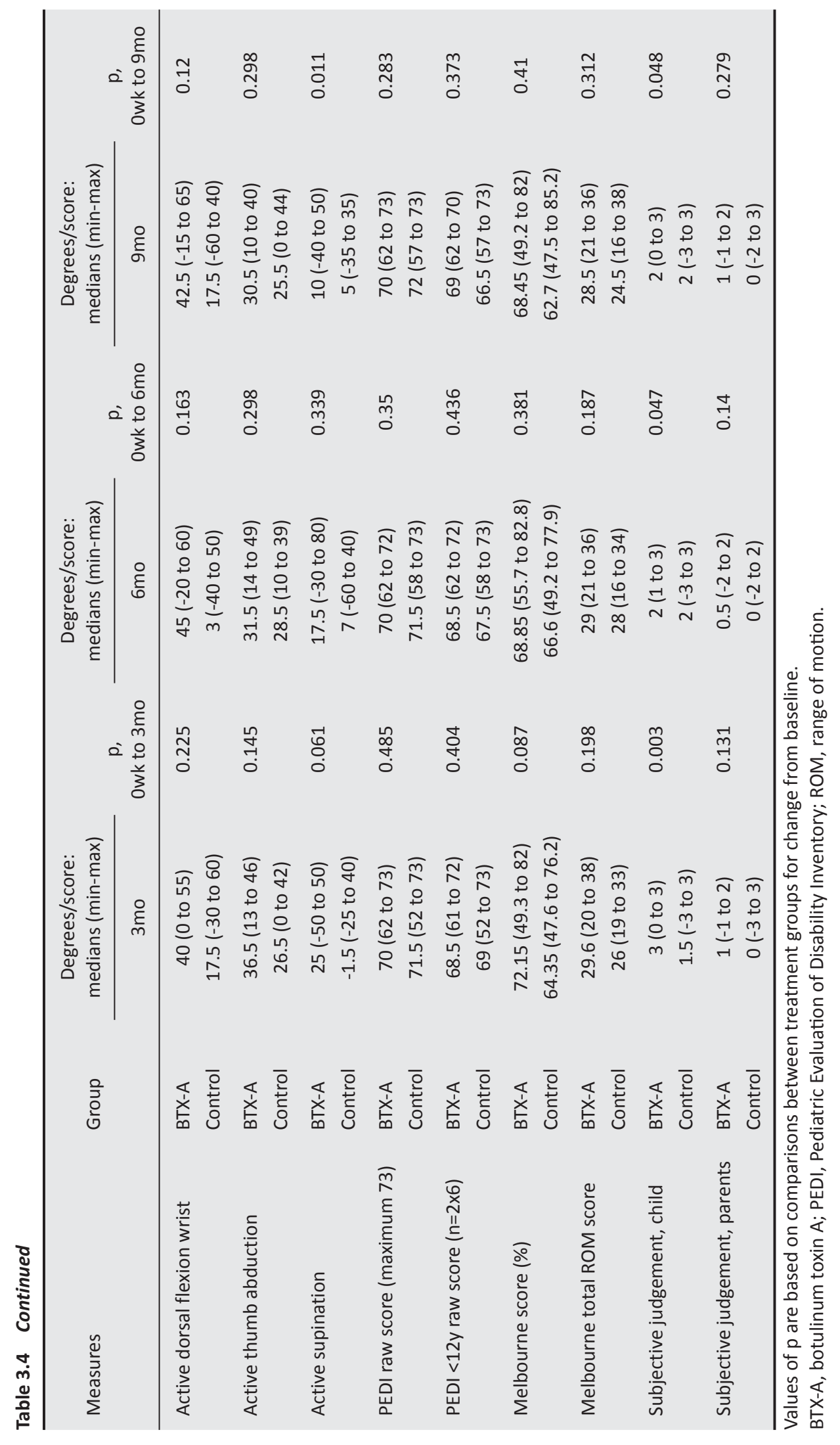


not expected to be improved by BTX-A injections. We, therefore, also analyzed the sum of those items of the Melbourne test in which the posture of thumb/fingers, wrist and elbow/ forearm are scored (Melbourne ROM score). With this item selection the BTX-A group showed some tendency towards improvement until the 6-week follow-up (although this was not a significant difference), whereas the control group did not.

With the PEDI self-care inventory neither the treatment nor the control group showed any substantial improvement. Because the children aged 12 years and above had a maximum score (ceiling effect) the analysis was also performed after excluding them. Among the younger children (six in each group) the change was indeed larger but was not statistically significant. At baseline both groups scored 10 points higher than in the Fehlings (2000) study, which leaves little opportunity for progression.

The children with a Zancolli IIB score and the youngest participant were unable to perform the nine-hole peg test. The remaining 11 children needed between 3.7 and 90 seconds. After 3 months the BTX-A-treated children were able to manipulate the nine pegs 11 seconds (SD 16) per peg faster. The control group children needed 2 seconds (SD 5) longer per peg. This difference is not statistically significant.

The BTX-A-treated children subjectively judged their hand function significantly better at 3, 6, and 9 months, whereas the children in the control group did not (Table 3.4). Nine children of the treatment group and six of the control group were satisfied and reached their goals. These varied from cutting with a knife, tying shoelaces, and carrying cups, to climbing, holding the bicycle handle, shaking hands, and hairdressing. However, the parents noted hardly any change.

\section{DISCUSSION}

We evaluated the additional effect of BTX-A injections in the upper limb in children with hemiparetic $\mathrm{CP}$ receiving an intensive occupational and physical therapy programme on function and activities in a randomized trial. As could be expected from earlier research (Corry et al.), ${ }^{8}$ this study showed a beneficial effect of BTX-A injections on wrist flexor tone. The effect was present as soon as 2 weeks after injection and remained for 9 months. In addition, dorsal flexion of the active wrist seems to be positively influenced by BTX-A injections for at least 9 months, although this effect did not reach statistical significance. The statistically significant negative effect of BTX-A treatment on supination that we found can be explained by the very low baseline scores of three patients in the control group. 
At ICF activity level, no significant effect of BTX-A treatment was detected. The children in the BTX-A group were clearly more satisfied with their treatment result than those in the control group; however, the judgements of the parents of the children in both groups did not differ greatly. The velocity in the treatment group improved (not statistically significant), in contrast with that in the control group.

This was for the most part a non-blinded study. Only during the scoring of the Melbourne assessment from videos was the treatment modality concealed. Therapists were aware of the treatment group of the patients. However, it does not seem probable that there will have been any appreciable bias in favour of the BTX-A group because both groups received intensive therapy. The absence of blinding makes interpretation of the subjective judgement of the children difficult, especially because the parents did not notice any clear improvement. The fact that this randomized study was small, and was based on an inhomogeneous study population, had a negative effect on the comparability of the two groups. It seems that the control group had a somewhat worse condition at baseline. Whether this biased the study towards a too large or a too small estimate of the treatment effect remains uncertain. Another negative effect of the small study size and non-homogeneous population is the negative influence on power to show existing effects. The same problem holds for the lack of sensitivity to change for the different effect measures. The Melbourne assessment, for example, might not be responsive enough because it contains many items relating to target accuracy and fluency, which are not expected to be influenced by BTX-A treatment. Indeed, we could show that the treatment effect was somewhat magnified when only ROM-related items were used.

All children received a relatively intense and prolonged course of rehabilitation therapy. This in itself might have led to some benefit in both groups of children, possibly reducing the extent of benefit to be detected. However, without therapy patients cannot avail themselves of potential benefit after BTX-A. So the effect of this course is uncertain.

Although some bias is likely because the study was not placebo-controlled and was only partly blinded, we believe that the results are valid. They are consistent with other related research (Corry et al., Fehlings et al.). ${ }^{8,10}$ They are internally consistent, with greater effects in measures that reflect most closely the effects of BTX-A.

At this stage the evidence specific to children with $\mathrm{CP}$ is insufficient to make any strong recommendations about the use of BTX-A in hypertonic arm muscles. 23 For future studies, 
Chapter 3 Additional effect BoNT-A to BIMT on bimanual skills in uCP

populations should preferably be larger and more homogeneous. In addition, it is necessary to develop outcome measures at ICF activity level that are more sensitive to change and to guarantee blinding where necessary without jeopardizing ethics.

\section{ACKNOWLEDGEMENTS}

We thank the children and their parents for their cooperation. This work was supported by the Phelps fund, the fund 'Het Gebrekkige kind', 'Het Profileringsfonds AZM'. 


\section{REFERENCES}

1 Brin MF. Botulinum toxin: chemistry, pharmacology, toxicity, and immunology. Muscle Nerve Suppl 1997; 6: S146-168.

2. Cosgrove AP, Corry IS, Graham HK. Botulinum toxin in the management of the lower limb in cerebral palsy. Dev Med Child Neurol 1994; 36: 386-396.

3. Graham HK, Aoki KR, Autti-Rämö I, Boyd RN, Delgado MR et al. Recommendations for the use of botulinum toxin $A$ in the management of cerebral palsy. Gait Posture 2000; 11(1): 67-79. Review.

4. Boyd RN, Morris ME, Graham HK. Management of upper limb dysfunction in children with cerebral palsy: a systematic review. Eur J Neurol 2001; 8(Suppl. 5): 150-166.

5. Wall SA, Chait LA, Temlett JA, Perkins B, Hillen G, Becker P. Botulinum A chemodenervation: a new modality in cerebral palsied hands. Br J Plastic Surg 1993; 46: 703-706.

6. Hurvitz EA, Conti GE, Brown SH. Changes in movement characteristics of the spastic upper extremity after botulinum toxin injection. Arch Phys Med Rehabil 2003; 84: 444-454.

7. Yang TF, Fu CP, Kao NT, Chan RC, Chen SJ. Effect of Botulinum toxin type A on cerebral palsy with upper limb spasticity. Am J Phys Med Rehabil 2003; 82: 284-289.

8. Corry IS, Cosgrove AP, Walsh EG, McClean D, Graham HK. Botulinum toxin A in the hemiplegic upper limb: a double-blind trial. Dev Med Child Neurol 1997; 39: 185-193.

9. World Health Organization. International Classification of Functioning, Disability and Health. ICF. Geneva: World Health Organization, 2001.

10. Fehlings D, Rang M, Glazier J, Steele C. An evaluation of botulinum-A toxin injections to improve upper extremity function in children with hemiplegic cerebral palsy. J Pediatrics 2000; 137: 331-337.

11. Huttenlocher PR. Morphometric study of human cerebral cortex development. Neuropsychologia 1990; 28: 517-527.

12. Zancolli EA, Zancolli E Jr. Surgical rehabilitation of the spastic upper limb in cerebral palsy. In DW Lamb (editor), The Paralyzed Hand (pp. 153-160). Edinburgh: Churchill Livingstone, 1987.

13. Hoeksma AF, Bos KE, Meester-Delver A. Operatieve mogelijkheden bij de spastisch verlamde arm en hand. Ned Tijdschr Geneeskd 1995; 139: 1643-1648.

14. House JH, Gwathmey FW, Fidler MO. A dynamic approach to the thumb-in-palm deformity in cerebral palsy. J Bone Joint Surg 1981; 63A: 216-225.

15. O'Brien CF. Injection techniques for botulinum toxin using electromyography and electrical stimulation. Muscle Nerve Suppl 1997; 6: 176-180.

16. Fitts PM, Posner MI. Human Performance. Belmont, CA: Brooks/Cole, 1967.

17. Ashworth B. Preliminary trial of carisoprodol in multiple sclerosis. Practitioner 1964; 192: 540-542.

18. Johnson LM, Randall MJ, Reddihough DS, Oke LE, Byrt TA, Bach TM. Development of a clinical assessment of quality of movement for unilateral upper-limb function. Dev Med Child Neurol 1994; 36: 965-973.

19. Randall M, Carlin JB, Chondros P, Reddihough D. Reliability of the Melbourne assessment of unilateral upper limb function. Dev Med Child Neurol 2001; 43: 761-767.

20. Haley SM, Coster SJ, Ludlow LH, Haltiwanger JT, Andrellos PJ. Pediatric Evaluation of Disability Inventory (PEDI): Development, Standardization, and Administration Manual. Boston: New England Medical Center and PEDI Research Group, 1992. 
Chapter 3 Additional effect BoNT-A to BIMT on bimanual skills in uCP

21. Custers JWH, van der Net J, Helders PJM. Pediatric Evaluation of Disability Inventory klinisch instrument om niveau zelfstandig functioneren bij kinderen te meten. Ned T Fysiother 1997; 107: 34-37.

22. Mathrowitz V, Weber K, Kashman N, Volland G. Adult norms for the nine hole peg test of finger dexterity. Occup Ther J Res 1985; 5: 24-38.

23. Forssberg H, Tedroff KB. Botulinum toxin treatment in cerebral palsy: intervention with poor evaluation? Dev Med Child Neurol 1997; 39: 635-640. 


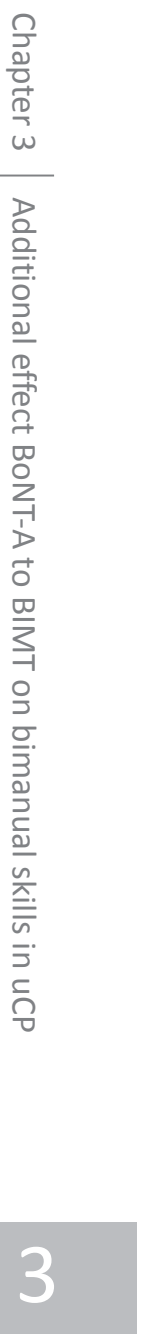




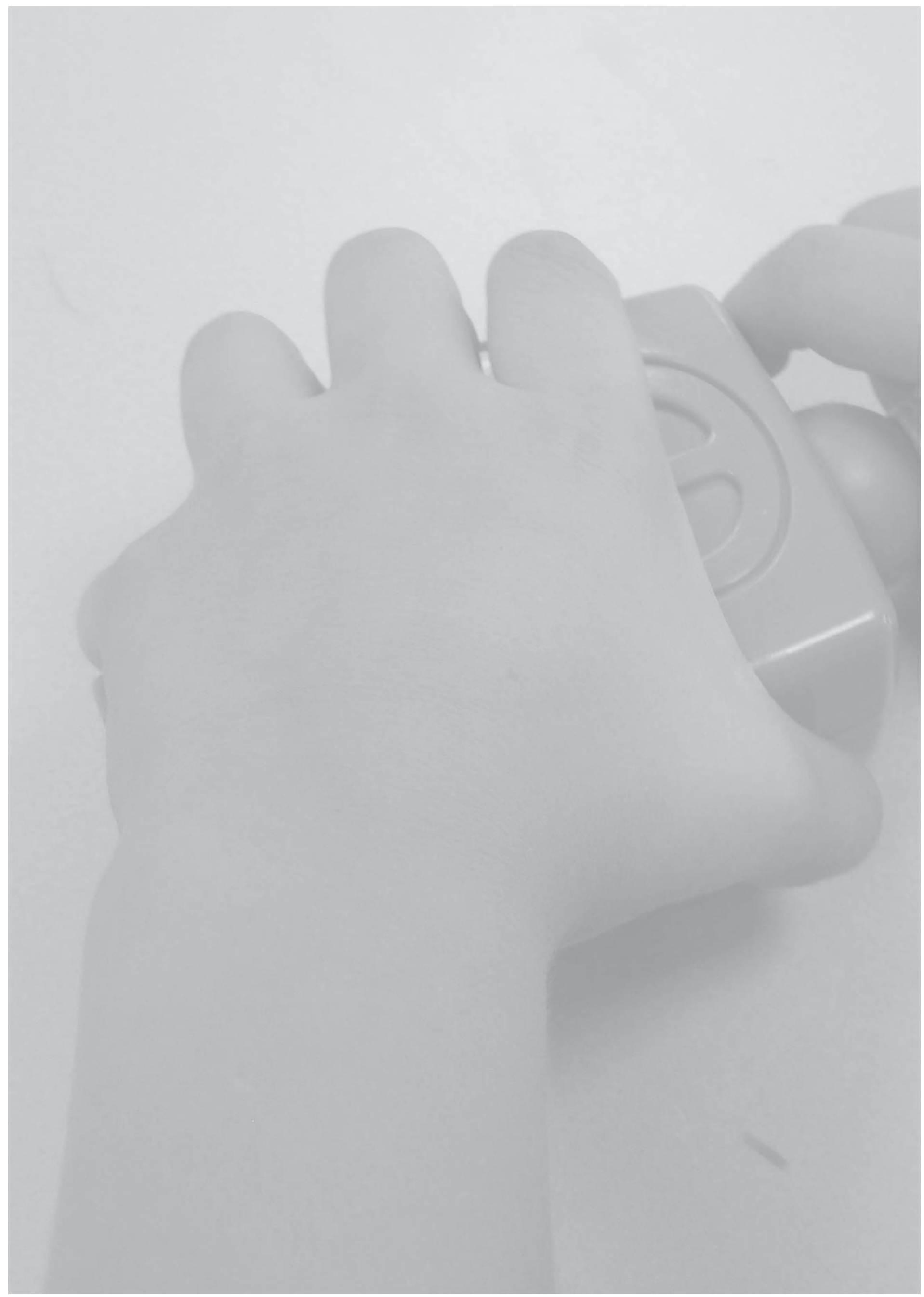




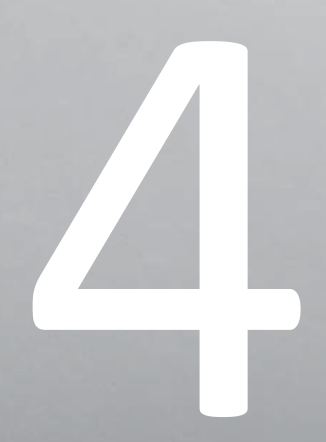

\section{Observational Skills Assessment Score: reliability in measuring amount and quality of use of the affected hand in unilateral Cerebral Palsy}

Lucianne Speth, Yvonne Janssen-Potten, Pieter Leffers, Eugene Rameckers, Anke Defesche, Richard Geers, Rob Smeets, Hans Vles 


\section{ABSTRACT}

\section{Background}

The Observational Skills Assessment Score (OSAS) measures amount and quality of use of the affected hand in children with unilateral Cerebral Palsy (CP) in bimanual activities and could therefore be a valuable addition to existing assessment tools. The OSAS consists of tasks that are age appropriate and require use of the affected hand.

\section{Aim}

To measure the agreement and reliability of the OSAS.

\section{Method}

A convenience sample of two groups of 16 children with unilateral spastic CP (2.5-6 and 12-16 years old), performed age specific bimanual tasks in 2 measurement sessions. Three experienced raters took part in testing and 8 in scoring. Intra class correlation (ICC) values for intra- and inter-rater reliability, and the mean and standard deviation of the differences between measurements were calculated. For test-retest reliability beside ICC scores, Smallest Detectable Differences (SDDs) were calculated in 16 older and 10 younger children.

\section{Results}

Generally, there seems to be good agreement between repeated measurements of the OSAS, as indicated by the small SDDs on most scales for quality of movement, compared to the range of their scales. This indicates potentially good sensitivity to change if used for patient evaluation purposes. The exceptions were the 'quality of reach' score for all tasks, and all quality scores for the stacking blocks task for the young children. As used in the present study, the OSAS has good discriminative capacity within patient populations as indicated by the high ICCs for most quality scores. Measuring the amount of use does not seem to be useful for either discrimination or evaluation.

\section{Conclusion}

In general, the OSAS seems to be a reliable tool for assessing the quality of use of the affected hand in bimanual activities in younger and older children with unilateral CP. Some modifications may improve its usefulness and efficiency. 


\section{BACKGROUND}

Children with clinically apparent unilateral Cerebral Palsy (CP) have specific hand function problems. If they use their affected hand, it is always as an assisting hand. Even with only minor impairment of their affected hand, they often do not use it to its full potential in bimanual tasks. This is called developmental disregard. ${ }^{1,2,3,4}$ Therefore, evaluation of hand function over time or after treatment should focus on the actual use of the affected hand in bimanual activities of daily life, i.e. bimanual performance, as well as on the ability to use the affected hand to its maximal potential in bimanual tasks performed in a standardized environment, which is called capacity. ${ }^{5,6}$

Several assessment tools have been developed for children with unilateral CP. Gilmore et al. $(2010)^{7}$ reviewed the psychometric properties and clinical utility of several upper limb measures at the International Classification of Functioning, Disability and Health (ICF) activity level. ${ }^{8}$ They concluded that the Melbourne Assessment of Unilateral Upper Limb Function (MUUL) ${ }^{9}$ is superior for measuring unilateral capacity, while the Assisting Hand Assessment $(\mathrm{AHA})^{10}$ and ABILHAND-Kids questionnaire ${ }^{11}$ have the best psychometric properties for measuring bimanual performance. Only the AHA is considered to be sufficiently responsive. $^{12}$

In 2005 we studied the effect of botulinum toxin A (BoNT-A) injections on upper limb functional skills in children with unilateral CP. ${ }^{13}$ We used the MUUL as primary outcome measure, because, at that time, it was the best available tool at the ICF activity level. No effect of BoNT-A could be demonstrated. In hindsight this is not surprising because the MUUL contains many items relating to target accuracy, and these are unlikely to be influenced by BoNT-A. Furthermore, it measures one hand at a time and contains tasks that are usually not done by the assisting hand. In 2003, the AHA was specifically developed to assess the effective use of the assisting hand in bimanual performance. Use of the affected hand is stimulated but not obligated in the AHA. We therefore felt the need for an instrument that measures the capacity of the affected hand in bimanual activities and so developed the Observational Skills Assessment Score (OSAS) using basic ideas of the Video Observation Aarts and Aarts (VOAA). ${ }^{14}$ Whereas the MUUL measures unilateral capacity and the AHA measures actual use in bimanual performance, the OSAS measures both the amount and the quality of use (capacity) of the affected hand in tasks in which both hands need to be used. Task performance, especially in young children, can be influenced by visual spatial insight, praxis and cognitive aspects. The OSAS' tasks were therefore chosen to be appropriate for 
the children's ages and their intellectual abilities to prevent these factors from affecting task performance. They involve many repetitions of actions so that quality of use can be assessed reliably. Task execution is filmed, allowing blind assessment. The amount and quality of use of the affected hand are scored every second in order to make the OSAS more sensitive to subtle differences in these features than the AHA. In the AHA, the performance that is observed most frequently during the play session, or sometimes the best performance, is scored.

The OSAS is still under development. It is intended for use in clinical practice to support choice of treatment and for treatment evaluation as well as for research purposes. Because, as a first step in its evaluation, it is important to know its ability to give the same results in repeated measurements, we assessed intra-rater, inter-rater and test-retest agreement and reliability using the Guidelines for Reporting Reliability and Agreement Studies (GRRAS). ${ }^{15}$

\section{Development and description of OSAS}

An expert team of three occupational therapists, three physiotherapists and one rehabilitation physician developed several age-appropriate, standardized bimanual motor tasks for children of 2.5 to 6 and 7 to 16 years old. These tasks cannot be performed by the child without repetitively using the affected hand. In the younger age group, the tasks are building with 'Pop-Onz' (Fisher Price ${ }^{\circledR}$ ), threading beads and stacking blocks. For the older children, the tasks are small and large screw and nut construction, and buttering and cutting bread. The child's performance is videotaped, allowing blind assessment.

\section{OSAS administration protocol}

The OSAS manual provides an exact description per task of how the child should be positioned at the table, table height, position of the materials needed, and what instructions should be given to the child. This manual is available from the corresponding author; an example is given in Additional file 4.1. Two synchronized cameras are used. Simultaneous frontal and cranial views make assessment of the use of the affected hand easier, because the positions of wrist, thumb and fingers are easier to see. The correct positioning of the cameras is also described in the manual. Administration of the three tasks takes about 45 minutes. 


\section{OSAS SCORING PROTOCOL AND DATA PROCESSING}

The quality of use of the affected hand is scored on an ordinal scale. Four domains of use were defined: reach, grasp (position thumb and fingers, and position wrist), hold (position thumb and fingers, and position wrist), and release. Each domain has 3 to 5 quality score levels ranging from poor to good quality. The same expert group that designed the tasks also formulated the quality criteria. These criteria are described in detail in Additional file 4.2.

The video recordings are analyzed with a user-dedicated software program (Figure 4.1) based on MATLAB (MathWorks inc). The frontal and cranial views are displayed next to each other. In the same window the quality criteria for scoring are shown as a pop-up menu. The video recordings are forwarded second-by-second. Every second both the quality of use of the affected hand and the use of the non-affected hand are scored according to the previously mentioned quality criteria. Scoring the video recording of one task takes 20 minutes for an experienced rater. To prevent scoring from taking too long, each task is limited to a maximum of 2.5 minutes. All participants were able to complete the tasks within this time. At least one of the quality criteria of the affected hand has to be scored every second unless the affected hand was not used. In that case, only the use of unaffected hand is scored. The amount of use of both hands during the task is expressed as a proportion of the total time needed to complete the task. The mean quality score of each domain has to be calculated separately for each task; a higher mean score corresponds to better quality of hand function.

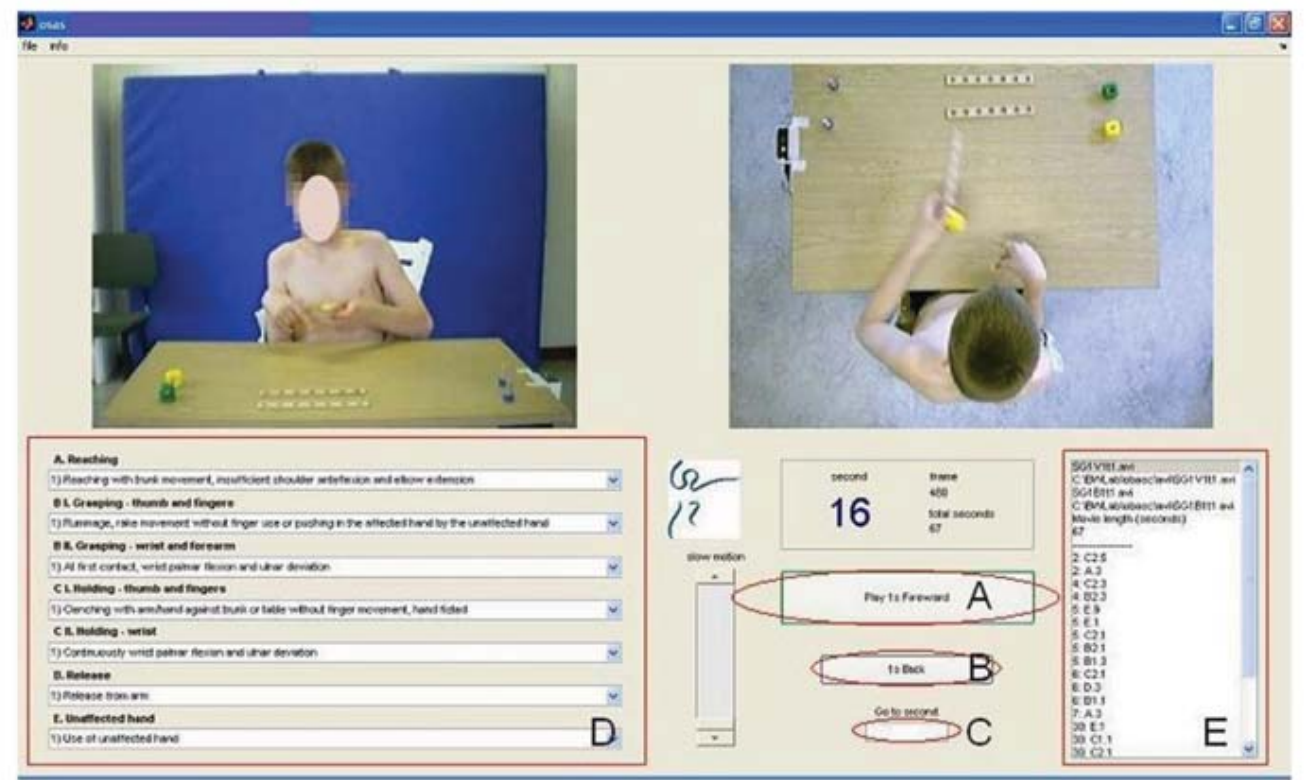

Figure 4.1 OSAS video recordings with quality criteria for scoring as a popup menu (given with the parents' written permission). 


\section{METHODS}

\section{Participants and study design}

A convenience sample of 16 children aged 12 to 16 years (older age group) and 16 children aged 2.5 to 6 years (younger age group) with unilateral spastic CP performed the tasks. The older children participated in a constrained induced therapy program and the younger children in a BoNT-A and/or specific therapy effect study. Children and parents gave their written informed consent to use data for research purposes. The study in which the children participated had medical ethics approval of the METC Atrium-Orbis-Zuyd (06-p-33) and the Dutch CCMO (ref: NL12005.096.06). Due to the study design and the therapy program, children with very severe hand impairments classified as Manual Ability Classification Score (MACS) IV or $\mathrm{V}^{16}$ who were not able to use their hand, were not enrolled in this reliability study. We used their baseline measures before any intervention took place. Three experienced therapists performed these measurements. In the older age group 5 children had a MACS I, 9 children a II and 2 had a MACS III score. In the younger age group 4 had MACSI, 8 MACSII, and 4 MACS III. All children were intellectually able to perform these tasks.

\section{Raters}

The three tasks for the 16 older children were performed twice during 2 sessions with 6 weeks in between in which no intervention took place. Considering their age, we did not expect them to change within this period. In the younger age group, because of the protocol of the study in which they were enrolled, the same was done with 10 children with 2 weeks between measurements. The videotapes of these task performances were scored by the same rater later for the test-retest reliability assessment. For 16 children from both the older and younger age groups, task performance of the second test session was scored by two raters to assess inter-rater reliability. The videotape of this second session task was renamed to allow twice blind scoring by the same raters with at least two weeks in between to determine intra-rater reliability (Figure 4.2). The raters were physiotherapists or occupational therapists trained by an occupational therapist who is a co-developer of the OSAS. This training consisted of scoring videotapes of these tasks performed by other CP children not involved in this study. This was first done in a group session and later practiced as individual home work exercises. There were 4 raters for both age groups; all raters scored the videotapes independently. 
Age 12-16

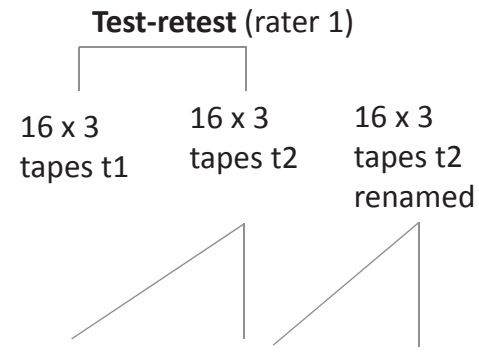

rater 2 rater $3+4 \quad$ rater $3+4$

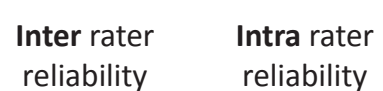

Age 2.5-6

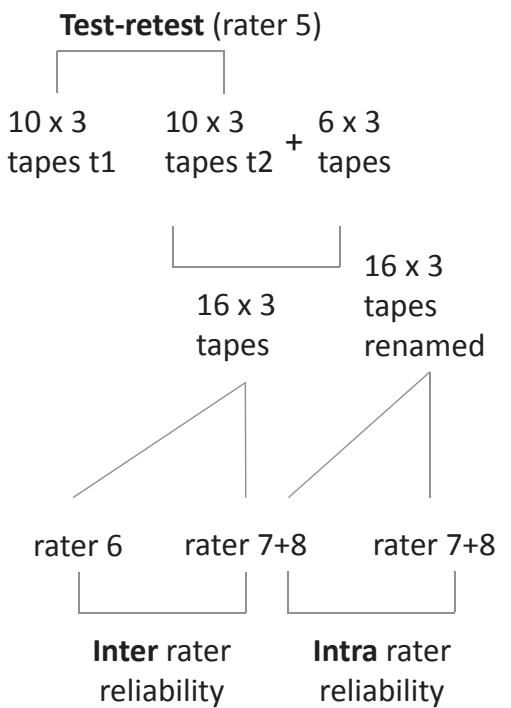

Figure 4.2 Reliability assessments. Rater $3+4$ and $7+8$ each scored half of the 2 times 16 ( 3 tasks) tapes.

\section{Statistics}

After data processing with MATLAB, the proportion of time that both hands were used during tasks (i.e. the percentage of use of both hands), and mean scores of the quality of use of the affected hand on the different domains (reach, grasp fingers, grasp wrist, hold fingers, hold wrist and release) were determined. The mean differences of the two measurements and their standard deviations (SD) were computed. Intra Class Correlation (ICC) values (95\% confidence interval) with a two-way random-effects analysis of variance model (absolute agreement type) of these mean scores were computed to determine the intra-rater, the interrater and test-retest reliability of both amount and quality of use. ${ }^{17}$ In addition we calculated the Standard Error of Measurement (SEM) and the Smallest Detectable Difference (SDD) as measures of agreement. ${ }^{18}$ The SDD was calculated as $1.96 \times \sqrt{ } 2 \times \mathrm{SEM}^{17}$ and represents the threshold that must be overcome to ensure that a change is real.

\section{RESULTS}

\section{Means and ranges}

The means and ranges for the amount and quality of use scores are shown in Figure 4.3 for the older age group and in Figure 4.4 for the younger age group. The amount of use of both 
hands by the older children was high, with little variation between children (Figure 4.3), especially in the construction tasks. With the younger children the amount of use of both hands was clearly lower and showed more variation.

\section{Mean score and range for the tasks of the older age group}

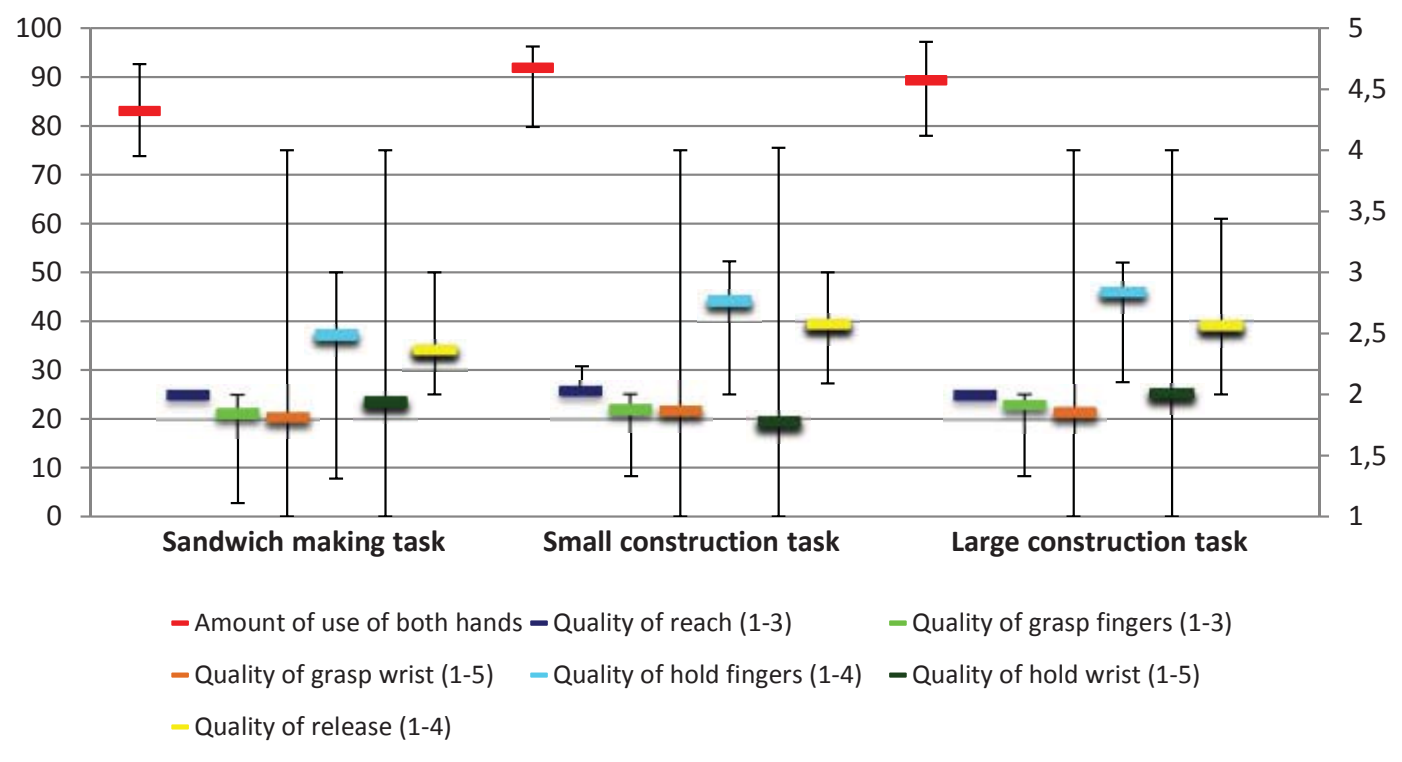

Figure 4.3 Mean score and range for the tasks of the older age group. Left Y-axis is amount of use (\%), right Y-axis is quality of use.

Mean score and range for the tasks of the younger age group

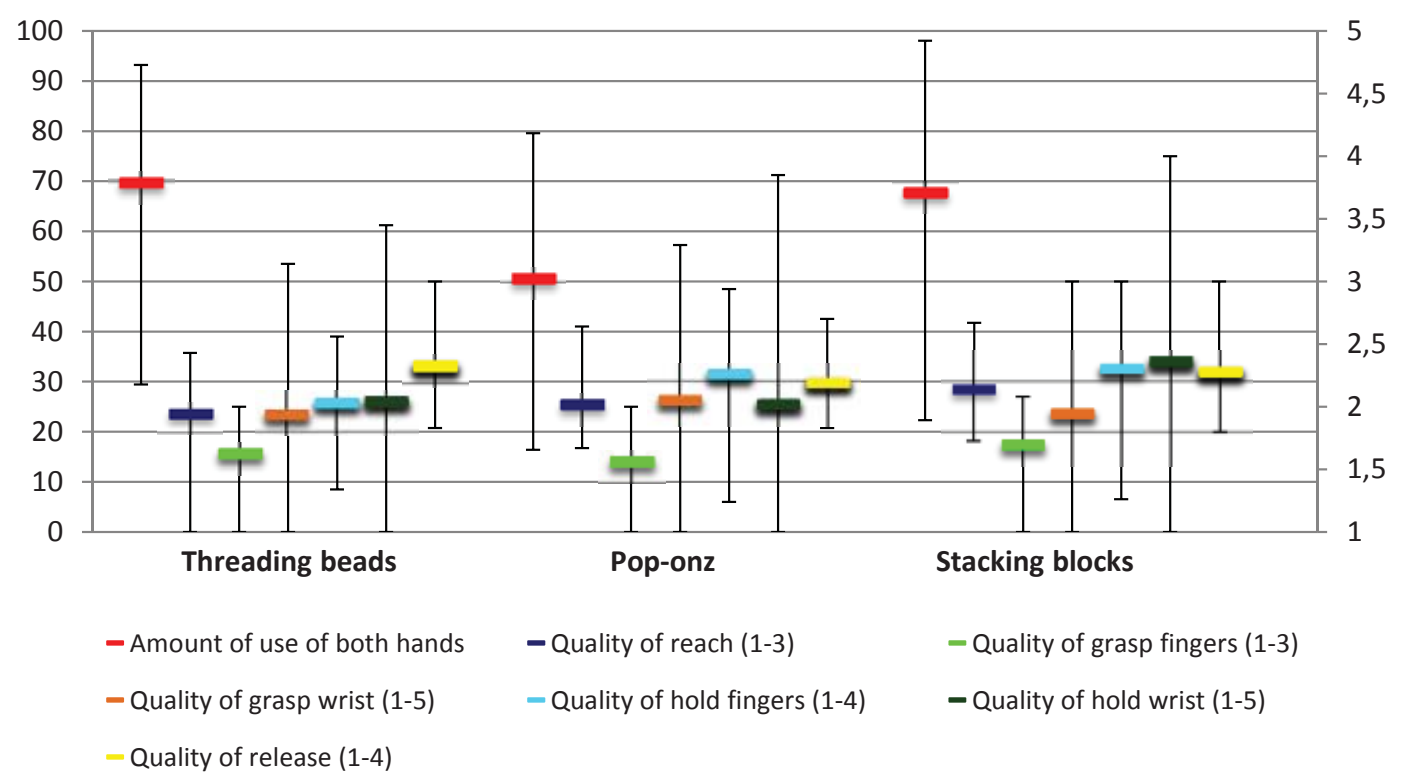

Figure 4.4 Mean score and range for the tasks of the younger age group. Left Y-axis is amount of use (\%), right $Y$-axis is quality of use. 
For quality of reach, the score was almost always 2 in the older age group; for the younger children there was some variation. In the older age group the quality of grasp wrist score had a larger range and the quality of hold fingers score was clearly higher, whereas the quality of hold wrist score was slightly lower and had a larger range compared to the younger children.

\section{Reliability data}

\section{Older age group}

The intra-rater, inter-rater and test-retest reliabilities expressed as ICC values (95\% confidence interval) of the percentage of use and mean quality scores of the three fine motor tasks of the 16 older children are shown in Tables 4.1, 4.2 and 4.3, respectively. Table 4.3 also shows the SDD of the percentage of use of both hands and the mean scores of the quality domains.

In the older age group the proportion of time that both hands were used (amount of use, second column) showed high intra- and inter-rater reliability ICC values, varying from 0.79 to 0.96 . The test-retest ICC values showed low agreement $(0.04,0.44$, and 0.45$)$. Correspondingly, mean differences and their SDs were also larger than in intra- and interrater reliability measurements. The SDD of the amount of use of both hands in these older children varied from $11.3 \%$ (making a sandwich) to $14.5 \%$ (construction task large). These numbers indicated high variation in relation to the mean percentages of use of both hands (83\%-92\%, see Figure 4.2).

The ICC values expressing intra-rater reliability of quality of use for all domains (Table 4.1, column 3 to 8 ) for the three tasks of the 16 older children varied from 0.75 to 0.99 , indicating good reliability. Only the ICC of the quality of grasp finger score of the large construction task was low: 0.09 . The ICCs for 'the quality of reach' of the sandwich making and the large construction tasks could not be calculated because too many mean scores were identical. We therefore reported the mean difference between the two measurements and its standard deviation. A difference in the mean of 'quality of reach' (Table 4.1) only emerged in one child.

In the older age group, inter-rater reliability of the quality of use showed good ICC scores for all measurements except for 'quality of reach' and 'quality of grasp fingers'. The SDs of the difference in these measurements were higher than in the test-retest measurements (Table 4.5). 


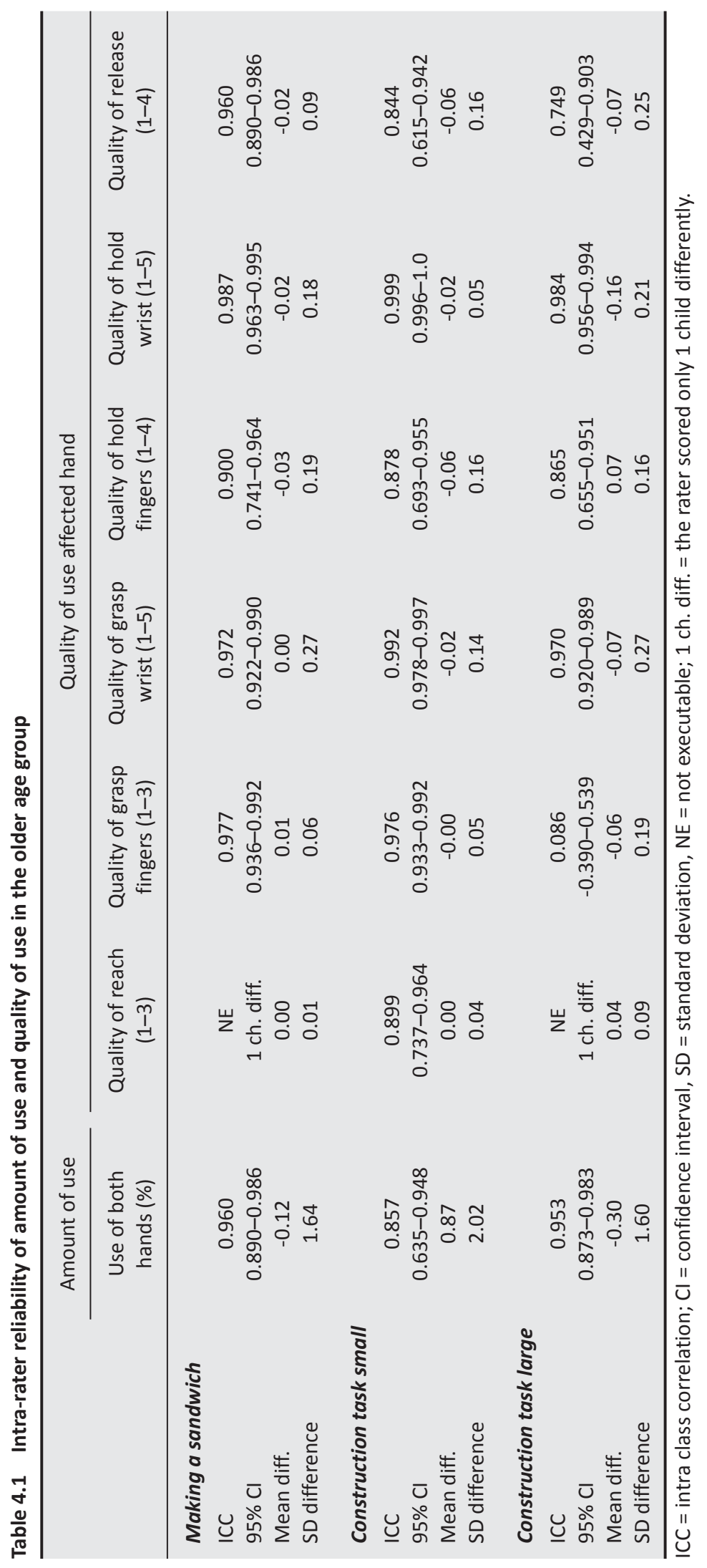




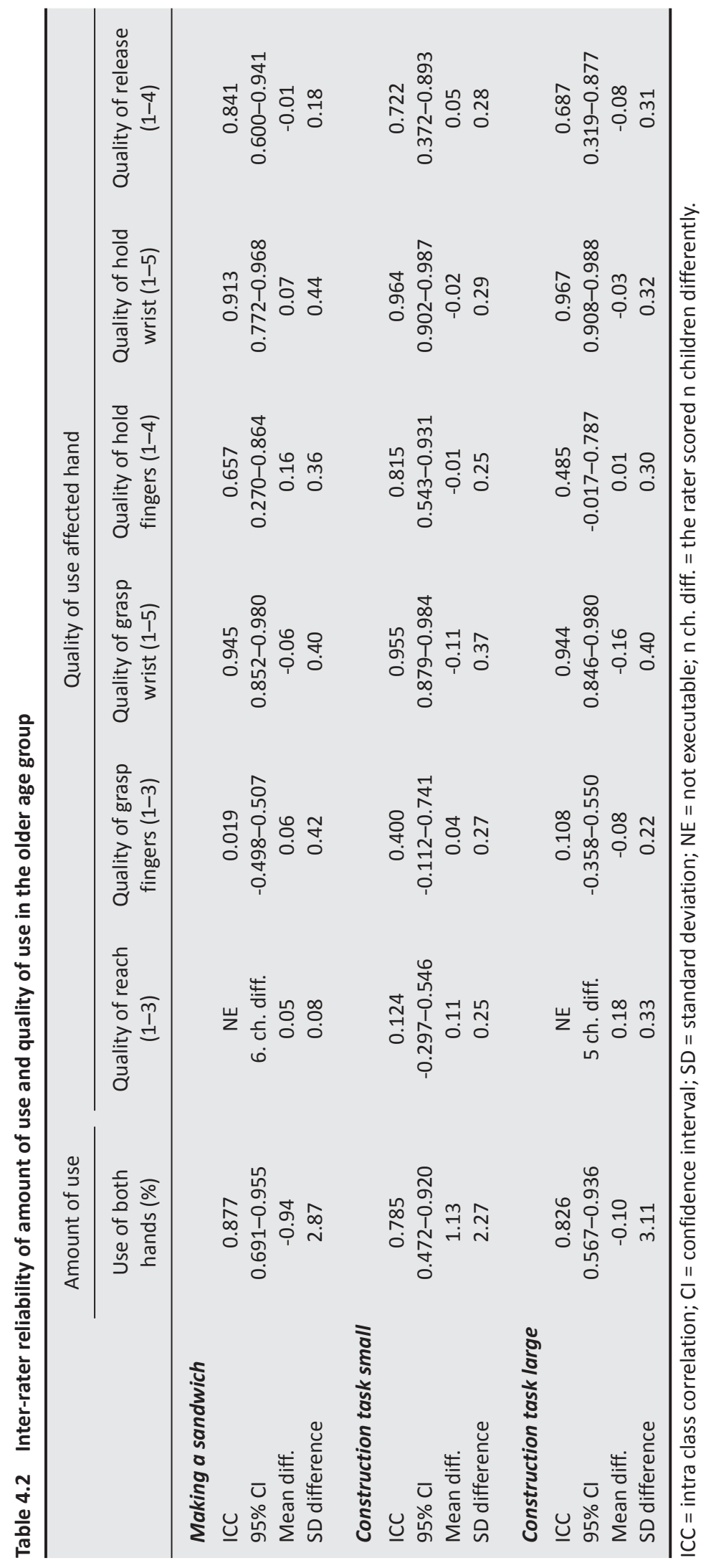




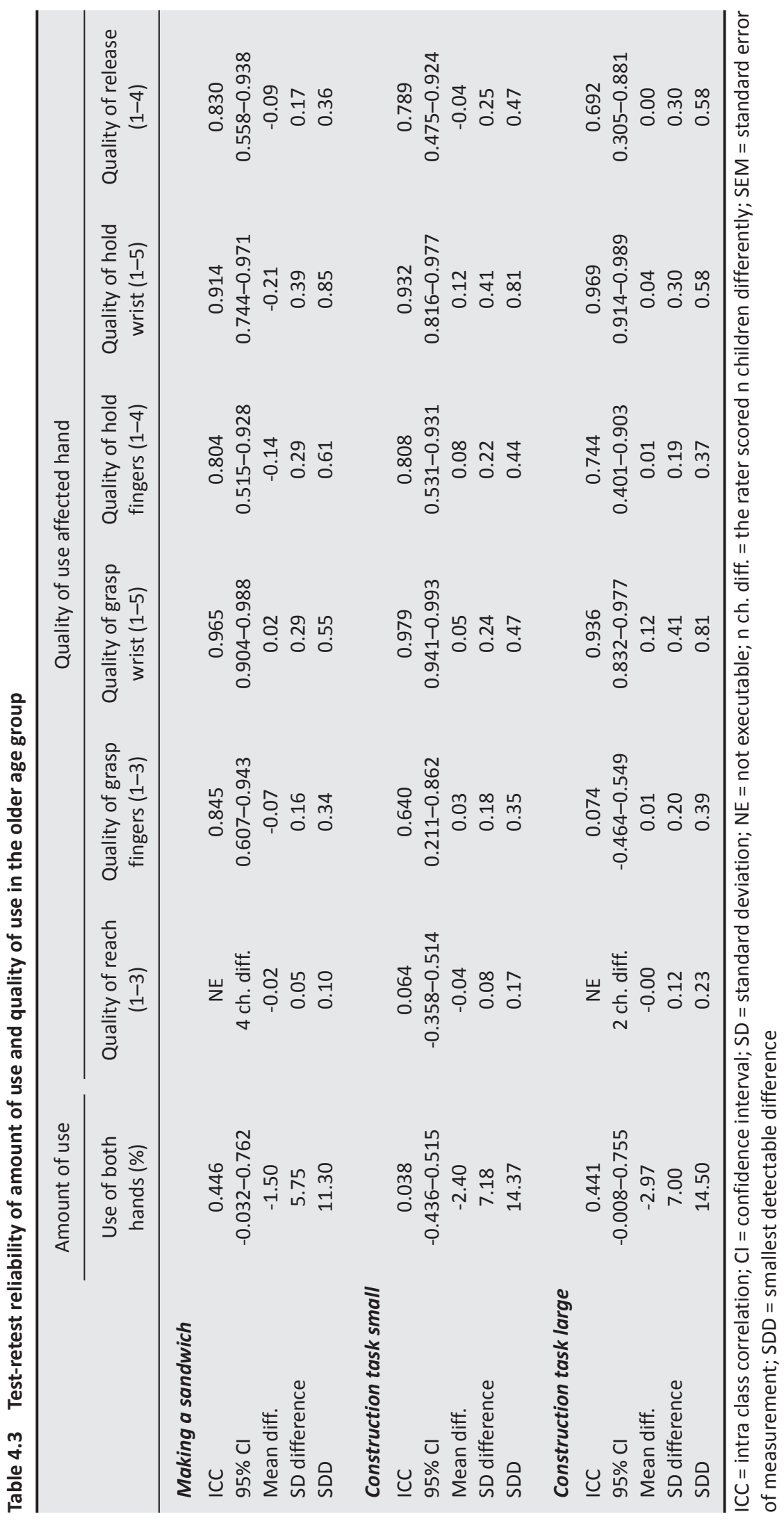




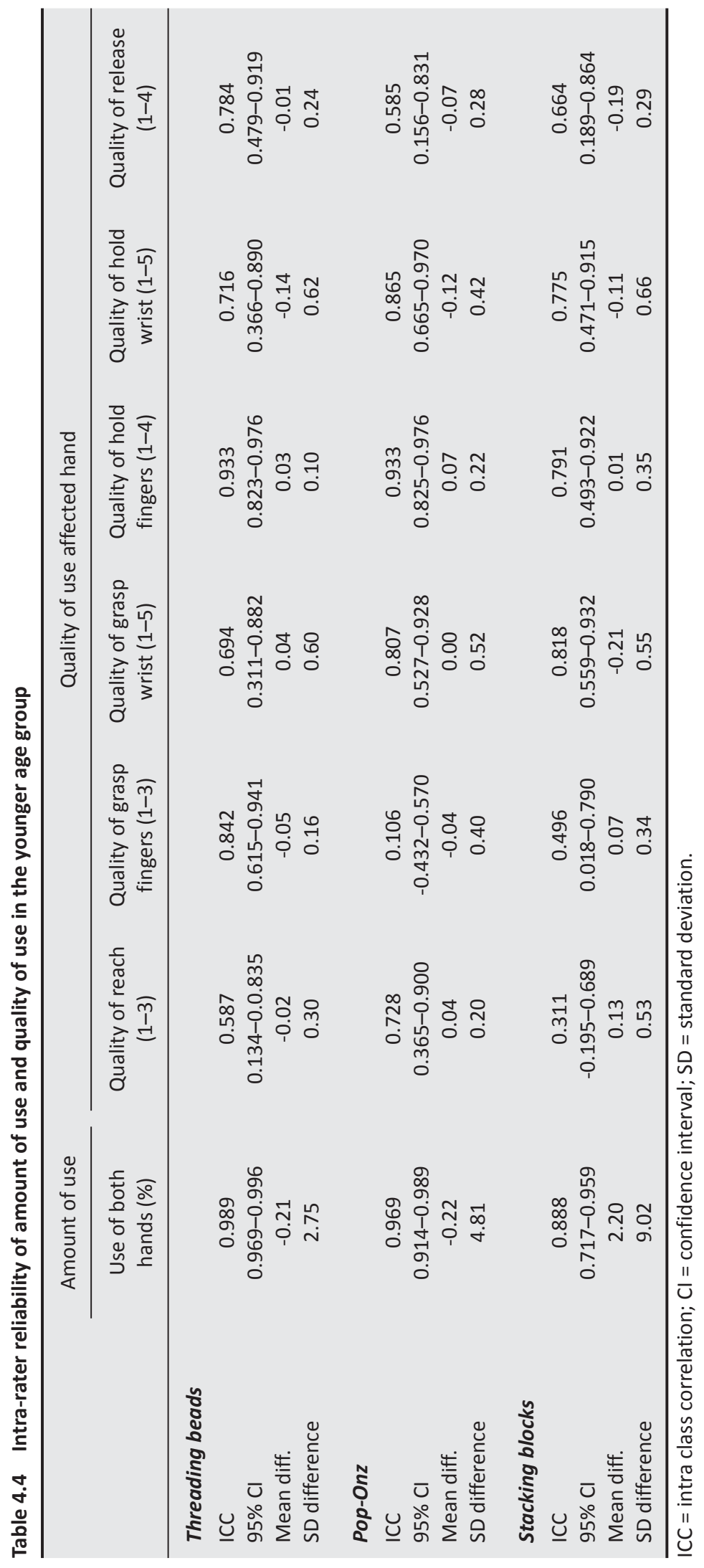




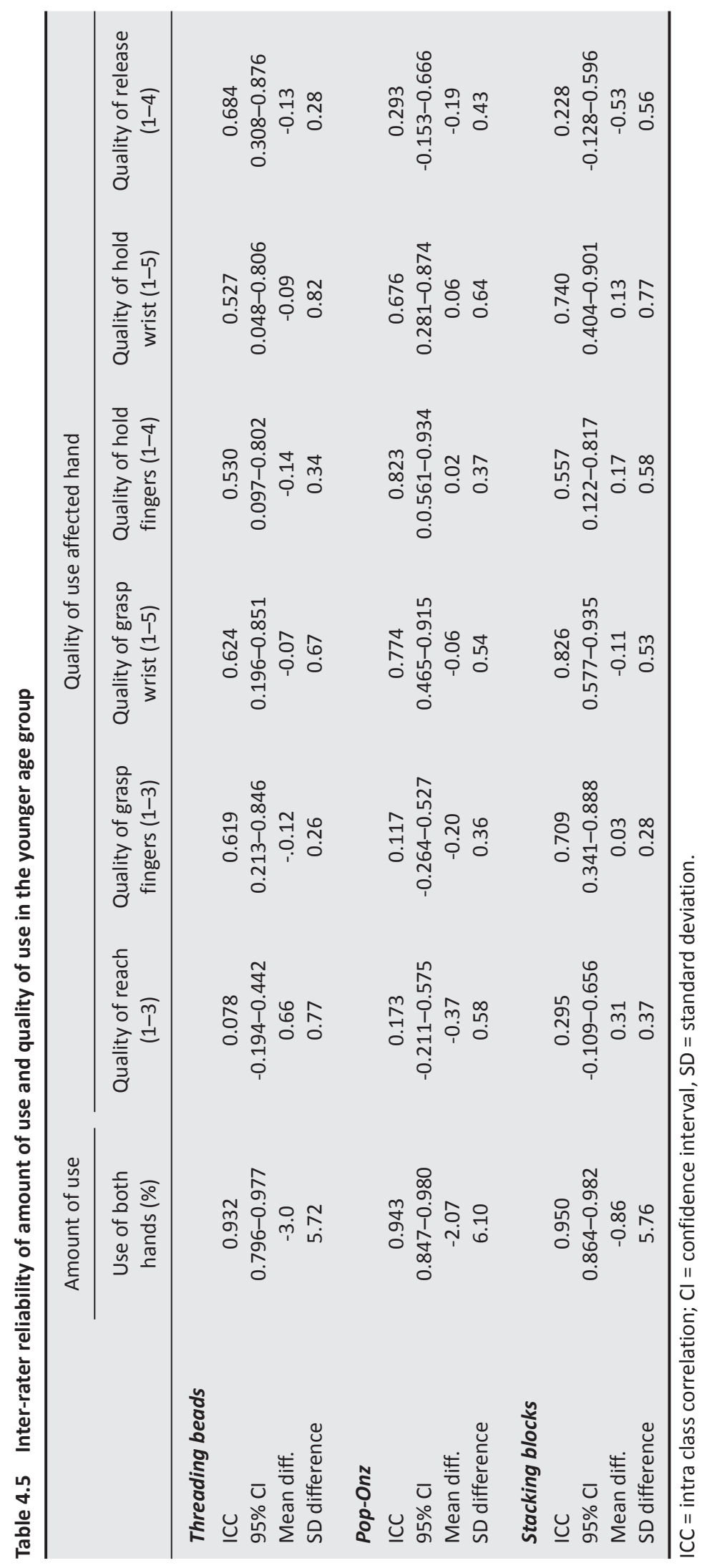


For test-retest reliability, high ICCs were found in most tasks. The 'quality of reach' score of the small construction task and the 'quality of grasp fingers' score of the large construction task had low ICC values. The ICCs for the 'quality of reach' of the sandwich making and large construction task could not be calculated, because there was too little variation. The SDD of the quality scores varied from 0.10 to 0.85 .

\section{Younger age group}

Tables 4.4, 4.5 and 4.6 present intra and inter-rater (16 children) and test-retest reliability (10 children) ICC values of the means for the three tasks of the younger children. Table 4.6 also shows the SDD.

In the younger age group the amount of use of both hands during the tasks showed high ICC values for intra-, inter-rater, and test-retest reliability, varying from 0.69 to 0.99 . The SDDs of the amount of use of all tasks with these children were clearly larger (22.7\% to $30.8 \%)$ than with the older children, and were highest in the Pop-Onz task. In this task especially, the mean amount of use of both hands was low (Figure 4.2) and had a wide range. The differences between the first and second measurement varied from 1.3 to 35.5. The larger range and greater variation in differences explain these higher SDD scores.

The intra-rater reliability of quality of use of the three tasks for the 16 younger children showed high ICC values varying from 0.59 to 0.93 . The exceptions were the 'quality of reach' during the stacking blocks task and 'quality of grasp fingers' in the Pop-Onz and stacking blocks tasks.

The inter-rater reliability in this age group showed good ICCs for most of the measurements except for 'quality of reach' of all the tasks, 'quality of grasp fingers' of the Pop-Onz task, and 'quality of release' in the Pop-Onz and stacking blocks tasks.

For test-retest reliability of quality of use for the younger children good ICC scores were found for most tasks but 'quality of reach and release' of several tasks indicated less agreement. The SDD of the quality of use domains varied from 0.43 and 0.44 ('quality of reach' Pop-Onz and 'quality of release' threading beads) to 1.49 and 1.53 ('quality of hold and grasp wrist' stacking blocks). 


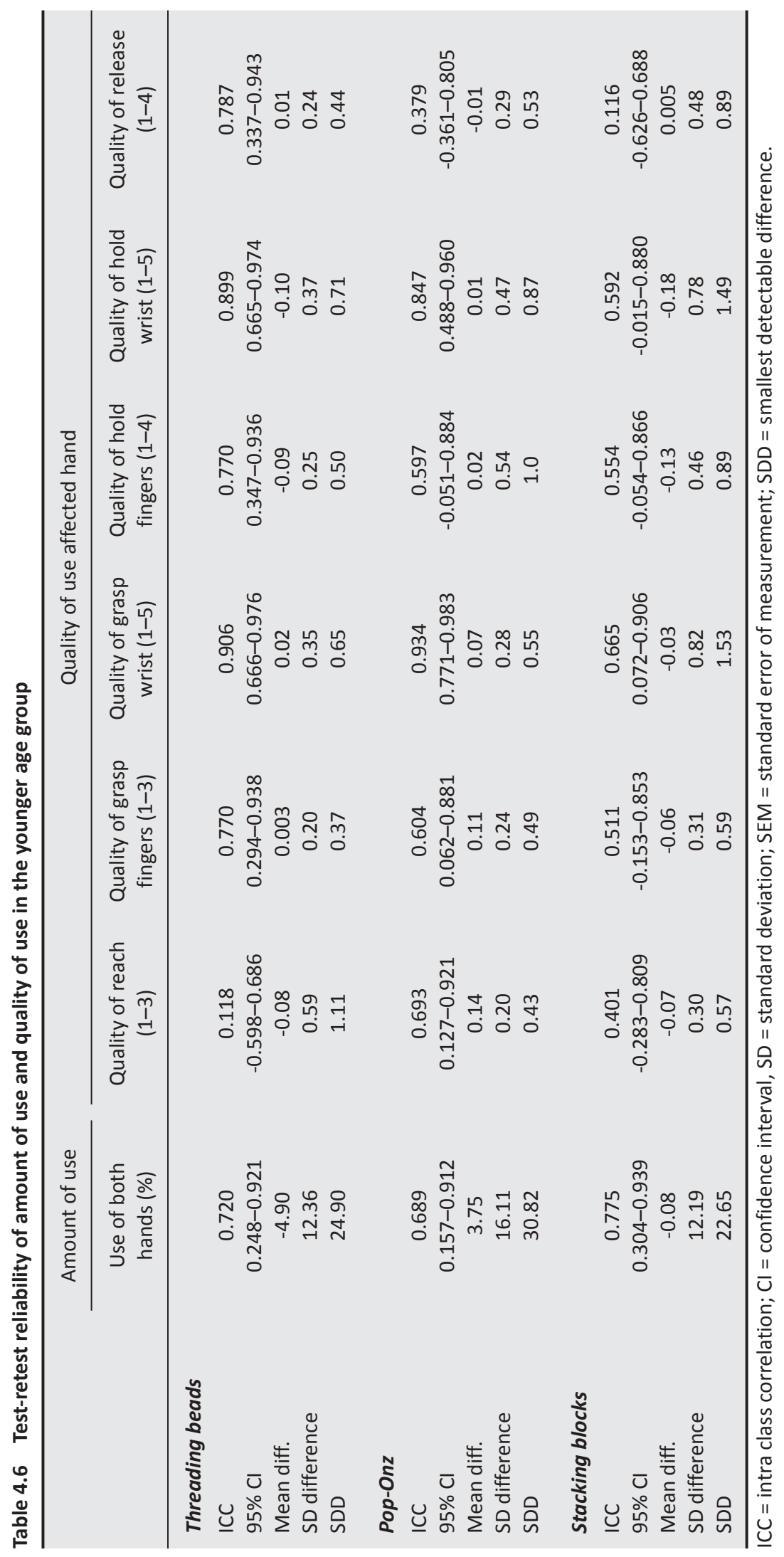




\section{DISCUSSION AND CONCLUSIONS}

We designed the OSAS to measure both the amount and quality of use of the affected hand in tasks in which repetitive bimanual use is demanded. It was developed primarily to measure treatment effect in research and clinical practice. In the present study, as a first evaluation, intra-rater, inter-rater and test retest reliability and agreement were determined using ICC, standard deviation of measurement differences and SDD. ${ }^{17,18}$

Because the ICC provides an index that relates to distinguishing patients within a specific group its importance for clinical evaluation of change is limited. However, based on the generally high ICC values in most tasks, it can be concluded that the OSAS has good discriminative capacity in patient groups resembling the study population. For the older children, an exception in this general pattern is the amount of use of both hands for which the variation is small in all tasks, which explains the low ICCs in test-retest reliability. The mean differences between the measurements for inter- and intra-rater reliability are generally small compared to the width of their scales, which indicates good agreement of measurements.

The largest SDD for the amount of use of both hands was $14.5 \%$ in the older age group and $30.8 \%$ for the younger children. As the SDD uses the same units as the original measurement, its interpretation for clinical use is straightforward. The high amount of use in the older children, in combination with large SDDs leads to a ceiling effect, rendering this measurement non-useful for follow-up. Because the OSAS demands the use of both hands to perform the tasks, this is not surprising. In the younger age group, in which movement patterns are not yet very stable, there was less use of both hands, more variation and large SDDs. This means that amount of use of the OSAS in younger children is not suited for evaluating individual changes but may still be used to compare groups in scientific research.

The 'quality of reach' has very low variation, which leads to low reliability in both age groups. The lack of variation may be explained by the fact that children with unilateral CP tend not to reach with their affected hand. If they do, it is only for a second and almost always with the same pattern. For the future it would be better to score the fact that the affected hand reached without an attached quality criterion.

The ICC of quality of use is good to excellent for 'grasp wrist', 'hold fingers', and 'hold wrist' in all children and all tasks. This is also the case for 'quality of release' in all tasks in the older age group and the threading beads task in the younger children. They do not yet show very consistent release patterns, which is especially obvious during the Pop-Onz and stacking 
blocks tasks. The ICC of 'quality of grasp fingers' is not good in the Pop-Onz task of the younger, and in the small and large construction tasks (only inter-rater reliability) of the older children. This means that better coaching of the observers in this criterion will be needed. Generally, the reliability for the older age group is better than for the younger children. This may be explained by the fact that older children show more consistent movement patterns. The SDDs of the quality items are generally small, but clearly larger in the stacking blocks task of the younger children. The largest SDDs are found in the 'quality of grasp' and 'hold wrist' mean score in the stacking blocks task. Therefore this task is not very useful to measure change. Apart from 'reach' the SDDs of the quality criteria for the OSAS tasks are low compared to the width of their scales which makes these criteria potentially useful for assessing change in patients.

The OSAS seems to be a useful addition to existing assessments of bimanual functioning for children with unilateral hand function problems, such as the AHA. The AHA measures actual spontaneous use of the affected hand in bimanual performance. With the OSAS, the amount and quality of use of the affected hand can be measured in a precise way, as a measure of capacity. The tasks are designed to force the child to use the affected hand repeatedly, are appropriate for the age group and do not interfere with visual spatial or praxis problems. In contrast to the MUUL, the OSAS measures the affected hand as an assisting hand in bimanual functioning. The simplicity and the short duration of the tasks make the OSAS easier to administer with young children. A disadvantage is that scoring takes longer, 20 minutes per task.

In the present study, 32 children between the age of 2.5 and 16 years were included in the intra- and inter-rater reliability analyses and 26 children in the test-retest reliability analysis. This number is limited. Moreover, children aged 7-11 years old were not included in the present study. However, part of the OSAS was developed for children aged 7-16 years old. Reliability data from this age group will need to be collected.

More agreement data is needed, with adapted scoring of the reach item. Only the frequency of reaching with the affected hand during the task can be scored. The stacking blocks task, which proved to be unreliable, might be removed. Precise coaching of observers is needed, especially for the assessment of 'quality of grasp fingers'. The next evaluation step is to measure concurrent validity. In the children aged twelve years or younger this is possible with the AHA. Because the AHA is not available for the older age group yet, the Jebsen test, ${ }^{19}$ which measures speed of movement of the affected hand, could be used instead. Concurrent 
validity will also be determined with the achievement of treatment goals assessed by the Goal Attainment Scaling (GAS) ${ }^{20}$ and performance scores of the COPM. ${ }^{21}$

In conclusion, the OSAS appears to be a reliable assessment tool, with good agreement between repeated measurements, for measuring the quality of use of the affected assisting hand in forced bimanual task execution in CP children. Some modifications as mentioned above, may improve agreement, reliability and ease of scoring. More agreement and reliability data should be gathered, and the responsiveness of the scores also needs to be tested.

\section{ACKNOWLEDGEMENTS}

This study was supported by grants provided by Johanna Kinderfonds, Stichting Rotterdams Kinderrevalidatie Fonds Adriaanstichting, Phelps Stichting, Profileringsfonds azM, Elisabeth Strouven Stichting, Kanunnik Salden-Nieuwenhof Stichting, and Adelante.

\section{AUTHORS' CONTRIBUTIONS}

LS is first corresponding author and participated in drafting the manuscript. She made main contributions to design, acquisition, analysis and interpretation of data. YJ and PL have been involved in drafting the manuscript, analysis and interpretation of data and critically revising it. ER and $A D$ were involved in data acquisition and development of the OSAS. RG designed the user-dedicated software program of the OSAS. RS and HV critically revised the intellectual content of the article. All authors red and approved the final manuscript. 


\section{REFERENCES}

1 Eliasson AC, Bonnier B, Krumlinde-Sundholm L. Clinical experience of constrained induced movement therapy in adolescents with hemiplegic cerebral palsy—a day camp model. Dev Med Child Neurol 2003; 45(5): 357-359.

Taub E, Ramey SL, DeLuca S, Echols K. Efficacy of constrained-induced movement therapy for children with cerebral palsy with asymmetric motor impairment. Pediatrics 2004; 113(2): 305-312.

Sutcliffe TL, Gaetz WC, Logan WJ, Cheyne DO, Fehlings DL. Cortical reorganization after modified constrained-induced movement therapy in pediatric hemiplegic cerebral palsy. J Child Neurol 2007; 22(11): 1281-1287.

Hoare B, Imms C, Carey L, Wasiak J. Constrained-induced movement therapy in the treatment of the upper limb in children with hemiplegic Cerebral Palsy: a Cochrane systematic review. Clin Rehabil 2007; 21: 675-685.

5 Holsbeeke L, Ketelaar M, Schoenmaker MM, Gorter JW. Capacity, capability en performance: different constructs or three of a kind? Arch Phys Med Rehabil 2009; 90(5): 849-855.

6 Lemmens RJ, Timmermans AA, Janssen-Potten YJ, Smeets RJ, Seelen HA. Valid and reliable instruments for arm-hand assessment at ICF activity level in persons with hemiplegia: a systematic review. BMC Neurol 2012; 12: 21.

7 Gilmore R, Sakzewski L, Boyd R. Upper limb activity measures for 5- to 16-year-old children with congenital hemiplegia: a systematic review. Dev Med Child Neurol 2010; 52: 14-21.

8 World Health Organization. International Classification of Functioning, Disability and Health. Geneva: World Health Organization, 2001.

9 Randall M, Carlin JB, Chondros P, Reddihough D. Reliability of the Melbourne assessment of unilateral upper limb function. Dev Med Child Neurol 2001; 43: 761-767.

10 Krumlinde-Sundholm L, Eliasson A. Development of the Assisting Hand Assessment: A Rasch-built measure intended for children with unilateral upper limb impairments. Scand J Occup Ther 2003; 10: $16-26$.

11 Arnould C, Penta M, Renders A, Thonnard JL. ABILHAND-Kids: a measure of manual ability in children with cerebral palsy. Neurology 2004; 63(6): 1045-1052.

12 Krumlinde-Sundholm L, Holmefur M, Kottorp A, Eliasson A-C. The Assisting Hand Assessment: current evidence of validity, reliability, and responsiveness to change. Dev Med Child Neurol 2007; 49: 259-264.

13 Speth LA, Leffers P, Janssen-Potten YJ, Vles JS. Botulinum toxin A and upper limb functional skills in hemiparetic cerebral palsy: a randomized trial in children receiving intensive therapy. Dev Med Child Neurol 2005; 47(7): 468-473.

14 Aarts PB, Jongerius PH, Aarts MA, Van Hartingsveldt MJ, Anderson PG, Beumer A. A pilot study of the Video Observations Aarts and Aarts (VOAA): a new software program to measure motor behaviour in children with cerebral palsy. Occup Ther Int 2007; 14: 113-122.

15 Kottner J, Audige L, Brorson S, Donner A, Gajewski BJ, Hróbjartsson A, Roberts C, Shoukri M, Streiner DL. Guidelines for Reporting Reliability and Agreement Studies (GRRAS) were proposed. Int J Nurs Stud 2011; 48: 661-671. 
16 Eliasson AC, Krumlinde-Sundholm L, Rosblad B, Beckung E, Arner M, Ohrvall AM, et al. The Manual Ability Classification System (MACS) for children with Cerebral Palsy: scale development and evidence of validity and reliability. Dev Med Child Neurol 2006; 48: 549-554.

De Vet HCW, Terwee CB, Mokkink LB, Knol DL. Measurement in Medicine. Cambridge University Press, 2011.

19 Taylor N, Sand P, Jebsen R. Evaluation of hand function in children. Arch Phys Med Rehabil 1973; 54: 129-135.

20 Steenbeek D, Ketelaar M, Galama K, Gorter JW. Goal attainment scaling in paediatric rehabilitation: a critical review of the literature. Dev Med Child Neurol 2007; 49(7): 550-556.

21 Verkerk GJ, Wolf MJ, Louwers AM, Meester-Delver A, Nollet F. The reproducibility and validity of the Canadian Occupational Performance Measure in parents of children with disabilities. Clin Rehabil 2006; 20(11): 980-988. 


\section{ADDITIONAL FILE 4.1}

\section{Building using construction material \\ Age 7-16 years}

\section{Setting}

Quiet room

Rectangular table with a hard tabletop that is adjustable in height

Table and chair adjusted to the correct height of the child

Webcam 1 stands in front of the table and provides a mid frontal view, approximately on shoulder height of the child: head, trunk, arms, hands and the entire working space come on screen

Webcam 2 is mounted on the ceiling above the table for a cranial view, both hands are visible.

This set-up is valid for a child with unilateral pareses on the right.
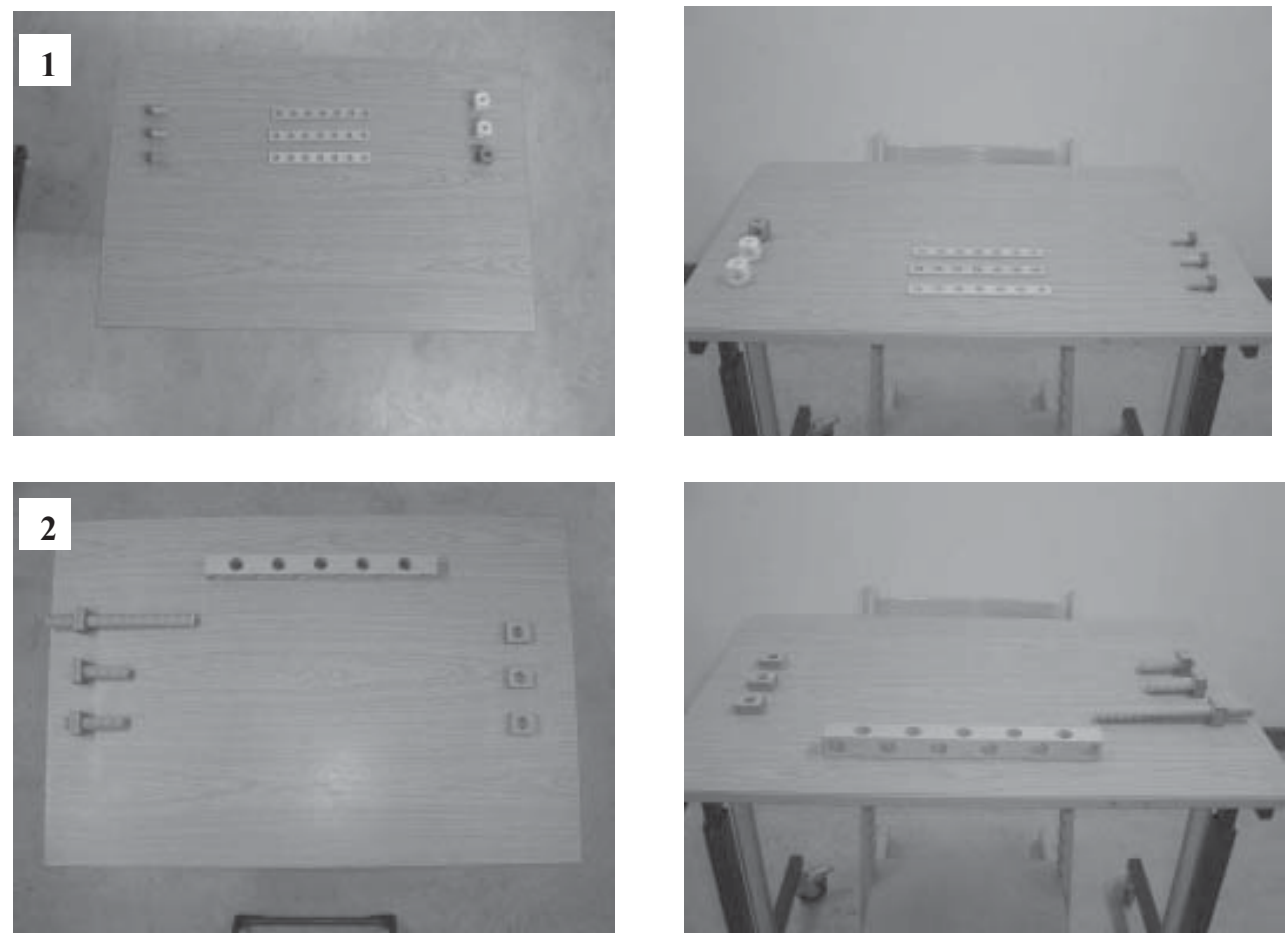

Cranial view

Frontal view 
Material:

- Session 1 small material : 3 screws, 3 little blocks, 3 slats (brand Baufix, base set)

- Session 2 big material: 3 sticks ( 2 short and one long stick) with screw thread and female screws, 3 female screws and one little beam $30 \mathrm{~cm}$ long.

\section{Starting position}

The child sits behind the table with both arms on the table. The chair and table are adjusted to the right height of the child. Both feet are on the floor or on a footrest. The child's upper body is undressed or is dressed in an undershirt.

Female screws and blocks are ready on both sides of the table.

Session 1:

- 3 slats lay in front of the child, in horizontal direction and within reaching distance of the child

- 3 coloured blocks lay on the table, on the affected side of the child

- 3 screws lay on the table, on het non-affected side of the child

Session 2:

- The little beam lays in front of the child, in horizontal direction and within reaching distance of the child

- 3 female screws lay on the table, on the affected side of the child, within reaching distance of the child

- 3 sticks with screw thread and female screws lay on the non-affected side of the child, within reaching distance of the child ( the 2 short sticks closest to the child and the long stick furthest away from the child, see picture 2)

\section{Instruction to the child}

The assessor tells the child he/she is going to build with construction material. Make sure the aim of het task is clear to the child and that the child understands how the task has to be performed.

Session 1:

"You may build using the construction material. Attach 1 coloured block to the slat using a screw. Attach the block to the first (or last) whole. Attach 1 block to each slat. Attention: 2 wholes of the blocks do not have screw thread! You may start when I say 'go'".

The assessor counts down: 3-2-1-go; at three the video starts recording, at 'go' the child starts performing the task.

When the child has finished the task, he/she puts the last slat with a block attached down on the table and the video recording stops.

Max time: 2.5 minutes. 


\section{Session 2:}

"You may build again. Attach a screw to the little beam using a female screw. Attach the other two screws to the little beam in the same manner (all female screws must be on the same side of the beam). You may start when I say 'go"'.

The Assessor counts down: 3-2-1-go; at three the video starts recording, at 'go' the child starts performing the task.

When the child has attached all three crews to the little beam, he/she puts the beam down on the table and the video recording stops.

Max time: 2.5 minutes

\section{Video instruction in case of problems:}

- In case the child does not know how to attach the screws, first give verbal instruction (e.g. put the screw into the block, turn the other way, choose a different whole in het block etc.), then indicate and finally demonstrate the child how the task is being done.

- In case the child has forgotten what has to be attached to what, repeat the instruction, or indicate.

- In case the child uses only one hand: do not respond to that.

\section{Maximal time: 5 minutes}

Max time per task: $2 \frac{1}{2}$ minutes.

Max time both tasks total: 5 minutes.

\section{Scoring:}

According to the quality criteria. 


\section{ADDITIONAL FILE 4.2}

\section{OSAS Quality Criteria}

\section{A. Reaching}

1. reaching with trunk movement, insufficient shoulder anteflexion and elbow extension

2. reaching with shoulder movement and partial elbow extension, only trunk movement if necessary

3. reaching with shoulder movement and complete elbow extension, only trunk movement if necessary

\section{B. Grasping}

\section{I. thumb and fingers}

1. rummage, rake movement without finger use or pushing in the affected hand by the unaffected hand

2. task oriented active grasping with thumb and finger movements, but not entirely appropriate

3. task oriented active finger opening and closing with thumb opposition

\section{II. wrist}

1. at first contact wrist palmar flexion and ulnar deviation

2. at first contact wrist palmar flexion no ulnar deviation

3. at first contact wrist in neutral position (or dorsal flexion) with ulnar deviation

4. at first contact wrist in neutral position

5. at first contact wrist in dorsal flexion or in appropriate position according to task

\section{Holding}

\section{I. thumb and fingers}

1. clenching with arm/hand against trunk or table without finger movement, hand fisted

2. holding with hand no active movement, thumb in or against hand

3. holding with hand no active movement and thumb out of hand

4. holding, varied grip with finger and thumb movement for positioning 


\section{II. wrist}

1. continuously wrist palmar flexion and ulnar deviation

2. continuously wrist palmar flexion no ulnar deviation

3. wrist in neutral position (or dorsal flexion) with ulnar deviation

4. wrist in neutral position or wrist extension no ulnar deviation, no variation, not always appropriate

5. wrist extension or neutral position wrist, appropriate for task

\section{Release}

1. release from arm

2. passive, pulled out by the unaffected hand or shaking/throwing loose or break up contact with fisted hand

3. active opening of the hand, gross release, no appropriate object positioning

4. active opening of the hand and appropriate object positioning

\section{E. Unaffected hand used}




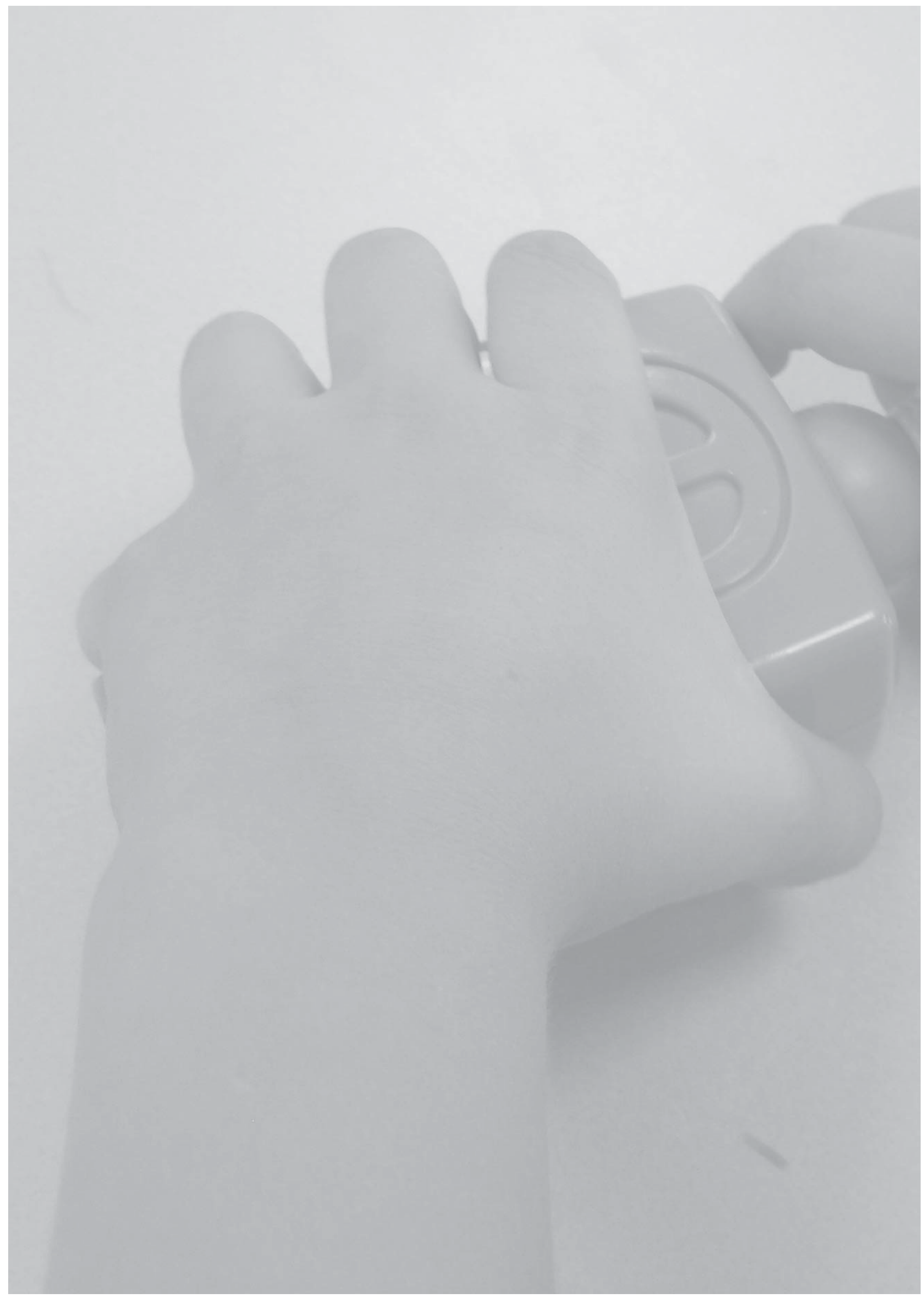




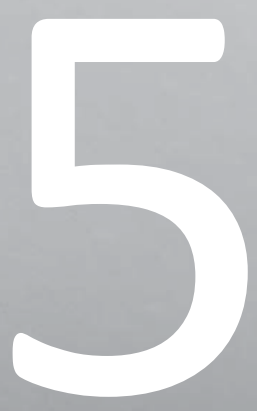

\section{Effects of botulinum toxin A and/or bimanual task-oriented therapy on upper extremity impairments in unilateral Cerebral Palsy: an explorative study}

Lucianne Speth, Yvonne Janssen-Potten, Pieter Leffers, Eugene Rameckers, Anke Defesche, Bjorn Winkens, Jules Becher, Rob Smeets, Hans Vles 


\section{ABSTRACT}

\section{Objective}

This study reports on the effects of botulinum toxin A (BoNT-A) injections in the upper extremity (UE) of children with unilateral Cerebral Palsy ( $U C P$ ) combined with bimanual task oriented therapy (BITT) or either treatment modality performed separately on UE range of motion (ROM), spasticity and (functional) strength.

\section{Methods}

Thirty-five children, mean age 7.14 years (SD 2.63) of whom 11 had a Manual Ability Classification Score (MACS) I, 15 MACS II and 9 MACS III, participated. The trial started with four study groups: BoNT-A-only ( $n=5)$, BITT-only $(n=11)$, BoNT-A+BITT $(n=13)$, and control $(n=6)$. Twenty-two children were randomized and, due to recruitment problems 13 children received their parents' preferred treatment: BoNT-A+BITT or BITT-only. Three comparisons were analysed: BITT (BoNT-A+BITT and BITT-only; $n=24$ ) versus no BITT (BoNT-A-only and control; $n=11$ ), BoNT-A (BoNT-A-only and BoNT-A+BITT; $n=18$ ) versus no BoNT-A (BITT-only and control; $n=17$ ), and the additional effect of BoNT-A (BoNT-A+BITT versus BITT-only).

\section{Results}

BoNT-A significantly decreased key grip strength and finger flexion tone, had a clinically relevant (additional) positive effect on active thumb abduction and supination and a significantly negative effect on unilateral functional strength. BITT+BoNT-A significantly increased active supination. BITT reduced elbow flexor tone and BITT-only resulted in more improvement than BoNT-A+BITT in functional unimanual and, to a lesser extent, in bimanual grip strength.

\section{Conclusions}

In comparison with BoNT-A+BITT, BITT-only gives more improvement on functional grip strength and, therefore, could possibly increase bimanual performance. In this case, the (additional) role of BoNT-A may be an increase in active supination and thumb abduction. 


\section{INTRODUCTION}

Grip strength ${ }^{1,2}$ and active forearm supination ${ }^{2}$ are good predictors for use of the affected arm in bimanual performance of children with predominantly unilateral Cerebral Palsy (uCP) and a Manual Ability Classification Score (MACS) I to III. ${ }^{3}$ Muscle weakness and spasticity are assumed to jointly contribute to activity limitations, reflected by the strong relationship between the ability to voluntarily activate a muscle and performance. ${ }^{4}$ Children with uCP have been treated with botulinum toxin A (BoNT-A) to reduce impairments in arm and hand function in order to improve use of the affected hand directly or to facilitate the effectiveness of physical and occupational therapy in achieving their individual goals at the activity level of the International Classification of Functioning, Disability and Health for Children and Youth (ICF-CY) of the World Health Organization (WHO) (http://www.who.int/ classifications/icf/en/).

In a randomised clinical trial (RCT) on the effect of BoNT-A injections in the UE of children with $\mathrm{UCP}$ who received intensive bimanual therapy, we found an increase of active wrist extension of more than $30^{\circ}$ and tone reduction of the wrist flexors. ${ }^{5}$ These findings were in line with the Cochrane review concluding that BoNT-A injections clearly reduce spasticity and improve range of motion (ROM), but that the effect on performance at activity level is less clearly esthablished. ${ }^{6}$ This uncertain effect of BoNT-A on the ICF activity level might be caused by insufficient sensitivity of the measurement instruments used in the trials to detect an existing improvement, or by the fact that BoNT-A might negatively influence muscle strength. Morphological comparison between wrist flexor and extensor muscles in children with $\mathrm{CP}$ shows myopathy of the wrist flexors. ${ }^{7}$ The strength in the wrist and finger flexors of the affected hand in children with uCP is only about one third of the strength of their non-affected hand, or that of typically developing children. ${ }^{8}$ An RCT on the effect of BoNT-A injections in children with $\mathrm{CP}$ receiving functional rehabilitation therapies for the UE showed that increase of muscle strength from therapy is attenuated by BoNT-A injections. ${ }^{9} \mathrm{Also}$, in studies on the effect of BoNT-A injections in UE muscles, a transient decrease in grip strength has frequently been reported as a side effect. ${ }^{6,10}$

In a pilot study of 10 children with $\mathrm{uCP}$, Elvrum et al. showed that additional resistance training after the use of BoNT-A resulted in temporary strengthening of the non-injected muscles, reduction of strength loss resulting from BoNT-A without increasing tone, and greater increase of active supination. ${ }^{11}$ Although the BoNT-A injections and the resistance training involved only the upper and forearm, and not the hand and wrist muscles, they 
found an improvement in grip strength in the resistance training group. However, the improvements of these impairments did not result in increased use of the affected hand. The authors questioned whether task-oriented training is a more effective approach than strength training to improve arm and hand use.

Bimanual performance is influenced by grip strength and, to a lesser extent, by active ROM (AROM) of wrist extension and supination. ${ }^{1,2}$ As bimanual intensive therapy has proven to have a positive effect on bimanual performance, ${ }^{12}$ the objective of the present explorative study is to report effects of BoNT-A injections in the UE in children with UCP combined with bimanual task-oriented therapy (BITT) or either treatment modality separately on UE AROM, spasticity and isometric and functional strength. The latter is used, because it is a better representative for actual strength in daily life. ${ }^{13}$

\section{METHODS}

\section{Design}

This explorative study is part of the BoBiVa (Botuline toxine Bimanuele Vaardigheden) study (http://www.controlled-trials.com/ISRCTN69541857). The BoBiVa study was designed as a multicentre, randomized controlled trial on the effect of BoNT-A injections combined with bimanual task oriented therapy (BITT), or either separately, in children with UCP on UE functions and skills. Medical ethics approval was provided by the METC Atrium-Orbis-Zuyd (ref: 06-p-33) and the Dutch CCMO (ref: NL12005.096.06). The parents gave their informed consent. Initially, besides Adelante/Maastricht University Medical Centre, two other centres participated in this trial. Due to disappointing patient enrolment, other centres joined later. In this paper, the results at the body function level of the ICF-CY are reported. A factorial design was used to determine the effects of BoNT-A and/or BITT (Table 5.1). As far as possible, the CONSORT guidelines for reporting parallel group randomized trials were followed. ${ }^{14}$

Table 5.1 Factorial study design

\begin{tabular}{lccc}
\hline & BoNT-A yes & BoNT-A no & \\
\hline BITT yes & BoNT-A+BITT $(n=13)$ & BITT-only $(n=11)$ & 24 \\
BITT no & BoNT-A-only $(n=5)$ & Control $(n=6)$ & 11 \\
& 18 & 17 & \\
\hline
\end{tabular}

BoNT-A = botulinum toxin A. BITT = bimanual task oriented therapy. 


\section{Participants}

Children with uCP, aged 2.5 to 12 years, MACS levels I-III, Zancolli hand impairment grade I to $\|^{15}$ who were mentally able to perform the measurements and attend the therapy programme, were included. Twenty-four were born at full term, 6 at 37 weeks and 5 were born prematurely (25-35 weeks gestation). The study excluded children without active hand function (Zancolli III), severe structural contractures (elbow extension deficit more than $20^{\circ}$ and/or supination deficit more than $45^{\circ}$ and/or wrist extension deficit more than $30^{\circ}$ ) and children who had undergone a treatment of the affected hand (BoNT-A injections less than nine months before, or hand surgery).

\section{Therapy programme}

The BITT program consisted of half an hour of physiotherapy (PT) and one hour of occupational therapy (OT), 2 times a week, for 12 weeks. At the start, bimanual goals were set using the Canadian Occupational Performance Measure (COPM). ${ }^{16}$ Examples of goals that were being targeted in therapy are: pulling up trousers and closing the button, cutting paper with scissors, pulling apart LEGO bricks, tying shoelaces, closing the zip of a jacket. These goal-directed activities were practiced as much as possible in the child's relevant context. The programme was individually tailored to the child based on a task analysis of the selected goals performed at the start of the treatment and was based on principles of motor learning, strength training and/or improving ROM. When weakness was the main problem in closing the button of a pair of jeans, then this was trained by asking the child to pull up his trousers and then close the button several times, starting with wider trousers and an easier clasp. When ROM was a problem and the finger flexors were shortened, the children had to wear a stretching night splint. Additionally, parents were asked to stimulate their child to practice these goal-directed dressing and playing activities every day in a home-exercise program. They practiced these activities several times a day during grooming and while playing. Parents reported that they spent 40 to 60 minutes a day in total practising these goals. All therapists of the participating centres were trained in this special goal-directed, task-specific bimanual therapy. ER and AD trained the therapists in the study how to perform the BITT programme during a 6 hours training course. During the BITT program these therapists were coached by AD. Feedback was given on their task analysis using video recordings of the child performing his individual goal. The children in the BoNT-A-only and control group continued their usual therapy with a maximum frequency of one hour a week. We requested their therapists not 
to work at improving bimanual goals. The PTs of the children in these treatment groups were unaware of the goal setting.

\section{BoNT-A injection technique and dosage}

The most spastic muscles hampering function and bimanual activities were injected once in both the BoNT-A treatment groups; in the BoNT-A+BITT group, the BoNT-A was injected 4 days to maximum 2 weeks before the start of the BITT programme. Based on a video of the child performing his or her most important goal and on UE spasticity measurements, the three physicians of the initial participating centres decided which muscle had to be treated and in what dose. Dysport ${ }^{\circledR}$ (Ipsen) was used with a dilution of $25 \mathrm{U} / 0.1 \mathrm{ml}$ and with a dose 3 times the dose of Botox ${ }^{\circledR}$ (Allergan), 6-9 U/kg body weight for the muscles above the elbow and 3-6 U/kg body weight for the muscles in the forearm, limited to no more than 150 units $(0.6 \mathrm{ml})$ at one injection site. In the intrinsic thumb muscles, the maximum dose was $50 \mathrm{U}$ per muscle, mostly $25 \mathrm{U}$ per muscle were injected. The maximum Dysport ${ }^{\circledR}$ dose was 1,000 $\mathrm{U}$ per child per session. ${ }^{17}$ The injections took place under general anaesthesia in the day care department of the three initial participating centres. The muscles that had to be injected were located by electro stimulation; the BoNT-A was injected with a special Teflon ${ }^{\circledR}$ coated needle. The most frequently injected muscles were the adductor pollicis, flexor carpi ulnaris and radialis and pronator teres (Table 5.2).

\section{Outcome measures}

There were two baseline measurement sessions with a maximum two weeks in between, and four follow up sessions at 6, 12, 18 and 24 weeks after BoNT-A/start therapy. As there were no significant differences between the two baseline measurements (Paired-samples T-Test), and high correlations (see below), the mean of these two measurements was taken as the baseline value. Outcome measures at body function level of the ICF-CY were spasticity (b735 muscle tone functions) in wrist and elbow (difference in angle of catch (AOC) and passive ROM, expressed as SPAT), ${ }^{18}$ active and passive ROM (b710 mobility of joint functions) of wrist (with flexed and extended fingers), elbow and thumb measured with a MIE ${ }^{\circledR}$ clinical goniometer (MIE ${ }^{\circledR}$ medical research Ltd), grip strength with E-LINK (Biometrics ${ }^{\circledR}$ Ltd) and functional grip strength (b730 muscle power functions). The E-LINK measures consisted of the mean of three maximal voluntary contractions (MVC) of fist grip and key grip. The Intra Class Correlation (ICC) value for the fist grip strength test-retest baseline measurements 


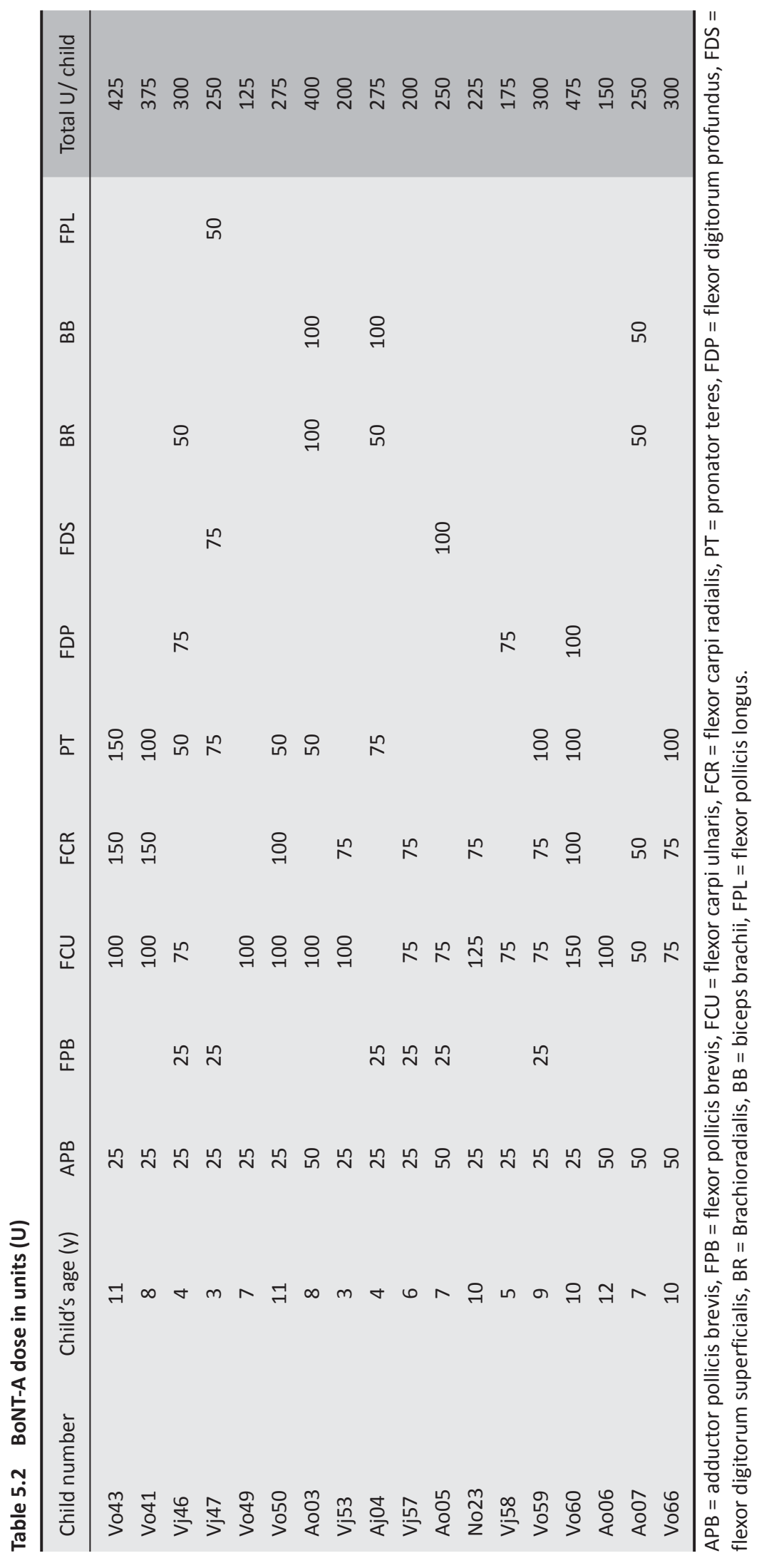


was 0.898 (95\% confidence interval (Cl) 0.808-0.947), for key grip strength $0.870(95 \% \mathrm{Cl}$ 0.755-0.933). These E-LINK grip strength measurements are a computerised version of the Jamar dynamometer, being a reliable measurement instrument. ${ }^{19}$ The functional strength measures, which were developed by our research PT and OT, were done unimanually and bimanually. For the unimanual functional strength the child, depending on its capability had to keep a jug filled with water upright for 5 seconds with the elbow flexed at $90^{\circ}$. For bimanual strength, the child had to lift a crate with lead-filled sacks (total weight that the child was able to carry) for 5 seconds with the elbows flexed at $90^{\circ}$. The ICC value for the unimanual functional strength test-retest baseline measurements was 0.917 (95\% Cl 0.839-0.957) and for bimanual functional strength 0.954 (95\% Cl 0.910-0.976). All measurements were carried out by experienced, trained PTs, who were blinded to group assignment, and not involved in the treatment.

\section{Sample size}

Power analysis was done on the Assisting Hand Assessment (AHA), ${ }^{20}$ as this was the main outcome measurement of the BoBiVa study at ICF-CY activity level. At that time, the study of Eliasson ${ }^{21}$ was the only known study that used the AHA as an evaluative measurement. We assumed that the difference between groups as found by Eliasson (mean change for the treatment group 1.23 (SD 1.04) and for the control group 0.24 (SD 0.85)) was the minimum clinically relevant difference to be detected in our study. Using the same variation, a twosided alpha of 0.05 and a beta of 0.10 (i.e. power of $90 \%$ ), a minimum of 50 children in total were needed to detect the main effects of the treatment comparisons (effect of BoNT-A, BITT or BoNT-A+BITT) on daily hand use.

\section{Randomisation}

The trial started with a factorial design in 2008. There were 4 study groups: 1) BoNT-A-only, 2) BITT-only, 3) BoNT-A+BITT and 4) control group. To improve comparability of groups, randomisation into the four treatment groups took place after pre-stratification for centre and age group: 2.5-6 and 7-12 years. Randomisation was done after the two baseline measurements and before start of the treatment. Allocation concealment was ensured by using opaque envelopes. PL generated random allocation sequence. LS and JB enrolled the participants. YJ assigned participants to the treatment group by handing out the opaque envelopes. Due to recruitment problems, we abandoned the randomization into 4 groups 
after official approval of the medical ethics committee. This adaptation was necessary because many parents did not want their child to participate, because they either had a strong preference for or aversion to BoNT-A treatment. Also, they considered the risk of allocation of their child to either the control or the only BoNT-A-only group to be too high. From March 2010, the children were only allocated to the BoNT-A+BITT or the BITT-only group. The scientific importance of random allocation was discussed with the parents. If the parents agreed, the children were randomised; otherwise, their child was allocated to the group of their preference. As this was the choice of the parents and not of a physician, we do not expect that this has led to confounding by indication.

\section{Statistical analysis}

Categorical and numerical variables were presented by number of patients (\%) and by means (SD), respectively. The longitudinal effects of bimanual therapy (BITT versus no BITT) and BoNT-A (BoNT-A versus no BoNT-A) on the outcome measures were assessed using linear mixed models to correct for baseline differences and to account for the correlations between repeated measures within the same patient and for missing data by using likelihood methods, which assume the data to be missing at random. The fixed part of the models included BITT (yes/no), BoNT-A (yes/no), time (0, 6, 12, 18 and 24 weeks), BITT*time, and BoNT-A*time. Restricted maximum likelihood estimation was used and the covariance structure for the repeated measures (compound symmetry (CS), heterogeneous CS, first-order autoregressive (AR1), heterogeneous AR1, Toeplitz (TP), heterogeneous TP or unstructured) was selected based on Akaike's information criterion. As for the additional effect of BoNT-A (BoNT-A+BITT versus BITT-only) on the outcome measures, a similar linear mixed model (without the variables BITT and BITT*time) was applied to the data of the patients who received either BITT-only or BoNT-A+BITT. A two-sided $p$-value $\leq 0.05$ was considered statistically significant. All analyses were performed using IBM SPSS Statistics for Windows (Version 20.0. Armonk, NY: IBM Corp).

\section{RESULTS}

Patients were enrolled from January 2008 until December 2010. The last follow-up measurement took place in September 2011. Initially, thirty-six children with uCP were enrolled in the study. One child, who was allocated to the BITT-only group, withdrew after 
the baseline measurements because the participating centre had problems organizing BITT. Therefore, a total of 35 children participated in the study. Twenty-two children were allocated by randomization; for 13 children the parents' preference was followed (Figure 5.1) of whom nine were allocated to the BoNT-A+BITT group and four to the BITT-only group. The parents of one young child in the latter group decided after the baseline measurements that they were not able to bring their child for therapy twice a week. They agreed to let him perform the measurements only, so the child was allocated to the control group.

Two children who were randomly assigned to the control group missed the outcome measurements of week 6,18 and 24 . One because she underwent surgery to improve walking; the parents of the other child did not want to cooperate with the measurements anymore. Their baseline and 12 week measurement results were analysed.

We used a registration form for Serious Adverse Events (SAEs) and Suspected Unexpected Serious Adverse Reactions (SUSARs), but no adverse reactions were reported. As strength was an outcome measure of this study, strength reduction was not reported as an adverse reaction. None of the children completely lost their grip strength.

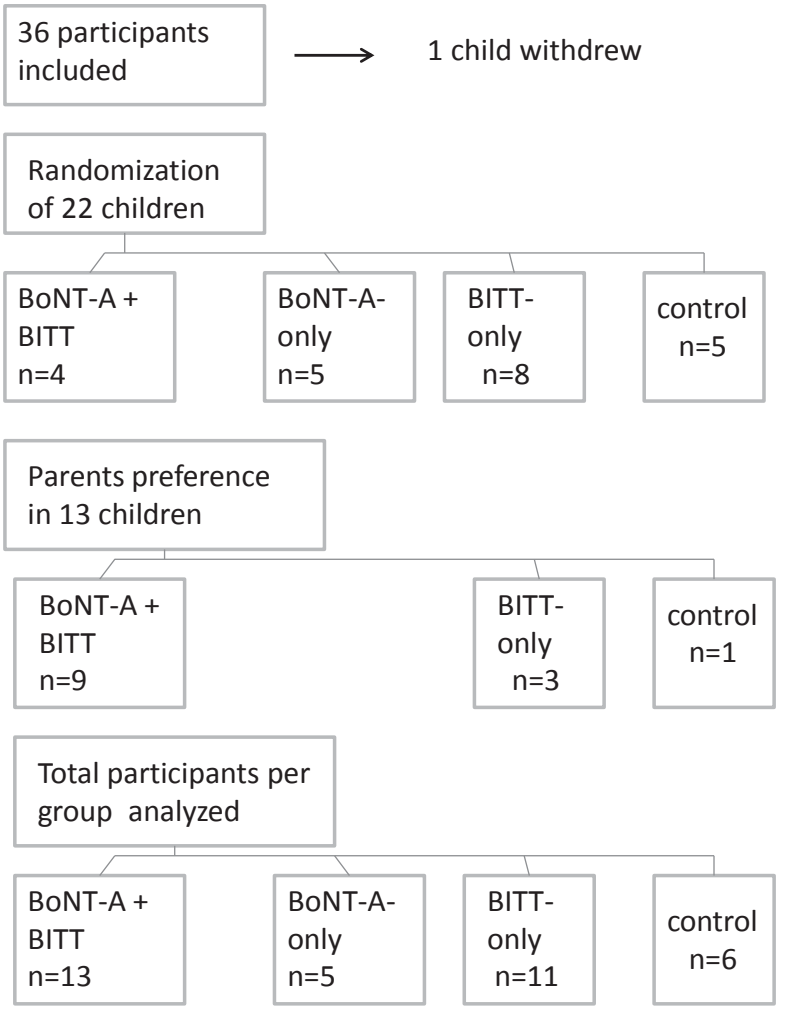

Figure 5.1 Allocation flow diagram participants.

After 2 baseline measurements. 
In Table 5.3, characteristics and relevant results of mean outcome measures at baseline are depicted for each study group. In the control group, the mean age was lowest, and Zancolli hand function impairment was worst, even though none of the children had a MACS III score. The mean baseline results of AROM wrist extension with fingers extended and flexed were worst in the control group. The MVC of fist grip baseline value was significantly lower in the BoNT-A-only and the control group (no BITT) than in the BoNT-A+BITT and BITT-only (BITT) group (Table 5.5). The functional unilateral strength baseline value was lowest in the BoNT-A-only group.

In Tables 5.4 and 5.5, three comparisons were made: a) BITT (BoNT-A+BITT and BITT-only; $n=24$ ) versus no BITT (BoNT-A-only and control; $n=11$ ), b) BoNT-A (BoNT-A-only and BoNT$A+B I T T ; n=18$ ) versus no BoNT-A (BITT-only and control; $n=17$ ), and $c$ ) the additional effect of BoNT-A, i.e. BoNT-A+BITT ( $n=13$ ) versus BITT-only ( $n=11)$.

In Table 5.4, effects at AROM and spasticity, expressed as SPAT, are depicted. Comparing BoNT-A versus no BoNT-A, or BoNT-A+BITT versus BITT-only, the BoNT-A group showed $9^{\circ}$ to $10^{\circ} \mathrm{improvement}$ in active thumb abduction at 6 weeks (clinically relevant) and even more at 12 weeks after the start of treatment. In the same comparisons, BoNT-A significantly reduced finger flexor spasticity at 6 and 12 weeks and overall (Figure 5.2). BITT in comparison to no BITT showed a $20^{\circ}$ elbow flexor SPAT reduction at 6 weeks, and a significant improvement in active supination at 12 weeks. BoNT-A has an additional positive effect $\left(15^{\circ}\right)$ on active supination (BoNT-A+BITT versus BITT-only).

In Table 5.5, effects at MVC of fist grip and key grip and unilateral and bimanual functional strength are depicted. Comparing BoNT-A versus no BoNT-A, or BoNT-A+BITT versus BITTonly, key grip strength was significantly lower in the BoNT-A+ group at 6,12 and 18 weeks post treatment (Figure 5.3). BoNT-A showed a significantly negative additional effect on the improvement of unilateral functional strength: the BITT-only group improved gradually from $131 \mathrm{ml}$ at baseline to $309 \mathrm{ml}$ at 24 weeks, whereas the BoNT-A+BITT group improved significantly less (from 162 to $215 \mathrm{ml}$ ) (Figure 5.3).

Comparing BITT with no therapy, both groups show an overall increase of about $2000 \mathrm{~g}$ in functional bimanual strength. In the BITT group there was a clear increase during the therapy period at 6 and 12 weeks (Figure 5.4). When comparing the BoNT-A+BITT to the BITT-only group, the latter group improves more (2,120 versus $1,888 \mathrm{~g})$ and sooner. 


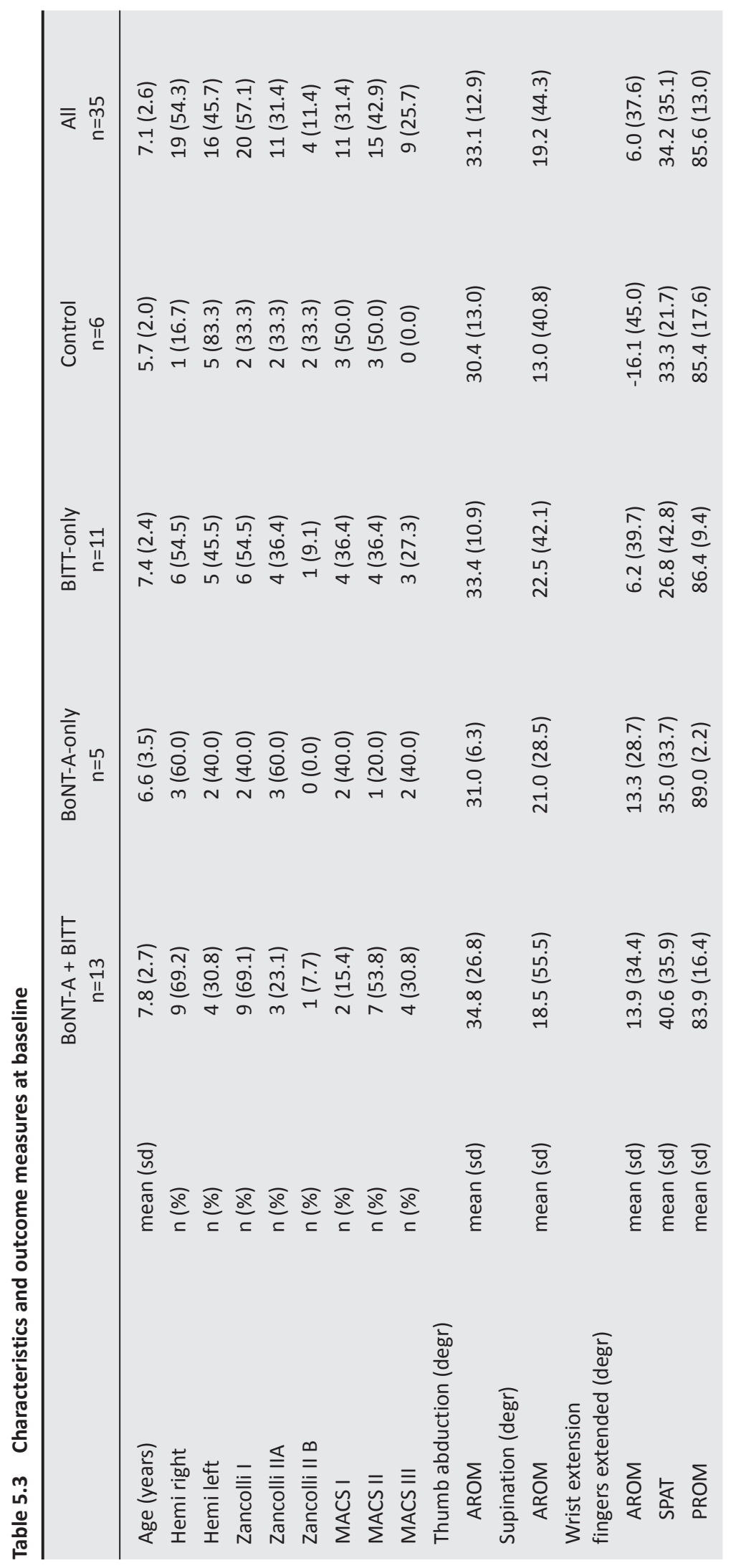




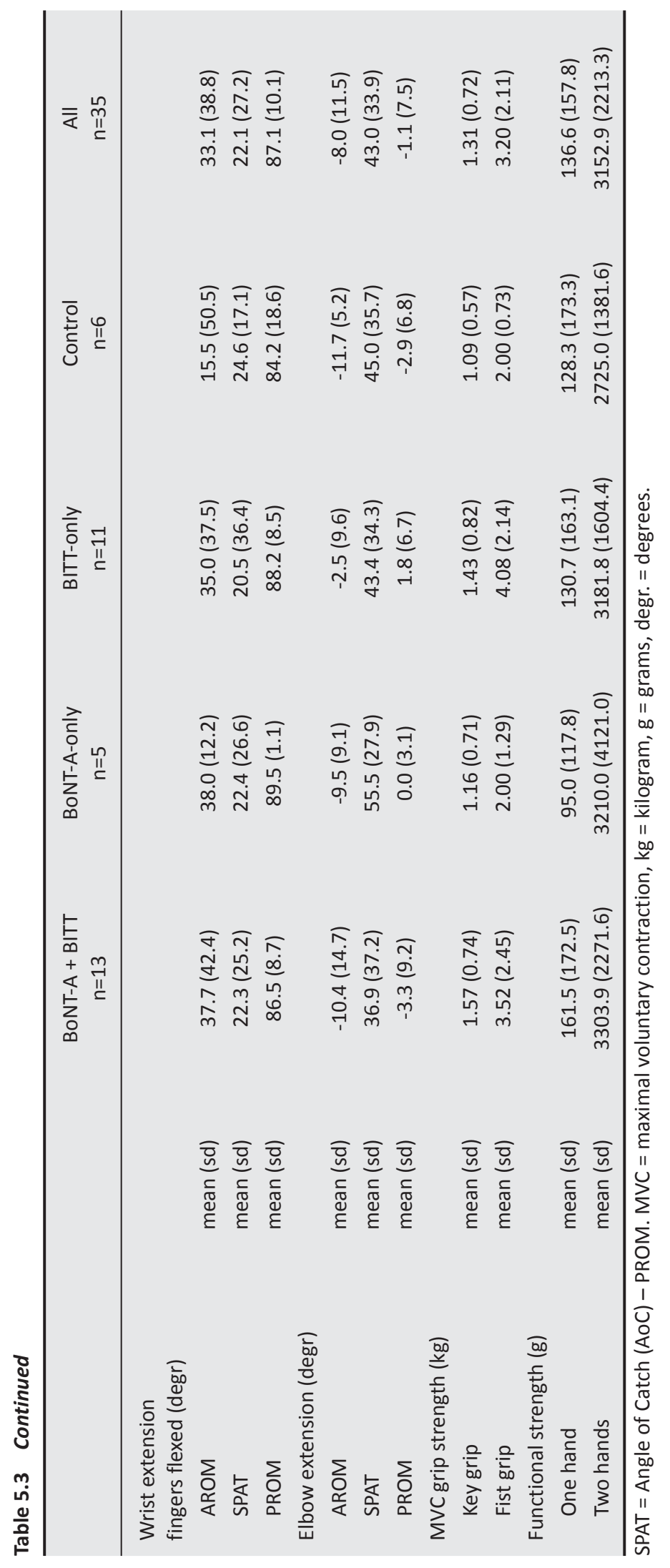




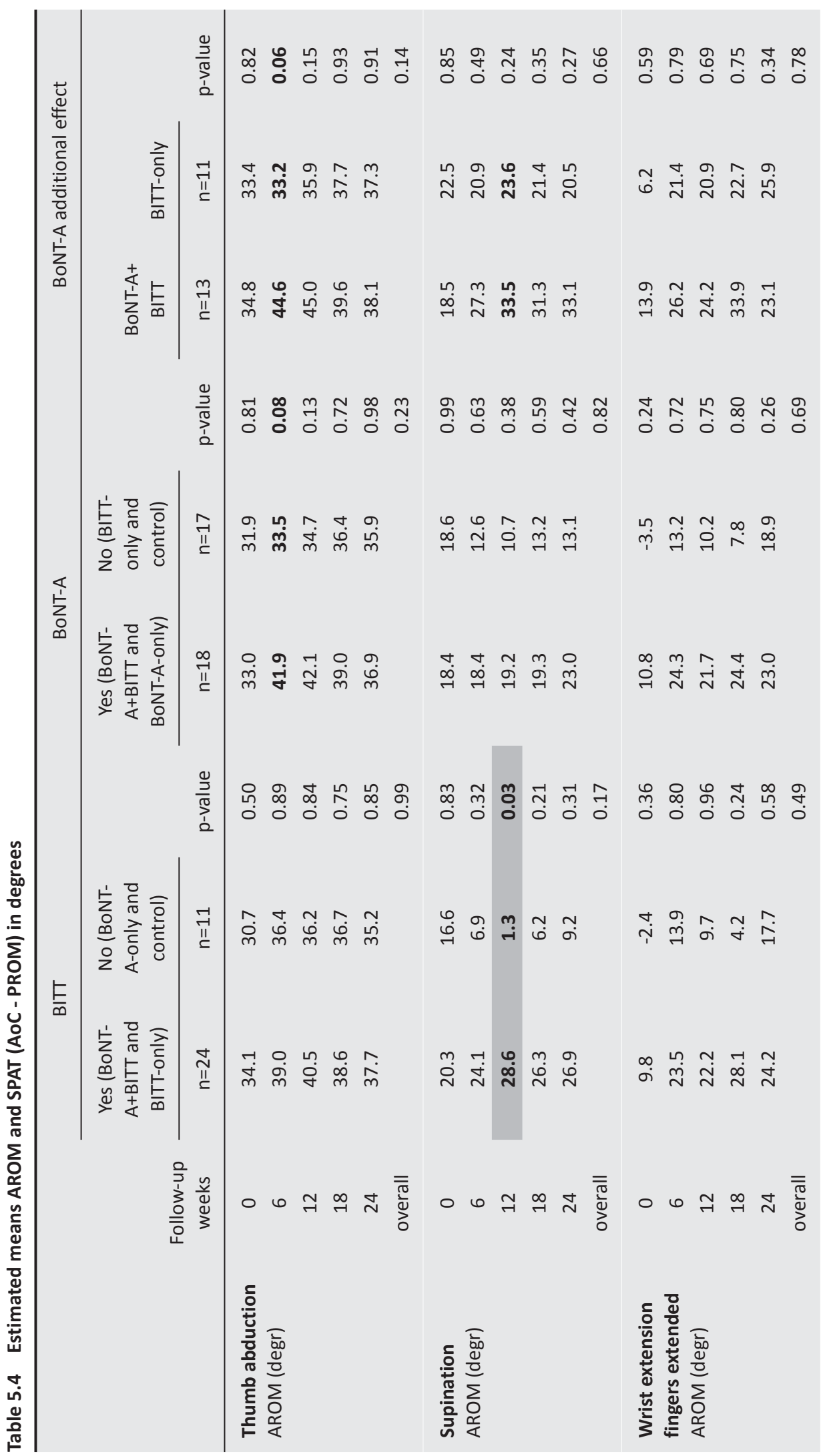




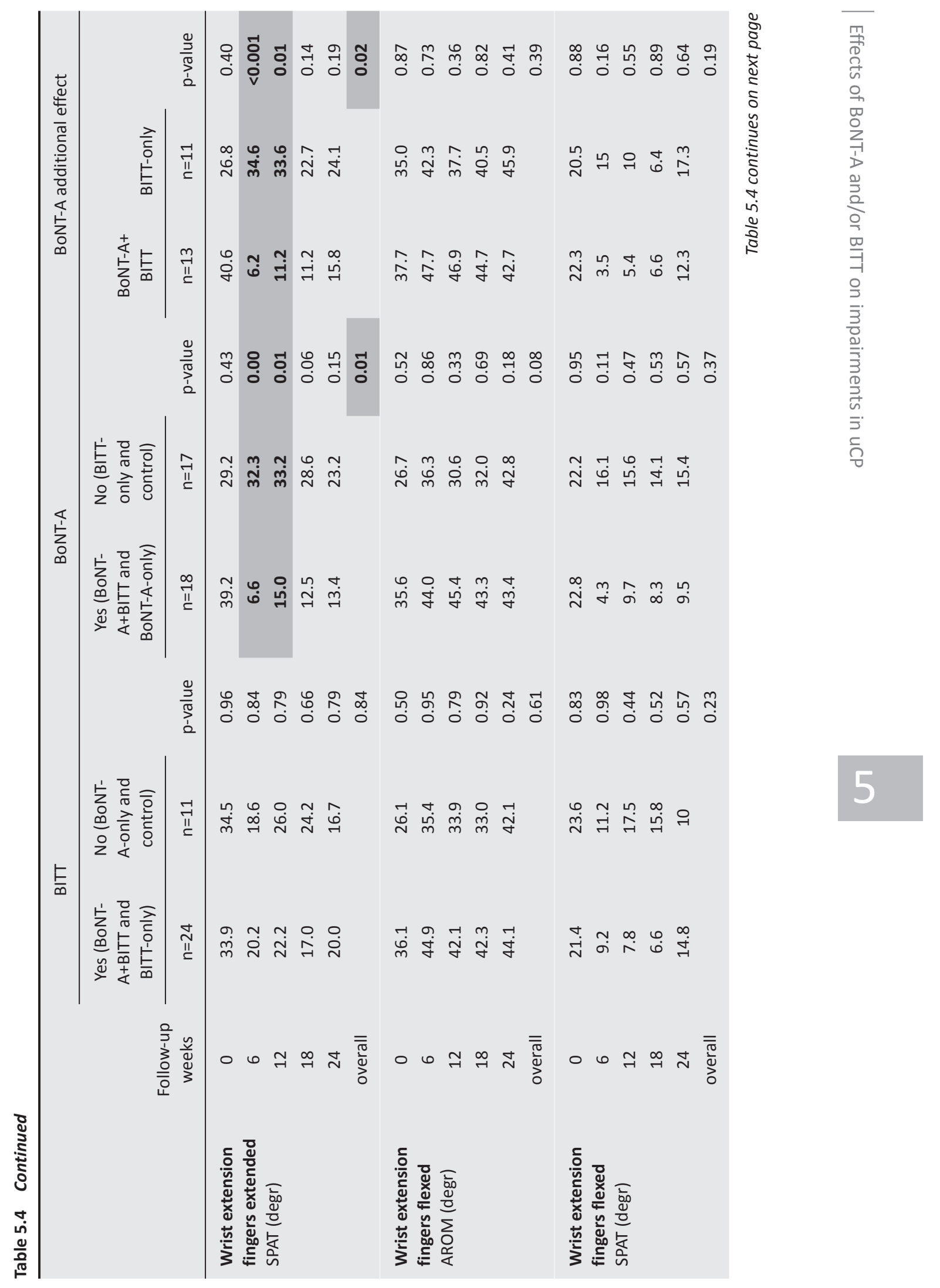




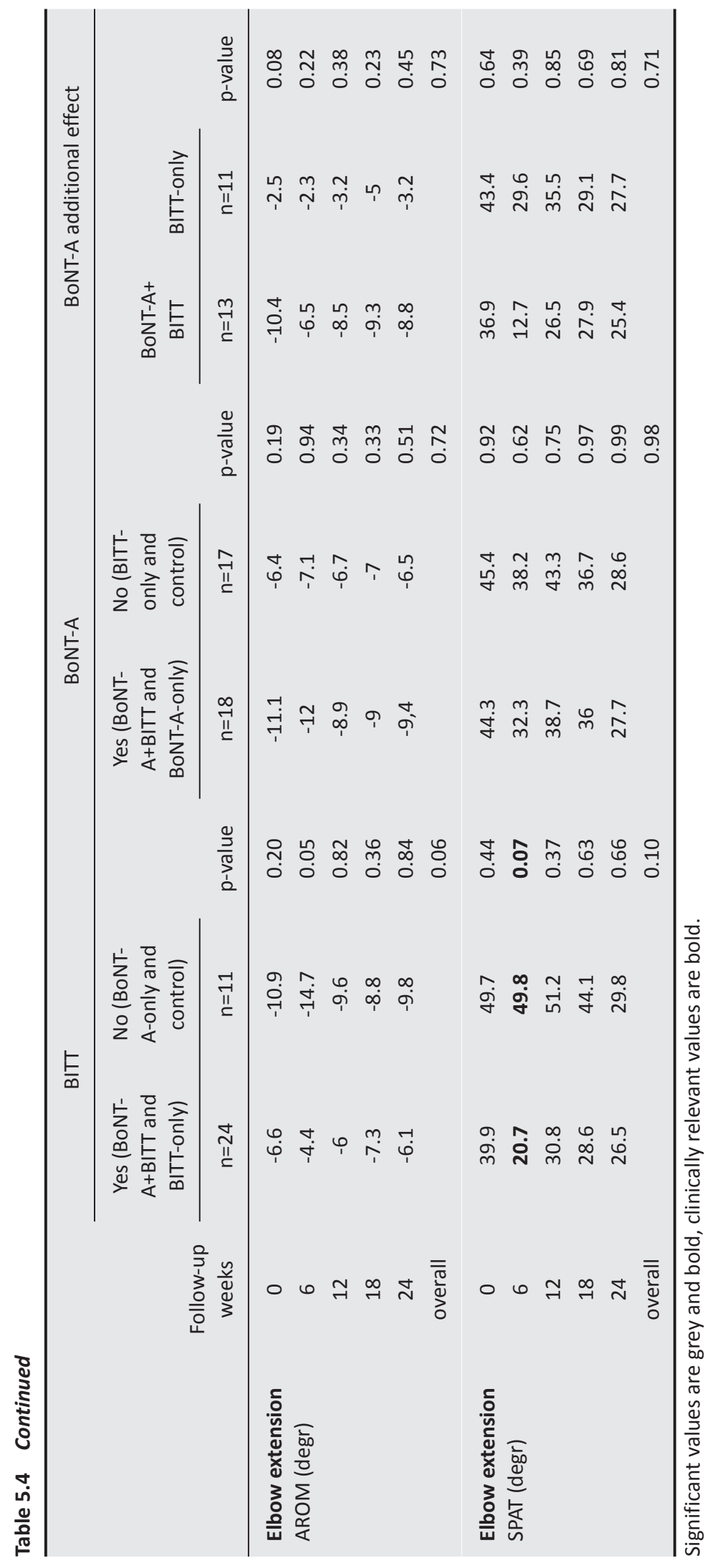




\section{DISCUSSION}

The present study investigated the effects of BoNT-A in the UE in children with uCP combined with BITT or either treatment modality separately on UE AROM, spasticity and (functional) strength. We found that BoNT-A causes significant reduction of spasticity of the finger flexors but also decreases key grip strength. BoNT-A has a clinically relevant (additional) effect at thumb abduction and a statistically significant negative additional effect at improving unilateral functional strength. BITT, in combination with BoNT-A, significantly increases active
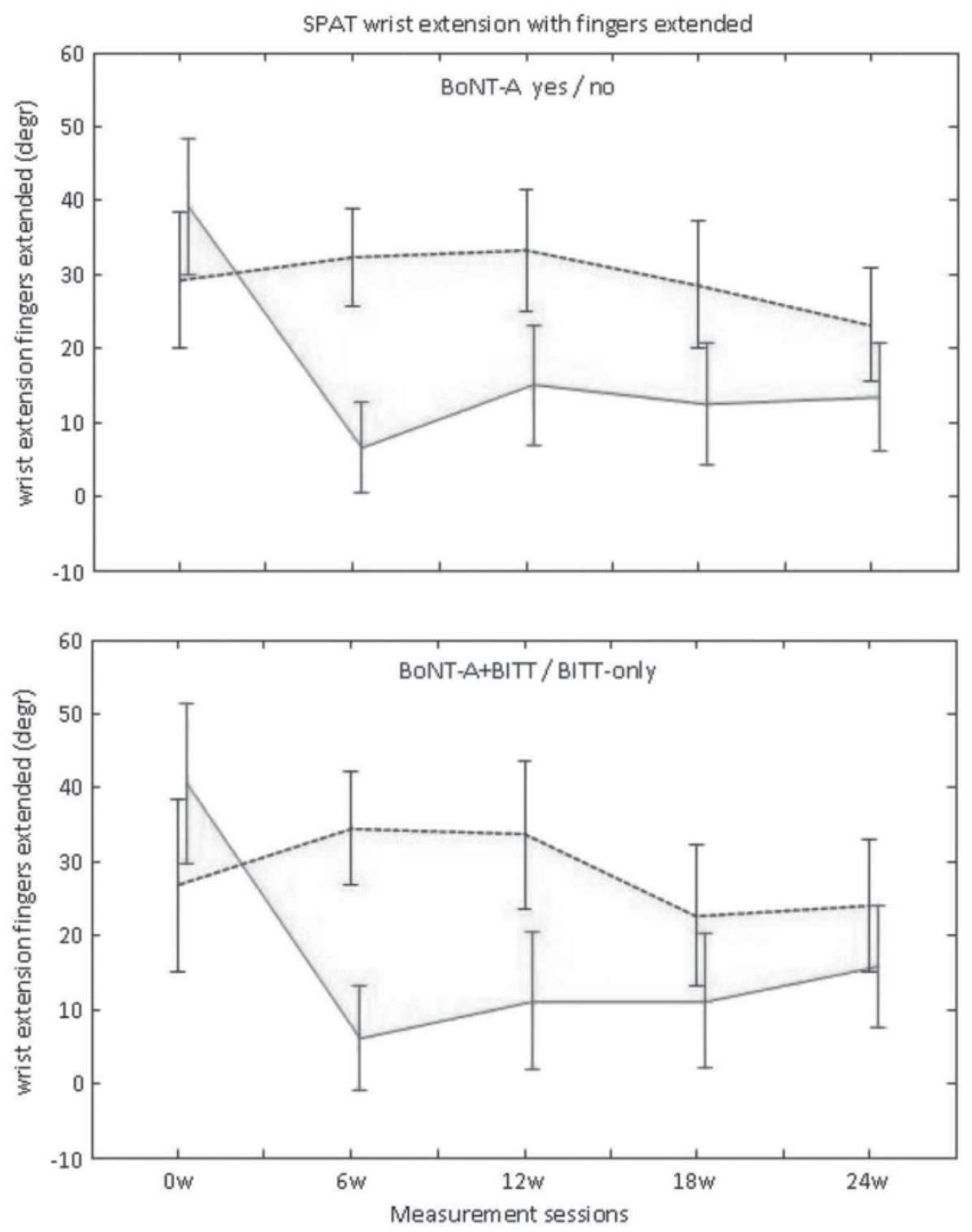

Figure 5.2 SPAT wrist extension fingers extended (degrees), solid line BoNT-A yes or BoNT-A+BITT, dotted line BoNT-A no or BITT-only. 


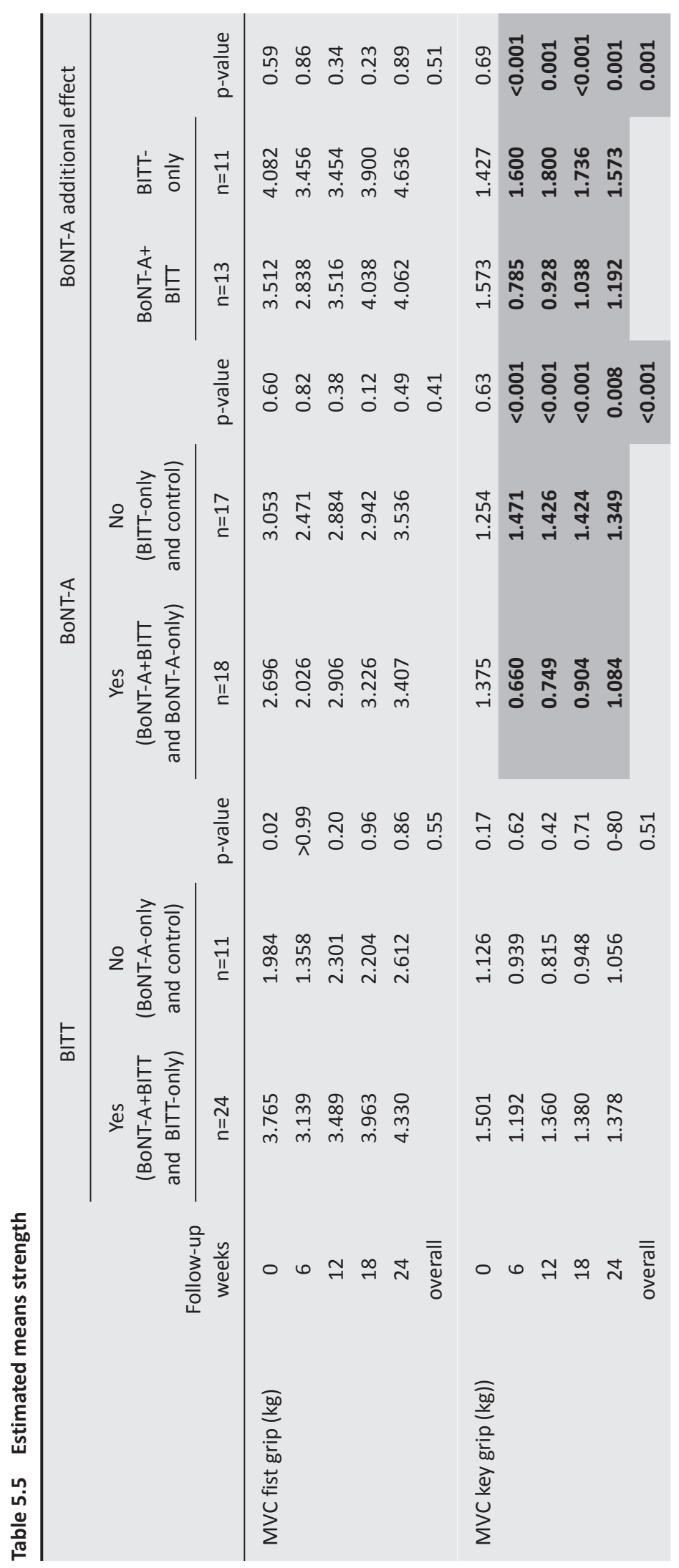




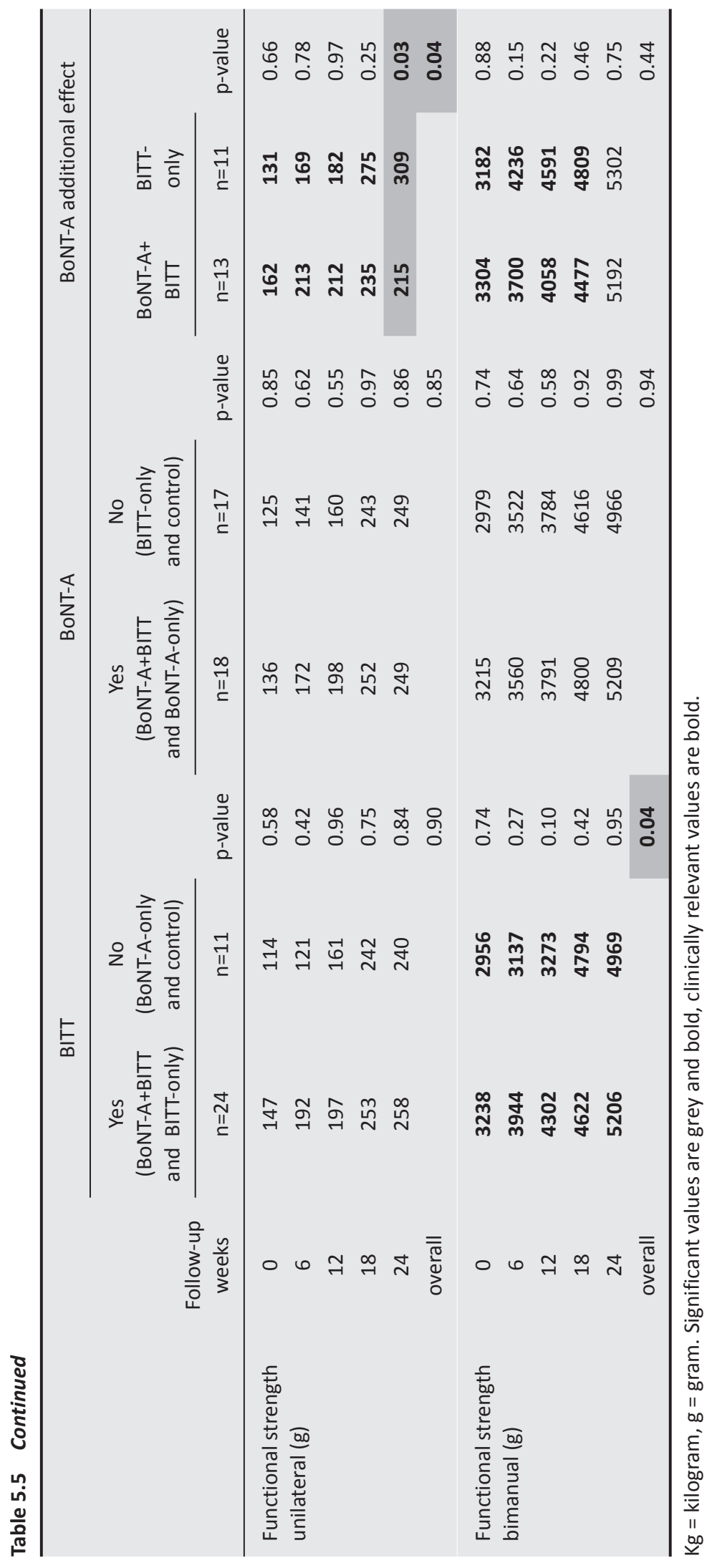



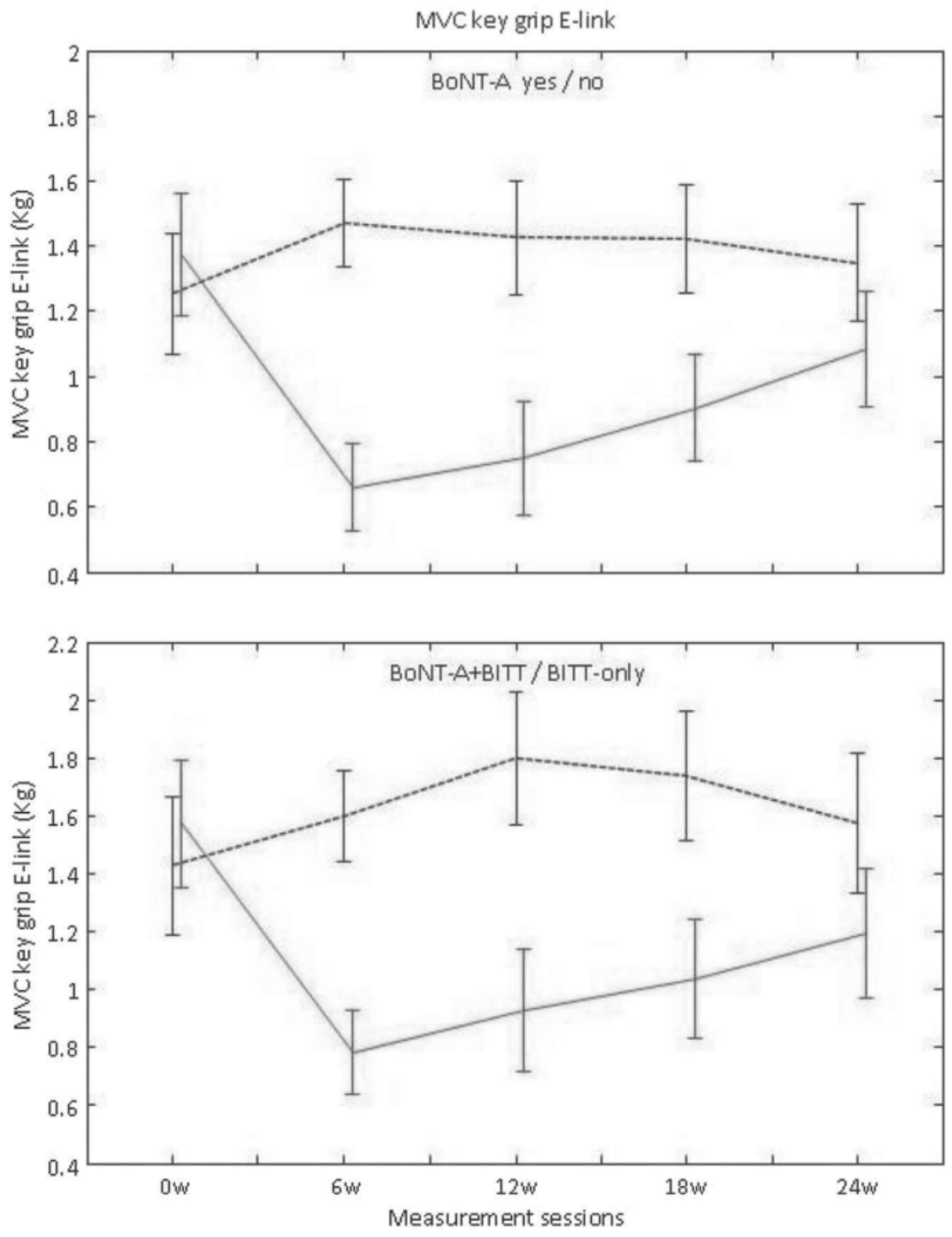

Figure 5.3 E-Link MVC key grip (kg), solid line BoNT-A yes or BoNT-A+BITT, dotted line BoNT-A no or BITT-only.

supination. BITT reduces elbow flexor spasticity and in comparison with BITT+BoNT-A, BITTonly gives more improvement of functional unimanual and, to a lesser extent, bimanual grip strength.

BoNT-A was administered predominantly in the thumb adductor, the wrist and finger flexors and pronator teres. This resulted in the observed reduced finger flexor spasticity, increased thumb abduction and supination, but also in a decreased key grip strength. Although there 


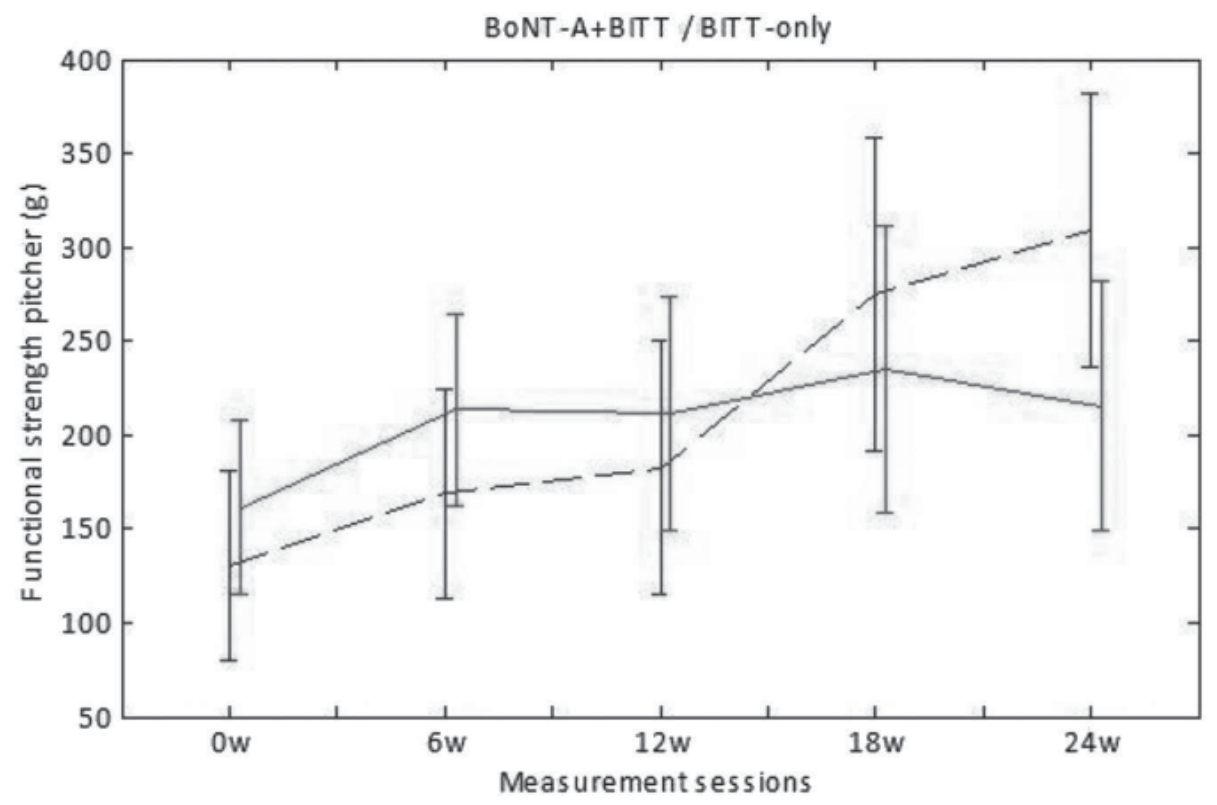

Figure 5.4 Functional unimanual strength (g), solid line BoNT-A+BITT, dotted line BITT-only.

was a significant reduction in finger flexor spasticity in the BoNT-A treated children, this did not result in more of an increase of active wrist extension, which is contrary to our previous study. ${ }^{5}$ In all treatment groups active wrist extension improved from baseline to 24 weeks. In our opinion, more wrist extension and/or less wrist and finger flexor spasticity could be assumed to be a prerequisite for better fist grip strength, or functional strength, because this leads to a better hand position to exert force. In this study, however, we found a negative effect of additional BoNT-A in the children who participated in the BITT group in unilateral functional strength: the children in the BITT-only group improved significantly more. This confirms the results of Rameckers et al. ${ }^{9}$ BITT led to a minor improvement in bimanual functional grip strength, especially during and shortly after therapy. Unfortunately, there was a significant baseline difference in MVC fist grip strength between the BITT and no BITT group. However, the statistics used were corrected for baseline differences so this is accounted for in the analysis. In all groups, MVC fist grip strength diminished at 6 weeks and then gradually improved towards the last measurement. BITT in combination with BoNT-A demonstrated a clinically relevant positive effect at active supination and BITT-only demonstrated a relevant decrease in elbow flexor tone during therapy.

Considering that grip strength and active supination can be of influence in improving the use of the affected hand in bimanual performance, ${ }^{1,2}$ the additional effect of BoNT-A is 
limited to a further increase of active supination besides BITT, and it has a negative effect at functional unimanual strength. As there are multiple factors contributing to a decrease in muscle growth and pathological changes in muscles in CP children, ${ }^{22}$ the effect of BoNT-A has been questioned before. ${ }^{23}$ BITT in comparison with BoNT-A+BITT, has a clear, positive effect at improving unilateral and, to a lesser extent, bimanual functional strength and is, therefore, promising in increasing bimanual performance.

Limitations of this study are the only partially realised randomisation and the limited number of participants. This was because the parents did not want their child to be randomized in either the BoNT-A-only or control group due to their preference for BoNT-A+BITT or BITTonly. Therefore, the initial factorial design had to be changed, resulting in a large group size variation. Nevertheless, this explorative study revealed consistent and clinical relevant results. Although BoNT-A worked as expected (spasticity reduction), it had a significantly negative effect at (functional) grip strength. In comparison with BoNT-A+BITT, BITT-only gave more improvement on functional grip strength. As strength is supposed to be of influence in bimanual performance, in children with UCP, MACS I-III, BITT has better prospects than BoNT-A for this purpose.

\section{ACKNOWLEDGEMENTS}

Participating centres: Free University Medical Centre, Mariendael, Via Reva, Revant, Blixembosch, Leijpark, Tolbrug, Vogellanden, Groningen University Medical Centre and St. Maartenskliniek.

This study was supported by grants provided by Johanna Kinderfonds, Stichting Rotterdams Kinderrevalidatie Fonds Adriaanstichting, Phelps Stichting, Profileringsfonds azM, Stichting Vooruit, Elisabeth Strouven stichting, Kanunnik Salden-Nieuwenhof stichting and Adelante. The Dysport ${ }^{\circledR}$ vials were provided by Ipsen Biopharm Ltd (UK). 


\section{REFERENCES}

$1 \quad$ Klingels K, Demeyere I, Jaspers E, De Cock P, Molenaers G, Boyd R, Feys H. Upper limb impairments and their impact on activity measures in children with unilateral cerebral palsy. Eur J Paediatr Neurol 2012; 16: 475-484.

2. Brændvik SM, Elvrum AKG, Vereijken B, Roeleveld K. Relationship between neuromuscular body functions and upper extremity activity in children with cerebral palsy. Dev Med Child Neurol 2010; 52: e29-e34.

3. Eliasson AC, Krumlinde-Sundholm L, Rosblad B, Beckung E, Arner M, Ohrvall AM, et al. The Manual Ability Classification System (MACS) for children with Cerebral Palsy: scale development and evidence of validity and reliability. Dev Med Child Neurol 2006; 48: 549-554.

4. Brændvik SM, Elvrum AKG, Vereijken B, Roeleveld K. Involuntary and voluntary muscle activation in children with unilateral cerebral palsy - Relationship to upper limb activity. Eur J Paediatr Neurol 2013; 17(3): 274-279.

5. Speth LA, Leffers $P$, Janssen-Potten YJ, Vles JS. Botulinum toxin A and upper limb functional skills in hemiparetic cerebral palsy: a randomized trial in children receiving intensive therapy. Dev Med Child Neurol 2005; 47(7): 468-473.

6. Hoare BJ, Wallen MA, Imms C, Villanueva E, Rawicki HB, Carey L. Botulinum toxin A as an adjunct to treatment in the management of the upper limb in children with spastic cerebral palsy (UPDATE). Cochrane Database Syst Rev 2010 Jan 20; (1): CD003469. Review.

7. Pontén E, Fridén J, Thornell LE, Lieber RL. Spastic wrist flexors are more severely affected than wrist extensors in children with cerebral palsy. Dev Med Child Neurol 2005; 47: 384-389.

8. Smits-Engelsman BCM, Rameckers EAA, Duysens J. Muscle force generation and force control of finger movements in children with spastic hemiplegia during isometric tasks. Dev Med Child Neurol 2005; 47: 337-342.

9. Rameckers EAA, Speth LAWM, Duysens J, Vles JSH, Smits-Engelsman BCM. Botulinum toxin-a in children with congenital spastic hemiplegia does not improve upper extremity motor-related function over rehabilitation alone: a randomized controlled trial. Neurorehabil Neural Repair 2009; 23: 218-225.

10. Fehlings D, Novak I, Berweck S, Hoare B, Stott NS, Russo RN. Botulinum toxin assessment, intervention and follow-up for paediatric upper limb hypertonicity: international consensus statement. Eur J Neurol 2010: 17(Suppl. 2): 38-56.

11. Elvrum AKG, Brændvik SM, Sæther R, Lamvik T, Vereijken B, Roeleveld K. Effectiveness of resistance training in combination with botulinum toxin-A on hand and arm use in children with cerebral palsy: a pre-post intervention study. BMC Pediatrics 2012; 12: 91.

12. Gordon AM, Schneider JA, Chinnan A, et al. Efficacy of a hand-arm bimanual intensive therapy (HABIT) in children with hemiplegic cerebral palsy: a randomized control trial. Dev Med Child Neurol 2007; 49: 830-838.

13. Verschuren $\mathrm{O}$, Ketelaar M, Takken $\mathrm{T}$, et al. Reliability of hand-held dynamometry and functional strength tests for the lower extremity in children with Cerebral Palsy. Disabil Rehabil 2008; 30(18): 1358-1366.

14. Schulz KF, Altman DG, Moher D. CONSORT 2010 Statement: Updated Guidelines for Reporting Parallel Group Randomized Trials. Ann Intern Med 2010; 152(11): 1-8.

15. Zancolli EA, Zancolli E Jr. Surgical rehabilitation of the spastic upper limb in cerebral palsy. In DW Lamb (editor), The Paralyzed Hand (pp. 153-160). Edinburgh: Churchill Livingstone, 1987. 
16. Verkerk GJ, Wolf MJ, Louwers AM, Meester-Delver A, Nollet F. The reproducibility and validity of the Canadian Occupational Performance Measure in parents of children with disabilities. Clin Rehabil 2006; 20(11): 980-988.

17. Heinen F, Desloovere K, Schroeder AS, et al. The updated European Consensus 2009 on the use of Botulinum toxin children with cerebral palsy. Eur F Paediatric Neurol 2010; 14(1): 45-66.

18. Scholtes VA, Becher JG, Beelen A, Lankhorst GJ. Clinical assessment of spasticity in children with cerebral palsy: a critical review of available instruments. Dev Med Child Neurol 2006; 48: 64-73.

19. Klingels $K$, de Cock $P$, Molenaers $G$ et al. Upper limb motor and sensory impairments in children with hemiplegic cerebral Palsy. Can they be measured reliably? Disabil Rehabil 2010; 32(5): 409-416.

20. Krumlinde-Sundholm L, Eliasson A. Development of the Assisting Hand Assessment: A Rasch-built measure intended for children with unilateral upper limb impairments. Scand J Occup Ther 2003; 10: 16-26.

21. Eliasson AC, Krumlinde-sundholm L, Shaw K, Wang C. Effects of constraint-induced movement therapy in young children with hemiplegic cerebral palsy: an adapted model. Dev Med Child Neurol 2005, 47: 266-275.

22. Gough M, Shortland AP. Could muscle deformity in children with spastic cerebral palsy be related to an impairment of muscle growth and altered adaptation? Dev Med Child Neurol 2012, 54: 495-499.

23. Gough M. Does botulinum toxin prevent or promote deformity in children with cerebral palsy? Dev Med Child Neurol 2009, 51: 88-91. 


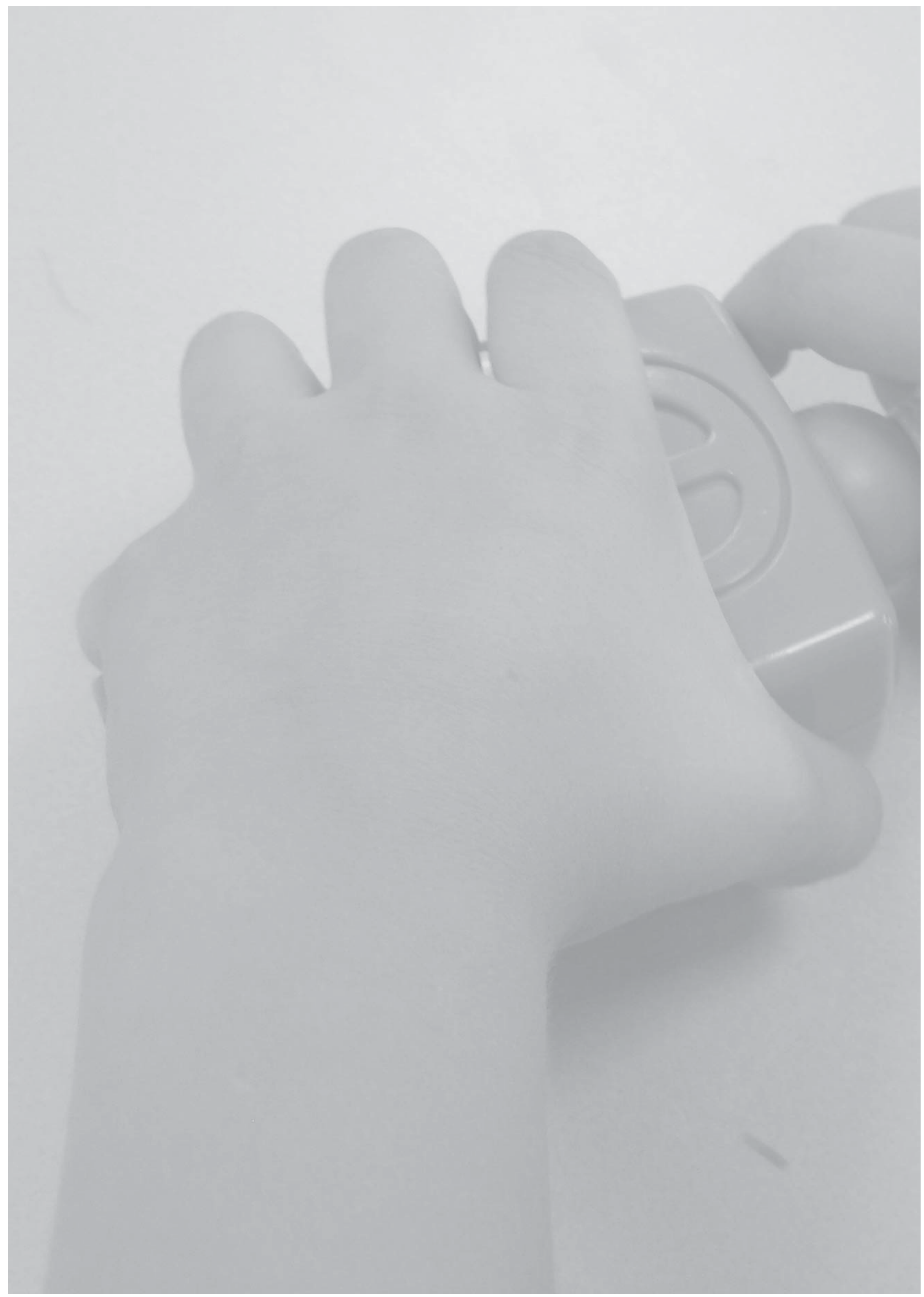




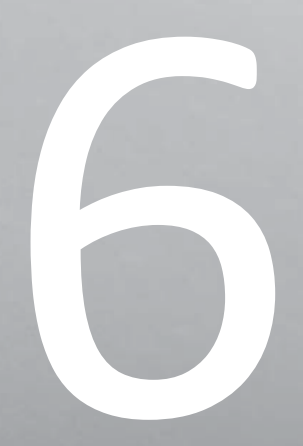

\section{Effects of botulinum toxin A and/or bimanual task-oriented therapy on upper extremity activities in unilateral Cerebral Palsy: a clinical trial}

Lucianne Speth, Yvonne Janssen-Potten, Eugene Rameckers, Anke Defesche, Bjorn Winkens, Jules Becher, Rob Smeets, Hans Vles 


\section{ABSTRACT}

\section{Background}

This study reports on the effects of botulinum toxin A (BoNT-A) injections in the upper extremity (UE) in children with unilateral Cerebral Palsy (UCP) combined with bimanual task-oriented therapy (BITT) or either treatment modality performed separately on activities, measured with the Assisting Hand Assessment (AHA), the ABILHand-Kids questionnaire (AK) and the Observational Skills Assessment Score (OSAS); and goal achievement, measured with Goal Attainment Scaling (GAS), using blind video assessment, and the Canadian Occupational Performance Measure (COPM).

\section{Methods}

Thirty-five children, mean age 7.14 years (SD 2.63) of whom 11 had a Manual Ability Classification Score (MACS) I, 15 MACS II and 9 MACS III, participated. The trial started with four study groups: BoNT-A-only ( $n=5)$, BITT-only ( $n=11)$, BoNT-A+BITT $(n=13)$, and control $(n=6)$. Twenty-two children were randomised and, due to recruitment problems, 13 children received their parents' preferred treatment: BoNT-A+BITT or BITT-only. Three comparisons were analysed: BITT (BoNT-A+BITT and BITT-only; $n=24$ ) versus no BITT (BoNT-A-only and control; $n=11$ ), BoNT-A (BoNT-A-only and BoNT-A+BITT; $n=18$ ) versus no BoNT-A (BITT-only and control; $n=17$ ), and the additional effect of BoNT-A (BoNT-A+BITT versus BITT-only). The follow-up time was 24 weeks.

\section{Results}

No significant differences between the groups were found on the AHA. The amount of use of both hands, measured with the OSAS, was significantly better in the BoNT-A group in two tasks (beading and sandwich-making). The BoNT-A group also showed improvement in the quality scores of the OSAS; specifically the wrist position during grasping and holding was significantly better in several tasks. This was demonstrated more and for a longer time in the younger children. The BITT group improved significantly on the AK and also significantly more on the performance and satisfaction scores of the COPM at 12 and 24 weeks in several goals, whereas the BoNT-A group showed a significant negative effect at 12 and 24 weeks in the most important goal. The BITT group, more than BoNT-A+BITT, showed a statistically significant positive effect on the GAS score at 12 weeks, and positive effects at 18 and 24 weeks.

\section{Conclusions}

BoNT-A has a positive effect on the quality of movement and the amount of use of the affected UE especially during the three months' working time and somewhat longer in younger children. BoNT-A has no additional effect on bimanual performance and goal achievement. BITT, on the other hand, has a clear positive effect on goal achievement and bimanual performance; even up to 6 weeks after therapy had stopped. 


\section{BACKGROUND}

According to the Cochrane review, ${ }^{1}$ the combination of botulinum toxin A (BoNT-A) in the upper extremity (UE) and intensive physiotherapy(PT)/occupational therapy(OT) is more effective than intensive therapy alone in improving the activity level of the International Classification of Functioning (ICF, http://www.who.int/classifications/icf/en/) and in goal achievement in children with unilateral spastic Cerebral Palsy (uCP). Assessments used to measure effects at the activity level in the studies in this review are the Melbourne Assessment of Unilateral Upper Limb Function (MUUL), ${ }^{2}$ the Quality of Upper Extremities Skills Test (QUEST) ${ }^{3}$ and the Pediatric Disability Inventory (PEDI). ${ }^{4}$ Goal achievement was measured with Goal Attainment Scaling $(\mathrm{GAS})^{5}$ and the Canadian Occupational Performance Measure (COPM). ${ }^{6}$

Although the studies themselves reported no significant differences on the MUUL and limited effects on the QUEST, a meta analysis of the pooled data in this review1 showed slight positive effects on both tests 3 months after injection of BoNT-A, which had disappeared at 6 months. On the PEDI functional skills score almost no effect was found. There were clear positive effects on GAS and limited positive effects on the COPM concluded. Olesch et al studied young children (mean age 3 years 8 months) with UCP and found no significant differences on the QUEST between repeated BoNT-A+OT and OT alone. However, they did find positive effects on GAS of BoNT-A+OT. ${ }^{7}$ The way GAS was performed in these studies (scoring by parents or therapists) had subjective elements. This should be taken into account, while interpreting these results.

Also, in a more recent review evaluating upper limb therapies for uCP there was a modest supplementary effect of BoNT-A as an adjunct to OT to improve unilateral capacity, quality of movement, with the MUUL and the QUEST, and a clear positive effect on achieving individualised treatment outcomes. ${ }^{8}$ In this review in only one study looking at the effect of BoNT-A on strength in children receiving resistance training, the assisting hand assessment (AHA) was used to measure bimanual performance. ${ }^{9}$

OT after BoNT-A, modified constraint induced movement therapy (mCIMT), bimanual intensive therapy (BIMT) and goal-directed and context-focused therapies are considered to be evidence-based effective improving UE activities. ${ }^{8,10}$ After BoNT-A, mCIMT and bimanual OT (BOT) each consisting of 16 one-hour therapy sessions during 6 weeks both with home therapy elements, were equally effective in young children with uCP, although 
in hindsight the home programme intensity in the BOT group was significantly less. ${ }^{11}$ In this study and in several studies reporting effects of CIMT and/or BIMT, they used the AHA, a reliable, responsive tool to measure the effective use of the assisting hand in bimanual performance. ${ }^{12,13}$ With the AHA, in several studies comparing the effects of two forms of intensive therapy currently often used in UCP, CIMT and BIMT, no difference between these treatments could be demonstrated..$^{14-16}$

At the start of our study, there were no studies measuring the effect of (additional) BoNT-A on bimanual performance. Because we considered this effect, the effective use of the affected hand in bimanual play and self-care, of utmost importance, we chose the AHA as main outcome measurement in this study.

BoNT-A has a clear effect on tone reduction, ${ }^{1,17}$ influencing movement fluency. As fluency corresponds with quality of use of the affected hand, measuring this aspect, i.e. the capacity of the affected hand as an assisting hand in bimanual activities, is necessary in our opinion. For this, the Observational Skills Assessment Score (OSAS) was developed and tested for its clinimetric properties. It appeared to be an appropriate instrument. ${ }^{18}$

Therefore, in the present study, we investigated the effects of BoNT-A injections in the UE combined with bimanual task-oriented therapy (BITT) or either treatment modality performed separately on the ICF activity level, on bimanual performance, measured with the AHAand the ABILHAND-Kids questionnaire (AK), ${ }^{19}$ on the amount of use and capacity of the assisting hand with the OSAS, and on goal achieving, measured with GAS (scored blindly on video recordings) and the COPM.

\section{METHOD}

\section{Design}

This study, called BoBiVa (Botuline toxine Bimanuele Vaardigheden), was designed as a multicentre randomised controlled trial on the effect of BoNT-A injections combined with bimanual task-oriented therapy (BITT), or either separately, in children with UCP on UE functions and skills. The trial was registered at the ISRCTN site: http://www.controlled-trials. com/ISRCTN69541857. The METC Atrium-Orbis-Zuyd (ref: 06-p-33) and the Dutch CCMO (ref: NL12005.096.06) provided medical ethics approval. The parents gave their informed consent for their children to participate in the measurements and therapies of this study. 
Initially, besides Adelante/Maastricht University Medical Centre, two other centres, VUMC in Amsterdam and UMC St. Radboud in Nijmegen, participated in this trial. Here, the BoNT-A injections were given. Due to disappointing patient enrolment, other centres, in which the BITT programme was performed, joined later. These recruitment problems also led to a change in study design: with approval of the METC this became a clinical study, as is further mentioned in the 'Randomisation' section. In this paper, the results at the ICF-activity level are reported. Originally we wanted to use a factorial design to determine the effects of BoNT-A, BITT, and the additional effect of BoNT-A to BITT (Table 6.1). As far as possible, the CONSORT guidelines for reporting parallel group randomised trials were followed. ${ }^{20}$

\section{Participants}

Children with spastic uCP, aged 2.5 to 12 years, Manual Ability Classification System (MACS) ${ }^{21}$ levels I-III, Zancolli hand impairment grade I to IIB, ${ }^{22}$ who were mentally able to perform the measurements and attend the therapy programme, were considered eligible for inclusion. The study excluded children without active hand function (Zancolli III), severe structural contractures (elbow extension deficit more than $20^{\circ}$ and/or supination deficit more than $45^{\circ}$ and/or wrist extension deficit more than $30^{\circ}$ ) and children who had undergone a treatment of the affected hand (BoNT-A injections less than nine months before, or hand surgery).

\section{Therapy programme}

The BITT programme consisted of half an hour of PT and one hour of OT, 2 times a week, for 12 weeks. Children in the outpatient clinic had the PT and OT (1.5 h) after each other, 2 times a week. Children who were at the special school had the therapy during school days. At the start, bimanual goals were set using the COPM. ${ }^{6}$ Examples of goals that were being targeted in the therapy are: pulling up trousers and closing the button, cutting paper with scissors, pulling apart LEGO bricks, tying shoelaces, closing the zip of a jacket. These goal-

Table 6.1 Factorial study design

\begin{tabular}{lccc}
\hline & BoNT-A yes & BoNT-A no & \\
\hline BITT yes & BoNT-A+BITT $(n=13)$ & BITT-only $(n=11)$ & 24 \\
BITT no & BoNT-A-only $(n=5)$ & Control $(n=6)$ & 11 \\
& 18 & 17 & \\
\hline
\end{tabular}

BoNT-A = botulinum toxin A. BITT = bimanual task oriented therapy. 
directed activities were practiced as much as possible in the child's relevant context. The programme was individually tailored to the child based on a task analysis of the selected goals performed at the start of the treatment and was based on principles of motor learning, strength training and/or improving range of motion (ROM). When weakness was the main problem in closing the button of a pair of jeans, this was trained by asking the child to pull up his trousers and then close the button several times, starting with wider trousers and an easier clasp. When ROM was a problem and the finger flexors were shortened, the children had to wear a finger flexor stretching night splint. Also day splints facilitating hand function were used. Additionally, parents were asked to stimulate their child to practice these goaldirected dressing and playing activities every day in a home-exercise programme. They practiced these activities several times a day during grooming and while playing. Parents reported that during the day they spent 40 to 60 minutes practising these goals (56-84h of exercise in total). All therapists of the participating centres were trained in this special goaldirected, task-specific bimanual therapy. ER and AD trained the therapists to perform the BITT programme during a 6 hours training course. During the BITT programme, these therapists were coached by AD. Feedback was given on their task analysis using video recordings of the child performing his/her individual goal. The children in the BoNT-A-only and control group continued their usual therapy with a maximum frequency of one hour a week. We requested their therapists not to work at improving bimanual goals. The physiotherapists of the children in these treatment groups were unaware of the goal setting.

\section{BoNT-A injection technique and dosage}

The most spastic muscles hampering function and bimanual activities were injected once in both the BoNT-A treatment groups; in the BoNT-A+BITT group, the BoNT-A was injected 4 days to a maximum of 2 weeks before the start of the BITT programme. Based on a video of the child performing his or her most important goal and on UE spasticity measurements, the three physicians of the initial participating centres decided during teleconferencing which muscle had to be treated and in what dose. Dysport ${ }^{\circledR}$ (Ipsen) was used with dilution $25 \mathrm{U} / 0.1 \mathrm{ml}$ and with a dose 3 times the dose of Botox ${ }^{\circledR}$ (Allergan), 6-9 U/kg body weight for muscles above the elbow and 3-6 $\mathrm{U} / \mathrm{kg}$ body weight for muscles in the forearm, limited to no more than 150 units $(0.6 \mathrm{ml})$ at one injection site. In the intrinsic thumb muscles, the maximum dose was $50 \mathrm{U}$ per muscle; mostly $25 \mathrm{U}$ per muscle was injected. The total maximum Dysport ${ }^{\circledR}$ dose was 1,000 U per child per session..$^{23}$ The injections took place under general anaesthesia in the day care department of the three initially participating centres. 
The muscles that had to be injected were located by electro-stimulation; the BoNT-A was injected with a special Teflon ${ }^{\circledR}$ coated needle. The most frequently injected muscles were the adductor pollicis, flexor carpi ulnaris and radialis and pronator teres. For dose and frequency of muscles injected see our publication of the effect of BoNT-A and/or BITT on upper extremity functions, ${ }^{17}$ or additional file A6.3.

\section{Outcome measures}

Two baseline measurement sessions with a maximum of two weeks in between, and four follow up sessions at $6,12,18$ and 24 weeks after BoNT-A/start BITT were performed. The $\mathrm{AHA}$, the primary outcome measure, was administered at the second baseline session and at 12 and 24 weeks. The AK was taken at the first baseline session and all follow-up sessions. Both the AHA (a video assessment) and the AK (a questionnaire) were performed to measure effectiveness of use of the affected hand $(\mathrm{AH})$ in bimanual performance. To measure amount and quality of use of the $\mathrm{AH}$ i.e. capacity, the OSAS ${ }^{18}$ was administered. The AHA and the OSAS were administered by a certified, experienced occupational therapist (OTst). With the COPM, which was administered at the first baseline session, 3 goals in which bimanual hand use was needed were determined. Evaluation of these goals with the COPM took place at 12 and 24 weeks. The most important problem that emerged from the COPM was video recorded at the second baseline measurement session. Watching this video, goal attainment scaling (GAS) was performed by the first author (LS) and an experienced OTst (AD). A 6-point scale was used with 0 representing the expected level of success, 2 clearly more than expected and -3 worse than before. ${ }^{5}$ At all the other measurement sessions, new video recordings of this main goal were made. Afterwards these GAS videotapes and those of the AHA and OSAS were renamed and scored by trained assessors (PTsts and OTsts). These assessors were not involved in the treatment and unaware at which time session the video was taken, so blinding was guaranteed. The AHA score was converted to the AHA 0-100 units score. Additionally, measurements at function level of the ICF were performed. These results have been reported earlier. ${ }^{17}$

\section{Sample size}

Power analysis was done on the AHA, as this was the main outcome measurement of the BoBiVa study at the ICF activity level. At the start of this study, the study of Eliasson ${ }^{24}$ was the only known study that used the AHA as an evaluative measurement. We assumed that 
the difference between groups (mCIMT and control) as found by Eliasson (mean change for the treatment group 1.23 (SD 1.04) and for the control group 0.24 (SD 0.85)) was the minimum clinically relevant difference to be detected in our study. Using the same variation, a two-sided alpha of 0.05 and a beta of 0.10 (i.e. power of $90 \%$ ), a minimum of 50 children in total were needed to detect the main effects of the treatment comparisons (effect of BoNT-A, BITT or BoNT-A+BITT) on daily hand use.

\section{Randomisation}

The trial started with a factorial design in 2008. There were 4 study groups: 1) BoNT-A-only, 2) BITT-only, 3) BoNT-A+BITT and 4) control group (Table 6.1). To improve comparability of the groups, randomisation into the four treatment groups took place after pre-stratification for centre and age group: 2.5-6 and 7-12 years. Randomisation was done after the two baseline measurements and before start of the treatment. Using opaque envelopes ensured allocation concealment. An independent researcher generated random allocation sequence. LS and JB enrolled participants. YJ assigned participants to the intervention by handing out the opaque envelopes. Because of recruitment problems, we abandoned the randomisation into 4 groups after official approval of the medical ethics committee. This adaptation was necessary because many parents did not want their child to participate, because they either had a strong preference for or aversion to BoNT-A treatment. Also, they considered the risk of allocation of their child to either the control or the BoNT-A-only group to be too high. From March 2010 on, the children were only allocated to the BoNT-A+BITT or the BITT-only group. The scientific importance of random allocation was discussed with the parents. If the parents agreed, the children were randomised; otherwise, their child was allocated to the group of their preference. As this was the choice of the parents and not of a physician, we do not expect that it has led to confounding by indication.

\section{Statistical analysis}

Categorical and numerical variables were presented by number of patients (\%) and by means (SD), respectively. The longitudinal effects of bimanual therapy (BITT versus noBITT) and BoNT-A (BoNT-A versus no-BoNT-A) on the numerical outcome measures were assessed using linear mixed models to correct for baseline differences and to account for the correlations between repeated measures within the same patient and for missing data by using likelihood methods, which assume the data to be missing at random. The fixed part 
of the models included BITT (yes/no), BoNT-A (yes/no), time $(0,6,12,18$ and 24 weeks), BITT*time, and BoNT-A*time. Restricted maximum likelihood estimation was used and the covariance structure for the repeated measures (compound symmetry (CS), heterogeneous CS, first-order autoregressive (AR1), heterogeneous AR1, Toeplitz (TP), heterogeneous TP or unstructured) was selected based on Akaike's information criterion. As for the additional effect of BoNT-A (BoNT-A+BITT versus BITT-only) on the outcome measures, a similar linear mixed model (without the variables BITT and BITT*time) was applied to the data of the patients who received either BITT-only or BoNT-A+BITT. For the ordinal GAS score, the differences between the groups were assessed using the Kruskal-Wallis test. A two-sided $p$-value $\leq 0.05$ was considered statistically significant. All analyses were performed using IBM SPSS Statistics for Windows (Version 20.0. Armonk, NY: IBM Corp).

\section{RESULTS}

Patients were enrolled from January 2008 until December 2010. The last follow-up measurement took place in September 2011. Initially, thirty-six children with uCP were enrolled in the study. One child, who was allocated to the BITT-only group, withdrew after the baseline measurements because the participating centre had problems organizing BITT. Therefore, a total of 35 children participated in the study. Twenty-four were born at full term, 6 at 37 weeks and 5 were born prematurely (25-35 weeks gestation).

Twenty-two children were allocated by randomisation; in 13 children the parents' preference was followed (Figure 6.1) of whom nine were allocated to the BoNT-A+BITT group and four to the BITT-only group. The parents of one young child in the latter group indicated after the baseline measurements that they were not able to bring their child for therapy twice a week. They agreed to let him perform the measurements only, so the child was allocated to the control group. Two children who were randomly assigned to the control group missed the outcome measurements of week 6, 18 and 24. One because she underwent surgery to improve walking; the parents of the other child were no longer willing to cooperate with the measurements. Their baseline and 12 week measurement results were analysed.

We used a registration form for Serious Adverse Events (SAEs) and Suspected Unexpected Serious Adverse Reactions (SUSARs), but no adverse reactions were reported.

In Table 6.2, characteristics and outcome measures at baseline of all children and treatment groups are depicted. The children in the control group and less in the BoNT-A-only group 


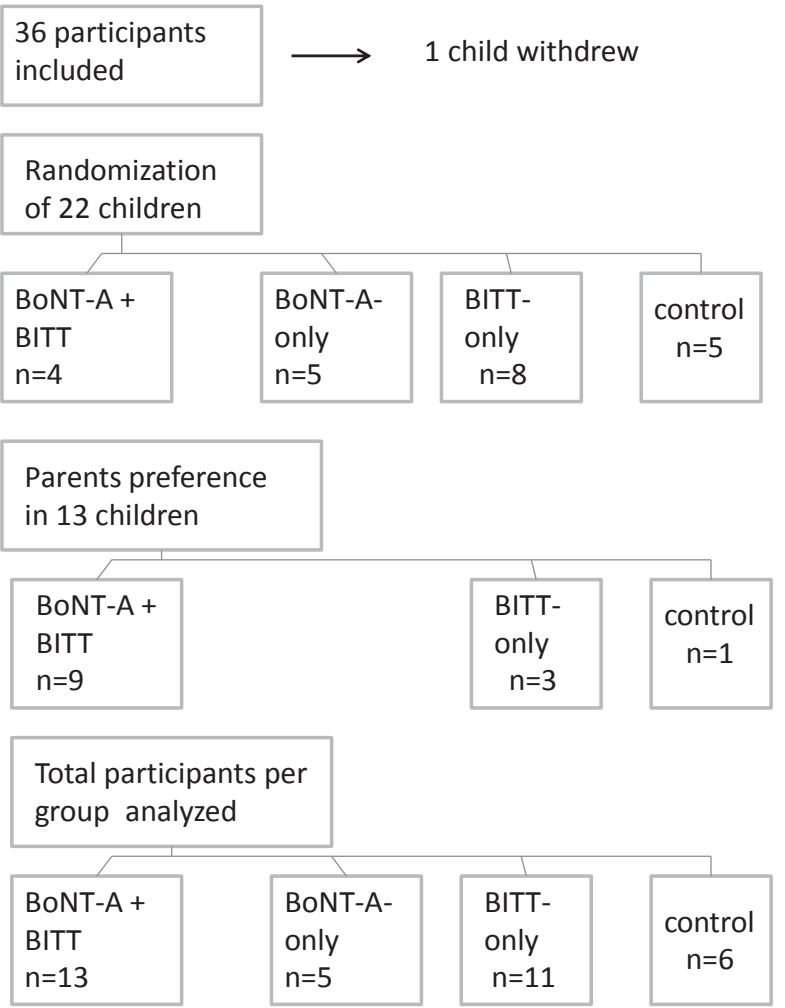

Figure 6.1 Allocation flow diagram participants.

After 2 baseline measurements.

were clearly younger. Hand function impairment (Zancolli grade) was worst in the control group and in the BoNT-A-only group bimanual performance i.e. the MACS was worst. Children in the control group scored relatively low on the AHA units and the ABILHANDKids logit units' score. Overall, there were no significant differences between the groups at baseline.

Because the OSAS has different standardised tasks for two age groups, 2.5 to 6 and 7 to 12 years old, the baseline values for these two age groups are given separately in the additional files A6.1 and A6.2. The group sizes were small in general. The younger children were more equally distributed across the four treatment groups. With a mean age of 3 years, the two young children in the BoNT-A-only group were clearly younger than their peers in the other treatment groups. Their performance was clearly worse in using both hands in the OSAS tasks. The control group contained only two children from the older age group and one of them performed badly on the AHA, and showed a low percentage of use in the OSAS construction tasks. 


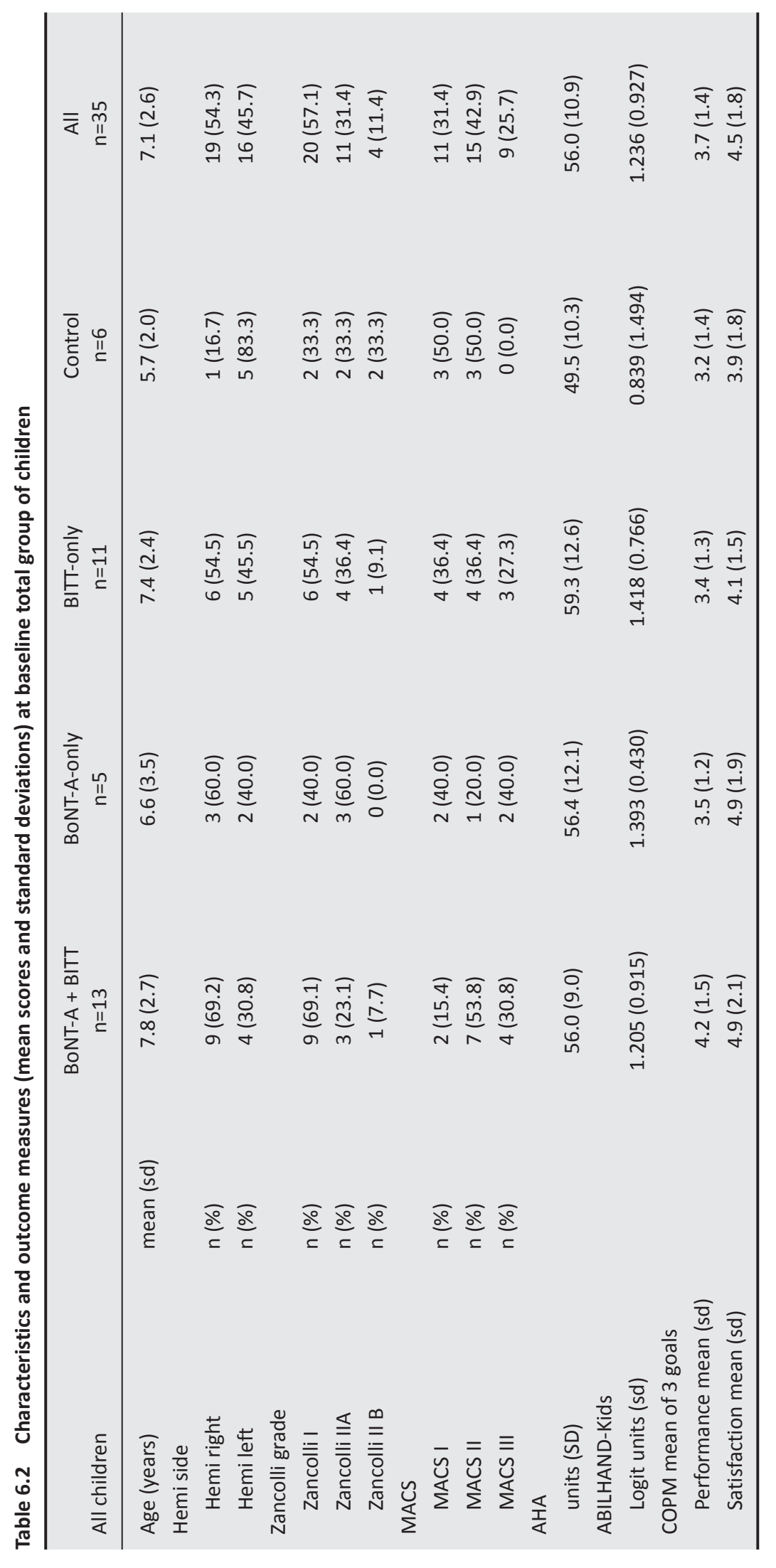




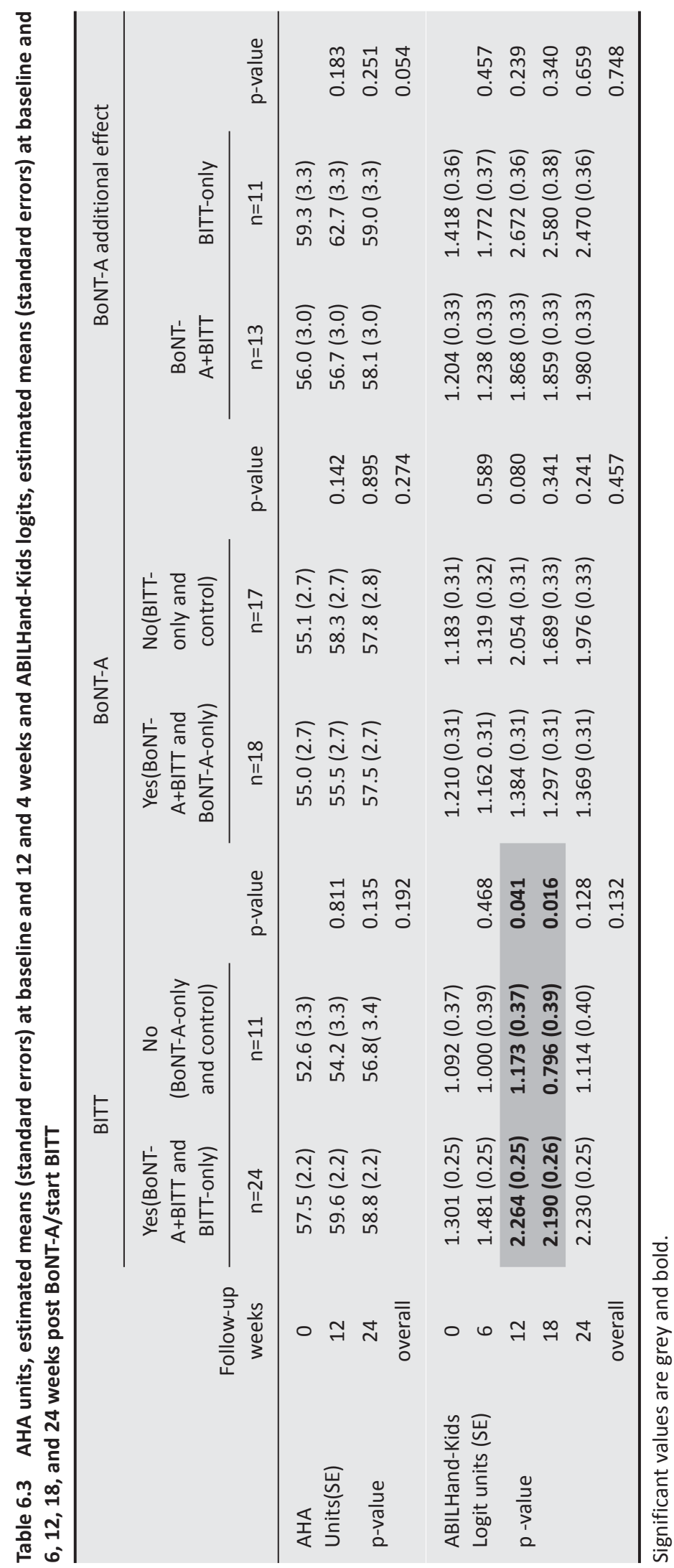




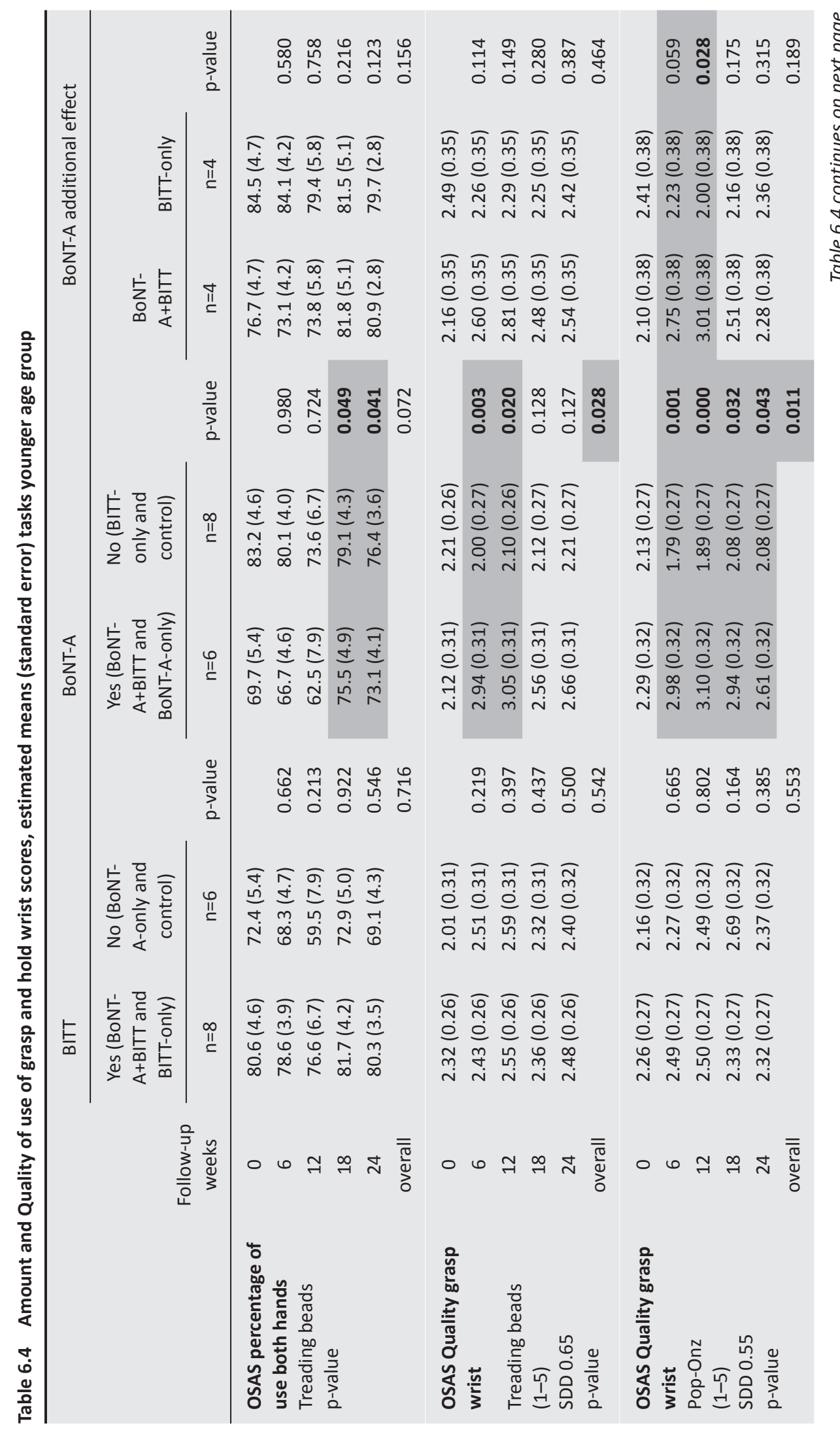

a 


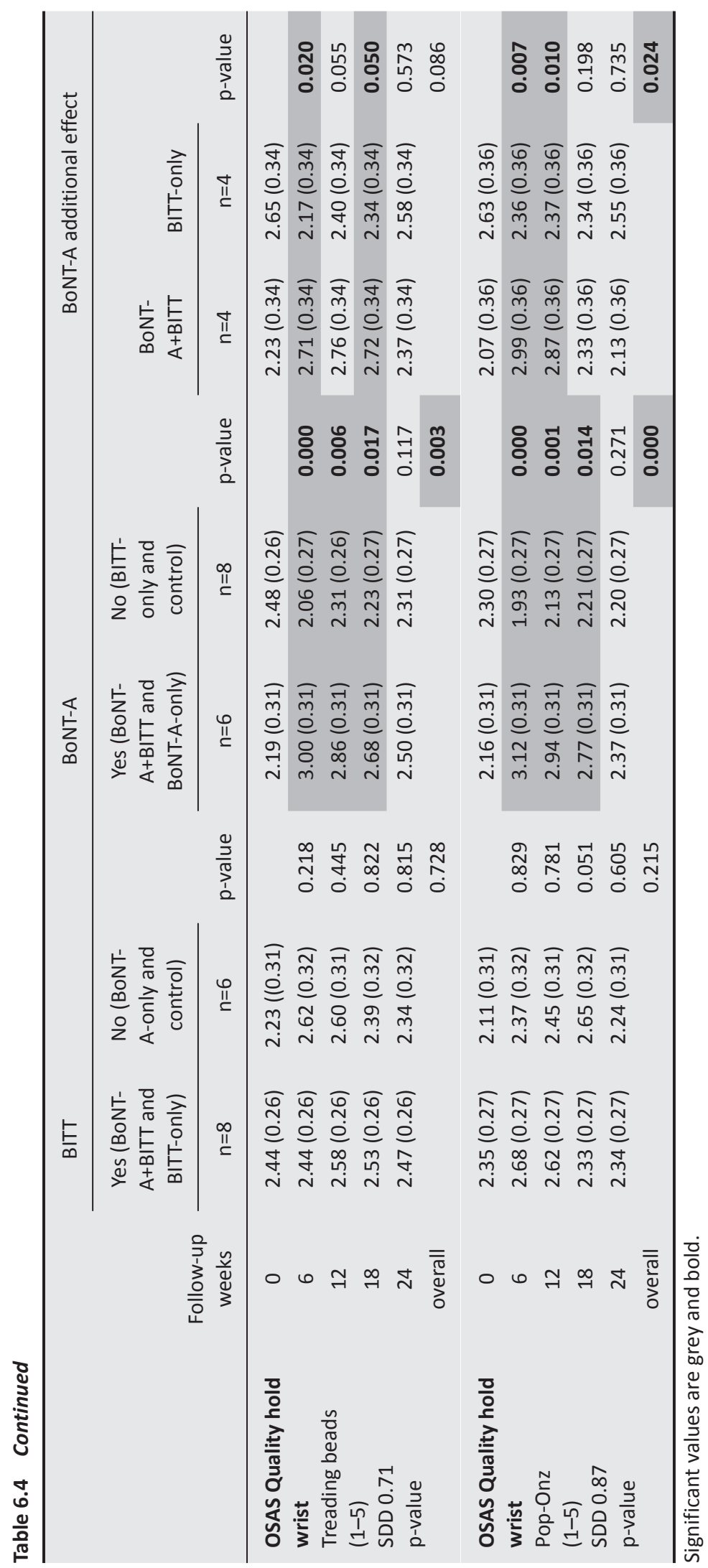




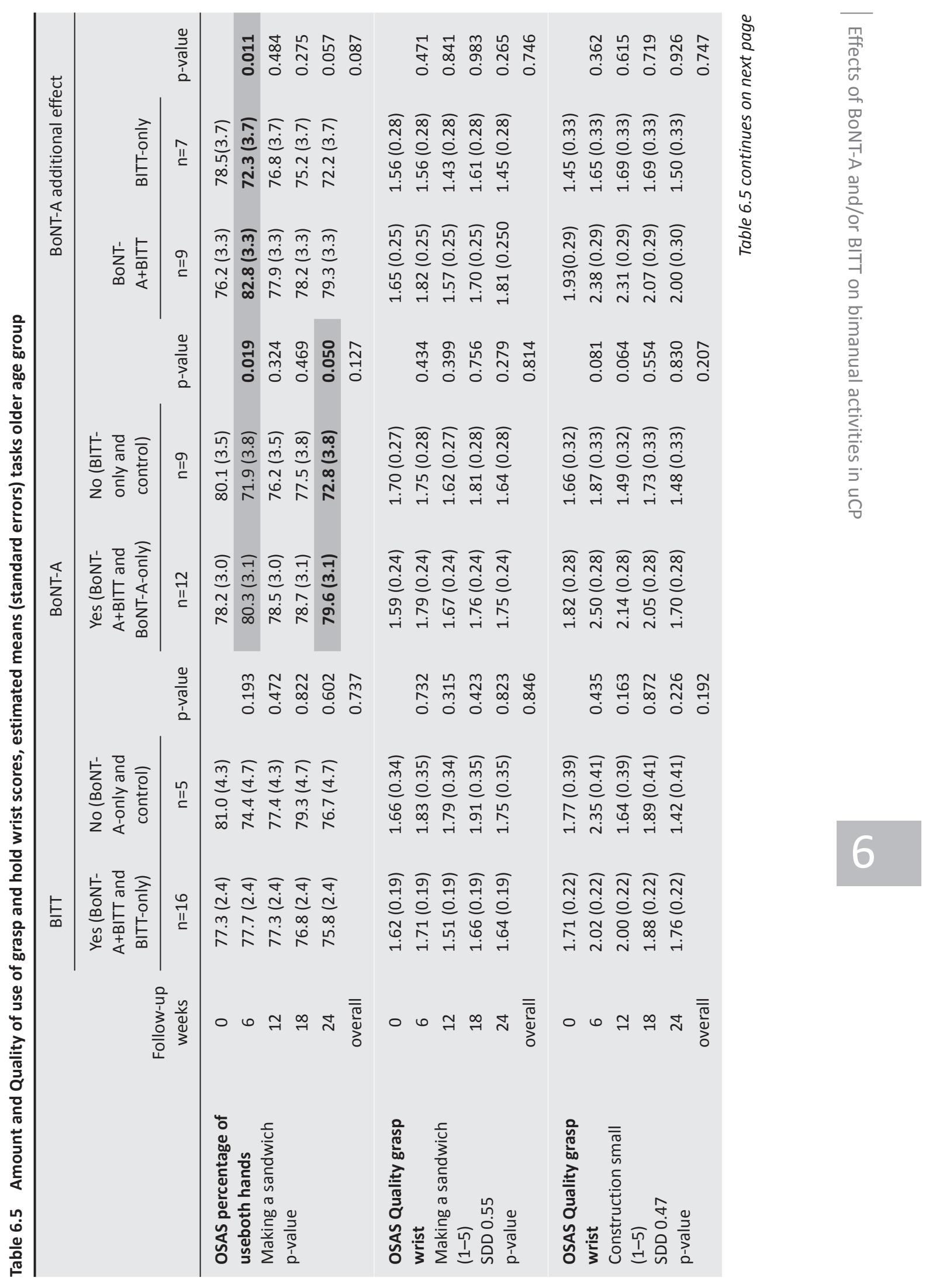




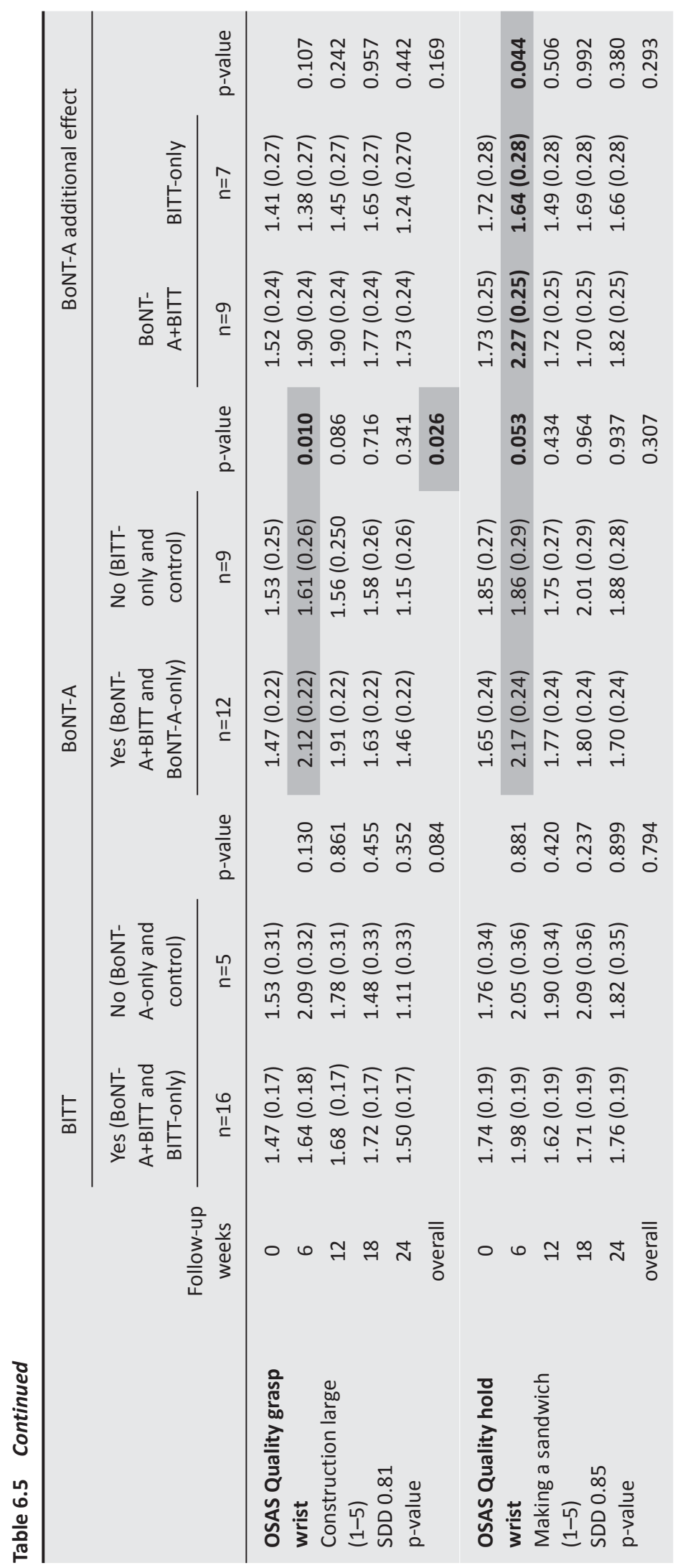




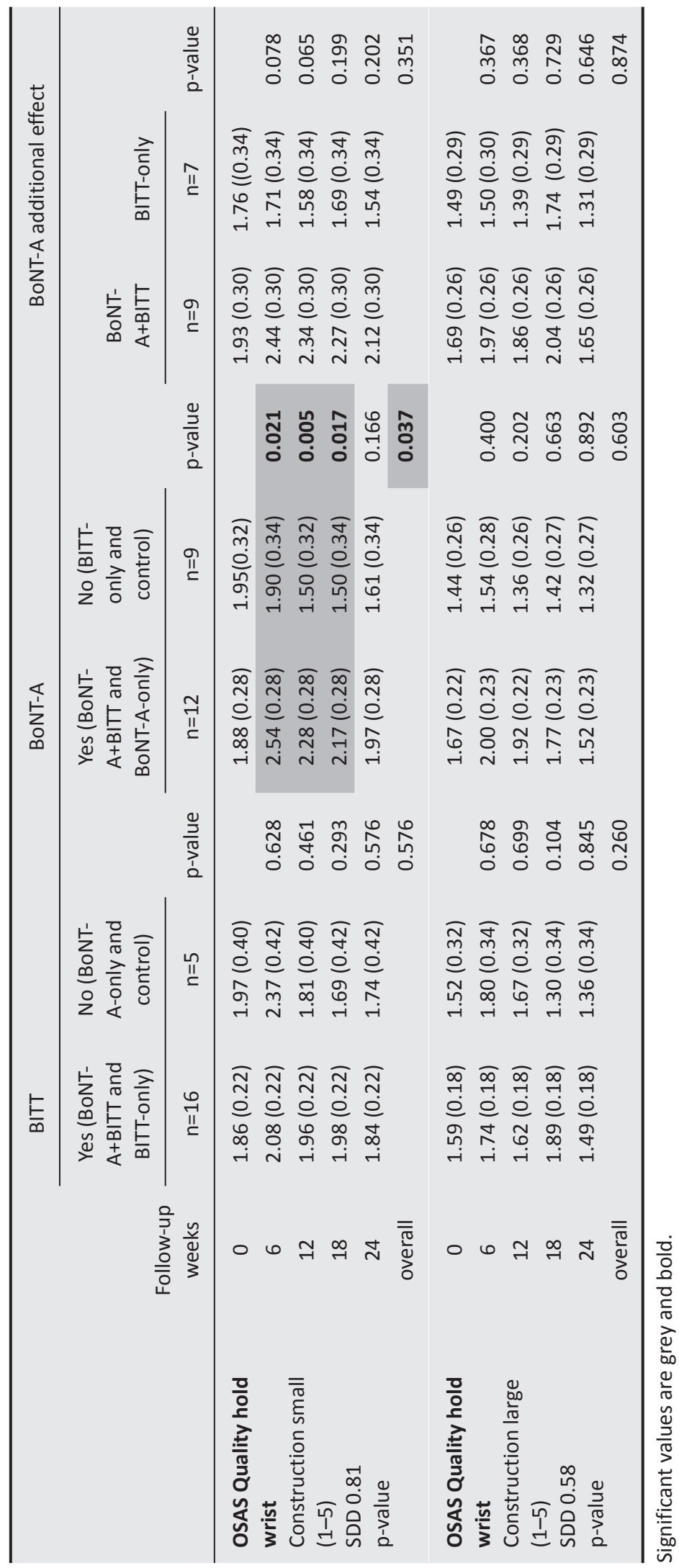




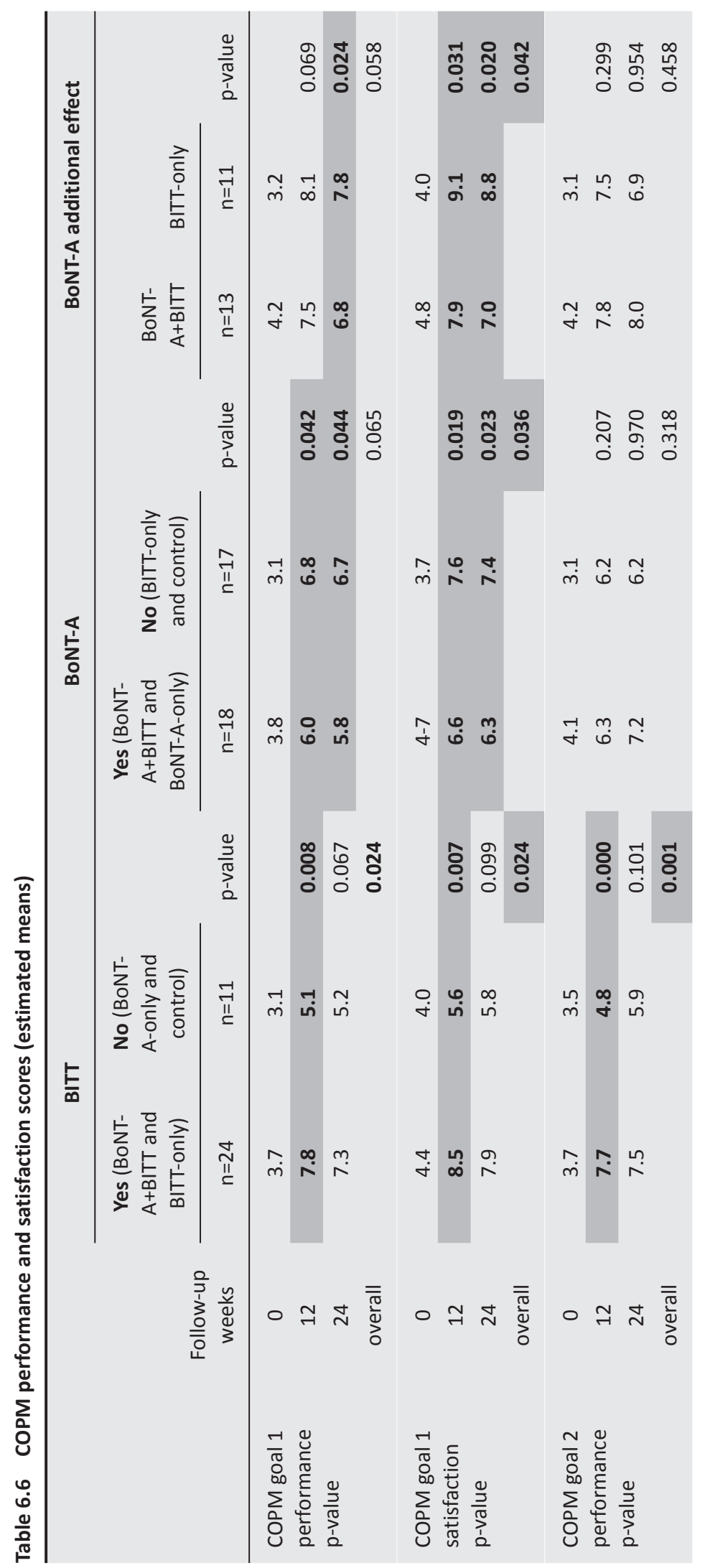




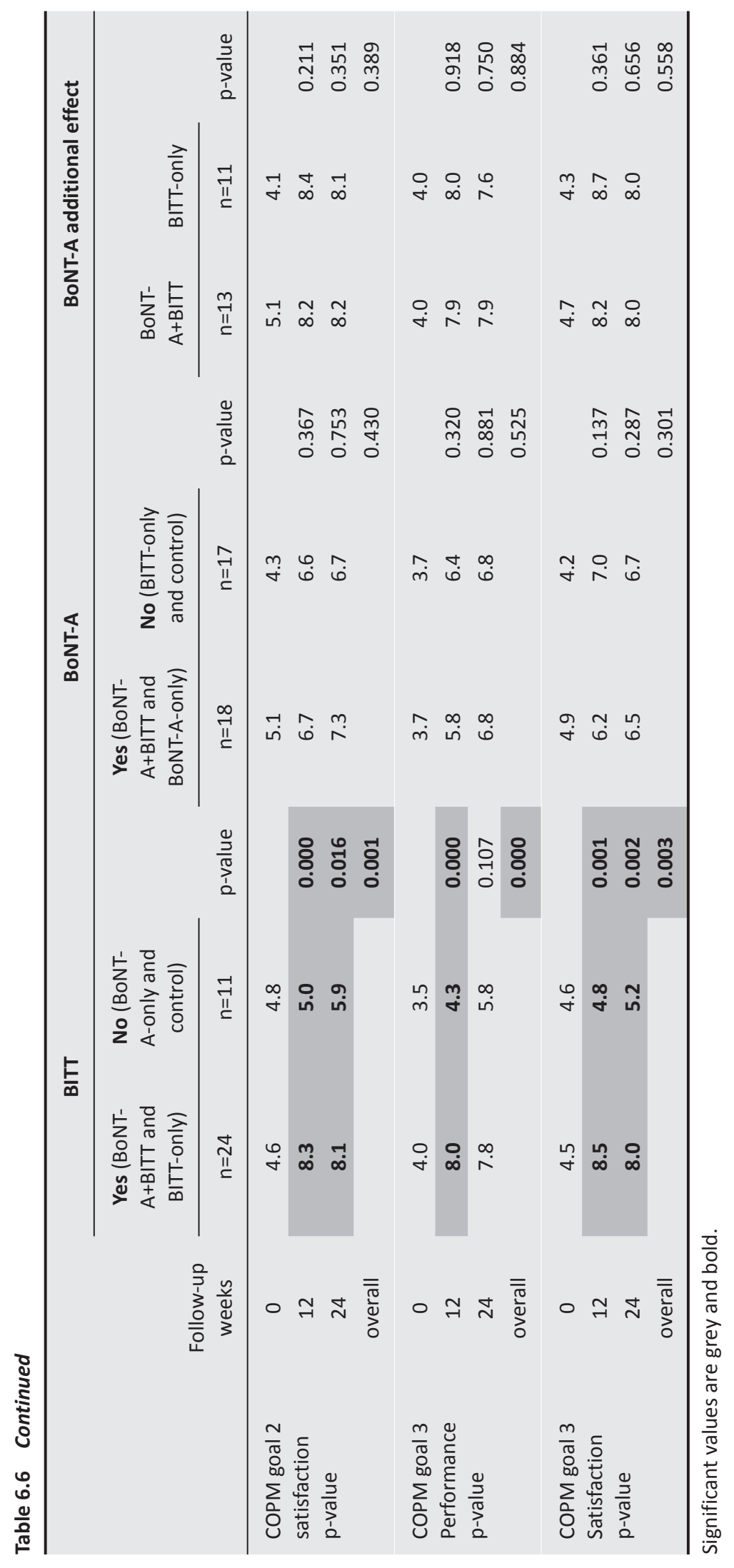


In Tables 6.3 to 6.6, the results of three comparisons are presented: a) BITT (BoNT-A+BITT and BITT-only) versus no-BITT (BoNT-A-only and control), b) BoNT-A (BoNT-A-only and BoNT$A+B I T T$ ) versus no-BoNT-A (BITT-only and control), and $c$ ) the additional effect of BoNT-A, i.e. BoNT-A+BITT versus BITT-only. The most relevant results of these comparisons will be discussed per table.

With the AHA, our primary outcome measurement, no significant differences between the groups could be demonstrated (Table 6.3). From baseline until 12 weeks, 6 children deteriorated in AHA unit score, all children had BoNT-A injections; those who had not showed no decline (see additional file A6.3 with individual AHA unit scores). Comparing BoNT-A versus no-BoNT-A and BoNT-A+BITT versus BITT-only, the groups in which the children did not receive BoNT-A showed a clear improvement from 0 to 12 weeks, whereas the BoNT-A groups did not. The children who received BITT scored significantly better at the ABILHANDKids logit units' score at 12 and 18 weeks (BITT from 1.301 to 2.264 and 2.190 and no-BITT from 1.092 to 1.173 and 0.796 ); and not significantly better at 24 weeks (BITT 2.230, no BITT 1.114). Comparing BoNT-A versus no-BoNT-A and BoNT-A+BITT versus BITT-only, the no-BoNT-A and the BITT-only groups showed a clear improvement in the AK logit units' score, maximum at 12 weeks.

In the younger age group the percentage of use of both hands of the OSAS treading beads task increased from $69.7 \%$ at baseline to $75.5 \%$ at 18 and $73.1 \%$ at 24 weeks in the BoNT-A group, which was significantly better than in the no-BoNT-A group (decrease from $83.2 \%$ at baseline to $79.1 \%$ at 18 and $76.4 \%$ at 24 weeks) (Table 6.4). In the older age group, BoNT-A had a significant positive effect on the percentage of use of both hands at 6 weeks and at 24 weeks in the sandwich-making OSAS task (Table 6.5).

In Table 6.4, the OSAS quality of use scores of the affected, assisting hand in the younger age group are shown. There was clear improvement in the grasp wrist and the hold wrist score at 6, 12, 18 and in the Pop-Onz task also at 24 weeks and overall in the BoNT-A group, comparing BoNT-A versus no-BoNT-A, and a decrease in the no-BoNT-A group in the beading and the Pop-Onz tasks, resulting in significant differences between these groups. Comparing BoNT-A+BITT to BITT-only, there were also significant differences in these tasks favouring BoNT-A at 6 and 12 weeks in the Pop-Onz task.

Table 6.5 displays the OSAS quality of use scores of the older children. Comparing BoNT-A to no-BoNT-A and BoNT-A+BITT to BITT-only, the grasp wrist score was significantly better favouring BoNT-A in the large construction task at 6 weeks and the hold wrist score in the 
sandwich-making task at 6 weeks and in the small construction task at 6,12 and 18 weeks and overall.

The grasp finger score of the sandwich-making task differed significantly at 6 weeks comparing BoNT-A to no-BoNT-A (1.18 to 1.88 versus 1.69 to 1.60, p 0.011) and comparing BoNT-A+BITT to BITT-only (1.78 to 1.84 versus 1.76 to $1.63, \mathrm{p} 0.020$ ) favouring BoNT-A.

Performance and satisfaction scores of the COPM are depicted in Table 6.6. In all three goals there was a significant difference in improvement of performance and satisfaction scores at 12 weeks and overall and in the second and third goal also at 24-week satisfaction scores in the BITT versus no-BITT comparison favouring BITT. In the first goal the no-BoNT-A (comparing BoNT-A versus no-BoNT-A) and the BITT-only group (BoNT-A+BITT versus BITTonly) improved significantly more.

In Figures 6.2 and 6.3 the medians and ranges of the GAS score per treatment group at 12 and 18 weeks are given. We did not compute the GAS T score, as the GAS, which was scored blindly on a video, was only performed at one treatment goal, so this had no statistical implications. ${ }^{25}$ The BITT-only group performed significantly better at 12 weeks compared to the other groups. In the BITT-only group, the GAS score improved from -2 (baseline) to 0.50 (median; interquartile range, IQR $0-2$ ), this is a significant difference. At 18 weeks the GAS improved to 1 (IQR $-0.25-1.25$ ) and at 24 weeks the GAS was 0 (IQR -0.25-1.25). The BoNT-A+BITT group also improved, but to a lesser extent, at 12 weeks to 0 (IQR -0.75-1.75), at 18 weeks to 0 (IQR -0.75-1.50) and at 24 weeks to 0 (IQR -1.0-0). The BoNT-A-only group scored worse at all measurement sessions.

\section{DISCUSSION}

In this study, which was set up as an RCT with a factorial design, we investigated the effect of BoNT-A in the upper extremity and/or BITT on bimanual performance, measured with the AHA and the AK questionnaire; on the amount and quality of use of the affected limb in standardized, age appropriate, bimanual tasks, measured with the OSAS; and on goal achievement, measured with the COPM and the, by video observation blinded, GAS score. Due to disappointing participant enrolment, the design had to be adapted to the parents' preference for either BoNT-A+BITT or just the BITT-only programme. Limitations of this study are the small numbers with unequal group sizes. Therefore, the original RCT became a clinical study. Nevertheless consistent results were found. 


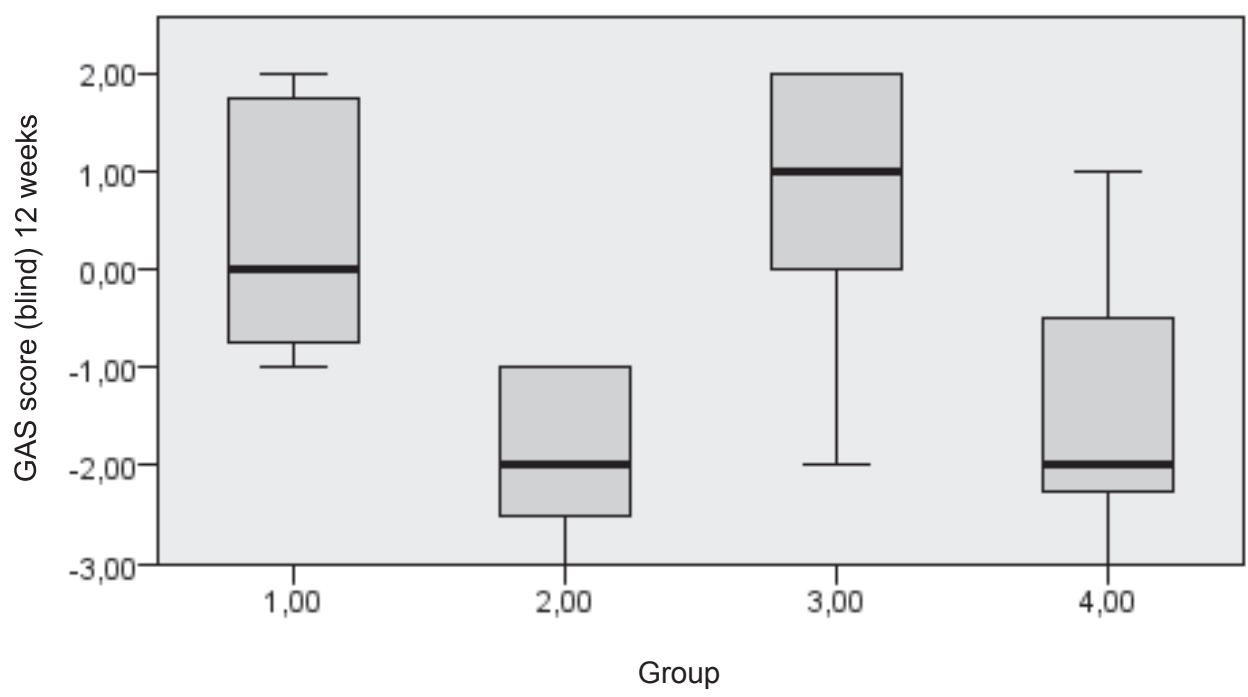

Figure 6.2 GAS blind score at 12 weeks medians and interquartile ranges per treatment group. Group 1 = BoNT-A+BITT, 2 = BoNT-A-only, 3 = BITT-only, $4=$ control. Kruskal Wallis test $p 0.002$.

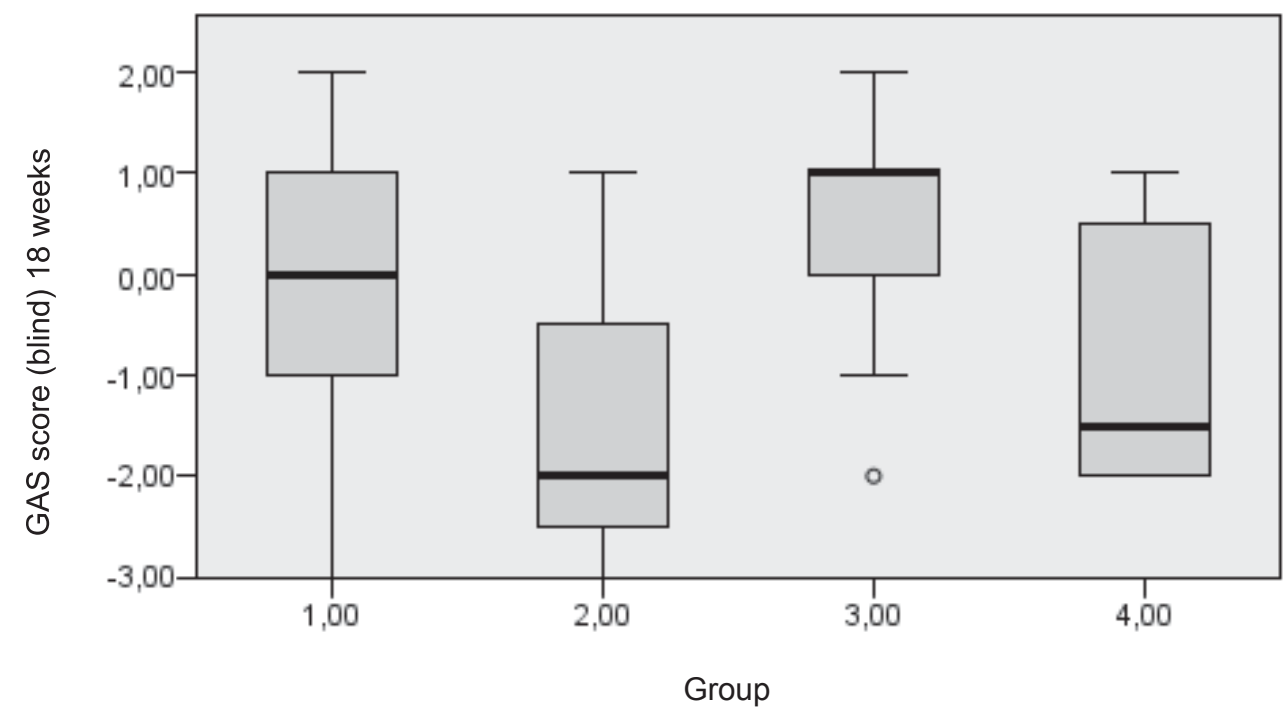

Figure 6.3 GAS blind score at 18 weeks medians and interquartile ranges per treatment group. Group 1 = BoNT-A+BITT, 2 = BoNT-A-only, 3 = BITT-only, 4 = control. Kruskal Wallis test p 0.059.

Although the differences between the groups were not significant, the children in the BITT group (and control group with younger children) showed a positive effect on the AHA score, which was our primary outcome measurement, at 12 weeks. BITT has a significant positive effect on bimanual performance, measured with the AK and on goal achievement, measured with the COPM and the blinded GAS score, not only at 12 weeks, the end of the therapy programme, but also later at 18 and 24 weeks. Task specific exercise clearly 
leads to achievement of the goals set by the children themselves and, to a lesser extent, to improvement in bimanual performance. Improvement of functional unimanual and bimanual grip strength by BITT ${ }^{17}$ possibly supports this.

In our study BoNT-A seems to have a negative effect on bimanual performance, measured with the AHA. The no-BoNT-A and the BITT-only group AHA score increased from 0 to 12 weeks, whereas the BoNT-A and the BoNT-A+BITT AHA score did not. This is in contradiction with the results of Ferrari et al., who found a significant increase of the AHA raw scores at 3 months in the BoNT-A group ( $n=11)$ in a placebo controlled trial of 27 children with $u C P$, aged 3 to 12 years old, who all received goal directed therapy. ${ }^{26}$ They stated that children with the House functional score ${ }^{27} 4$ and 5 would possibly benefit most from BoNT-A combined with goal directed therapy. These children are comparable with the children in our study. At 6 months both groups showed equal improvement on the AHA in their study. Another recent RCT investigating the effects of repeated BoNT-A injections combined with OT and splinting compared with OT alone in very young children with uCP (median age 3y 1 month) showed that 6 out of 10 children of the BoNT-A/OT group $(n=10)$ improved $>5 u$ on the AHA at 12 months compared with 1 out of 10 in the OT group $(n=10) .{ }^{28}$ This study concerns very young children with a lower House functional score (1-3) but a similar degree of severity of impairment according to the Zancolli grade. Olesh et al. who studied also very young children, did not found a positive effect of additional BoNT-A on the activity level, measured with the QUEST, but they found positive effects on the GAS. ${ }^{7}$

Also in our study, BoNT-A had a negative effect in achieving the first COPM goal and the GAS score. In the study of Ferrari et al. ${ }^{26}$ goal achievement with the GAS was significantly better in the BoNT-A group, whereas in the study of Lidman et al. ${ }^{28}$ there was no significant difference between the study groups in improvement on the COPM.

With the OSAS we found that BoNT-A has a positive effect on the amount of use of the affected hand; especially during the time it works at 6 weeks in the sandwich-making task, but also later on in the beading task in the younger age group. The grasp finger score in the BoNT-A group of the sandwich-making task showed significantly more improvement at 6 weeks when comparing BoNT-A to no-BoNT-A. This is consistent with the increase in the amount of use in this task at 6 weeks and the fact that BoNT-A was injected in the thumb adductor, leading to improved thumb abduction, which is necessary for this task. BoNT-A injections in the wrist and finger flexors led to a significantly improved wrist position in the quality of grasp and hold wrist scores in several tasks, due to the effect of tone reduction 
of the wrist and finger flexors, during the working time at 6 and 12 weeks in the older age group. In the younger children this effect lasted even longer. Given that the known smallest detectable differences of the quality of grasp and hold wrist scores in these tasks vary from 0.34 to 0.87 , the found differences are substantial. ${ }^{18}$

Our OSAS results of improvement of wrist position and thumb abduction after BoNT-A are in agreement with the positive effect of BoNT-A and OT, compared to OT alone, found in two reviews ${ }^{1,8}$ at three months on the MUUL and the QUEST, as these instruments measure also quality of movement, wrist position and fluency.

Improvement at the GAS score by BoNT-A+OT was also reported in these reviews and in the study of Ferrari et al. ${ }^{26}$ The GAS T-score of several goals used in the studies in the reviews were not blinded. This may have biased their results because in contrast, in our study a negative additional effect of BoNT-A on the GAS score was found. Here, trained OTsts scored the GAS on a videotape of the main goal; unaware at which measurement session the videotape was taken. Although in this study the children who received BoNT-A improved also at the COPM, the improvement was clearly less than in the children who did not receive BoNT-A or those who received BITT-only. As the study of Ferrari et al. ${ }^{26}$ was a placebo controlled RCT, their positive findings on the GAS of BoNT-A speak against our results. However, they discussed the importance of the individualised goal directed therapy and goal setting, because also the placebo group achieved their goals.

In conclusion, BoNT-A has a positive effect on the quality of movement and amount of use of the affected UE especially during the expected working time and somewhat longer in younger children. Contrary to other studies, we found no additional effect of BoNT-A on bimanual performance and goal achievement. BITT on the other hand, has a clear positive effect on goal achievement and bimanual performance. To improve bimanual performance and goal achievement in children with spastic UCP who are able to actively open their hand, intensive task specific bimanual training is, in our opinion, the first choice of treatment. In children aged 6 years or younger with severe spasticity of the affected hand leading to limited functional hand use, additional BoNT-A injections are to be considered. 


\section{ACKNOWLEDGEMENTS}

This study was supported by grants provided by Johanna Kinderfonds, Stichting Rotterdams

Kinderrevalidatie Fonds Adriaanstichting, Phelps Stichting, Profileringsfond sazM, Elisabeth Strouven Stichting, Kanunnik Salden-Nieuwenhof Stichting, and Adelante.

The Dysport ${ }^{\circledR}$ vials were provided by Ipsen. 


\section{REFERENCES}

1 Hoare BJ, Wallen MA, Imms C, Villanueva E, Rawicki HB, Carey L. Botulinum toxin A as an adjunct to treatment in the management of the upper limb in children with spastic cerebral palsy (UPDATE). Cochrane Database Syst Rev 2010 Jan 20; (1): CD003469. Review.

2. Randall M, Carlin JB, Chondros P, Reddihough D. Reliability of the Melbourne assessment of unilateral upper limb function. Dev Med Child Neurol 2001; 43: 761-767.

3. DeMatteo C, Law M, Russell D, Pollock N, Rosenbaum P, Walter S. The reliability and validity of the quality of upper extremity skills test. Phys Occ Ther Pediatr 1993; 13(2): 1-18.

4. Feldman $A B$, Haley SM, Coryell J. Concurrent and construct validity of the Pediatric Evaluation of Disability Inventory. Phys Ther 1990; 10: 602-610.

5. Steenbeek D, Ketelaar M, Galama K, Gorter JW. Goal attainment scaling in paediatric rehabilitation: a critical review of the literature. Dev Med Child Neurol 2007; 49(7): 550-556.

6. Verkerk GJ, Wolf MJ, Louwers AM, Meester-Delver A, Nollet F. The reproducibility and validity of the Canadian Occupational Performance Measure in parents of children with disabilities. Clin Rehabil 2006; 20(11): 980-988.

7. Olesch CA, Greaves S, Imms C, Reid SM, Graham HK. Repeat botulinum toxin-A injections in the upper limb of children with hemiplegia: a randomized controlled trial. Dev Med Child Neurol 2010; 52: 79-86.

8. Sakzewski L, Ziviani J, Boyd RN. Efficacy of upper limb therapies for unilateral cerebral palsy: a metaanalysis. Pediatrics 2014; 133(1): e175-204.

9. Elvrum AK, Brændvik SM, Sæther R, Lamvik T. Effectiveness of resistance training in combination with botulinum toxin-A on hand and arm use in children with cerebral palsy: a pre-post intervention study. BMC Pediatr 2012; 12: 91.

10. Novak I, Mclntyre S, Morgan C, Campbell L, Dark L, Morton N, Stumbles E, Wilson SA, Goldsmith S. A systematic review of interventions for children with cerebral palsy: state of the evidence.Dev Med Child Neurol 2013; 55(10): 885-910.

11. Hoare B, Imms C, Villanueva E, Rawicki HB, Mattyas T, Carey L. Intensive therapy following upper limb botulinum toxin $A$ injection in young children with unilateral cerebral palsy: a randomized trial. Dev Med Child Neurol 2013; 55: 238-247.

12. Krumlinde-Sundholm L, Eliasson A. Development of the Assisting Hand Assessment: A Rasch-built measure intended for children with unilateral upper limb impairments. Scand J Occup Ther 2003; 10: 16-26.

13. Krumlinde-Sundholm L, Holmefur M, Kottorp A, Eliasson A-C. The Assisting Hand Assessment: current evidence of validity, reliability, and responsiveness to change. Dev Med Child Neurol 2007; 49: 259-264.

14. Gordon AM, Hung YC, Brandao M, Ferre CL, Kuo HC, Friel K, Petra E. Bimanual Training and ConstraintInduced Movement Therapy in Children With Hemiplegic Cerebral Palsy: A Randomized Trial. Neurorehabil Neural Repair 2011; 25: 692-702.

15. Sakzewski L, Ziviani J, Abbott JF, Macdonell RA, Jackson GD, Boyd RN. Randomized trial of constraintinduced movement therapy and bimanual training on activity outcomes for children with congenital hemiplegia. Dev Med Child Neurol 2011; 53: 313-320. 
16. Deppe W, Thuemmler K, Fleischer J, Berger C, Meyer S, Wiedemann B. Modified constraint-induced movement therapy versus intensive bimanual training for children with hemiplegia - a randomized controlled trial. Clin Rehabil 2013; 27(10): 909-920.

17. Speth L, Janssen-Potten Y, Leffers P, Rameckers E, Defesche A, Winkens B, Becher J, Smeets R, Vles H. Effects of botulinum toxin $A$ and/or bimanual task-oriented therapy on upper extremity impairments in unilateral Cerebral Palsy: an explorative study. Eur J Paediatr Neurol 2015; 19(3): 337-348.

18. Speth L, Janssen-Potten Y, Leffers P, Rameckers E, Defesche A, Geers R, et al. Observational skills assessment score: reliability in measuring amount and quality of use of the affected hand in unilateral cerebral palsy. BMC Neurol 2013; 13: 152.

19. Arnould C PM, Renders A, Thonnard JL. ABILHAND-Kids: a measure of manual ability in children with cerebral palsy. Neurology 2004; 63: 1045-1052.

20. Schulz KF, Altman DG, Moher D. CONSORT 2010 statement: updated guidelines for reporting parallel group randomized trials. Ann Intern Med 2010; 152(11): 1-8.

21. Eliasson AC, Krumlinde-Sundholm L, Rosblad B, Beckung E, Arner M, Ohrvall AM, et al. The Manual Ability Classification System (MACS) for children with Cerebral Palsy: scale development and evidence of validity and reliability. Dev Med Child Neurol 2006; 48: 549-554.

22. Zancolli EA, Zancolli E Jr. Surgical rehabilitation of the spastic upper limb in cerebral palsy. In DW Lamb (editor), The Paralyzed Hand (pp. 153-160). Edinburgh: Churchill Livingstone, 1987.

23. Heinen F, Desloovere K, Schroeder AS, et al. The updated European Consensus 2009 on the use of Botulinum toxin children with cerebral palsy. Eur J Paediatric Neurol 2010; 14(1): 45-66.

24. Eliasson AC, Krumlinde-sundholm L, Shaw K, Wang C. Effects of constraint-induced movement therapy in young children with hemiplegic cerebral palsy: an adapted model. Dev Med Child Neurol 2005; 47: 266-275.

25. Turner-Stokes L. Goal attainment scaling (GAS) in rehabilitation: a practical guide. Clin Rehabil 2009; 23: $362-370$.

26. Ferrari A, Maoret AR, Muzzini S, Alboresi S, et al. A randomized trial of upper limb botulinum toxin versus placebo injection, combined wuth physiotherapy, in children with hemiplegia. Res Dev Disabil 2014; 35(10): 2505-2513.

27. House JH, Gwathmey FW, Fidler MO. A dynamic approach to the thumb-in-palm deformity in cerebral palsy. J Bone Joint Surg Am 1981; 63(2): 216-225.

28. Lidman G, Nachmeson A, Peny-Dahlstrand M, Himmelmann K. Botulinum toxin A injections and occupational therapy in children with unilateral spastic cerebral palsy: a randomized controlled trial. Dev Med Child Neurol 2015 Mar 22. doi: 10.1111/dmcn.12739. [Epub ahead of print] 


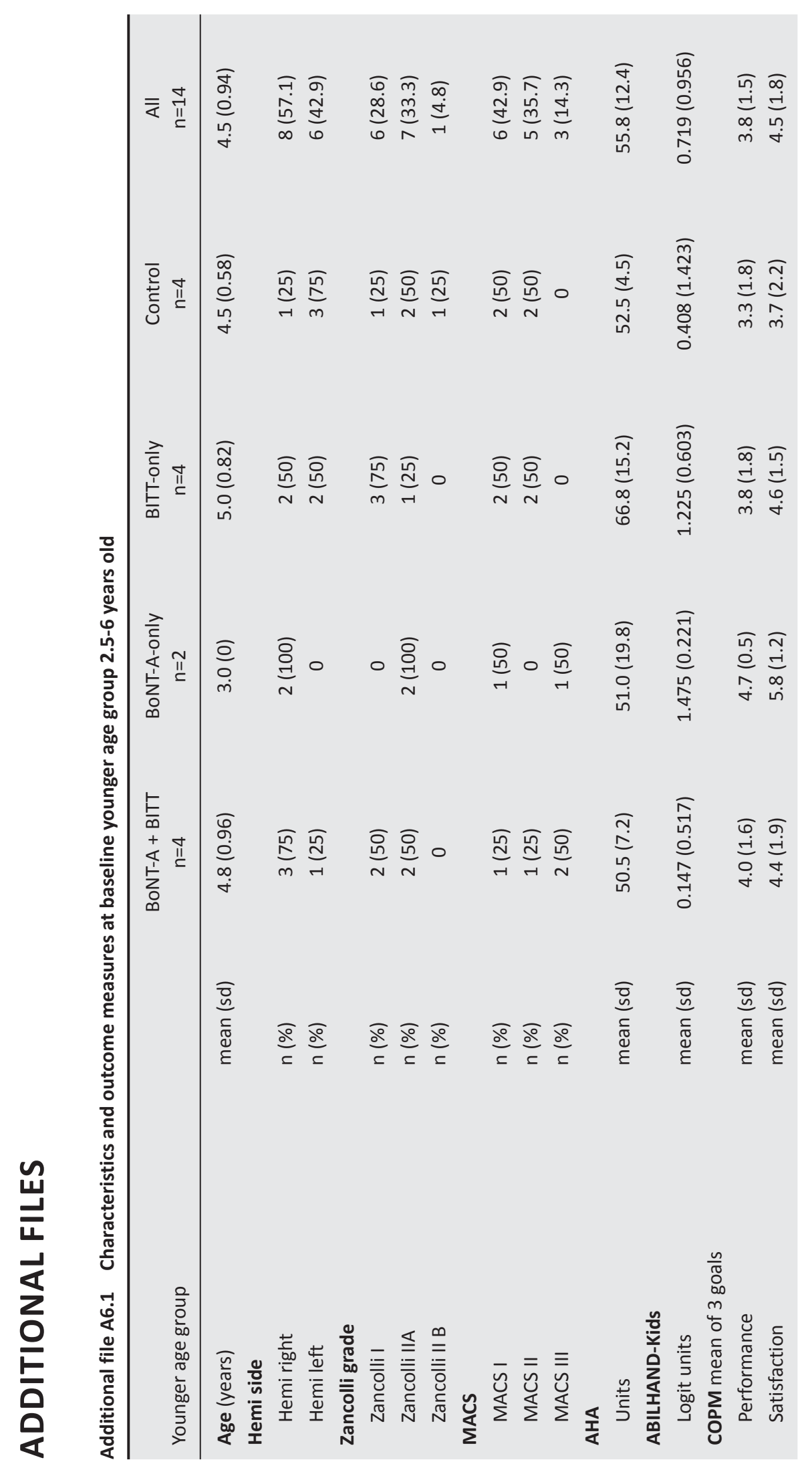




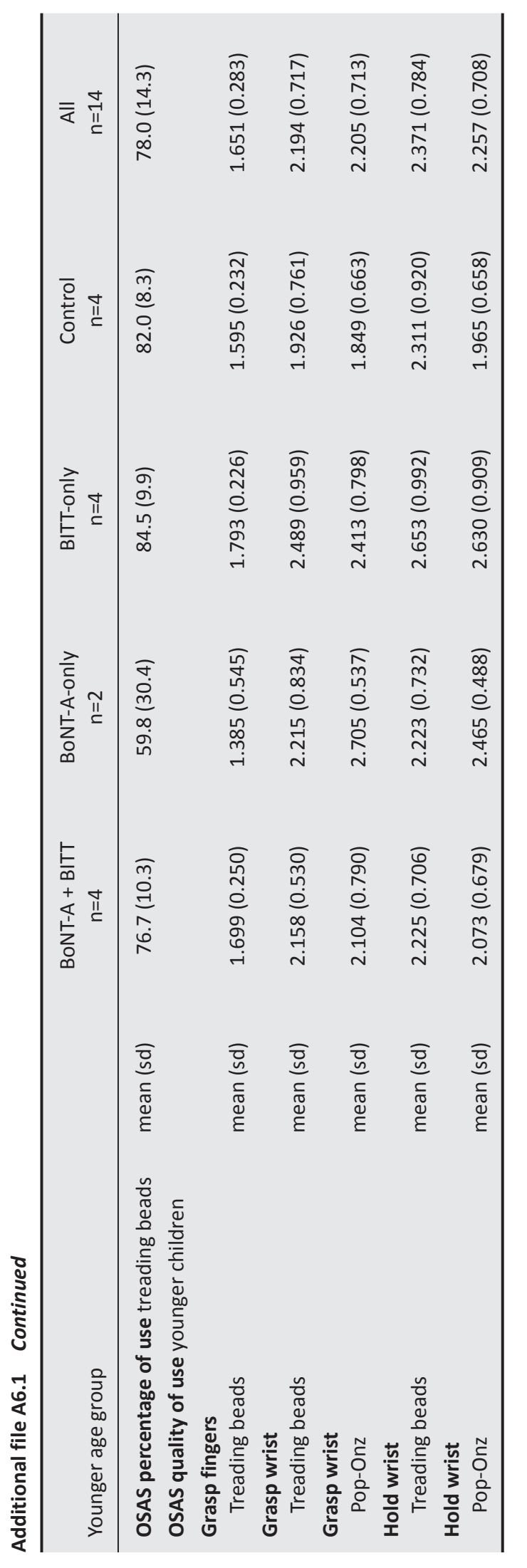




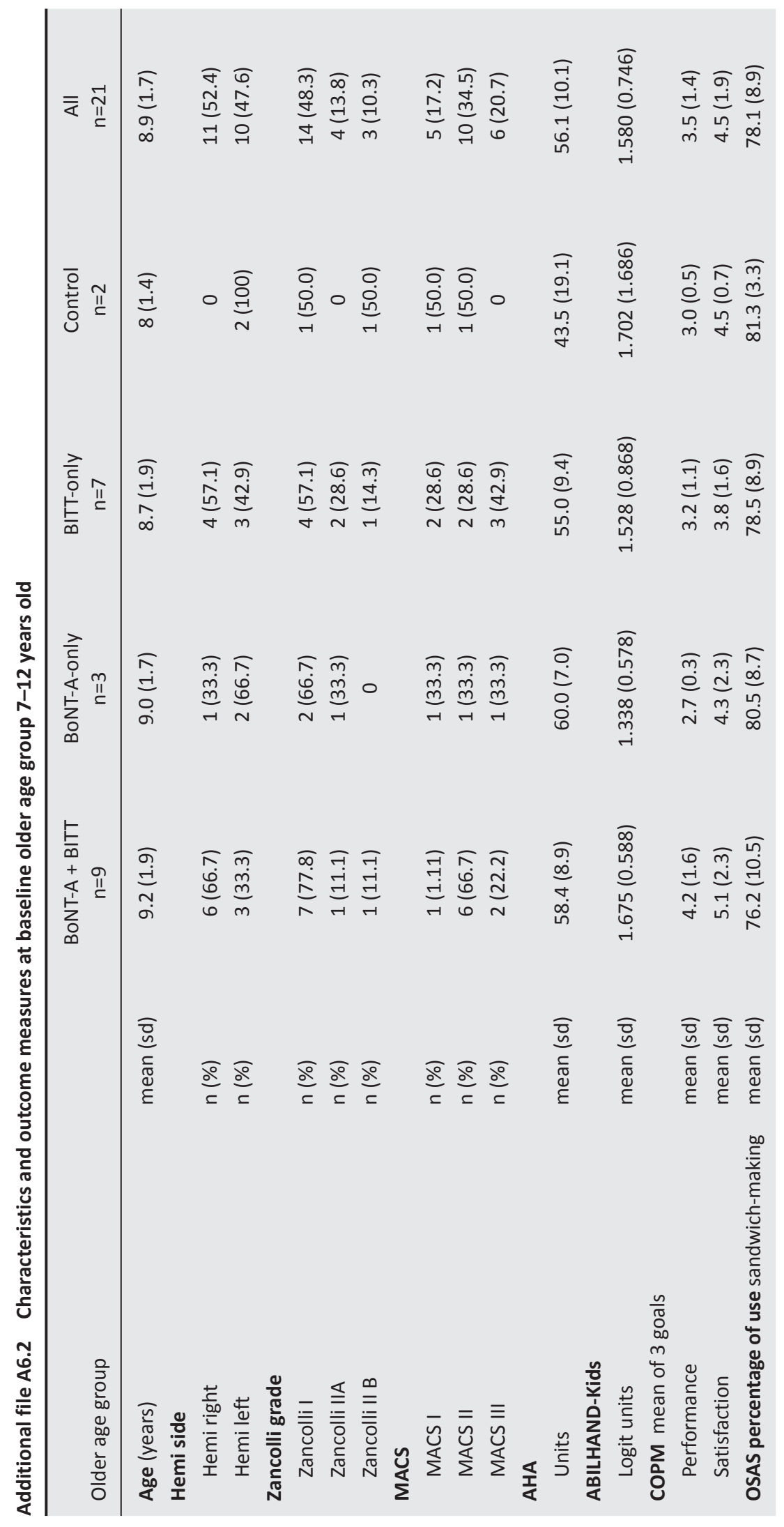




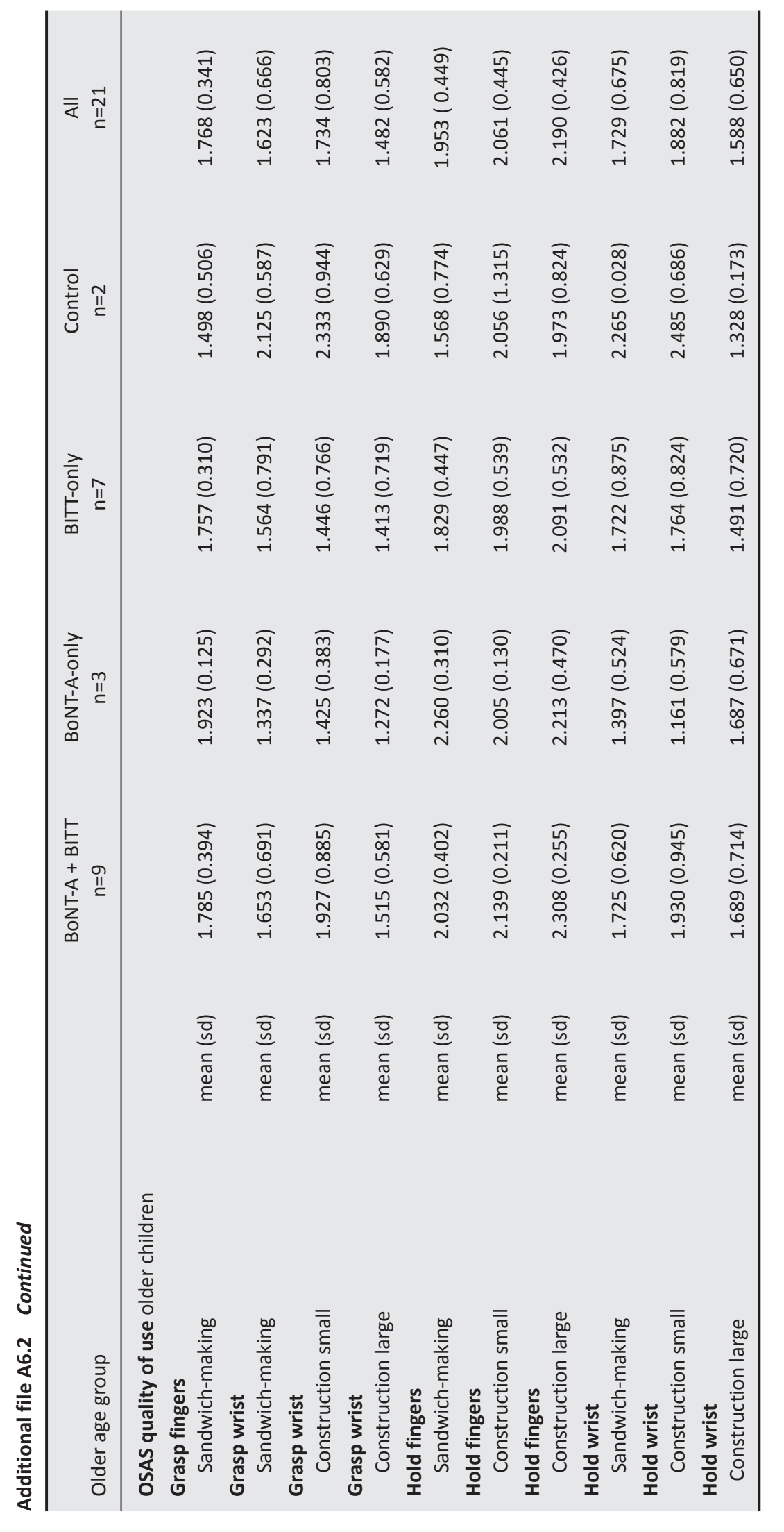




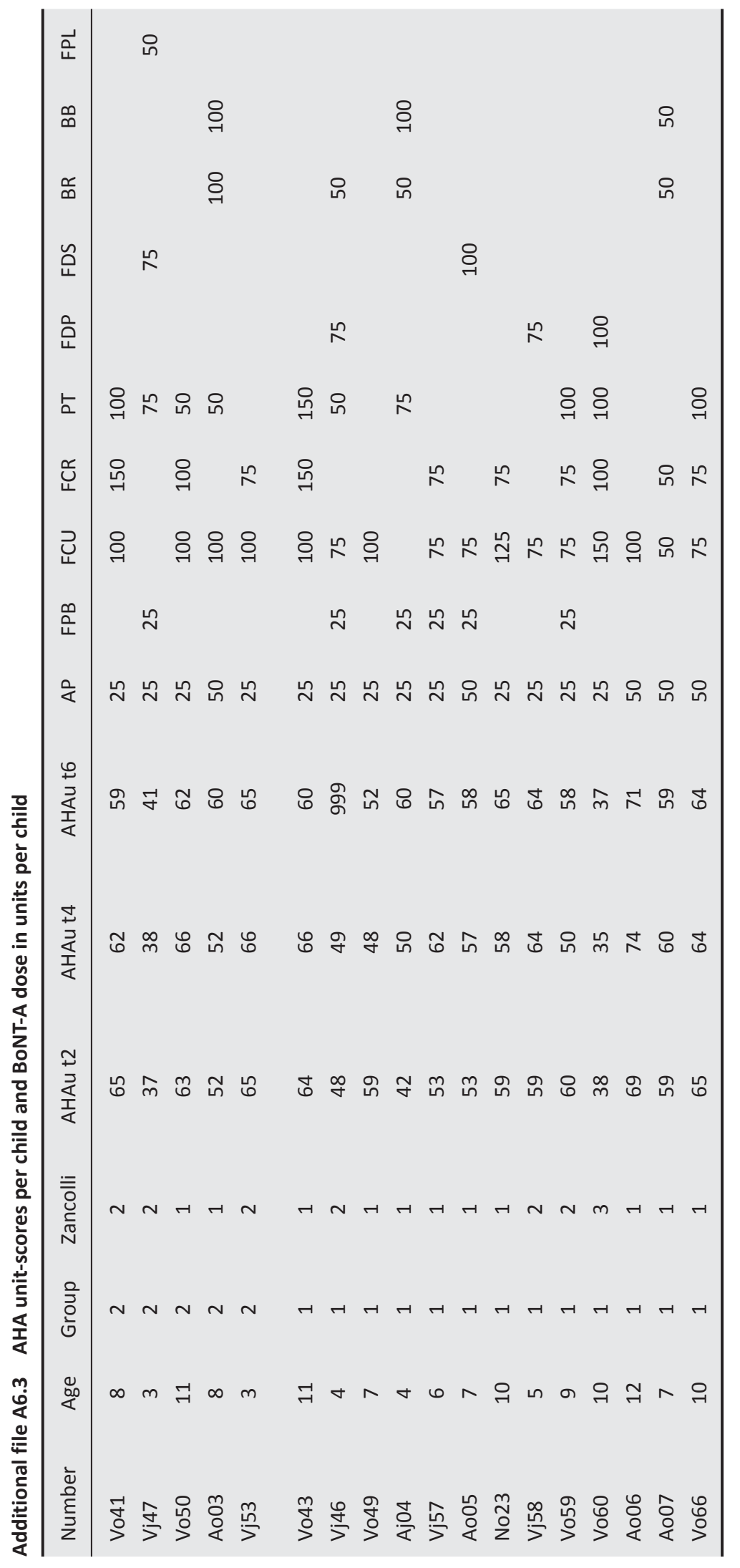




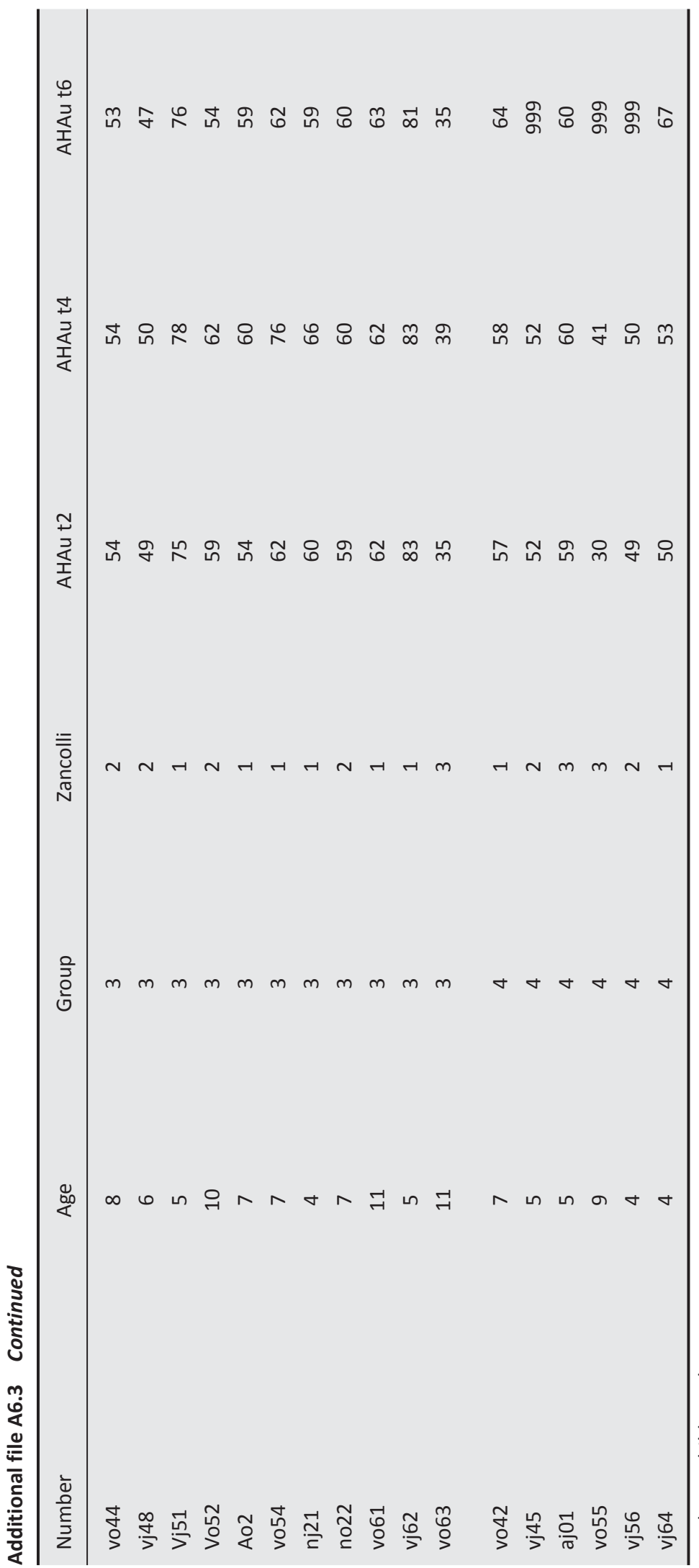




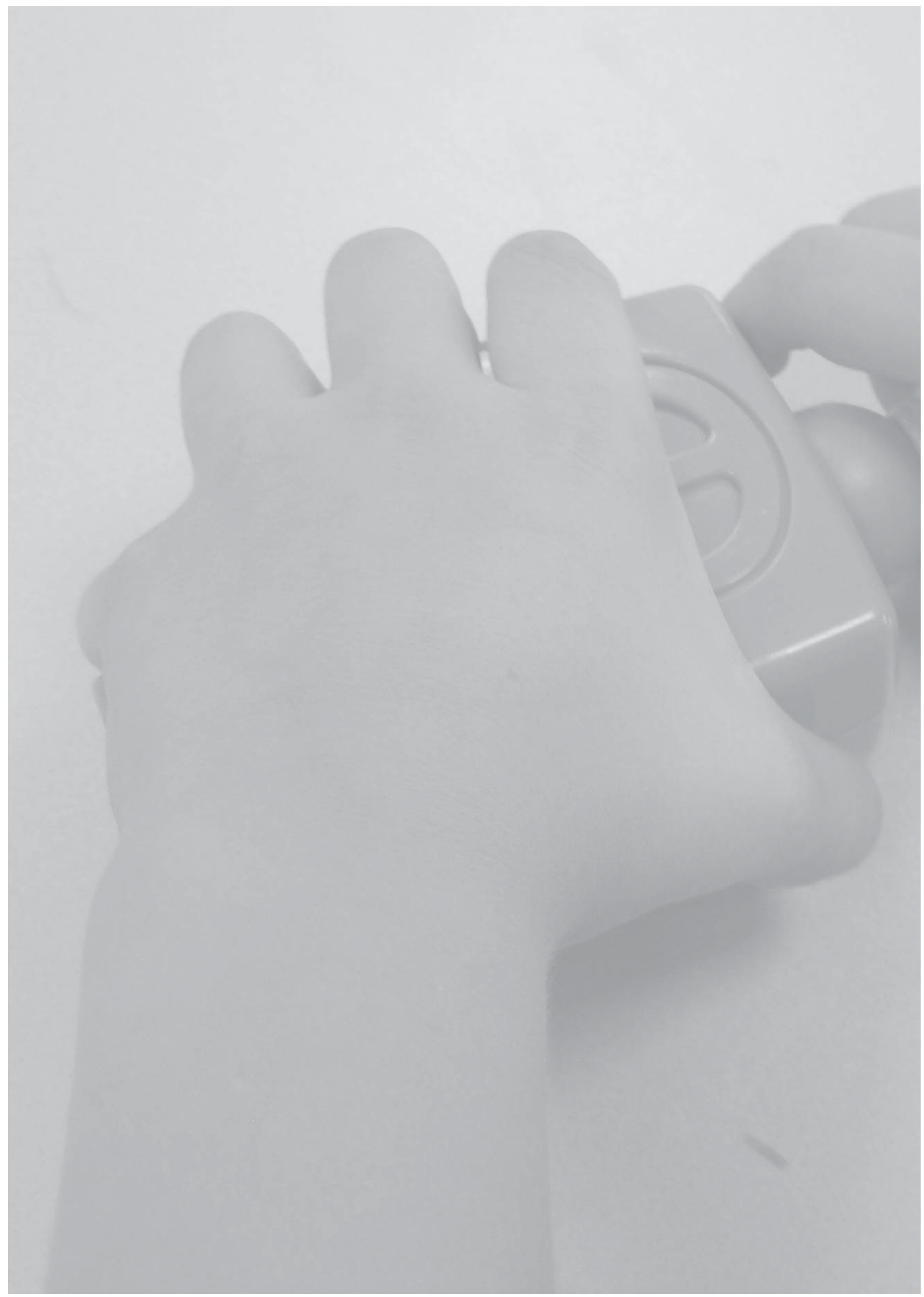




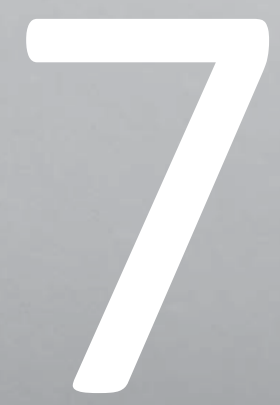

Discussion and conclusions 
In this thesis the results of effect studies of botulinum toxin A (BoNT-A) injections and of bimanual task-oriented therapy (BITT) performed in combination or separately in children with hand impairments in unilateral Cerebral Palsy ( $\mathrm{UCP}$ ), are presented. To evaluate the effects of the BoNT-A injections and the BITT, we developed the Observational Skills Assessment Score (OSAS), an assessment tool that measures quality of movement of the affected hand in bimanual, standardised, age appropriate tasks. We investigated the agreement and reliability of the OSAS.

\section{Methodological considerations}

The objective of the RCT described in chapter 3 was to determine whether the use of BoNT-A increased upper extremity (UE) functions and skills in the context of a specific therapy programme. This intensive programme was the precursor of BITT that was performed in the BoBiVa (Botuline toxine Bimanuele Vaardigheden) study described in chapters 5 and 6. Two groups of ten children were compared in the first study; one group received the therapy programme and BoNT-A, the other only the therapy programme. Although the study groups were small and inhomogeneous, the additional effect of BoNT-A in this study was beneficial for wrist flexor tone reduction and active wrist extension. In this study participated children from 4 to 16 years of age. Because the younger children seemed to show more improvement from BoNT-A, in the BoBiVa study younger children from 2.5 to 12 years were included.

The BoBiVa study was set up as a factorial design, to be able to compare four study groups: BoNT-A-only, BoNT-A+BITT, BITT-only and a control group (therapy as usual not aimed at improving bimanual goals). The Assisting Hand Assessment was chosen as primary outcome measurement, because we considered bimanual performance very important and the AHA is validated specifically for this age group. Limitations of the BoBiVa study are the partially realised randomisation and the limited number of participants. This was because the parents did not want their child to be randomized in either the BoNT-A-only or control group due to their preference for BoNT-A+BITT or BITT-only. Therefore, the initial factorial design had to be changed, resulting in a large group size variation. This is why we analysed the following three comparisons in the BoBiVa study in chapters 5 and 6: a) BITT (BoNT-A+BITT and BITT-only; $n=24$ ) versus no BITT (BoNT-A-only and control; $n=11$ ), b) BoNT-A (BoNT-Aonly and BoNT-A+BITT; $n=18$ ) versus no BoNT-A (BITT-only and control; $n=17$ ), and $c$ ) the additional effect of BoNT-A, i.e. BoNT-A+BITT ( $n=13)$ versus BITT-only $(n=11)$. So, the original 
factorial design had to be abandoned and the BoBiVa study became a clinical trial. In spite of the limited number of participants, this study revealed consistent and clinical relevant results.

\section{Treatment}

BoNT-A was injected in the most spastic muscles, hampering function and use of the affected hand in bimanual skills. In the BoBiVa study, the physicians of the participating centres decided based on a video of the child performing his or her most important goal, in combination with the spasticity measurements which muscle had to be injected and in what dose.

The specific therapy programme to improve bimanual skills which we developed for the first RCT described time and degree of stretching, wearing of orthoses, time of strength and coordination training and task-specific training and was tailored to the individual patient, based on individual goal setting and clinical reasoning. These last aspects are also key elements in the BITT protocol that was further developed for the BoBiVa study. The programme was based on principles of motor learning, strength training and/or improving Range of Motion (ROM). At the start bimanual goals were set using the Canadian Occupational Performance Measure (COPM). After a task analysis at the start of the treatment of these goals, they were practiced as much as possible in the child's relevant context. The last mentioned aspect, practising of meaningful goals in the child's own context, is necessary to guarantee frequent use of the affected hand and contributes therefore to the intensity and the treatment effect of the therapy programme.

\section{Outcome assessment}

With the primary outcome measure at activity level of the ICF in the first RCT, the Melbourne Assessment of Unilateral Upper Limb Function (MUUL), no additional effect of BoNT-A on the total percentage score was found. We believed this was because some items of the MUUL specifically address target accuracy, which we expected not to be improved by BoNT-A injections. With an item selection of the MUUL in which the posture of thumb/fingers, wrist and elbow/forearm are scored, the BoNT-A group showed some tendency towards improvement until the 6-week follow-up. Also we noticed that the younger children had difficulties in performing some items of the MUUL, as these items (for example writing with a crayon) are normally performed with the dominant, non-affected hand. 
Therefore, we developed the OSAS, which measures both amount and quality of use of the affected hand in children with uCP using age appropriate tasks that require the use of the affected hand. In chapter 4 , the agreement and reliability of the OSAS in a convenience sample of two different age groups of 16 children with unilateral spastic CP (2.5-6 and 12-16 years old) was investigated. The OSAS was developed by an expert team of occupational therapists, physiotherapists and a rehabilitation physician. Several age-appropriate, standardized bimanual motor tasks in which the children have to use their affected hand repetitively were chosen for children from 2.5 to 6 and 7 to 16 years of age. After reliability analysis it became clear that some tasks, i.e. the stacking blocks task, were not useful to measure change. The 'quality of reach' criterion showed low reliability and we recommended it to be used otherwise. The other quality of movement criteria in the Pop-Onz and bead-threading tasks for the younger children and the sandwich-making and construction tasks for the older age group demonstrated good agreement as indicated by the small SDDs and so are suited to measure individual change. The amount of use score of the OSAS turned out not to be suitable for evaluating individual changes but may still be used to compare groups in scientific research. We recommend further reliability research of the above-mentioned reliable tasks with adapted scoring of the 'reach' item and better coaching of the observers especially in the 'grasp finger' and 'release' criterion.

In the BoBiVa study the Assisting Hand Assessment (AHA) was used as a main outcome measurement for bimanual performance, as we found this aspect of treatment effect very important. Because developmental disregard plays an important role in children with uCP, not only the actual use of the affected hand in bimanual activities of daily life, i.e. bimanual performance, is relevant, but also the ability to use the affected hand to its maximum potential in bimanual tasks performed in a standardized environment, which is called capacity. This latter aspect is measured by the OSAS, which consequently turned out to be additional to the AHA. With the OSAS, we found significant quality of movement (grasp and hold wrist positions) improvements in the children who received BoNT-A, whereas with the AHA no significant differences between the treatment groups could be established. This may have promising implications regarding responsiveness of the OSAS.

These improvements in the BoNT-A group in quality of movement such as the wrist grasp and hold position were presumably due to tone reduction in the wrist and finger flexors, measurements at the function level of the ICF. Therefore, in the explorative study in chapter 5 we studied the effects of BoNT-A injections in the UE combined with BITT or either treatment modality performed separately on UE ROM, spasticity in wrist and elbow and grip 
strength, Maximal Voluntary Contractions (MVC) of fist grip and key grip, measured with the E-LINK dynamometer and functional strength, for which we developed an unimanual and a bimanual measurement. For the unimanual functional strength, the child, depending on its capability had to keep a jug filled with water upright for 5 seconds with the elbow flexed at $90^{\circ}$. For bimanual strength, the child had to lift a crate with lead-filled sacks (total weight that the child was able to carry) for 5 seconds with the elbows flexed at $90^{\circ}$. We developed these functional strength measures, because we expected them to have more influence on bimanual performance than the dynamometer grip strength measurements. Also, the younger children were more easily motivated to perform these functional strength measurements compared to the E-LINK measurements. Although high correlations between the two baseline E-LINK and functional strength measurements were found, further development and reliability analysis of the functional strength measurements is needed.

\section{Effects of BoNT-A and BITT}

In the explorative part of BoBiVa study in chapter 5, we studied the effects of BoNT-A injections in the UE combined with BITT or either treatment modality performed separately on UE ROM, spasticity and (functional) grip strength. We found a significant tone reduction of the finger flexors and a clear improvement of active thumb abduction in the children who received BoNT-A. This is in agreement with the findings in our first RCT and the Cochrane review. ${ }^{1}$

This tone reduction in the wrist and finger flexors, may have led to significant quality of movement (grasp and hold wrist positions) improvements found on the OSAS in the BoNT-A group. There was a negative effect of BoNT-A on unimanual functional and key grip strength, which possibly played a role in the negative effect of BoNT-A on bimanual performance, as is known from literature mentioned in the introduction in chapter 5.

The children in the BITT-only group showed significantly more improvement on unilateral functional grip strength and a minor improvement in bimanual functional grip strength during and shortly after BITT. Therefore, BITT was presumed to have positive effects on bimanual performance.

In chapter 6 the results of the BoBiVa study at the activity level of the ICF are described. We investigated the effect of BoNT-A in the UE and/or BITT on bimanual performance, measured with the AHA and the ABILHAND-Kids questionnaire (AK); on the amount and quality of use 
of the affected limb with the OSAS; and on goal achievement, measured with the Canadian Occupational Performance Measure (COPM) and the, by video observation blinded, Goal Attainment Scaling (GAS). The BITT-only (and control group with younger children) showed a non-significant but positive effect on the AHA score, our primary outcome measurement, at 12 weeks. BITT had a significant positive effect on bimanual performance, measured with the AK and on goal achievement, measured with the COPM and the blinded GAS score, not only at 12 weeks, the end of the therapy programme, but also at 18 and 24 weeks. Task specific exercise clearly led to achievement of the goals set by the children themselves and, to a lesser extent, to improvement in bimanual performance. BoNT-A seemed to have a negative effect on bimanual performance, measured with the AHA. The BoNT-A and the BoNT-A+BITT AHA score did not increase from 0 to 12 weeks contrary to de BITT-only and control group. Also, BoNT-A had a negative effect in achieving the first COPM goal and on the GAS score. As was mentioned earlier, the negative effect of BoNT-A on (functional) strength was supposed to play a role here. BoNT-A injections in the wrist and finger flexors led to a significantly improved wrist position in the quality of grasp and hold wrist scores in several tasks of the OSAS, due to the effect of tone reduction in the wrist and finger flexors, during the working time at 6 and 12 weeks in the older age group and lasting even longer in the younger children. These are substantial differences given the known smallest detectable differences in the quality of grasp and hold wrist scores in these tasks. Also, a positive effect of BoNT-A on the amount of use of the affected hand in the beading and the sandwich-making tasks of the OSAS was found. As the BoNT-A group improves in these tasks and the no BoNT-A group deteriorates and this effect is also present in the comparison BoNT-A+BITT versus BITT-only, these are consistent results. Contrary to the Cochrane review, ${ }^{1}$ in the BoBiVa study a negative additional effect of BoNT-A on GAS and also on the COPM was found. This may be caused by the fact that in this study the GAS was scored from video recordings of the performance of the main goal by trained therapists who were unaware at which measurement session the videotape was taken, so the GAS was scored blindly.

\section{Conclusions and clinical implications}

In conclusion, BoNT-A has a positive effect on the quality of movement and amount of use of the affected UE especially during the expected working time and somewhat longer in younger children. It has, however, no additional effect on bimanual performance and goal achievement. BITT on the other hand, has a clearly positive effect on goal achievement and bimanual performance. This finding is consistent with the results of Charles and 
Gordon, who also found positive effects of bimanual intensive movement therapy (BIMT) on bimanual performance, measured with the AHA. ${ }^{2}$ Comparing CIMT and BIMT, both treatment options lead to improvement in unilateral capacity and bimanual performance with no clear difference between these treatment options, yet CIMT seems to have more effect on unilateral capacity and BIMT on bimanual performance (chapter 2). It is important to consider that the children have to be brought under general anaesthesia to inject the BoNT-A in the correct muscles, and that this could have a serious impact on the children and their parents. Therefore, to improve bimanual performance and goal achievement in children with $\mathrm{UCP}$, intensive task specific bimanual training is, in our opinion, the first choice of treatment. In children aged 6 years or younger with severe spasticity of the wrist and finger flexors of the affected hand, preventing them to actively open their hand, additional BoNT-A injections are to be considered.

\section{Implications for further research}

Further research of the Pop-Onz and bead-threading tasks for the younger children and the sandwich-making and construction tasks for the older age group of the OSAS with adapted scoring of the 'reach' item and better coaching of the observers is necessary to improve its use and reliability in clinical practice and research in measuring the capacity of the affected hand in bimanual skills. Besides, the validity of the OSAS needs to be investigated.

Because of the expected influence of functional strength on bimanual performance, further development of the functional strength measurements and reliability analysis is necessary. Also, the specific correlation between (functional) strength and bimanual capacity and performance should be investigated to be able to discriminate prognostic factors contributing to bimanual performance.

As described in chapter 2, the severity of the brain lesion, whether or not the basal ganglia are affected, and the type of central motor reorganisation, contralateral or ipsilateral, may have influenced the outcome of our trials. However, MRI findings were not included in our studies, because these were not always available. A proposal for further studies regarding treatment effects should be to obtain brain-imaging findings to be able to register the effect of central motor reorganisation on treatment outcome.

Chapter 2 mentions also that in an animal study, training in early childhood of the affected limb in combination with restraint of the non-affected limb is more effective in restoring 
central nervous system structure, than training in adolescence or restraint alone. ${ }^{3}$ Neural plasticity mechanisms in the developing brain are enhanced at a younger age, which has positive and negative implications. Exercise leads to improvement of trained skills by reorganization of neuronal networks with more effect if training takes place at a younger age, in which there is a post-natal burst in synaptogenesis followed by activity-dependent pruning of excessive synapses later in the post-natal period. Due to the vulnerability associated with plasticity of the developing brain, environmental enrichment has a positive effect on learning and memory ability. However, sensory deprivation has negative effects, because developing neurons are dependent on a stable level of neuronal depolarization and are vulnerable to loss of stimulation by excitatory neurotransmitters. ${ }^{4}$ Therefore, restriction of the less affected upper limb should be done moderately at an early age. Training of the affected limb from an early age on, as an assisting hand in bimanual play and meaningful skills to achieve bimanual goals seems to be supported by this evidence.

Future research should, therefore, focus on the effects of training programmes from an early age (from one year, once the Cerebral Palsy has been diagnosed). It is important that the skills that have to be learned are fun to do for the child and meaningful for the child and its parents, because this leads to frequent use of the affected hand. As the intensity of a therapy programme also influences the outcome, this fact should be taken into account. Because these very young children are most of the time at home with their parents and caregivers, this kind of therapy needs to be done in the form of home-based training programmes, in which the children are challenged to use their affected hand repeatedly (in play), and imposing stress on their parents needs to be prevented. The presence of brain imaging in these children is important to be able to investigate the effects of the size and location of the brain lesion on treatment outcome. 


\section{REFERENCES}

1 Hoare BJ, Wallen MA, Imms C, Villanueva E, Rawicki HB, Carey L. Botulinum toxin A as an adjunct to treatment in the management of the upper limb in children with spastic cerebral palsy (UPDATE). Cochrane Database Syst Rev 2010 Jan 20; (1):CD003469. Review.

2. Gordon AM, Schneider JA, Chinnan A, et al. Efficacy of a hand-arm bimanual intensive therapy (HABIT) in children with hemiplegic cerebral palsy: a randomized control trial. Dev Med Child Neurol 2007; 49: 830-838.

3. Friel K, Chakrabarty S Kuo HC, Martin J. Using motor behavior during an early critical period to restore skilled limb movement after damage to the corticospinal system during development. J Neurosci 2012; 32(27): 9265-9276.

4. Johnston MV. Plasticity in the Developing Brain: Implications for Rehabilitation. Dev Disabil Res Rev 2009; 15: 94-101. 


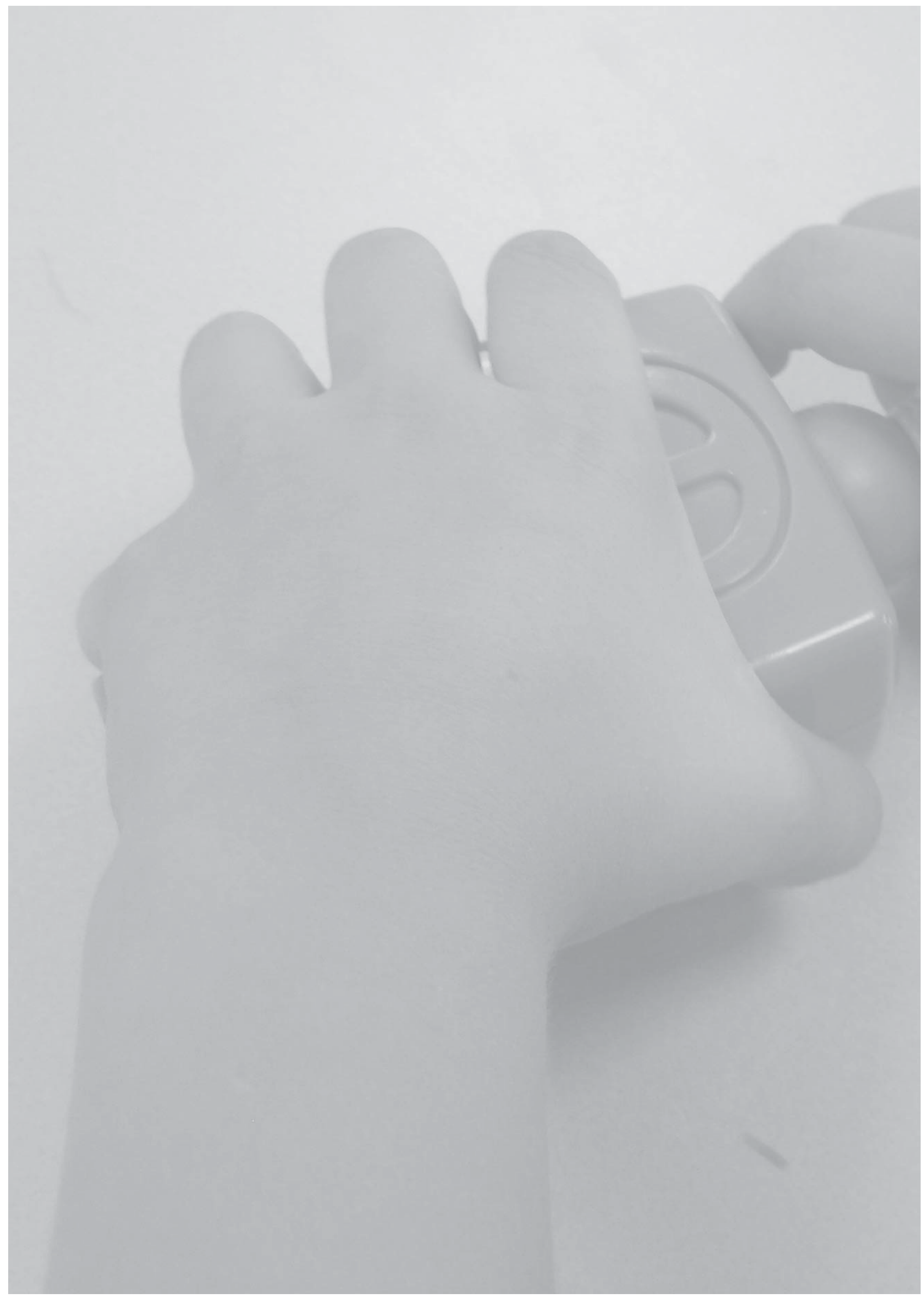




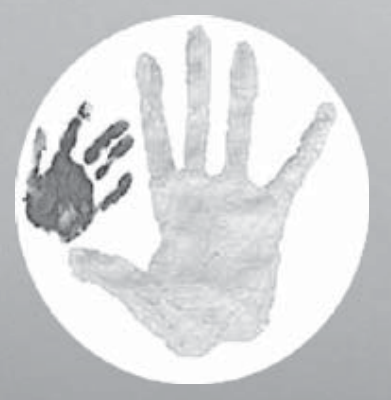

Samenvatting en discussie 
In dit proefschrift worden de resultaten beschreven van effectstudies van botuline toxine $A$ (BoNT-A) injecties en van bimanuele taak-georiënteerde oefentherapie (BITT), die afzonderlijk of in combinatie (BITT na BoNT-A injecties) uitgevoerd zijn bij kinderen met een spastische handfunctiestoornis bij een unilaterale Cerebrale Parese (uCP). Om de effecten van deze behandelingen goed te kunnen evalueren hebben we de Observational Skills Assessment Score (OSAS), een meetinstrument dat het gebruik en de kwaliteit van bewegen van de aangedane hand in tweehandige, gestandaardiseerde, leeftijdsadequate taken meet, ontwikkeld. Ook werd de betrouwbaarheid van de OSAS onderzocht.

Hoofdstuk 1 is een inleidend hoofdstuk. De inhoud van het proefschrift wordt toegelicht en in de historische context geplaatst.

In hoofdstuk 2 worden de epidemiologie, etiologie en beeldvorming bij kinderen met uCP beschreven, specifiek gericht op de spastische handfunctiestoornis en vervolgens wordt ingegaan op de behandelmogelijkheden hiervan. ${ }^{1}$

UCP, vroeger hemiparese genoemd, heeft een prevalentie van 0,6 per 1000 levend geborenen en bedraagt ongeveer $30 \%$ van de kinderen met een spastische CP. ${ }^{2} \mathrm{MRI}-$ bevindingen die het meest gezien worden bij uCP zijn periventriculaire witte stof laesies, grijze stof laesies, meestal infarcten van de arteria cerebri media, en malformaties van de hersenen. Er blijkt een correlatie te bestaan tussen het totale volume van de laesie en de ernst van de Wallerse degeneratie van de pyramidebanen in het anterieure deel van het posterieure been van de capsula interna met de motorische functiestoornis in de hand..$^{3-6}$

Er zijn twee soorten van centrale motorische reorganisatie in uCP. Kinderen met contralaterale corticale motorprojecties naar hun hemiparetische hand hebben een betere handfunctie dan kinderen met ipsilaterale projecties. Alle kinderen bij wie de basale kernen aangedaan zijn, hebben ipsilaterale projecties. In dit laatste geval is de handfunctie meestal meer aangedaan en zijn spiegelbewegingen aanwezig. Bij kinderen met periventriculaire witte stof laesies werd een betere handfunctie gevonden dan bij kinderen met grijze stof laesies. ${ }^{7}$

Developmental disregard (tijdens de ontwikkeling gaan verwaarlozen) van de aangedane hand is een probleem dat zich vaak voordoet bij kinderen met uCP. Taub et al. beschreven voor het eerst learned non-use in CVA-patiënten. Zij introduceerden de Constraint Induced Movement Therapy (CIMT) bij deze patiënten, waarbij zij het gebruik van de aangedane hand stimuleerden door het gebruik van de niet-aangedane hand te beperken. ${ }^{8} \mathrm{CIMT}$ en ook bimanuele therapie (BIMT) hebben bewezen effectieve behandelmogelijkheden te zijn 
bij kinderen met uCP om de uitvoering van de tweehandige vaardigheden in de activiteiten van het dagelijks leven (ADL), de bimanual performance, te verbeteren. ${ }^{9-11}$

Wanneer we CIMT en BIMT met elkaar vergelijken, leiden beide behandelopties tot verbetering in de mogelijkheid om de aangedane hand te kunnen gebruiken naar maximaal vermogen bij tweehandige gestandaardiseerde taken, unilateral capacity, en bimanual performance met geen duidelijk verschil tussen beiden, hoewel CIMT meer effect op unilateral capacity lijkt te hebben en BIMT op bimanual performance. ${ }^{12-14}$

De gerandomiseerde klinische studie, beschreven in hoofdstuk 3, had als doel het additionele effect van BoNT-A te bepalen op functies en vaardigheden van de bovenste extremiteit $(B E)$ in de context van een speciaal ontwikkeld taakspecifiek therapieprogramma. ${ }^{15}$ Dit therapieprogramma was een voorloper van BITT, dat verder ontwikkeld werd voor de BoBiVa (Botulline Toxine Bimanuele Vaardigheden) studie, beschreven in hoofdstuk 5 en 6. Dit behandelprogramma is gebaseerd op het stellen van behandeldoelen afhankelijk van de hulpvraag van het individuele kind samen met de ouders. Eerst wordt een taakanalyse verricht van de activiteiten die uitgevoerd moeten worden om deze doelen te kunnen realiseren. Door middel van klinisch redeneren worden de tijdsduur van het taakspecifiek oefenen, de kracht- en coördinatietraining en de tijd en mate van het rekken van de spastische pols- en vingerbuigers en het eventuele gebruik van orthesen bepaald. Dit zijn ook de belangrijkste elementen van het BITT programma in de BoBiVa studie. Hierbij wordt zoveel mogelijk in de context behandeld. De taak wordt indien mogelijk in zijn geheel geoefend in de setting waarin deze uitgevoerd moet worden. Het additionele effect van BoNT-A in deze eerste studie bestond uit tonusreductie van de pols- en vingerflexoren en verbetering van de actieve polsextensie. Onze belangrijkste uitkomstmaat was de Melbourne Assessment of Unilateral Upper Limb Function (MUUL); hiermee werd geen verschil tussen beide behandelgroepen op de totale score gevonden. Wij meenden dat dit veroorzaakt werd door het feit dat sommige items van de MUUL doelgerichtheid betreffen, waarvan wij verwachtten dat dit niet beïnvloed werd door de BoNT-A injecties. Bij analyse van een itemselectie van de MUUL, waarin de houding van pols en vingers gescoord wordt, toonde de BoNT-A groep een tendens tot verbetering tot en met de 6 weken follow-upmeting. Verder zagen we dat vooral de jongere kinderen moeite hadden om sommige items van de MUUL uit te voeren, omdat deze items (bijvoorbeeld tekenen met een krijtje) normaal uitgevoerd worden met de dominante niet-aangedane hand. Vanwege bovengenoemde redenen hebben we de OSAS ontwikkeld. Dit instrument meet de inzet (uitgedrukt in percentage gebruik beide handen tijdens de taak) en kwaliteit van 
bewegen van de aangedane hand in kinderen met uCP in taken passend bij de leeftijd, waarbij het gebruik van de aangedane hand onmisbaar is. In hoofdstuk 4 staan de resultaten beschreven van een studie naar de betrouwbaarheid van de OSAS in twee verschillende leeftijdsgroepen van kinderen met unilaterale spastische CP (2,5-6 en 12-16 jaar oud). ${ }^{16}$ De OSAS is ontwikkeld door een expertteam van ergotherapeuten, fysiotherapeuten en een revalidatiearts. Verschillende, gestandaardiseerde taken passend bij de leeftijdsgroepen 2,5 tot 6 en 7 tot 16 jaar werden uitgezocht, waarin het kind de aangedane hand repetitief moet gebruiken als ondersteunende hand. Na de betrouwbaarheidsanalyses werd duidelijk dat sommige taken, bijvoorbeeld de blokkenstapeltaak, niet bruikbaar zijn om verandering te meten. Het criterium 'kwaliteit van reiken' bleek niet betrouwbaar en we adviseerden dit criterium op een andere manier te gaan scoren, namelijk het aantal keren tellen dat het kind reikt met de aangedane hand. De overige 'kwaliteit van bewegen' criteria toonden een goede betrouwbaarheid voor de jongere kinderen in de Pop-Onz en kralenrijgtaak en voor de oudere kinderen in de broodsmeertaak en de constructie taken. Verder bleek uit de Smallest Detectable Differences (SDD's), dat betrouwbaar individuele verschillen gemeten kunnen worden bij deze criteria in deze taken. Het percentage gebruik van beide handen tijdens de taak bleek niet betrouwbaar om individuele verschillen te meten, maar kan wel gebruikt worden om groepen te vergelijken in een wetenschappelijke studie. Daarom adviseren we om opnieuw betrouwbaarheidsonderzoek van de bovenvermelde betrouwbaar gebleken taken te gaan doen met een aangepaste score van het 'kwaliteit van reiken' criterium en een betere training van de beoordelaars in het 'grijpen vingers' en 'loslaat' criterium.

In de BoBiVa studie, waarvan we de resultaten in hoofdstuk 5 en $\mathbf{6}$ gerapporteerd hebben, was de Assisting Hand Assessment (AHA) de belangrijkste uitkomstmaat. ${ }^{17}$ De AHA is een maat voor de uitvoering van de tweehandige vaardigheden in de $A D L$, de bimanual performance. Juist dit aspect vonden we een bijzonder belangrijke uitkomst in onze studie. Omdat developmental disregard van de aangedane hand een belangrijke rol speelt bij kinderen met $u C P$, is niet alleen de bimanual performance van belang, maar ook de mogelijkheid om de aangedane hand te kunnen gebruiken naar maximaal vermogen bij tweehandige gestandaardiseerde taken, de unilateral capacity. Dit laatste aspect wordt beter gemeten met de OSAS, die daarom aanvullend aan de AHA bleek te zijn. Met de OSAS vonden we een significante verbetering van kwaliteit van bewegen (de stand van de pols bij het grijpen en vasthouden) in de kinderen die de BoNT-A injecties toegediend kregen, terwijl met de AHA geen verschillen tussen de kinderen die wel en niet BoNT-A gekregen hadden kon worden aangetoond. Dit zou veelbelovende implicaties voor de responsiviteit van de OSAS kunnen hebben. 
Deze verbeteringen in de BoNT-A groep in kwaliteit van bewegen zoals bij de stand van de pols bij het grijpen en vasthouden, kunnen verklaard worden door de tonusreductie van de pols- en vingerflexoren, metingen op functieniveau van de International Classification of Functioning, Disability and Health (ICF).

In hoofdstuk 5 beschreven we daarom de bevindingen van het exploratieve deel van de BoBiVa studie naar de effecten van BoNT-A toegediend vooraf aan BITT of van beide behandelmogelijkheden apart uitgevoerd, op functieniveau van de ICF, namelijk de bewegingsuitslag van de $\mathrm{BE}$, de spasticiteit in de pols en de elleboog, en de knijpkracht, de Maximal Voluntary Contractions (MVC) van de vuist- en de sleutelgreep, gemeten met de E-LINK dynamometer en de functionele kracht, waarvoor we een uni- en een bimanuele meting ontwikkelden. ${ }^{18}$ Voor de eenhandige krachtmeting moest het kind een maatbeker gevuld met water 5 seconden tillen met de onderarm in 90 graden elleboogflexie. Voor de bimanuele krachtmeting moest het kind een krat, gevuld met zakjes met lood zoveel als het kind kon dragen, 5 seconden tillen met de onderarmen in 90 graden elleboogflexie. Hoewel er hoge correlaties gevonden werden tussen de twee basismetingen van de E-LINK en van de functionele kracht, is verdere ontwikkeling en betrouwbaarheidsanalyse van de functionele krachtmetingen wenselijk. We hebben deze functionele krachtmetingen ontwikkeld, omdat we verwachtten dat ze meer invloed op de bimanual performance zouden hebben dan de dynamometerkrachtmetingen. Ook bleken de jongere kinderen beter te motiveren om deze functionele krachtmetingen te doen in vergelijking met de E-LINK krachtmetingen. BoNT-A bleek een negatief effect op de eenhandige functionele kracht en de sleutelgreepkracht te hebben. Dit heeft mogelijk een rol gespeeld in het negatieve effect van BoNT-A op bimanual performance (zie verder bij hoofdstuk 6). Dit aspect behoeft nog nader onderzoek door middel van specifieke correlatieanalyse. De kinderen die alleen BITT kregen toonden significant meer verbetering in eenhandige functionele kracht en iets meer verbetering in bimanuele kracht tijdens en kort na BITT. Op grond hiervan namen wij aan, dat BITT een positief effect op bimanual performance zou kunnen hebben.

De BoBiVa studie kende een aantal beperkingen, namelijk de slechts gedeeltelijk gerealiseerde randomisatie en het beperkte aantal onderzoekdeelnemers. Dit werd veroorzaakt door het feit dat de ouders hun kind niet wilden laten deelnemen aan de BoNT-A of controlegroep, omdat zij een sterke voorkeur hadden voor BoNT-A+BITT of juist alleen BITT. Wij hebben daarom de oorspronkelijke studieopzet moeten aanpassen, hetgeen resulteerde in een grote variatie in groepsgrootte. In deze studie hebben we 3 vergelijkingen onderzocht: a) BITT (BoNT-A+BITT en BITT-alleen; $n=24$ ) versus geen BITT (BoNT-A-alleen en controle; $n=11$ ), b) BoNT-A (BoNT- 
A-alleen en BoNT-A+BITT; $n=18$ ) versus geen BoNT-A (BITT-alleen en controle; $n=17$ ), en $c$ ) het additionele effect van BoNT-A, i.c. BoNT-A+BITT ( $n=13$ ) versus BITT-alleen ( $n=11)$. Ondanks deze aanpassingen kwamen er consistente en klinisch relevante resultaten uit de BoBiVa studie.

In hoofdstuk 6 zijn de resultaten van deze studie op activiteitenniveau van de ICF beschreven. ${ }^{19}$ We hebben de effecten van BoNT-A in de BE en/of BITT onderzocht op bimanual performance met de AHA en de ABILHAND-Kids (AK) vragenlijst; op inzet en kwaliteit van bewegen van de aangedane hand met de OSAS en op het bereiken van de gestelde doelen met de Canadian Occupational Performance Measure (COPM) en Goal Attainment Scaling (GAS), gescoord op videobeelden (geblindeerd).

De BITT-alleen groep (en de controlegroep met jongeren kinderen) liet een niet-significant positief effect op de AHA, onze primaire uitkomstmaat, zien bij 12 weken. BITT had een significant positief effect op bimanual performance gemeten met de AK en op het bereiken van de gestelde doelen, gemeten met de COPM en de geblindeerde GAS-score, niet alleen aan het einde van het 12 weken durende therapieprogramma, maar ook bij 18 en 24 weken. Taakspecifiek oefenen heeft duidelijk geleid tot het bereiken van de door de kinderen en hun ouders gestelde doelen en in mindere mate tot verbetering in bimanual performance.

BoNT-A leek, gemeten met de AHA, een negatief effect op bimanual performance te hebben: de BoNT-A en de BoNT-A+BITT AHA score verbeterde niet van 0 tot 12 weken in tegenstelling tot de BITT-alleen en de controlegroep. Ook had BoNT-A een negatief effect op het bereiken van het eerste COPM-doel en op de GAS-score. Zoals eerder aangegeven zijn wij van mening dat het negatieve effect van BoNT-A op (functionele) kracht hierin mogelijk een rol speelt. De BoNT-A injecties in de pols- en vingerflexoren hebben geleid tot een significante verbetering van de kwaliteit van bewegen-scores van grijpen en vasthouden van de pols in verschillende taken van de OSAS als gevolg van de tonusreductie in de pols- en vingerflexoren bij 6 en 12 weken, de werkingsduur van BoNT-A, bij de oudere kinderen en zelfs langer bij de jongere kinderen. Wanneer we de kleine SDD's van deze kwaliteit van bewegen-scores van grijpen en vasthouden van de pols in acht nemen, zijn dit substantiële verschillen. Verder heeft BoNT-A een positief effect op het percentage gebruik van beide handen in de kralenrijg- en broodsmeertaak van de OSAS. Bij vergelijking van BoNT-A versus geen BoNT-A en BoNT$\mathrm{A}+\mathrm{BITT}$ versus BITT-alleen in deze taken, verbetert de BoNT-A groep en de niet BoNT-A groep gaat achteruit. Dit zijn duidelijke en consistente bevindingen.

In tegenstelling tot de Cochrane review, ${ }^{20}$ en de studie van Ferrari et al. ${ }^{21}$ werd in de BoBiVa studie een negatief additioneel effect van BoNT-A op de COPM en de GAS-score gevonden. 
Dit zou verklaard kunnen worden door het feit dat in deze studie de GAS-score bepaald werd op video-opnames van het belangrijkste doel door getrainde therapeuten, die niet wisten op welk meetmoment de video gemaakt was. De GAS-score is nu dus een geblindeerde uitkomstmaat geworden.

De discussie en de conclusies van dit proefschrift staan in hoofdstuk 7 vermeld. Samenvattend heeft BoNT-A een positief effect op kwaliteit van bewegen en de inzet van de aangedane hand, zeker gedurende de werkingstijd en iets langer bij de jongere kinderen. Het heeft echter geen additioneel effect op bimanual performance en het bereiken van de gestelde doelen. BITT daarentegen, heeft een duidelijk positief effect op het bereiken van doelen en in mindere mate op de tweehandige uitvoering van activiteiten in de ADL. Deze bevinding is consistent met de bevindingen van Charles en Gordon, die ook positieve effecten van bimanuele intensieve bewegingstherapie (BIMT) vonden op bimanual performance gemeten met de AHA. ${ }^{22}$

Het is van belang in de overwegingen mee te nemen, dat de kinderen voor het toedienen van de BoNT-A injecties in de juiste spieren (d.m.v. elektrostimulatie) onder narcose gebracht moeten worden, hetgeen een behoorlijke impact kan hebben op kind en ouders.

Daarom is naar onze mening intensieve taakspecifieke oefentherapie de eerste behandelkeuze bij kinderen met UCP ter verbetering van bimanual performance en het bereiken van hun gestelde doelen. Bij kinderen onder de leeftijd van 6 jaar met aanzienlijke spasticiteit van de pols- en vingerflexoren, waardoor zij niet in staat zijn hun hand actief te openen, zouden BoNT-A injecties overwogen kunnen worden.

De ernst van de hersenbeschadiging, of de basale kernen wel of niet aangedaan zijn, en het type van centraal motorische reorganisatie, contralateraal of ipsilateraal, zou de uitkomsten van onze studies beïnvloed kunnen hebben (zie hoofdstuk 2). We hebben in de oorspronkelijke studieopzet echter geen MRI-bevindingen meegenomen, omdat deze vaak niet beschikbaar waren. Daarom is het belangrijk, dat bij de opzet van nieuwe studies de bevindingen van de MRI-scan van de hersenen aanwezig zijn en dat onderzocht wordt wat de gevolgen van de aard en de ernst van de hersenbeschadiging zijn op de effecten van onze behandelingen.

In een dierexperimentele studie bleek training van de aangedane extremiteit vroeg in de kinderleeftijd in combinatie met een opgelegde beperking, een restraint, van de nietaangedane extremiteit effectiever om de structuren van het centrale zenuwstelsel te 
herstellen, dan training in adolescentie of alleen een restraint. ${ }^{23}$ Het feit dat de neurale plasticiteit in het zich ontwikkelende brein hoger is op jongere leeftijd, heeft positieve en negatieve gevolgen. Oefening leidt tot verbetering van geleerde vaardigheden door middel van reorganisatie van neurale netwerken met een groter effect wanneer de training plaatsvindt op jongere leeftijd, omdat er dan een postnatale uitbarsting van synaptogenese is, gevolgd door een activiteit-afhankelijke vermindering van excessieve synapsen later in de postnatale periode. Door de gevoeligheid van het zich ontwikkelende brein gepaard gaande met plasticiteit, heeft omgevingsverrijking een positief effect op leren en geheugen. Sensorische deprivatie heeft echter negatieve effecten, omdat ontwikkelende neuronen afhankelijk zijn van een stabiel niveau van neuronale depolarisatie en gevoelig zijn voor gebrek aan stimulatie door excitatoire neurotransmitters. ${ }^{24}$

Daarom moet voorzichtig omgegaan worden met het aanbrengen van een beperking van de niet-aangedane extremiteit op jonge leeftijd. Training van de aangedane arm daarentegen vanaf jonge leeftijd als ondersteunende hand in tweehandig spel en bij betekenisvolle tweehandige vaardigheden en doelen, lijkt ondersteund te worden door deze bewijsvoering. Toekomstig onderzoek zou zich daarom moeten richten op trainingsprogramma's op zeer jonge leeftijd (vanaf één jaar, wanneer de diagnose Cerebrale Parese gesteld kan worden). Dit moeten dan behandelprogramma's thuis zijn, waarbij de kinderen uitgedaagd worden om hun aangedane hand herhaaldelijk te gebruiken, zonder dat dit leidt tot stress bij de ouders. Beeldvorming van de hersenen zal dan aanwezig moeten zijn om de effecten van de grootte en locatie van de laesie op de behandelresultaten te kunnen onderzoeken. 


\section{REFERENCES}

1 Speth L, Vles J. Unilateral Cerebral Palsy: Epidemiology, Etiology, Imaging and Treatment of Hand Function Problems. Handbook on Cerebral Palsy. Editor: Harold Yates. 2014 Nova Science Publishers. ISBN: 978-1-63321-852-9: 41-51.

2. Krägeloh-Mann I, Cans C. Review Article. Cerebral palsy update. Brain Dev 2009; 31: 537-544.

3. De Vries LS, Van der Grond J, Van Haastert IC, Groenendaal F. Prediction of outcome in new-born infants with arterial ischaemic stroke using diffusion-weighted magnetic resonance imaging. Neuropediatrics 2005; 36: 12-20.

4. Staudt M, Niemann G, Grodd W, Krägeloh-Mann I. The Pyramidal Tract in Congenital Hemiparesis: Relationship between Morphology and Function in Periventricular Lesions. Neuropediatrics 2000; 31: 257-264.

5. Bleyenheuft $Y$, Grandin CB, Cosnard G, Olivier E, Thonnard JL. Corticospinal Dysgenesis and Upper-Limb Deficits in Congenital Hemiplegia: A Diffusion Tensor Imaging Study. Pediatrics 2007; 120; e1502-e1511.

6. Holmström L, Lennartsson F, Eliasson AC, Flodmark $O$ et al. Diffusion MRI in corticofugal fibers correlates with hand function in unilateral cerebral palsy. Neurology 2011; 77: 775-783.

7. Holmström L, Vollmer B, Tedroff K, Islam M et al. Hand function in relation to brain lesions and corticomotor-projection pattern in children with unilateral cerebral palsy. Dev Med Child Neurol 2010; 52: $145-152$.

8. Taub E, Uswatte G, Pidikiti R. Constraint-induced movement therapy: A new family of techniques with broad Application to Physical Rehabilitation-A Clinical Review. J Rehabil Res Dev 1999; 36(3): 237-251. Review.

9. Hoare BJ, Wasiak J, Imms C, Carey L. Constraint-induced movement therapy in the treatment of the upper limb in children with hemiplegic cerebral palsy. Cochrane Database Syst Rev 2007; (2): CD004149.

10. Aarts PB, Jongerius PH, Geerdink YA, van Limbeek J, Geurts AC. Effectiveness of Modified ConstraintInduced Movement Therapy in Children With Unilateral Spastic Cerebral Palsy: A Randomized Controlled Trial. Neurorehabil Neural Repair 2010; 24: 509-518.

11. Gordon AM, Schneider JA, Chinnan A, et al: Efficacy of a hand-arm bimanual intensive therapy (HABIT) in children with hemiplegic cerebral palsy: a randomized control trial. Dev Med Child Neurol 2007; 49: 830-838.

12. Gordon AM, Hung YC, Brandao M, Ferre CL, Kuo HC, Friel K, Petra E. Bimanual Training and ConstraintInduced Movement Therapy in Children With Hemiplegic Cerebral Palsy: A Randomized Trial. Neurorehabil Neural Repair 2011; 25: 692-702.

13. Sakzewski L, Ziviani J, Abbott JF, Macdonell RA, Jackson GD, Boyd RN. Randomized trial of constraintinduced movement therapy and bimanual training on activity outcomes for children with congenital hemiplegia. Dev Med Child Neurol 2011; 53: 313-320.

14. Deppe W, Thuemmler K, Fleischer J, Berger C, Meyer S, Wiedemann B. Modified constraint-induced movement therapy versus intensive bimanual training for children with hemiplegia - a randomized controlled trial. Clin Rehabil 2013; 27(10): 909-920.

15. Speth LA, Leffers $P$, Janssen-Potten YJ, Vles JS. Botulinum toxin A and upper limb functional skills in hemiparetic cerebral palsy: a randomized trial in children receiving intensive therapy. Dev Med Child Neurol 2005; 47(7): 468-473. 
16. Speth L, Janssen-Potten $\mathrm{Y}$, Leffers P, Rameckers E, Defesche A, Geers R, et al. Observational skills assessment score: reliability in measuring amount and quality of use of the affected hand in unilateral cerebral palsy. BMC Neurol 2013; 13: 152.

17. Krumlinde-Sundholm L, Holmefur M, Kottorp A, Eliasson A-C. The Assisting Hand Assessment: current evidence of validity, reliability, and responsiveness to change. Dev Med Child Neurol 2007; 49: 259-264.

18. Speth L, Janssen-Potten Y, Leffers P, Rameckers E, Defesche A, WinkensB, Becher J, Smeets R, Vles H. Effects of botulinum toxin $A$ and/or bimanual task-oriented therapy on upper extremity impairments in unilateral Cerebral Palsy: an explorative study. Eur J Paediatr Neurol 2015; 19(3): 337-348.

19. Speth L, Janssen-Potten Y, Leffers P, Rameckers E, Defesche A, Winkens B, Becher J, Smeets R, Vles H. Effects of botulinum toxin $A$ and/or bimanual task-oriented therapy on upper extremity activities in unilateral Cerebral Palsy: a clinical trial. BMC Neurol; Submitted 29-01-2015.

20. Hoare BJ, Wallen MA, Imms C, Villanueva E, Rawicki HB, Carey L. Botulinum toxin A as an adjunct to treatment in the management of the upper limb in children with spastic cerebral palsy (UPDATE). Cochrane Database Syst Rev 2010; (1): CD003469. Review.

21. Ferrari A, Maoret AR, Muzzini S, Alboresi S, et al. A randomized trial of upper limb botulinum toxin versus placebo injection, combined wuth physiotherapy, in children with hemiplegia. Res Dev Disabil 2014; 35(10): 2505-2513.

22. Gordon AM, Schneider JA, Chinnan A, et al: Efficacy of a hand-arm bimanual intensive therapy (HABIT) in children with hemiplegic cerebral palsy: a randomized control trial. Dev Med Child Neurol 2007; 49: 830-838.

23. Friel K, Chakrabarty S Kuo HC, Martin J. Using Motor Behavior during an Early Critical Period to Restore Skilled Limb Movement after Damage to the Corticospinal System during Development. The Journal of Neuroscience 2012; 32 (27): 9265-9276.

24. Johnston MV. Plasticity in the Developing Brain: Implications for Rehabilitation. Dev Disabil Res Rev 2009; 15: 94-101. 


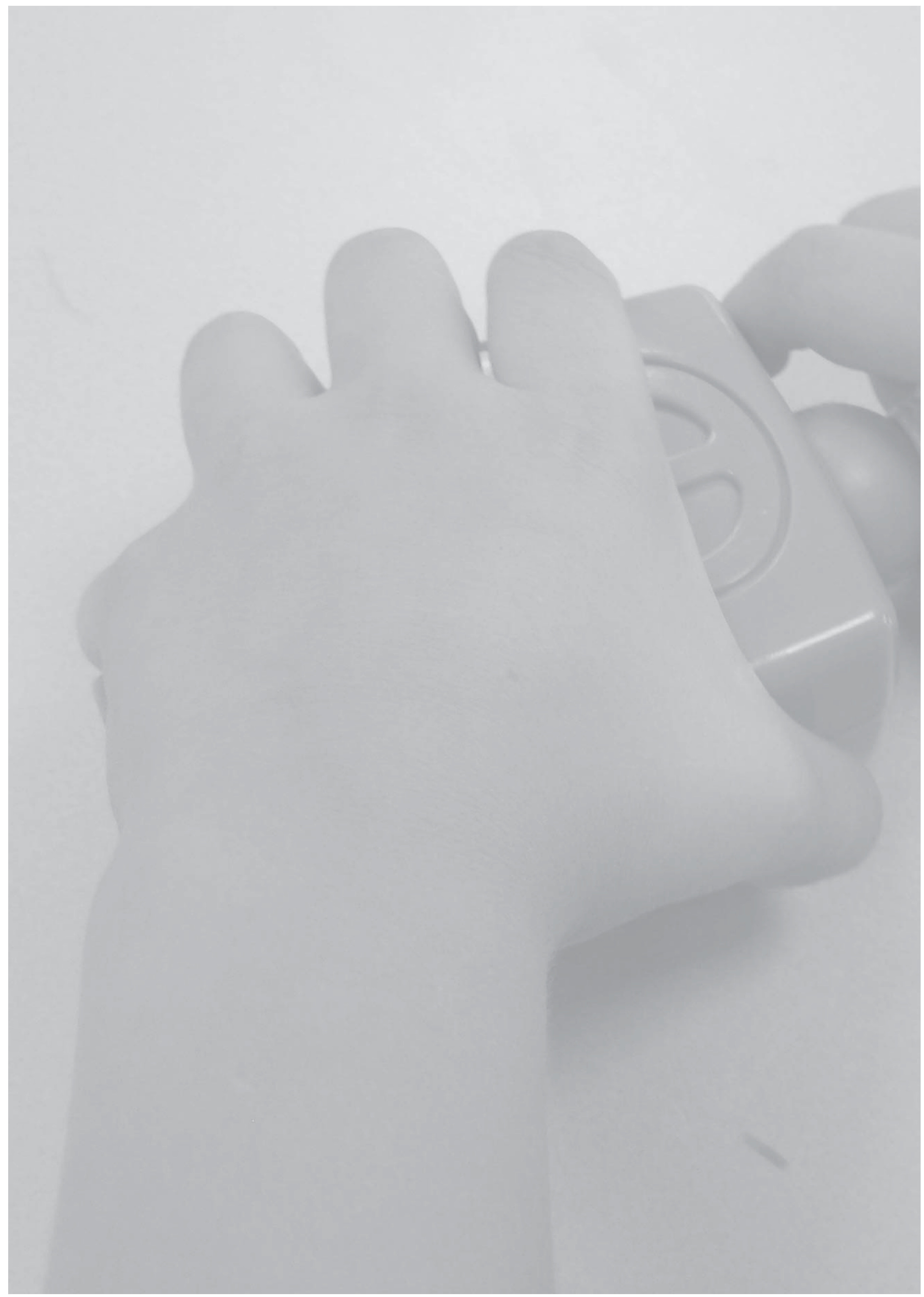




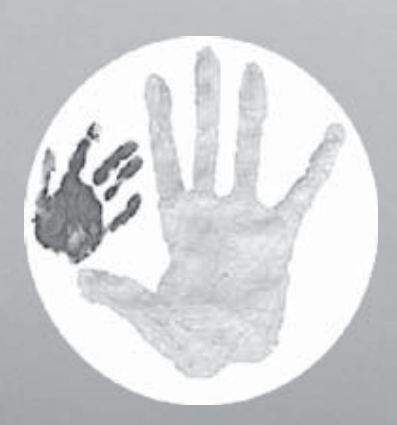

Addendum Valorisatie

Vertaling van de wetenschap naar de maatschappij 
De Vereniging van Samenwerkende Nederlandse Universiteiten (VSNU) beschrijft in haar publicatie "Raamwerk valorisatie-indicatoren" (http://www.vsnu.nl/files/documenten/ Domeinen/Onderzoek/Valorisatie/130422\%20-\%20VSNU\%20Raamwerk\%20Valorisatieindicatoren_web.pdf) dat valorisatie een breed begrip is, dat vele vormen kan hebben. Naast de traditionele, "harde" vormen van valorisatie gericht op economische vermarkting (patenten, licenties en spin-offs) moet ook ruimte zijn voor vaak minder eenvoudig te tellen ("zachte") vormen van maatschappelijke waardecreatie. In deze publicatie wordt de volgende definitie van valorisatie gehanteerd: "Het proces van waardecreatie uit kennis, door kennis geschikt en/of beschikbaar te maken voor economische en maatschappelijke benutting en geschikt te maken voor vertaling in concurrerende producten, diensten, processen en nieuwe bedrijvigheid". Valorisatie van wetenschappelijk onderzoek levert een belangrijke bijdrage aan de Nederlandse kenniseconomie; het is naast het verrichten van onderzoek en het geven van onderwijs een van de kerntaken van de universiteiten.

\section{Maatschappelijke relevantie}

De prevalentie van unilaterale spastische Cerebrale Parese (uCP) is 0,6 per 1000 levend geborenen. Het aantal levend geborenen in Nederland in 2013 en 2014 bedroeg volgens het CBS respectievelijk 171.341 en 174.507. Dit betekent dat er in Nederland in de laatste jaren 103 tot 105 kinderen per jaar met een uCP geboren zijn. In dit proefschrift worden de resultaten van effectstudies van botuline toxine $A$ (BoNT-A) injecties al dan niet gecombineerd met een speciaal ontwikkeld bimanueel intensief taakspecifiek therapieprogramma (BITT) op handfuncties en vaardigheden beschreven bij deze groep van kinderen met een eenzijdige spastische handfunctiestoornis. Deze handfunctiestoornissen kunnen leiden tot problemen op het gebied van activiteiten en participatie van de International Classification of Functioning, Disability and Health (ICF), namelijk bij spel (klimmen, bouwen met blokken, knutselen, puzzelen), voortbewegen (kruipen, gaan staan, fietsen), zelfredzaamheid (broek optrekken en dichtmaken, veters strikken, met mes en vork eten, zakjes en pakjes openen), functioneren op school (knippen, knutselen, omkleden bij de gymles, meedoen aan sommige oefeningen bij de gymles, problemen bij het leren typen indien nodig bij schrijfproblemen bij gedwongen linkshandigheid) en later bij beroepsgerichte vervolgopleidingen en sommige beroepen, evenals bij autorijden. Daarnaast speelt de developmental disregard (tijdens de ontwikkeling gaan verwaarlozen) van de aangedane hand een belangrijke rol bij kinderen met uCP. Het is daarom van belang de effecten van deze behandelmethoden te onderzoeken, zodat deze kinderen op basis van wetenschappelijke bewijsvoering leren hun hand zo effectief mogelijk te gebruiken in het dagelijks leven. 


\section{Resultaten}

Kort samengevat komen de resultaten van deze effectstudies op het volgende neer. Om tweehandige vaardigheden te verbeteren bij kinderen met een eenzijdige spastische handfunctiestoornis, die actief in staat zijn om hun hand te openen (Zancolli I, Ila en IIB), is BITT de behandeloptie van eerste keuze. Hierbij is het nodig dat voor kind en ouders betekenisvolle taken herhaaldelijk geoefend worden, zodat ze geïntegreerd worden in het patroon van het dagelijks leven, waardoor kind en ouders als het ware hun eigen therapeut geworden zijn. Dit is nodig, omdat hierdoor de intensiteit van de inzet/het gebruik van de aangedane hand hoog is, waardoor het resultaat verbetert, en omdat hierdoor developmental disuse voorkomen wordt. BITT heeft een duidelijk positief effect op het daadwerkelijke gebruik van de aangedane hand bij de uitvoering van tweehandige vaardigheden in het dagelijks leven, de bimanual performance en op het bereiken van de gestelde doelen op het gebeid van het tweehandig functioneren.

BoNT-A injecties hebben een positief effect op kwaliteit van bewegen, vooral de stand van de pols, gedurende de werkingstijd van de BoNT-A, en iets langer bij de jongere kinderen. Dit is een gevolg van de spanningsreductie in de pols- en vingerbuigers als gevolg van de BoNT-A. Daarnaast zien we bij sommige taken een betere inzet van de hand na BoNT-A. BoNT-A heeft echter een negatief effect op de (functionele) kracht, op de bimanual performance en op het bereiken van de gestelde doelen. Aangezien de kinderen voor het toedienen van de BoNT-A injecties in de juiste spieren (d.m.v. elektrostimulatie) onder narcose gebracht moeten worden, hetgeen een behoorlijke impact kan hebben op kind en ouders en daarnaast de nodige kosten met zich meebrengt, moet daarom afgezien worden van BoNT-A toediening bij deze kinderen, die actief in staat zijn hun hand te openen, met als doel tweehandige vaardigheden te verbeteren.

De resultaten van deze studies hebben dus duidelijke gevolgen voor de behandelwijze van deze kinderen.

\section{Doelgroepen}

De Observational Skills Assessment Score (OSAS) is speciaal ontwikkeld bij kinderen met een UCP in de leeftijd van 2,5 tot 18 jaar. In deze groep patiënten is ook het betrouwbaarheidsonderzoek verricht. Door het kiezen van leeftijdsadequate taken, waarbij de aangedane hand per se gebruikt moet worden, blijkt het een instrument dat zeer geschikt 
is om de capacity, het vermogen van de aangedane hand, te meten en blijkt het geschikt als aanvulling op de AHA, die een maat is voor de bimanual performance.

De OSAS zou ook gebruikt kunnen worden voor andere diagnosegroepen, waarbij er sprake is van een eenzijdige handfunctiestoornis, zoals bij de kinderen met een aangedane hand bij een obstetrische plexus brachialis laesie. Echter, omdat er hier sprake is van perifere neurologische problematiek, moeten de scoringscriteria dan aangepast worden en vervolgens moet natuurlijk opnieuw betrouwbaarheidsonderzoek plaatsvinden.

Mogelijk zijn er ook toepassingen bij mensen met een unilaterale handfunctiestoornis na een CVA. Bij deze groep van patiënten speelt ook, dat er mogelijk gewisseld moet worden van handdominantie, hetgeen bij de kinderen met een uCP geen rol speelt. De taken die gebruikt worden bij de oudere leeftijdsgroep, de broodsmeer- en de constructietaken, kunnen op zich gebruikt worden met andere scoringscriteria, waarbij rekening gehouden wordt met het feit of er een handfunctiestoornis aan de dominante of niet-dominante zijde bestaat. Het therapieprogramma, BITT, speciaal gericht op het trainen van de tweehandige doelen, die voor kind en ouders relevant zijn, zou natuurlijk ook gebruikt kunnen worden bij kinderen met een obstetrische plexus brachialis laesie, waarbij de hand ook aangedaan is. In hun geval speelt niet zo zeer de developmental disuse maar meer het feit, dat ze door de spierdisbalans, afhankelijk van de soort laesie, soms bijvoorbeeld niet goed kunnen proneren, waardoor de hand steeds meer in supinatiestand komt te staan. Door kind en ouders te leren om de hand daadwerkelijk in te zetten, bij voorbeeld bij het typen, of het prikken met de vork bij het snijden, zou deze stand mogelijk voorkomen kunnen worden.

Ook bij patiënten met een handfunctiestoornis bij een hemiparese na een CVA en bij patiënten met een handfunctiestoornis bij een hoge dwarslaesie is het BITT programma in aangepaste vorm gebruikt. ${ }^{1,2}$

\section{Producten}

De OSAS is speciaal ontwikkeld om kwaliteit van bewegen en percentage inzet van de aangedane hand als ondersteunende hand per taak voor kinderen met een spastische handfunctiestoornis bij een uCP te meten. De betrouwbaarheid bij kinderen met $u C P$ is onderzocht, maar deze moet nog nader onderzocht worden in de betrouwbare taken (de kralenrijgtaak en de Pop-Onz-taak bij de jongere kinderen en de broodsmeer- en de constructietaken bij de oudere kinderen) bij deze diagnosegroep met de aangepaste 
scoringscriteria van het reiken en betere training van de beoordelaars in het 'grijpen vingers' en 'loslaat' criterium.

Zoals hierboven vermeld, zou de OSAS in aangepaste vorm ontwikkeld kunnen worden voor andere diagnosegroepen, waarbij er een eenzijdige handfunctiestoornis aanwezig is. Het bimanuele taakspecifieke therapieprogramma wordt al gebruikt bij adolescenten met een uCP in het "hand in hand" BIMT-kamp in Adelante.

Het taakspecifiek intensief oefenen, zoveel als mogelijk in de context, wordt in de kinderrevalidatie steeds meer toegepast in het kader van het hulpvraaggerichte werken aan betekenisvolle doelen voor kinderen en ouders. Zoals hierboven vermeld kan het ook gebruikt worden bij kinderen met een handfunctiestoornis bij een obstetrische plexus brachialis laesie, of bij mensen met een handfunctiestoornis na een niet-aangeboren hersenletsel, zoals een CVA of een contusio cerebri. De essentie in alle gevallen is, dat er een goede taakanalyse vooraf verricht wordt, zodat het behandelprogramma juist uitgevoerd wordt.

\section{Kennisoverdracht}

Aangezien dit klinisch onderzoek betrof, zijn de resultaten van belang voor de behandeling van kinderen met een UCP en hun ouders. De BOSK, de vereniging van mensen met een aangeboren lichamelijke handicap, is van begin af aan betrokken bij dit onderzoek. Lucianne Speth en Hans Vles schreven een hoofdstuk in het boek "Kind en hemiparese. Beleven en behandelen." uitgegeven door de BOSK.

Al in de eerste RCT is de Zancolliclassificatie gebruikt om de ernst van de handfunctiestoornis vast te leggen. Dit naar aanleiding van een artikel van A. Hoeksma en A. Meester-Delver (1995) over de operatieve mogelijkheden van de spastische hand, gepubliceerd in het NTvG. ${ }^{3}$ Deze indeling wordt nu in de $\mathrm{CBO}$ richtlijn "diagnostiek en behandeling van kinderen met een spastische Cerebrale Parese" aanbevolen om de ernst van de handfunctiestoornis bij kinderen met een uCP vast te leggen. Ook zijn de resultaten van deze studie, de Cochrane review "Botulinum toxin $A$ as an adjunct to treatment in the management of the upper limb in children with spastic cerebral palsy (UPDATE)" (Hoare BJ, 2010) ${ }^{4}$ en de bevindingen van de BoBiVa studie gebruikt om de vraag "Wat is de meerwaarde van botulinetoxine-A (BoNT-A) bij de behandeling van kinderen met spastische CP op vaardigheidsniveau van de hand?" opnieuw te beantwoorden. Bij update van deze richtlijn is ook de BOSK intensief betrokken. Zij zijn zo ook op de hoogte van de bevindingen van de studies in dit proefschrift. 
De resultaten van de eerste studie naar het additionele effect van BoNT-A bij kinderen met uCP die een intensieve revalidatiebehandeling krijgen, zijn gebruikt in de meta-analyse van de Cochrane review uit 2010. Naar deze studie uit 2005 wordt verwezen in verschillende reviews, zoals in "A systematic review of interventions for children with cerebral palsy: state of the evidence" (Novak I, 2013 DMCN). ${ }^{5}$

Over de studieopzet van de BoBiVa studie is melding gemaakt in een poster in de International Cerebral Palsy Conference (ICPC) in Sydney in 2009 en de eerste voorlopige resultaten zijn vermeld in een presentatie in de 4th World Cerebral Palsy Conference in Pisa in 2012.

Over het BITT programma zijn workshops gegeven samen met o.a. Eugene Rameckers en Yvonne Janssen-Potten op de ICPC in Sydney in 2009 en op de American Academy of Cerebral Palsy and Developmental Medicine in Washington in september 2010. Op de spasticity management course in Bodrum in oktober 2010 is een workshop gegeven naar aanleiding van dit onderzoek met als titel: 'Spastic hand function impairment in (unilateral) $\mathrm{CP}$ : Classification, measurements and treatment options'.

In 2005, 2008, 2011 en 2014 heeft Lucianne Speth een voordracht gegeven op de VRA (Vereniging van Revalidatieartsen) basiscursus Cerebrale Parese over de behandelmogelijkheden van kinderen met een unilaterale spastische handfunctiestoornis.

Hoofdstuk 2 "Unilateral Cerebral Palsy: Epidemiology, Etiology, Imaging and Treatment of Hand Function Problems" is op verzoek van de editor op grond van onze expertise geschreven en gepubliceerd als hoofdstuk in "The Handbook on Cerebral Palsy". De hoofdstukken over de OSAS met als titel "Observational skills assessment score: reliability in measuring amount and quality of use of the affected hand in unilateral cerebral palsy" en over het exploratieve deel van de BoBiVa studie met als titel "Effects of botulinum toxin $A$ and/or bimanual taskoriented therapy on upper extremity impairments in unilateral Cerebral Palsy: An explorative study" zijn gepubliceerd in peer reviewed journals. Het voorlaatste hoofdstuk getiteld "Effects of botulinum toxin $A$ and/or bimanual task-oriented therapy on upper extremity activities in unilateral Cerebral Palsy: a clinical trial" is ingediend bij een wetenschappelijk tijdschrift.

\section{Toekomst}

De eerste fase van een studie, gefinancierd vanuit het derde ZonMw-programma Revalidatiegeneeskunde, naar de verschillen tussen impliciet en expliciet leren in een thuistherapieprogramma, waarin de ouders van kinderen met een uCP in de leeftijd van 1,5 tot 8 jaar 
gecoacht worden hoe het gebruik van de aangedane hand te stimuleren, is opgestart vanuit Adelante/vakgroep revalidatiegeneeskunde UM in samenwerking met de Maartenskliniek en de vakgroep revalidatiegeneeskunde/orthopedagogiek Radboud UMC in Nijmegen. Het meenemen van de bevindingen van de beeldvormende diagnostiek, evenals de gegevens over de cognitieve mogelijkheden van de kinderen voor zover bekend en het opleidingsniveau van de ouders is in dezen belangrijk omdat zij de uitkomst kunnen beïnvloeden.

Momenteel is er onderzoek gaande naar de functionele krachtmeting als voorbereiding op een onderzoek naar het effect van functionele krachttraining bij kinderen met uCP in de leeftijd van 7 tot 18 jaar.

Verder onderzoek naar de validiteit en de betrouwbaarheid van de OSAS moet plaats gaan vinden bij kinderen met UCP. Daarnaast kan de OSAS ontwikkeld en onderzocht gaan worden in andere diagnosegroepen, zoals eerder vermeld.

Ook zouden de effecten van het BITT programma, eventueel in aangepaste vorm, bij andere diagnosegroepen nog nader onderzocht kunnen worden op effectiviteit. 


\section{LITERATUUR}

1 Timmermans AA, Lemmens RJ, Montfrance M, Geers RP, et al. Effects of task-oriented robot training on arm function, activity, and quality of life in chronic stroke patients: a randomized controlled trial. J Neuroeng Rehabil 2014; 11: 45.

2. Spooren Al, Janssen-Potten YJ, Kerckhofs E, Bongers HM, et al. Evaluation of a task-oriented clientcentered upper extremity skilled performance training module in persons with tetraplegia. Spinal Cord 2011; 49(10): 1049-1054.

3. Hoeksma AF, Bos KE, Meester-Delver A. Operatieve mogelijkheden bij de spastisch verlamde arm en hand. Ned Tijdschr Geneeskd 1995; 139: 1643-1648.

4. Hoare BJ, Wallen MA, Imms C, Villanueva E, Rawicki HB, Carey L. Botulinum toxin A as an adjunct to treatment in the management of the upper limb in children with spastic cerebral palsy (UPDATE). Cochrane Database Syst Rev 2010; (1): CD003469. Review.

5. Novak I, McIntyre S, Morgan C, Campbell L, Dark L, Morton N, Stumbles E, Wilson SA, Goldsmith S. A systematic review of interventions for children with cerebral palsy: state of the evidence. Dev Med Child Neurol 2013; 55(10): 885-910. 


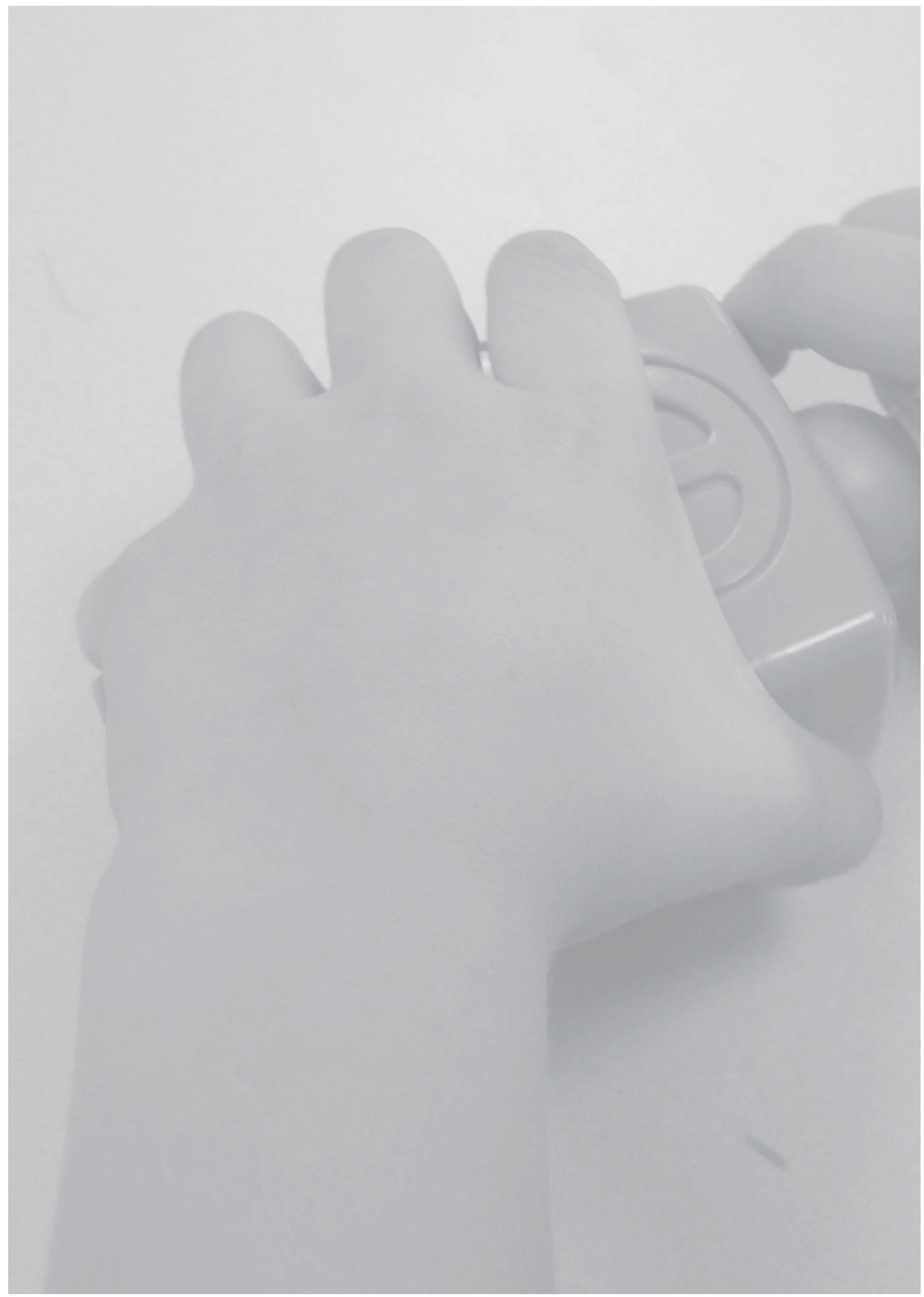




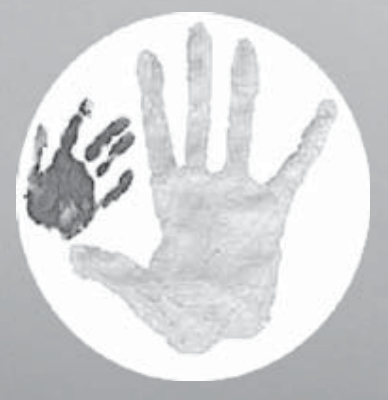

Dankwoord 
$\mathrm{Na}$ ongeveer 15 jaar met ups en downs hiermee bezig te zijn geweest, is het proefschrift dan eindelijk af! Het doen van wetenschappelijk onderzoek met een voor dit doel niet geregistreerd middel bij wilsonbekwamen, kinderen, blijkt geen sinecure te zijn. Het spreekwoord 'de aanhouder wint' is in mijn geval zeker van toepassing. Het heeft me veel gebracht: naast kennisverdieping en specialisatie in mijn eigen vakgebied, de kinderrevalidatiegeneeskunde, ook kennis en vaardigheden in andere vakgebieden, aanpalend, de kinderneurologie, maar ook het leren interpreteren van de resultaten, het leren gebruiken van verschillende statistiekprogramma's en het leren presenteren op congressen. Het belangrijkste voor mij is echter de samenwerking en de contacten die het opgeleverd heeft met alle collega's, in ons centrum Adelante, in het MUMC en Atrium MC, maar ook landelijk in het VUmc, in de St. Maartenskliniek, in Mariëndael in Apeldoorn, in de Libra zorggroep in Eindhoven en Tilburg, in Revant in Breda, in Groningen en internationaal, in België, Australië, Zweden en in New York in de centra die zich bezighouden met wetenschappelijk onderzoek op het gebied van de spastische hand bij kinderen met een Cerebrale Parese (CP).

Zonder deze samenwerking en deze contacten was dit proefschrift nooit tot stand gekomen. Omdat ik niemand wil vergeten wil ik daarom iedereen, waarop bovenstaande van toepassing is en met wie ik hoe dan ook samengewerkt heb, nu alvast bedanken!

In dit proefschrift staan de resultaten van twee studies beschreven, waar kinderen met een spastische handfunctiestoornis bij een unilaterale CP als proefpersonen aan meegedaan hebben. Zonder hun medewerking en die van hun ouders hadden we dit onderzoek uiteraard niet kunnen verrichten. Daarom wil ik bovenal alle kinderen en hun ouders heel hartelijk danken! Ook ben ik dank verschuldigd aan de patiëntenvereniging, de BOSK, en aan alle subsidiegevers, zonder hen was dit ook niet mogelijk geweest.

Natuurlijk wil ik een aantal mensen persoonlijk bedanken voor hun bijdrage.

Allereerst mijn promotieteam.

Prof. dr. J.S.H. Vles, beste Hans, jij bent de aanzet tot het schrijven van dit proefschrift. De onderzoeksvraag uit de studie die gepubliceerd is in 2005 kwam voort uit onze samenwerking in de werkgroep spasticiteit in het MUMC. Vanuit deze werkgroep deden we samen mee aan de Bolien studie. Jij maakte meedoen aan deze studie mogelijk door de oprichting van het laboratorium voor bewegingsanalyse, het ganglab, in het MUMC. Jij stimuleerde me om de eerste studie te starten en wilde als promotor optreden. Hoewel onze samenwerking ook stroevere periodes heeft gekend, heb ik je altijd zeer gewaardeerd om je deskundigheid in 
je vakgebied, de kinderneurologie, maar ook je interesse in de kinderrevalidatie, en je inzet en bevlogenheid naar de patiënten, de kinderen, toe. Nu het zover is dank ik je zeer dat jij dit hebt geïnitieerd en dat je me ondanks alles hebt willen blijven begeleiden. Ik heb veel van je geleerd.

Dr. Y.J.M. Janssen-Potten, Yvonne, mijn copromotor, zonder jouw zeer intensieve bijdrage was het niet gelukt, heel veel dank hiervoor! Je hielp me met het zoeken naar subsidiegevers, met het kritisch doorlezen van de onderzoeksvoorstellen, de aanvragen naar de subsidiegevers, de brieven en aanvraagformulieren naar de verschillende METC's en de CCMO, en het opstellen en verdedigen van de begroting van de onderzoeksprojecten naar de verschillende managers toe in de verschillende organisatiestructuren, die het kinderrevalidatiecentrum en het kenniscentrum van Adelante gehad heeft in de lange periode waarin deze onderzoeken liepen. Wij hebben samen vele uren doorgebracht op de kamer van de statisticus, eerst Pieter Leffers, later Bjorn Winkens. Al mijn artikelen en brieven naar de editors werden door jou positief kritisch doorgelezen en becommentarieerd. Ons handenteam werd een landelijk expertiseteam, mede dankzij jouw ondersteuning op het gebied van wetenschappelijk onderzoek.

Prof. dr. R.J.E.M. Smeets, Rob, toen jij hoogleraar revalidatiegeneeskunde werd vanuit Adelante in het MUMC+ heb ik je, in overleg met Hans, gevraagd om tweede promotor te zijn. In Sydney hebben wij jou voor het eerst ontmoet als toekomstig hoogleraar revalidatiegeneeskunde. Wij waren toen als handenteam op de 'International Cerebral Palsy Conference' met verschillende bijdrages. Hoewel dit type onderzoek geheel buiten jouw specialiteit en interessegebied tot dan toe viel, heb je onze artikelen steeds zorgvuldig doorgelezen en van commentaar voorzien. Als relatieve buitenstaander in dit deel van de kinderrevalidatiegeneeskunde, stelde je vaak vragen ter verduidelijking, die een positieve invloed hadden op de helderheid van het artikel. Dank hiervoor.

Prof. dr. J.A.M.F.C. Verbunt, beste Jeanine, dank dat je voorzitter wilde zijn van de leescommissie. Ook wil ik je danken voor de samenwerking op de poli revalidatie in het MUMC, en voor het betrekken van de kinderrevalidatie in het keuzeblok revalidatiegeneeskunde.

Verder wil ik de leden van de leescommissie, prof. dr. A.C.H. Geurts, prof. dr. A.M. Gordon (thank you), prof. dr. L.W. van Rhijn en dr. J. Vermeulen, danken voor hun bereidheid zitting te nemen in deze commissie en mijn proefschrift door te lezen. 
Dan de mensen met wie ik in Adelante het meest intensief samengewerkt heb.

Eugene, samen met Yvonne hebben wij het handenteam in Adelante opgericht. In die tijd heb jij je Master of Research gehaald en later ben je gepromoveerd op onderzoek op de data die je vergaarde vanuit de metingen die je verrichte gekoppeld aan de metingen voor de RCT, gepubliceerd in 2005, naar het additionele effect van botuline toxine injecties op twee handige vaardigheden bij kinderen met een eenzijdige spastische handfunctiestoornis. Sinds die tijd hebben wij intensief samengewerkt. Jij hebt de eerste opzet gemaakt voor het taakspecifieke bimanuele oefentherapieprogramma. Wij hebben samen geparticipeerd in de CBO-richtlijn en hebben samen met Yvonne en Anke later verschillende workshops op congressen gegeven. Ons Hand-in-Hand survivalkamp, in 2007 gestart met CIMT, maar ook hulpvraaggericht bimanueel werken, was er niet geweest als jij niet hiertoe de aanzet gegeven had. Ook bij de metingen voor BoBiVa en het verder ontwikkelen van het taakspecifieke therapieprogramma was jij betrokken. Heel veel dank voor deze vruchtbare samenwerking, die gelukkig nog steeds voortduurt in nieuwe onderzoeksprojecten.

Anke, sinds jij het handenteam bent komen versterken als ergotherapeut heb je hierin heel veel ervaring en deskundigheid opgebouwd en je altijd volledig ingezet. Nu ben jij de dragende kracht van het handenteam. Samen met Eugene heb jij ons hulpvraaggerichte, taakspecifieke bimanuele oefenprogramma voor het BoBiVa onderzoek verder ontwikkeld en gecommuniceerd met de therapeuten uit de andere participerende centra. Jij hebt, samen met Eugene, het land doorgereisd voor alle metingen voor BoBiVa en hebt de therapeuten gecoacht in het taakspecifiek bimanueel werken. Zonder jou was het ontwikkelen van de OSAS en het doen van de betrouwbaarheidsstudie niet mogelijk geweest. In onze pilot van het mini-BIMT zorgprogramma heb je veel deskundigheid getoond in het coachen van de perifeer werkende therapeuten in het bimanuele oefenen van voor kind en ouders betekenisvolle doelen. Ik wil je hartelijk danken voor al je inzet en ondersteuning, voor al je mooie foto's en filmpjes en het toch steeds weer gaan voor de inhoud, ook al loopt alles niet even gemakkelijk.

Prof. dr. J.G. Becher, beste Jules, toen jij in oktober 2005 je inaugurele rede als hoogleraar kinderrevalidatie in het VUmc hield, mocht ik bij het symposium dat je ter gelegenheid hiervan organiseerde een voordracht houden over het effect van botuline toxine injecties in de arm bij kinderen met unilaterale CP op functies en vaardigheden. Je vroeg me ook om de uitgangsvragen in de $\mathrm{CBO}$-richtlijn diagnostiek en behandeling van kinderen met een spastische CP betreffende de arm/hand mee te helpen beantwoorden. Dit heb ik zeer 
gewaardeerd. Ons onderzoek en ons handenteam kregen hierdoor landelijke bekendheid. Wij hebben vanuit het MUMC/Adelante meegedaan aan het Bolien onderzoek, dat vanuit het VUmc opgezet was. Vanuit het VUmc is met een aantal deelnemers geparticipeerd in het BoBiVa onderzoek. Jij bent betrokken bij de publicaties hierover. Wij kwamen elkaar regelmatig tegen op internationale congressen. Voor deze prettige samenwerking en gezellige contacten wil ik je graag bedanken.

Mevr. J.W. Weber, beste Biene, jij bent als onafhankelijk arts betrokken bij het BoBiVa onderzoek. Steeds als ik je tegenkwam als consulent in Adelante, en later in het spina bifidateam in het MUMC, vroeg je geïnteresseerd hoe het ervoor stond. Dank voor je interesse en de fijne samenwerking.

Beste Pieter, jij was intensief betrokken bij de methodologie en de statistiek van onze eerste RCT. Daarna volgde de studieopzet van het BoBiVa onderzoek en de ontwikkeling van de OSAS en het betrouwbaarheidsonderzoek. Samen met Yvonne hebben we heel prettig verlopende discussies gehad. Jij weet hoe moeilijk het doen van klinisch wetenschappelijk onderzoek is. Dank voor je begeleiding hierbij.

Bjorn, bij de statistische verwerking van de BoBiVa-data heb ik veel ondersteuning van je mogen ontvangen, dank je wel.

Diane, als 'native English speaker' las je de laatste artikelen door. De wetenschappelijke teksten waren soms moeilijk door te ploegen, maar vanuit je roots en vakgebied ben je uitstekend in staat de grammatica goed te beoordelen. Thank you!

Mijn voormalige collega's in Adelante van begin af aan, Denis Jaeken en Ad Reekers, wil ik danken voor het feit dat zij me destijds het wetenschappelijk onderzoek toebedeelden en mij hierin mijn gang lieten gaan.

Nienke, wij hebben helaas maar kort in Adelante samen kunnen werken. Jij bent geïnteresseerd in onderzoek, goed op de hoogte van de laatste ontwikkelingen in de kinderrevalidatie en hebt mij altijd ondersteund hierin. Hiervoor wil ik je hartelijk danken.

Peter, Ruud en Jeroen, mijn directe collega's in Adelante, en natuurlijk Birgit, onze fellow sociale pediatrie, naar mijn mening hebben we een goed team met een fijne samenwerking, waarvoor mijn dank.

Alle therapeuten, verpleegkundigen, maatschappelijk werkenden, psychologen en de medewerkers van onderwijs met wie ik destijds in team 2, specifiek met René als teammanager, 
nu in het team vroeg-revalidatie, en natuurlijk in het handenteam samenwerk in Adelante, wil ik hartelijk danken hiervoor. Ik ben ervan overtuigd dat wij, als inhoudelijken, de kwaliteit van de zorg voor de kinderen gezamenlijk zo goed mogelijk vorm proberen te geven, ondanks regelmatig onvoldoende ondersteuning hiervoor.

Nicole, Diana, Lieke, Karin, Sylvia en Marjo destijds, graag wil ik jullie danken voor alle secretariële en plan-technische ondersteuning.

Lieve pap, jij hebt mij, samen met mam, gevormd tot wie ik ben. Je was rustig aanwezig en had altijd een luisterend oor. Ik dank je hiervoor. Helaas heb je de geboorte van je eerste kleinkind niet mee mogen maken, maar je wist gelukkig wel, dat ik zwanger was. Ik weet dat je trots op me geweest zou zijn.

Lieve mam, ik ben blij, dat je dit mee kunt maken. Jij hebt ons altijd gestimuleerd te studeren en het beste uit ons zelf te halen. Je stond altijd voor ons klaar en voor opa en oma, die je, kort nadat pap overleden was, ook moest missen. Net toen je dacht samen met pap te kunnen gaan genieten, brak een sombere periode in je leven aan door dit verlies. Daarna kon je gelukkig langzaamaan de draad weer oppakken en genoot je van het zien opgroeien van je kleinkinderen. Je hebt aangegeven, dat je trots bent op wat ik bereikt heb. Bedankt voor alles.

Lieve Rino, jij was mijn chaperonne en het lijntje naar huis, toen ik studeerde in Utrecht. Wij hebben regelmatig lekker uit gegeten in Utrecht, maar ook samen gekookt in Hintham. Ik heb genoten van vele zomervakanties in Frankrijk met jou. Na het overlijden van opa en oma ben je terug naar Limburg gekomen. Het is fijn, dat mam en jij nu samen in een appartementencomplex wonen, waardoor jullie steun hebben aan elkaar. Merci pour tout! Lieve Jean, mijn man, maatje en minnaar, wij zijn intussen al heel wat jaren bij elkaar, maar ik vind het nog steeds niet saai. Nadat de kinderen uit huis waren gegaan om te studeren, hebben we een goede modus vivendi gevonden. Je ontspannen, optimistische aard biedt een goed tegenwicht tegen mijn steeds maar weer moeten. Laisser faire, laisser passer dans la douce France! Merci mon amour!

Lieve kinderen, Willemiek en Bas, wat hebben wij van jullie genoten toen jullie klein waren. Dit is passé, jullie zijn uitgegroeid tot fijne volwassen persoonlijkheden. Je gaat ieder je eigen weg en probeert er iets van te maken in het leven. Willemiek, dank je voor het doorlezen van mijn artikelen, je positieve feedback en voor het meehelpen met de lay-out van dit boekje. Bas, je hebt wat te verduren in ons gezin als enige niet-medicus. Maar het is fijn te horen 
hoe jij de wereld op jouw manier bekijkt en dank voor de feedback op het persoonlijke vlak. Wij zijn trots op jullie beiden en ik waardeer het zeer dat jullie de rol van paranimf op je hebt willen nemen. Merci! 


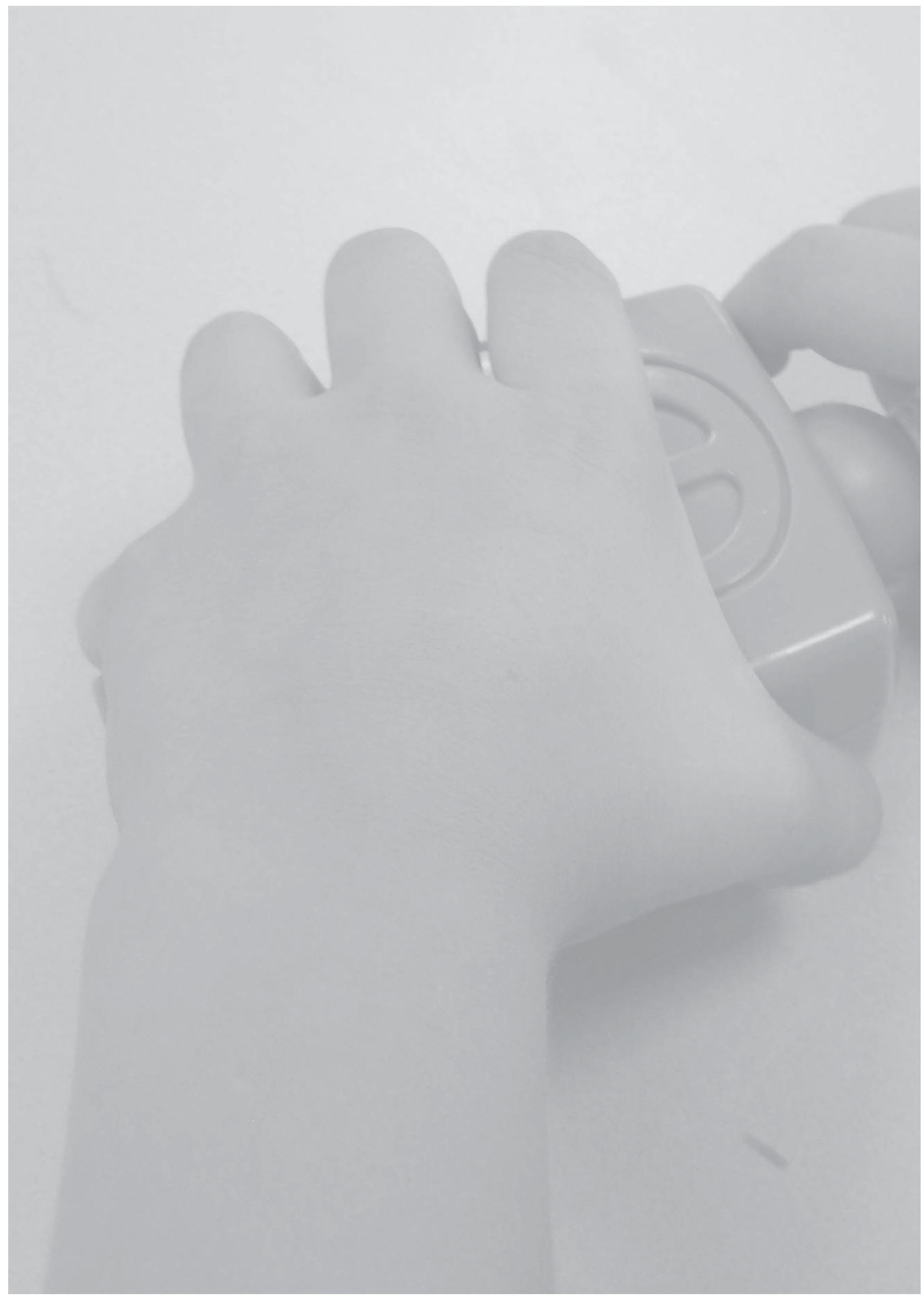




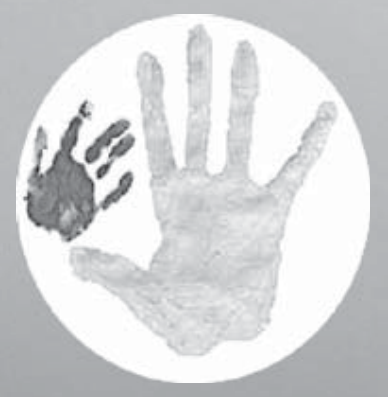

Curriculum Vitae 


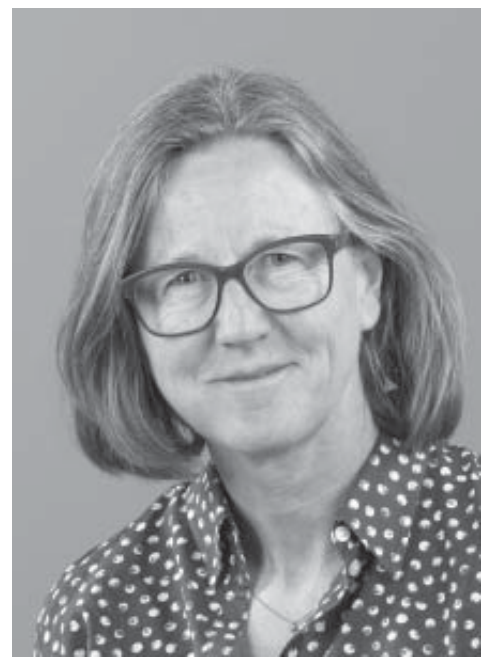

Lucianne Speth werd geboren op 12 juni 1958 op de Heerenweg 33 te Heksenberg, Heerlen. Nadat zij hier de lagere school gevolgd had, ging ze van 1970 tot 1976 naar het Coriovallum College te Heerlen, waar zij haar Gymnasium B diploma haalde. Vervolgens begon zij in 1976 de geneeskundestudie aan de Rijksuniversiteit te Utrecht. Haar artsexamen haalde zij op 29 april 1983. Hierna werkte zij een jaar als AGNIO interne geneeskunde en cardiologie in het St. Jozef ziekenhuis in Kerkrade. In juni 1984 startte zij met de opleiding revalidatiegeneeskunde in het circuit Leiden-Katwijk met als opleider prof. J.C. Jongbloed. Aan het einde van deze opleiding volgde zij een extra stage in de kinderrevalidatie bij in het Bio kinderrevalidatiecentrum te Arnhem.

Op 15 juli 1988 kwam zij als revalidatiearts in dienst in Franciscusoord, het huidige Adelante, in Valkenburg, waar zij nu nog werkzaam is als kinderrevalidatiearts. De eerste twee jaar werkte zij fulltime, daarna parttime, en sinds september 2005 weer fulltime. Haar caseload bestond jarenlang grotendeels uit kinderen met aangeboren hersenproblematiek (Cerebrale Parese, DCD, PMR).

Op 24 juni 1989 is zij getrouwd met Jean Zweiphenning, tandarts, die overigens tegelijk met Lucianne op 29 april 1983 zijn tandartsexamen haalde. Zij kregen twee kinderen: Willemiek, geboren op 13 februari 1991 en Sebastian, geboren op 15 september 1992.

Van november 1996 tot november 1998 was zij docent aan de opleiding ergotherapie bij de Hogeschool Limburg. Van november 1999 tot november 2007 was zij bestuurslid van de SBOK (Stichting in Ontwikkeling Bedreigde Kind, nascholingscursussen voor paramedici). Van 1994 tot 1997 gaf zij als docent bij de NDT (neuro developmental treatment) cursus voor paramedici enkele uren over de achtergronden van en behandelmethoden voor spasticiteit. Sinds 1998 is zij lid van de werkgroep spasticiteit in het Maastricht Universitair Medisch Centrum (MUMC), die destijds door prof. Dr. J.S.H. Vles opgericht is. Vanuit de werkgroep spasticiteit is de onderzoeksvraag voor de eerste studie ontstaan: wat is het additionele affect van botuline toxine injecties in de bovenste extremiteit bij kinderen met een unilaterale spastische Cerebrale Parese ( $\mathrm{UCP}$ ), die intensieve revalidatie krijgen, op tweehandige vaardigheden? 
Begin 2000 is gestart met de inclusie van de eerste deelnemers van deze randomized clinical trial (RCT). Kort tevoren was in Adelante het handenteam opgericht, waar aanvankelijk Yvonne Janssen-Potten als bewegingswetenschapper en Eugene Rameckers als kinderfysiotherapeut bij betrokken waren en later Anke Defesche bijkwam als ergotherapeute. In samenwerking met prof. Vles in het MUMC ontwikkelde dit team zich tot een expertteam met ervaring in de behandeling van kinderen met een (eenzijdige) spastische handfunctiestoornis. Sindsdien heeft Lucianne, al dan niet samen met de leden van het handenteam, regelmatig voordrachten gegeven over de behandeling van kinderen met een spastische handfunctiestoornis bij een uCP. Ook is zij in 2005, samen met Eugene Rameckers, op basis van deze deskundigheid, gevraagd om te participeren bij de CBO-richtlijn 'Diagnostiek en behandeling van kinderen met een spastische CP' om de vragen die betrekking hebben op de diagnostiek en behandeling van de spastische hand te beantwoorden.

In september 2001 is zij gedetacheerd naar het Atrium MC, waar zij op de afdeling kindergeneeskunde een dagdeel per week poliklinische consulten deed. Deze poli is in 2008 overgenomen door collega Nienke Haga.

In oktober 2001 nam zij samen met prof. Vles deel aan de Bolien studie, een multicenter studie, opgezet in het VU medisch centrum onder supervisie van prof. dr. J.G. Becher, naar het effect van botuline toxine injecties op loopvaardigheden bij kinderen met een bilaterale spastische CP.

Sinds januari 2002 is Lucianne voor een dagdeel gedetacheerd naar het klinisch laboratorium voor bewegingsanalyse, 'het ganglab', in het MUMC, dat opgericht is onder verantwoordelijkheid van prof. Vles met medewerking van prof. dr. H. Kingma. Hier beoordeelt zij samen met Yvonne-Janssen en aanvankelijk Eugene Rameckers, later Marcel Coenen, de ganganalyses en wordt een op consensus gebaseerd behandeladvies gegeven.

In september 2007 volgde een detachering van een dagdeel extra naar het MUMC, waar zij op de polikliniek revalidatiegeneeskunde op de vrijdagochtend de poliklinische en klinische consulten kinderrevalidatiegeneeskunde doet tot op heden.

In 2007 zijn door haar en het handenteam in Adelante samen met prof. Vles in het MUMC de eerste voorbereidingen gedaan voor de BoBiVa (Botuline toxine Bimanuele Vaardigheden) studie, een multicenter studie naar het effect van botuline toxine injecties in de bovenste extremiteit, al dan niet gecombineerd met een bimanueel taakspecifiek oefenprogramma op handfuncties en vaardigheden bij kinderen met een unilaterale handfunctiestoornis bij 
uCP. Hiervoor is samenwerking gezocht met prof. dr. J.G. Becher, hoogleraar kinderrevalidatiegeneeskunde in het VUmc en met de St. Maartenskliniek te Nijmegen.

Sinds najaar 2012 heeft zij collega Ad Reekers opgevolgd als lid van het spina bifida team in het MUMC.

Zij is sinds juni 2014 op maandagmiddag weer aanwezig in het Atrium MC in Heerlen als lid van de plexus brachialis werkgroep. Daarvoor had zij dit kortdurend van 2007 tot 2008 al gedaan. 


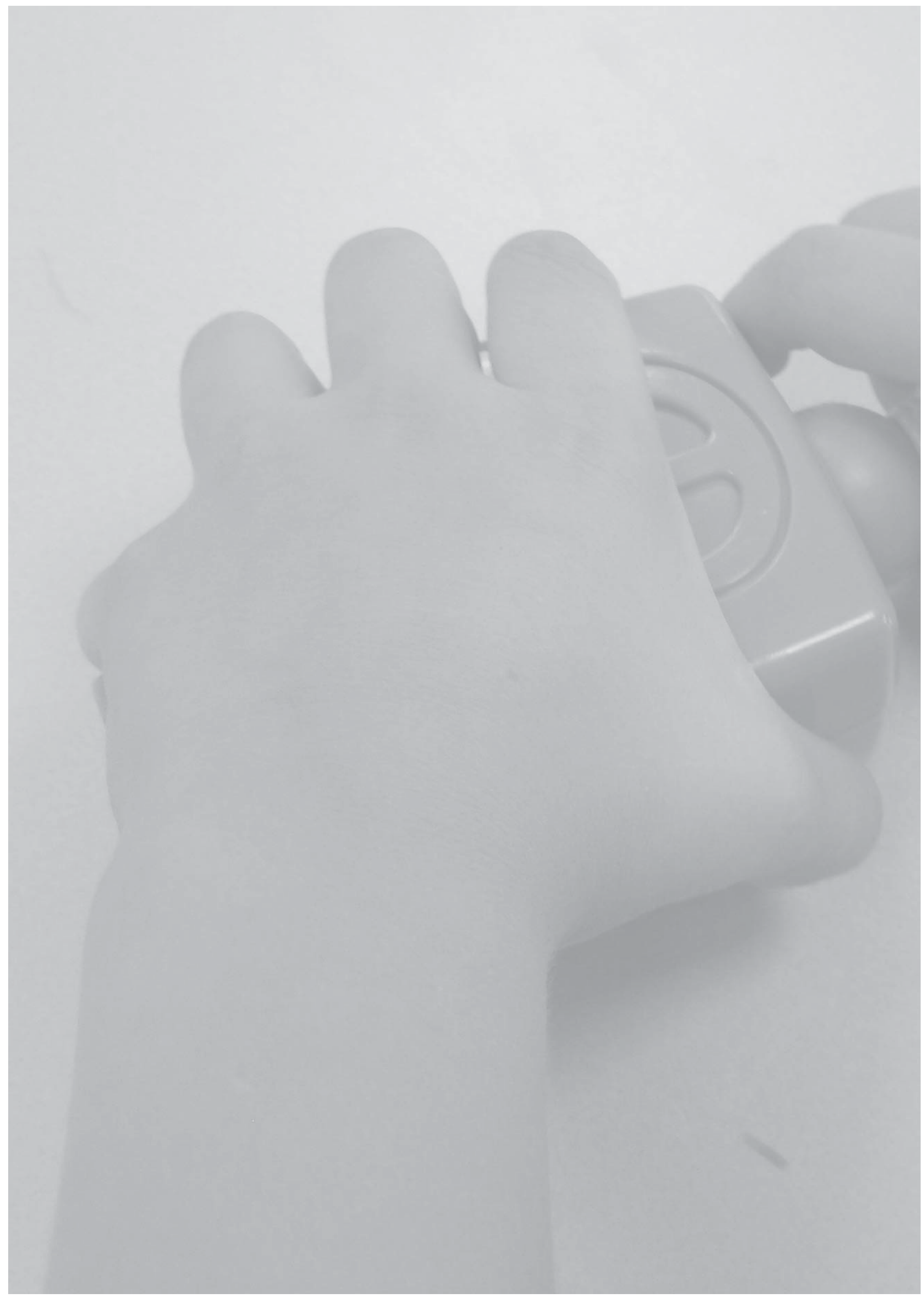




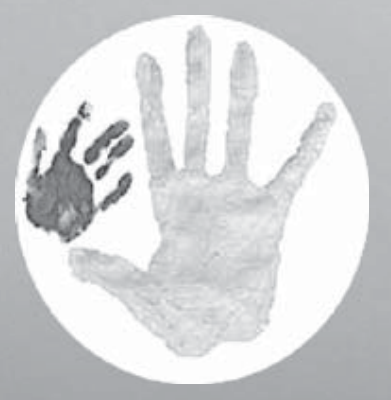

List of publications and international workshops 


\section{INTERNATIONAL JOURNALS}

Speth L, Janssen-Potten Y, Leffers P, Rameckers E, Defesche A, Winkens B, Becher J, Smeets $\mathrm{R}$, Vles $\mathrm{H}$. Effects of botulinum toxin A and/or bimanual task-oriented therapy on upper extremity activities in unilateral Cerebral Palsy: a clinical trial. Submitted in BMC Neurology 29-01-2015.

Speth L, Janssen-Potten Y, Leffers P, Rameckers E, Defesche A, Winkens B, Becher J, Smeets $\mathrm{R}$, Vles JS. Effects of botulinum toxin $\mathrm{A}$ and/or bimanual task-oriented therapy on upper extremity impairments in unilateral Cerebral Palsy: An explorative study. Eur J Paediatr Neurol 2015 May; 19(3): 337-348.

Lemmens RJ, Janssen-Potten YJ, Timmermans AA, Defesche A, Speth LA, Smeets RJ, Seelen HA. Arm hand skilled performance in cerebral palsy: activity preferences and their movement components. BMC Neurol 2014 Mar 19; 14: 52.

Speth L, Janssen-Potten Y, Leffers P, Rameckers E, Defesche A, Geers R, Smeets R, Vles H. Observational skills assessment score: reliability in measuring amount and quality of use of the affected hand in unilateral cerebral palsy. BMC Neurol 2013 Oct 21; 13: 152.

Rameckers EA, Duysens J, Speth LA, Vles HJ, Smits-Engelsman BC. Effect of addition of botulinum toxin-A to standardized therapy for dynamic manual skills measured with kinematic aiming tasks in children with spastic hemiplegia. J Rehabil Med 2010 Apr; 42(4): 332-338.

Vles GF, Hendriksen JG, Visschers A, Speth L, Nicolai J, Vles JS. Levetiracetam therapy for treatment of choreoathetosis in dyskinetic cerebral palsy. Dev Med Child Neurol 2009 Jun; 51(6): 487-490.

Rameckers EA, Speth LA, Duysens J, Vles JS, Smits-Engelsman BC. Botulinum toxin-a in children with congenital spastic hemiplegia does not improve upper extremity motor-related function over rehabilitation alone: a randomized controlled trial. Neurorehabil Neural Repair 2009 Mar-Apr; 23(3): 218-225.

Vles GF, de Louw AJ, Speth LA, van Rhijn LW, Janssen-Potten YJ, Hendriksen JG, Vles JS. Visual Analogue Scale to score the effects of Botulinm Toxin A treatment in children with cerebral palsy in daily clinical practice. Eur J Paediatr Neurol 2008 May; 12(3): 231-238.

Rameckers EA, Speth LA, Duysens J, Vles JS, Smits-Engelsman BC. Kinematic aiming task: measuring functional changes in hand and arm movements after botulinum toxin- $A$ injections 
in children with spastic hemiplegia. Am J Phys Med Rehabil 2007 Jul; 86(7): 538-547.

Scholtes VA, Dallmeijer AJ, Knol DL, Speth LA, Maathuis CG, Jongerius PH, Becher JG. Effect of multilevel botulinum toxin a and comprehensive rehabilitation on gait in cerebral palsy. Pediatr Neurol 2007 Jan; 36(1): 30-39.

Scholtes VA, Dallmeijer AJ, Knol DL, Speth LA, Maathuis CG, Jongerius PH, Becher JG. The combined effect of lower-limb multilevel botulinum toxin type a comprehensive rehabilitation on mobility in children with cerebral palsy: a randomized clinical trial. Arch Phys Med Rehabil 2006 Dec; 87(12): 1551-1558.

Speth LA, Leffers P, Janssen-Potten YJ, Vles JS. Botulinum toxin A and upper limb functional skills in hemiparetic cerebral palsy: a randomized trial in children receiving intensive therapy. Dev Med Child Neurol 2005 Jul; 47(7): 468-473.

Van den Berg-Emons RJ, Van Baak MA, Speth L, Saris WH. Physical training of school children with spastic cerebral palsy: effects on daily activity, fat mass and fitness. Int J Rehabil Res 1998 Jun; 21(20): 179-194.

Van den Berg-Emons RJ, van Baak MA, de Barbanson DC, Speth L, Saris WH. Reliability of tests to determine peak aerobic power, anaerobic power and isokinetic muscle strength in children with spastic cerebral palsy. Dev Med Child Neurol 1996 Dec; 38(120): 1117-1125. Van Leeuwen JL, Speth LA, Daanen HA. Shock absorption of below-knee prostheses: a comparison between the SACH and the multiflex foot. J Biomech 1990; 23(5): 441-446.

\section{BOOK CHAPTERS}

Speth L, Vles J. Unilateral Cerebral Palsy: Epidemiology, Etiology, Imaging and Treatment of Hand Function Problems. Handbook on Cerebral Palsy. Editor: Harold Yates. 2014 Nova Science Publishers. ISBN: 978-1-63321-852-9: 41-51.

Speth L, Vles JS. Hemiparese: oorzaak, klinische verschijnselen, geassocieerde problemen. Kind en Hemiparese. Beleven en behandelen. Redactie: E.H.H. van Loen en J.M.A. Verheijden. BOSK, 2005, tweede druk 2008. ISBN: 90-807537-4-2. 


\section{CONFERENCE PUBLICATIONS AND WORKSHOPS}

Speth L. Spastic hand function impairment in (unilateral) CP: Classification, measurements and treatment options. Workshop Spasticity Management Course Bodrum. 10-12 October 2010. Rameckers E, Speth L, Gordon A, Fehlings D, Janssen-Potten YJ. Constrained induced movement therapy and bimanual training in children and adolescents with unilateral Cerebral Palsy: a guide to integrating research into practice. Workshop AACPDM Washington 64th annual meeting. 22-25 September 2010.

Rameckers E, Speth L, Defesche A, Coenen M, Kissels M, Vanstipelen S, Janssen-Potten Y. Intensive task oriented upper limb therapy for children with unilateral Cerebral Palsy. Workshop international Cerebral Palsy conference Sydney. 18-21 February 2009.

Speth L, Vles JS, Rameckers E. Additional effect of botulinum toxin A treatment on upper limb functional skills in children with hemiparetic cerebral palsy. Neuromodulation $2005 \mathrm{Jul}$; 8(3): 191-192. Abstract in conference proceedings.

Janssen-Potten YJ, Coenen ML, Rameckers EA, Speth LA, Vles JS. Variabilty in gait analysis data in spastic children. Neuromodulation 2005 Jul; 8(3): 189-190. Abstract in conference proceedings.

\section{OTHER CONTRIBUTIONS}

Lucianne Speth. EBRO richtlijn Diagnostiek en behandeling van kinderen met een spastische Cerebrale Parese uit 2006. Beantwoording uitgangsvraag: Wat is de meerwaarde van botulinetoxine $\mathrm{A}$ bij de behandeling van kinderen met een spastische $\mathrm{CP}$ op vaardigheidsniveau van de hand? http://www.artsennet.nl/Richtlijnen/Richtlijn/120208/Spastische-CerebraleParese-bij-kinderen.htm

2014 Update van de vraag: Wat is de meerwaarde van botulinetoxine-A (BoNT-A) bij de behandeling van kinderen met spastische $\mathrm{CP}$ op vaardigheidsniveau van de hand?

Lucianne Speth. Spastische hand: Bimanual Task-specific Therapy (BIMT/BITT), Constraint Induced Movement Therapy (CIMT) en botuline toxine behandeling. Voordracht basiscursus VRA Cerebrale Parese, 31 januari 2014. 